\title{
The gut microbiota and childhood weight development
}

Citation for published version (APA):

Mbakwa, C. A. (2016). The gut microbiota and childhood weight development. [Doctoral Thesis, Maastricht University]. Proefschriftmaken.nl || Uitgeverij BOXPress.

https://doi.org/10.26481/dis.20161006cm

Document status and date:

Published: 01/01/2016

DOI:

$10.26481 /$ dis. $20161006 \mathrm{~cm}$

Document Version:

Publisher's PDF, also known as Version of record

\section{Please check the document version of this publication:}

- A submitted manuscript is the version of the article upon submission and before peer-review. There can be important differences between the submitted version and the official published version of record.

People interested in the research are advised to contact the author for the final version of the publication, or visit the DOI to the publisher's website.

- The final author version and the galley proof are versions of the publication after peer review.

- The final published version features the final layout of the paper including the volume, issue and page numbers.

Link to publication

\footnotetext{
General rights rights.

- You may freely distribute the URL identifying the publication in the public portal. please follow below link for the End User Agreement:

www.umlib.nl/taverne-license

Take down policy

If you believe that this document breaches copyright please contact us at:

repository@maastrichtuniversity.nl

providing details and we will investigate your claim.
}

Copyright and moral rights for the publications made accessible in the public portal are retained by the authors and/or other copyright owners and it is a condition of accessing publications that users recognise and abide by the legal requirements associated with these

- Users may download and print one copy of any publication from the public portal for the purpose of private study or research.

- You may not further distribute the material or use it for any profit-making activity or commercial gain

If the publication is distributed under the terms of Article $25 \mathrm{fa}$ of the Dutch Copyright Act, indicated by the "Taverne" license above, 
The Gut Microbiota And Childhood Weight Development 


\section{caphri}

Maastricht University in Lending inming!

The research presented in this dissertation was conducted at CAPHRI School for Public Health and Primary Care of Maastricht University which focuses on Healthcare Innovation and Public Health Research.

\section{TíFN}

The studies presented in this thesis were performed within the framework of TI Food and Nutrition (TIFN). Financial support from TIFN (GH003; Wageningen, The Netherlands).

\section{The Gut Microbiota And Childhood Weight Development}

\section{Dissertation}

To obtain the degree of doctor at Maastricht University, on the authority of the Rector Magnificus, Prof. dr. Rianne M. Letschert, in accordance with the decision of the board of Deans, to be defended in public on Thursday, $6^{\text {th }}$ of October 2016 at 12:00

Cover design: Catherine Akwi Mbakwa \& Proefschriftmaken.nl, The Netherlands Cover picture: Used with permission from Charles Mackay

Layout: Catherine Akwi Mbakwa

Printed by: Proefschriftmaken.nl, The Netherlands 


\section{Promotor}

Prof. dr. Ilja C. W. Arts

\section{Co-promotors}

Dr. John Penders

Dr. Carel Thijs

\section{Assessment committee}

Prof. dr. E.E. Blaak, (chair)

Prof. dr. C. A. M. V. A. Bruggeman

Prof. dr. N. Hens, Hasselt University, Belgium

Prof. dr. T. Nawrot, Hasselt University \& KU Leuven, Belgium

\section{Table of Contents}

Chapter 1 General introduction

Chapter 2 The intestinal microbiota composition and weight development in children: the KOALA Birth Cohort Study. (Published: Int J Obes 2015;39:16-25)

Chapter 3 Gut microbiota and body weight in healthy school-aged children: The KOALA Birth Cohort Study. (Submitted)

Chapter 4 Colonisation of the gut with the archaeon Methanobrevibacter smithii is associated with childhood weight development. (Published: Obesity (Silver Spring) 2015;23:2508-16)

Chapter 5 Early Life Antibiotic Exposure and Weight Development in Children.

(Published: The Journal of pediatrics 2016; 10.1016/j. jpeds.2016.06.015.

Chapter 6 Reduction of high dimensional data of the gut microbiota in relation to BMI z-score trajectories.

(To be submitted)

Chapter 7 Summary and General Discussion

Valorisation

Acknowledgement

About author

Curriculum Vitae

All rights reserved. No part of this thesis may be reproduced, distributed and stored in a retrieval system, or transmitted in any form or by any means without prior permission from the author. 
CHAPTER 1

GENERAL INTRODUCTION 


\section{Background}

Despite all measures put in place in the controlling of childhood overweight, its prevalence, severity, and societal burden have increased over the past decades. ${ }^{1-3}$ In general, overweight is the result of an imbalance in energy intake and energy expenditure, over a long period. ${ }^{4,5}$ In 2009, 12.8\% of Dutch boys and 14.8\% of Dutch girls aged 2-21 years were overweight, while $1.8 \%$ of the boys and $2.2 \%$ of the girls were classified as obese. This resulted in a two to three-fold increase in the prevalence of overweight and four to six-fold increase in obesity since $1980 .{ }^{6}$ Moreover, it has been predicted that $8 \%$ of men and $9 \%$ of women will suffer from obesity by $2030 .^{7}$ Childhood overweight is a major health concern because of its dramatic increasing prevalence, its persistency into adulthood, association with relative number of detrimental health outcomes such as type 2 diabetes, ${ }^{8}$ and burden on the healthcare systems. It is proposed that the prevention and management of this pandemic should begin in childhood ${ }^{9}$ as treatment has been shown to be difficult for children already suffering from obesity ${ }^{10}$. Numerous factors that are subjected to genetic, environmental and behavioural influences (e.g., dietary intake or food habits, physical activity or sedentary lifestyles, and sleep duration $)^{11-16}$ have been suggested to be associated with obesity. Even though some of these factors have been established as causal factors, the etiology of overweight and obesity remains complex and this makes it challenging to develop effective preventive programs and strategies. ${ }^{17}$ Moreover, there is growing evidence that the increasing prevalence of obesity might not only be explained by these factors. Recent studies (reviewed in ${ }^{18}$ ) have proposed that the composition of the gut microbiota (the community of microorganisms that live in the intestinal tract) may be a potential factor associated with obesity.

\section{The human gut microbiota}

The gastrointestinal (GI) tract is inhibited by almost 1000 microbial species (including bacteria, archaea and eukaryotic microorganisms), which collectively contain 3.3 million unique genes ${ }^{19}$ and are referred to as the GI microbiome. The density of microbial cells increases along the length of the intestine to almost $10^{11}-10^{12}$ per gram of lumina content in the distal colon (Figure 1). ${ }^{20}$ Additionally, the diversity of microorganisms in the colon exceeds the diversity in other parts of the intestinal tract ${ }^{21}$ and microbial fermentation also occurs mainly in the colon.

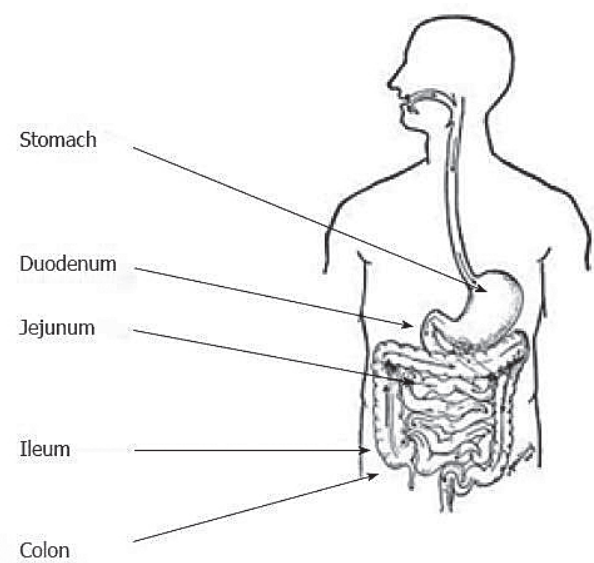

Figure 1. Density and composition of the human gut microbiota. Microbial concentration (represented as microorganisms per gram for each section of the gastrointestinal tract) increase towards the lower gastrointestinal tract with highest concentrations found in the colon. Adapted from (Leser and Molbak, 2009)

However, sampling from colonic microbiota is not possible without invasive approaches ${ }^{22}$ and therefore most of the studies focusing on the gut microbiota of humans have been performed on faecal samples. Studies, mostly performed in adults, have revealed that the gut microbiota in an average healthy human is dominated by bacterial species belonging to two major phyla; Bacteriodetes (gram-negative) and Firmicutes (gram-positive), and to a lesser extent by microorganisms from the phyla Actinobacteria, Proteobacteria, and Verrucomicrobia. ${ }^{23,24}$ Next to bacteria, the microbiota also consists of eukaryotic microorganisms and archaea. The archaea are a separate domain of prokaryotic microorganisms that are different from the prokaryotic eubacteria as well as from the eukaryotes, although recent insights indicate that eukaryotes are best classified within the archaea rather than being a separate branch of the evolutionary tree. ${ }^{25}$ In contrast to the many bacterial species, only three archaeal species: Methanobrevibacter smithii, ${ }^{26}$ Methanosphaera stadtmanae ${ }^{27}$ and Methanomassiliicoccus luminyensis, ${ }^{28}$ all belonging to 
the phylum Euryachaeota, have been recovered from the human GI tract. Together these microorganisms live in a symbiotic relationship with and exert multiple health beneficial functions for its host. These functions include the prevention of colonization of the intestinal lumen by pathogenic bacteria (so called colonization resistance) maturation of the intestine, metabolic functions (i.e. the breaking down of indigestible food particles and synthesis of short-chain fatty acids and micronutrients) and immune modulation and regulation. ${ }^{29} 30$

\section{Development and determinants of the Gut Microbiota}

As indicated by several recent studies, microbial colonization of the intestinal tract might already start before birth by microbial transfer through the placenta. ${ }^{31-33}$ However, it is only during and upon birth, when the infant is exposed to a wide variety of parental and environmental bacteria and massive colonization starts. During the first year of life the infant intestinal tract subsequently becomes progressively colonized with a mixture and high density of microbes. By the age of 2 to 3 years an adult-like microbiota has established ${ }^{34-37}$, although maturation of the microbiota may still continue for several years. The developmental process of the infant microbiota is mainly influenced by factors such as mode of delivery, type of infant feeding and antibiotic use (Figure 2)..$^{38-4}$ Short-term treatment in humans with a single dose of oral antibiotics can dramatically affect the gut microbiota composition, although it then tends to revert to its original composition within several weeks or months. ${ }^{42}$

The final gut microbiota composition is then influenced by colonization history, host physiology, environmental factors, ${ }^{43}$ and host genetic make-up. ${ }^{43-46} 1$

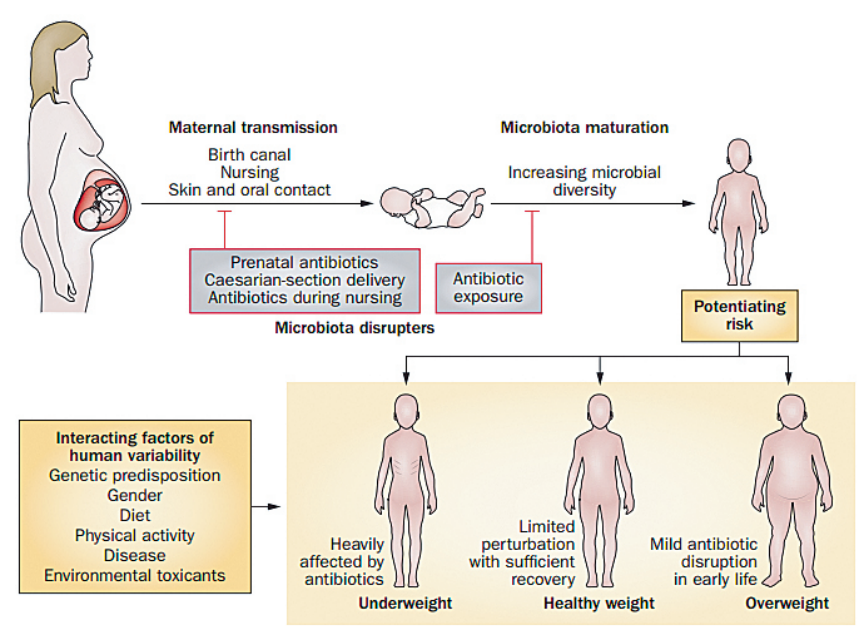

Figure 2. A representation of factors influencing microbiota transmission, maturation and perturbation in the first years of life and possible effects on weight. Data taken from (Cox \& Blaser, 2014)
The gut microbiota of individuals from the same household are more similar compared to those from a different household. ${ }^{34}$ In addition, the microbiota of monozygotic twins living apart, have been reported to be more similar than the microbiota of unrelated individuals. ${ }^{44}$ Also, recent studies have shown that the composition of the gut microbiota is altered in overweight/obesity leading to a reduction in both microbial diversity and richness. $^{23,47-50}$

\section{Gut microbiota and obesity}

The composition of the gut microbiota during early life has been suggested to be associated with childhood overweight/obesity. ${ }^{51}$ Changes in the ratio of the major phyla Firmicutes and Bacteroidetes as well as specific bacterial groups have previously been associated with obesity (reviewed in $\left.^{18}\right)$. However, there has been a lack of a consensus between studies with regards to the direction of these associations where some studies reported a positive ${ }^{52,53}$, while other reported a negative $e^{4,54-58}$ or no association ${ }^{47,59-63}$ between either the Bacteroidetes to Firmicutes ratio or specific bacterial groups (e.g. Bacteroides fragilis, ${ }^{25}$ Bifidobacterium spp, Staphylococcus spp, ${ }^{26}$ Akkermansia muciniphila ${ }^{27}$ and Faecalibacterium prausnitzii) ${ }^{20}$ or archaeal species (e.g. Methanobrevibacter smithii) ${ }^{28}$ Additionally some, but not all studies reported a lower microbial richness (counts of unique bacterial groups present in the gut) and/or diversity (counts of unique bacterial groups while taking into account their relative abundances) in obese as compared to lean subjects ${ }^{49,58,64}$. In this regards, the exact role of the gut microbiota in human obesity still remains unclear. The lack of consensus may be explained by the fact that studies done in rodent models have their limitations in terms of gut microbiota composition, fermentation process (e.g. location) and dietary practices (coprophagia). ${ }^{65,66} \mathrm{With}$ regards to studies in humans, this is likely due to differences of the gut microbiota composition between individuals, different methods used for DNA isolation and microbial analysis, geographical location, diet, and ethnicity. Although convincing in mouse models, it remains difficult to conclude whether disturbances in gut microbiota are cause or just consequence of obesity in humans. Transplantations of gut microbiota from lean or obese mice to germ-free recipients have revealed that the obesity phenotype is transferable by the microbiota. Hence, gut microbiota from genetically obese and diet-induced obese mice are capable of causing obesity in recipients. ${ }^{67,68}$ Interestingly, there seems to be a similar causal relationship in humans. There has been a case-study of a woman who suffered from recurrent Clostridium difficile infection and was successfully treated with faecal microbiota transplantation, but later on developed obesity after receiving the stool transplant from a healthy but overweight donor. ${ }^{69}$ Furthermore, transplantation of intestinal microbiota from lean donors to recipients suffering from metabolic syndrome resulted in improved glucose metabolism and insulin sensitivity together with increased levels of butyrate-producing bacteria. $^{70}$ 


\section{Mechanism of action of gut microbiota in weight development}

Dysbiosis, an imbalance in the composition of the intestinal bacteria, may lead to obesity via several proposed mechanisms. The obesity-associated microbiome might have an increased capacity to harvest energy from the diet due to the more efficient breakdown of dietary non-digestible carbohydrates to short chain fatty acids (SCFA) such as acetate, propionate and butyrate (Figure 3) that serve as an energy source for the host. ${ }^{68}$ Methanogenic microorganisms use hydrogen, a by-product of bacterial fermentation, to produce methane. The removal of hydrogen accelerates the bacterial fermentation of polysaccharides and other carbohydrates, leading to the more efficient production of short-chain fatty acids. ${ }^{68,71-74}$

Another proposed mechanism is that, the gut microbiota interplays with the signalling and regulatory network of the host and thereby regulates the energy balance. It has been shown that the gut microbiota promotes monosaccharide absorption and regulates the expression of the fasting-induced adipocyte factor (FIAF) in the intestinal tissue, which is an inhibitor of lipoprotein lipase (LPL). The modification of the gut microbiota causes a decrease in the expression of FIAF resulting in increased lipase activity which

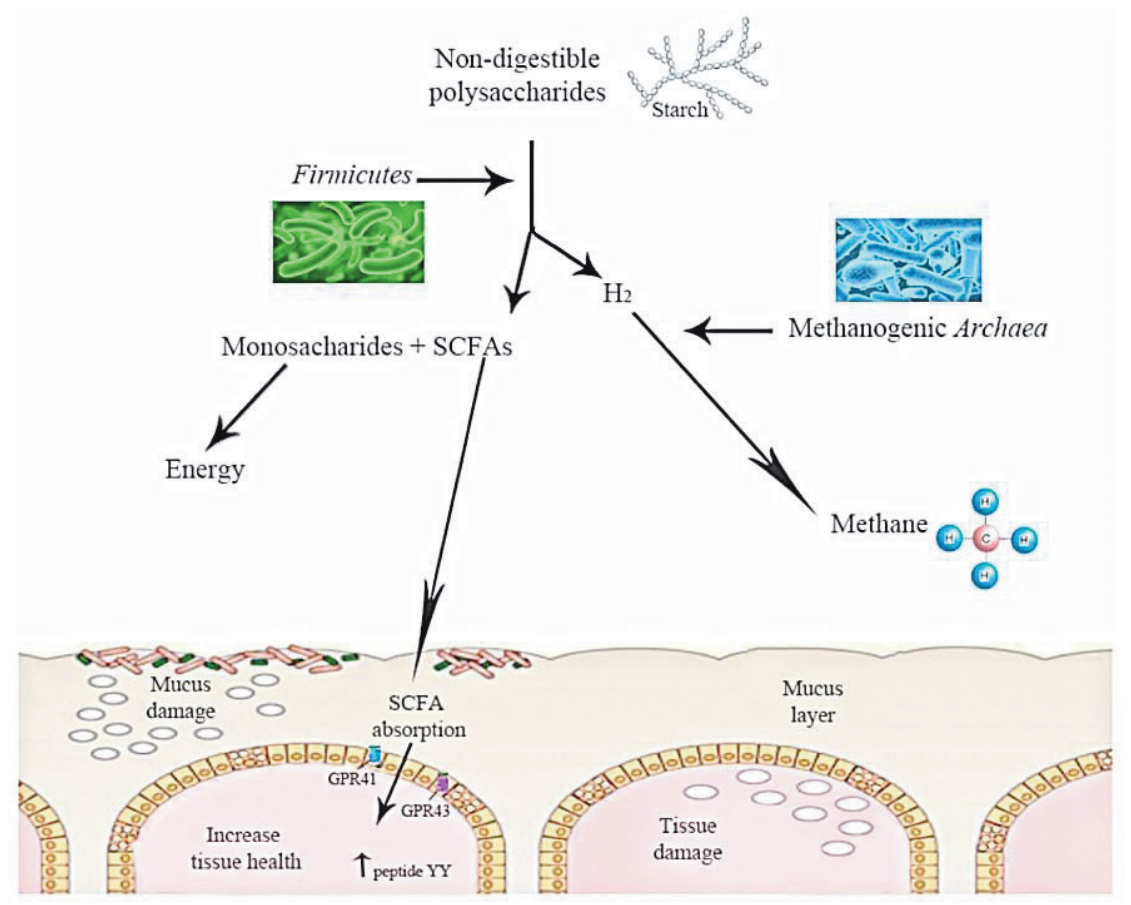

Figure 3. An overview of metabolism by the gut microbiota. Gut microbiota converts polysaccharides into monosaccharides, short-chain fatty acids and other end products. The binding of SCFAs to two G-protein-coupled receptors (GPR41 and GPR4) activates them to induce the production of peptide YY. Data obtained from (Moreno-Indias et al, 2014) ${ }^{88}$ in turn promotes increased uptake of fatty acids and triacylglycerol accumulation in adipocytes. ${ }^{75,76}$ In addition, SCFAs play a signalling role by binding on the G-proteincoupled receptors, Gpr41 and Gpr4377,78 stimulating a cascade which leads to increased fat storage and energy preservation. A study in Gpr41 deficient mice (which are leaner than their wild type littermates) suggested that activation of Gpr41 by SCFA was responsible for the production of Peptide YY (PYY) that conveys a sense of "fullness" and regulates appetite. ${ }^{79,80}$ This was because the Gpr41 deficient mice have lower expression of PYY (a gut derived hormone responsible for slowing down gastrointestinal transit). The elimination of Gpr41 from these mice which were being fed with highcarbohydrate, high-fat diet resulted in reduced levels of PYY and increased gut transit rates, resulting in more energy being lost with faeces compared with their wild-type littermates. ${ }^{77}$

Consumption of a high-fat diet can also lead to alteration of the gut microbiota composition in such a way that it negatively impacts the gut barrier. The increased permeability of the gut may subsequently lead to the translocation of harmful substances such as lipopolysaccharide (LPS, a component of the cell wall of gram-negative bacteria) from the intestinal lumen to the circulation, resulting in metabolic endotoxemia. ${ }^{81-86}$ LPS can bind to TLR4/CD14 receptors leading to the production of cytokines such as TNF-alpha and IL-6, which are involved in the development of obesity. In addition, LPS molecules can also stimulate adipogenesis by stimulating $\mathrm{CB}_{1}$ receptors, which are responsible for the activation of the endocannabinoid system. ${ }^{44,84}$

\section{The KOALA Birth Cohort Study}

The KOALA Birth Cohort Study aims at identifying factors that influence the development of allergic diseases as well as weight development with a main focus on lifestyle (e.g. anthroposophy, vaccinations, antibiotics, and dietary habits), breastfeeding and breast milk composition, intestinal microbiota composition, infections during first year of life, and gene-environment interactions. From October 2000 until December 2002, a total of 2834 pregnant women were recruited at 34 weeks of gestation. Pregnant women with a conventional lifestyle $(n=2343)$ were recruited from an ongoing prospective cohort study $(\mathrm{n}=7020)$ on pregnancy-related pelvic girdle pain in the Netherlands. ${ }^{87}$ A second group of pregnant women $(\mathrm{n}=491)$ was recruited through alternative channels, organic food shops, Steiner schools, magazines and anthroposophic doctors and midwives. Information of other relevant variables were first obtained from the pregnant mothers and covered the first and third trimester as well as early childhood. This was done through the use of repeated questionnaires at 14-18,30, and 34 weeks of gestation and 3, 7, 12, and 24 months post-partum. Physical activity and dietary intake (using food frequency questionnaires (FFQ) were obtained from the children at 4-5 
years of age. A subgroup of participants, including both conventional and alternative lifestyles, was asked to give their consent to maternal blood sampling during pregnancy, maternal breast milk collection, collection of a faecal sample of the child at one month post-partum and 6-7 years of age, capillary blood at age 1 year, and venous blood at 2 and 6-7 years.

Additionally, anthropometric variables (such as height, and weight) were obtained from the children at different follow-up points through the use of questionnaires filled ou by the parents and during home visits at 6-7 years of age by trained nurses. The parents were asked to measure and report the child's height $(\mathrm{cm})$ and weight $(\mathrm{kg}$, specified to one decimal) without clothes or shoes at ages $0-1,2-3,4-5,6-7,7-8,8-9$, and 9-10 years respectively (Figure 4)

\section{Aim and outline of the thesis}

The main aims of this thesis were to: 1) examine associations between the gut microbiota composition and childhood (over)weight development; 2) examine the impact of childhood exposure to oral antibiotics and (over)weight development; and 3) address the methodological challenge of reducing high dimensional data of the gut microbiota in relation to latent BMI z-scores trajectories. To address these aims, a combination of advanced molecular microbial methods, a well-designed prospective epidemiological study and state-of-the-art biostatistical methods were used.

Chapter 2 of this thesis presents a study on the association between the infant gut microbiota composition at one month of age as determined by real-time PCR, and the development of childhood overweight using anthropometric measures (weightand BMI z-score, and overweight) over a period of ten years. Generalised estimation equations were used to take into account correlations between repeated anthropometric measurements within children. Chapter 3 examines the gut microbiota of children at the age of 6-7 years in association childhood overweight. At this age the microbiota is assumed to be more stable, resilient and adult-like. In addition, instead of measuring a few species of the gut microbiota, a broad, high-resolution interrogation of the entire gut microbial community using the Human Intestinal Tract Chip (HITChip) was performed. Advanced statistical methods (Elastic net, and Redundancy data analysis (RDA)) were then applied for both the reduction of the high dimensionality data obtained and investigating the association of the gut microbiota with childhood body weight. In chapter 4, we identified the presence of two species of archaea, Methanobrevibacter smithii, and Methanosphaerae stadtmanae, in the faecal samples of 472 children at 6-7 years of age using real-time qPCR assays. After identification of

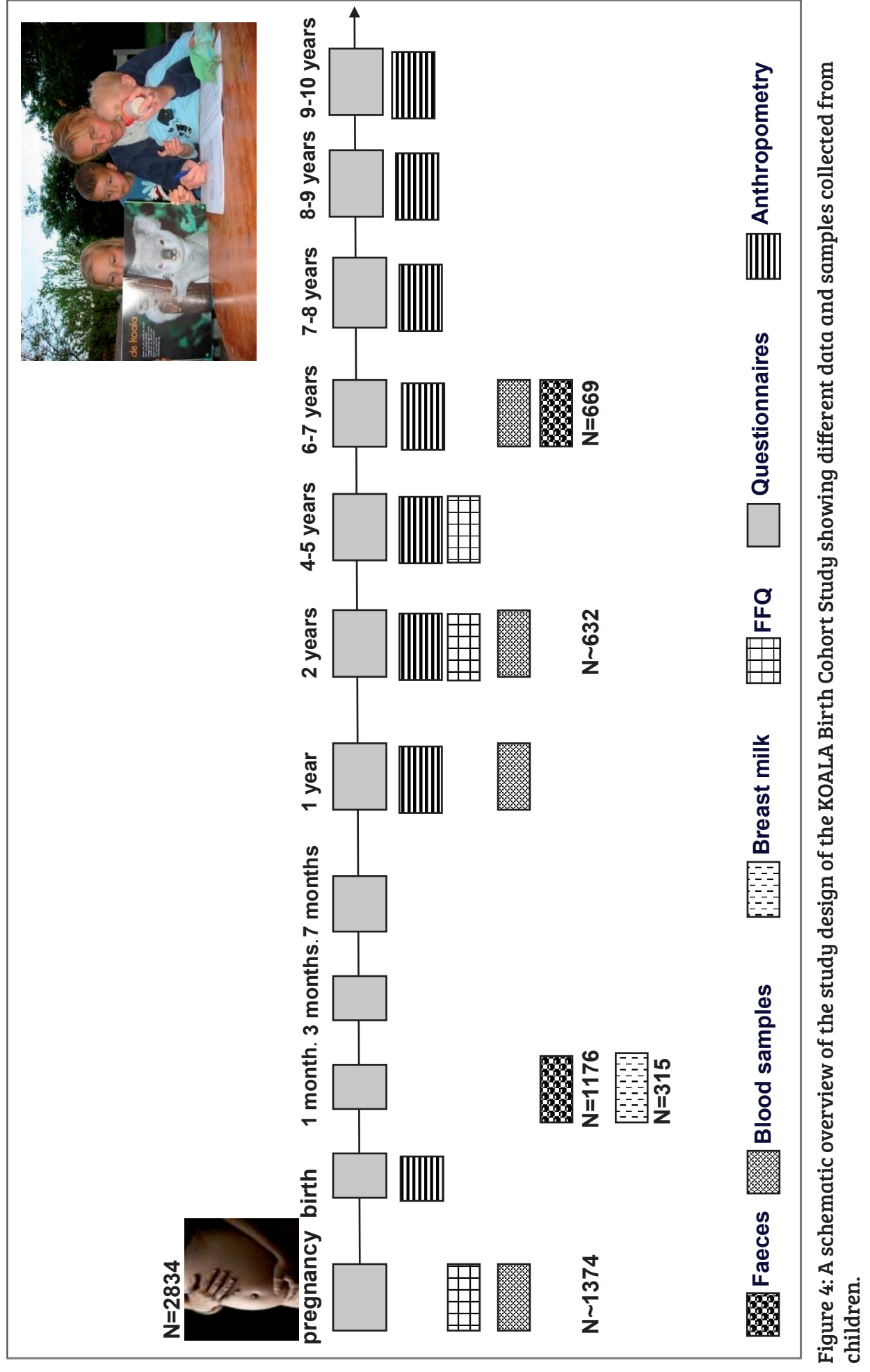


these archaea, their associations with childhood weight development from $6-10$ years of age were investigated.

There is evidence suggesting that oral administration of antibiotics may lead to childhood overweight, through modulation of the composition of the normal healthy gut microbiota. The work presented in chapter 5 was aimed at examining the association between childhood exposure to oral antibiotics (including the timing, frequency and type) over a period of $0-10$ years in relation to anthropometric outcomes (weightheight- and BMI z-scores) measured repeatedly over this period.

Group-based trajectory modelling (GBTM) was used to delineate and visualize distinct childhood weight developmental patterns (BMI z-scores trajectories) from 6 to 10 years of age. Data from the gut microbiota was then used to investigate if there exist potential bacterial group candidates that could be used to differentiate these BMI z-score trajectories (chapter 6). The final chapter, chapter 7, summarises and discusses the findings of this thesis and provides recommendations for future research.

\section{References}

1. Johnson W, Soloway LE, Erickson D, Choh AC, Lee M, Chumlea WC et al. A changing pattern of childhood BMI growth during the 20th century: $70 \mathrm{y}$ of data from the Fels Longitudinal Study. The American journal of clinical nutrition 2012 95: 1136-43.

2. Ogden CL, Carroll MD, Kit BK, Flegal KM. Prevalence of childhood and adult obesity in the United States, 2011-2012. Jama 2014; 311: 806-14.

3. Karnik S, Kanekar A. Childhood obesity: a global public health crisis. International journal of preventive medicine 2012; 3: 1-7.

4. Steinbeck KS. The importance of physical activity in the prevention of overweight and obesity in childhood: a review and an opinion. Obesity reviews : an official journal of the International Association for the Study of Obesity 2001; 2: 117-30.

5. Swinburn BA, Caterson I, Seidell JC, James WP. Diet, nutrition and the prevention of excess weight gain and obesity. Public health nutrition 2004; 7: 123-46.

6. Schonbeck Y, Talma H, van Dommelen P, Bakker B, Buitendijk SE, Hirasing RA et al. Increase in prevalence of overweight in Dutch children and adolescents: a comparison of nationwide growth studies in 1980, 1997 and 2009. PloS one 2011; 6: e27608.

7. Organization WH. Global health observatory data repository [database]. Available: Accessed 2013; 24

8. Whitaker RC, Wright JA, Pepe MS, Seidel KD, Dietz WH. Predicting obesity in young adulthood from childhood and parental obesity. N Engl J Med 1997; 337: 869-73.

9. Smith JD, Montano Z, Dishion TJ, Shaw DS, Wilson MN. Erratum to: Preventing weight gain and obesity: indirect effects of the family check-up in early childhood. Prevention science : the offcial journal of the Society for Prevention Research 2015; 16 420.

10. Ben-Sefer E, Ben-Natan M, Ehrenfeld M. Childhood obesity: current literature, policy and implications for practice. International nursing review 2009; 56: $166-$ 73.

11. Booth KM, Pinkston MM, Poston WS. Obesity and the built environment. Journal of the American Dietetic Association 2005; 105: S110-7.

12. Hill JO, Wyatt HR, Reed GW, Peters JC. Obesity and the environment: where do we go from here? Science (New York, N.Y.) 2003; 299: 853-5.

13. Guo X, Zheng L, Li Y, Yu S, Sun G, Yang H et al. Differences in lifestyle behaviors, dietary habits, and familial factors among normal-weight, overweight, and obese Chinese children and adolescents. The international journal of behavioral nutrition and physical activity 2012; 9: 120. 
14. Chaput JP, Despres JP, Bouchard C, Tremblay A. Longer sleep duration associates with lower adiposity gain in adult short sleepers. International journal of obesity (2005) 2012; 36: 752-6.

15. Bolijn R, Gubbels JS, Sleddens EF, Kremers SP, Thijs C. Daytime sleep duration and the development of childhood overweight: the KOALA Birth Cohort Study. Pediatric obesity 2015.

16. Labree W, van de Mheen D, Rutten F, Rodenburg G, Koopmans G, Foets M. Differences in Overweight and Obesity among Children from Migrant and Native Origin: The Role of Physical Activity, Dietary Intake, and Sleep Duration. PloS one 2015; 10: e0123672.

17. Lytle LA. Examining the etiology of childhood obesity: The IDEA study. American journal of community psychology 2009; 44: 338-49.

18. Koleva PT, Bridgman SL, Kozyrskyj AL. The infant gut microbiome: evidence for obesity risk and dietary intervention. Nutrients 2015; 7: 2237-60

19. Qin J, Li R, Raes J, Arumugam M, Burgdorf KS, Manichanh C et al. A human gut microbial gene catalogue established by metagenomic sequencing. Nature 2010 464: 59-65.

20. Backhed F, Ley RE, Sonnenburg JL, Peterson DA, Gordon JI. Host-bacteria mutualism in the human intestine. Science (New York, N.Y.) 2005; 307: 1915-20.

21. Zoetendal EG, Raes J, van den Bogert B, Arumugam M, Booijink CC, Troost FJ et al. The human small intestinal microbiota is driven by rapid uptake and conversion of simple carbohydrates. The ISME journal 2012; 6: 1415-26.

22. Serino M, Chabo C, Burcelin R. Intestinal MicrobiOMICS to define health and disease in human and mice. Current pharmaceutical biotechnology 2012; 13: 74658.

23. Ley RE, Backhed F, Turnbaugh P, Lozupone CA, Knight RD, Gordon JI. Obesity alters gut microbial ecology. Proceedings of the National Academy of Sciences of the United States of America 2005; 102: 11070-5.

24. Brahe LK, Astrup A, Larsen LH. Is butyrate the link between diet, intestinal microbiota and obesity-related metabolic diseases? Obesity reviews : an official journal of the International Association for the Study of Obesity 2013; 14: 950-9.

25. Spang A, Saw JH, Jorgensen SL, Zaremba-Niedzwiedzka K, Martijn J, Lind AE et al. Complex archaea that bridge the gap between prokaryotes and eukaryotes. Nature 2015; 521: 173-9.

26. Miller TL, Wolin MJ, Conway de Macario E, Macario AJ. Isolation of Methanobrevibacter smithii from human feces. Applied and environmental microbiology 1982; 43: 227-32.

27. Miller TL, Wolin MJ. Methanosphaera stadtmaniae gen. nov., sp. nov.: a species that forms methane by reducing methanol with hydrogen. Arch Microbiol 1985 141: $116-22$.
28. Dridi B, Fardeau ML, Ollivier B, Raoult D, Drancourt M. Methanomassiliicoccus luminyensis gen. nov., sp. nov., a methanogenic archaeon isolated from human faeces. International journal of systematic and evolutionary microbiology 2012; 62 1902-7.

29. Hooper LV, Midtvedt T, Gordon JI. How host-microbial interactions shape the nutrient environment of the mammalian intestine. Annual review of nutrition 2002; 22: 283-307.

30. Cummings JH. Microbial digestion of complex carbohydrates in man. The Proceedings of the Nutrition Society 1984; 43: 35-44

31. Aagaard K, Ma J, Antony KM, Ganu R, Petrosino J, Versalovic J. The placenta harbors a unique microbiome. Science translational medicine 2014; 6: $237 \mathrm{ra65}$.

32. DiGiulio DB. Diversity of microbes in amniotic fluid. Seminars in fetal \& neonatal medicine 2012; 17: 2-11.

33. Funkhouser LJ, Bordenstein SR. Mom knows best: the universality of materna microbial transmission. PLoS biology 2013; 11: e1001631.

34. Yatsunenko T, Rey FE, Manary MJ, Trehan I, Dominguez-Bello MG, Contreras $\mathrm{M}$ et al. Human gut microbiome viewed across age and geography. Nature 2012 486: $222-7$.

35. Koenig JE, Spor A, Scalfone N, Fricker AD, Stombaugh J, Knight R et al. Succession of microbial consortia in the developing infant gut microbiome. Proceedings of the National Academy of Sciences of the United States of America 2011; 108 Suppl 1: 4578-85.

36. Palmer C, Bik EM, DiGiulio DB, Relman DA, Brown PO. Development of the human infant intestinal microbiota. PLoS biology 2007; 5: e177.

37. Hollister EB, Riehle K, Luna RA, Weidler EM, Rubio-Gonzales M, Mistretta TA et al. Structure and function of the healthy pre-adolescent pediatric gut microbiome. Microbiome 2015; 3: 36.

38. Penders J, Thijs C, van den Brandt PA, Kummeling I, Snijders B, Stelma F et al. Gut microbiota composition and development of atopic manifestations in infancy: the KOALA Birth Cohort Study. Gut 2007; 56: 661-7.

39. Jandhyala SM, Talukdar R, Subramanyam C, Vuyyuru H, Sasikala M, Nageshwa Reddy D. Role of the normal gut microbiota. World journal of gastroenterology : WJG 2015; 21: 8787-803.

40. Penders J, Thijs C, Vink C, Stelma FF, Snijders B, Kummeling I et al. Factors influencing the composition of the intestinal microbiota in early infancy. Pediatrics 2006; 118: 511-21.

41. Rodriguez JM, Murphy K, Stanton C, Ross RP, Kober OI, Juge N et al. The composition of the gut microbiota throughout life, with an emphasis on early life. Microbial ecology in health and disease 2015; 26: 26050 
42. Dethlefsen L, Huse S, Sogin ML, Relman DA. The pervasive effects of an antibiotic on the human gut microbiota, as revealed by deep $16 \mathrm{~S}$ rRNA sequencing. PLoS biology 2008; 6: e280.

43. Zoetendal EG, Akkermans AD, Akkermans-van Vliet WM, de Visser JAG, de Vos WM. The host genotype affects the bacterial community in the human gastronintestinal tract. Microbial ecology in health and disease 2001; 13: 129-134.

44. Turnbaugh PJ, Hamady M, Yatsunenko T, Cantarel BL, Duncan A, Ley RE et al. A core gut microbiome in obese and lean twins. Nature 2009; 457: 480-4.

45. Dethlefsen L, McFall-Ngai M, Relman DA. An ecological and evolutionary perspective on human-microbe mutualism and disease. Nature 2007; 449: 811-8.

46. Zoetendal EG, Vaughan EE, de Vos WM. A microbial world within us. Molecular microbiology 2006; 59: 1639-50.

47. Duncan SH, Lobley GE, Holtrop G, Ince J, Johnstone AM, Louis P et al. Human colonic microbiota associated with diet, obesity and weight loss. International journal of obesity (2005) 2008; 32: 1720-4.

48. Furet JP, Kong LC, Tap J, Poitou C, Basdevant A, Bouillot JL et al. Differential adaptation of human gut microbiota to bariatric surgery-induced weight loss: links with metabolic and low-grade inflammation markers. Diabetes 2010; 59: 3049-57.

49. Le Chatelier E, Nielsen T, Qin J, Prifti E, Hildebrand F, Falony G et al. Richnes of human gut microbiome correlates with metabolic markers. Nature 2013; 500: 541-6.

50. Turnbaugh PJ, Ridaura VK, Faith JJ, Rey FE, Knight R, Gordon JI. The effect of diet on the human gut microbiome: a metagenomic analysis in humanized gnotobiotic mice. Science translational medicine 2009; 1: 6ra14.

51. Vael C, Verhulst SL, Nelen V, Goossens H, Desager KN. Intestinal microflora and body mass index during the first three years of life: an observational study. Gut pathogens 2011; 3: 8 .

52. Xu P, Li M, Zhang J, Zhang T. Correlation of intestinal microbiota with overweight and obesity in Kazakh school children. BMC microbiology 2012; 12: 283.

53. Zhang H, DiBaise JK, Zuccolo A, Kudrna D, Braidotti M, Yu Y et al. Human gut microbiota in obesity and after gastric bypass. Proceedings of the National Academy of Sciences of the United States of America 2009; 106: 2365-70.

54. Bervoets L, Van Hoorenbeeck K, Kortleven I, Van Noten C, Hens N, Vael C et al. Differences in gut microbiota composition between obese and lean children: a cross-sectional study. Gut pathogens 2013; 5: 10

55. Zuo HJ, Xie ZM, Zhang WW, Li YR, Wang W, Ding XB et al. Gut bacteria alteration in obese people and its relationship with gene polymorphism. World journal of gastroenterology : WJG 2011; 17: 1076-81.

56. Ley RE, Turnbaugh PJ, Klein S, Gordon JI. Microbial ecology: human gut microbes associated with obesity. Nature 2006; 444: 1022-3.
57. Kasai C, Sugimoto K, Moritani I, Tanaka J, Oya Y, Inoue H et al. Comparison of the gut microbiota composition between obese and non-obese individuals in a Japanese population, as analyzed by terminal restriction fragment length polymorphism and next-generation sequencing. BMC gastroenterology 2015; 15 100.

58. Verdam FJ, Fuentes S, de Jonge C, Zoetendal EG, Erbil R, Greve JW et al. Human intestinal microbiota composition is associated with local and systemic inflammation in obesity. Obesity (Silver Spring, Md.) 2013; 21: E607-15.

59. Balamurugan R, George G, Kabeerdoss J, Hepsiba J, Chandragunasekaran AM, Ramakrishna BS. Quantitative differences in intestinal Faecalibacterium prausnitzii in obese Indian children. The British journal of nutrition 2010; 103: 335-8.

60. Mai V, McCrary QM, Sinha R, Glei M. Associations between dietary habits and body mass index with gut microbiota composition and fecal water genotoxicity: an observational study in African American and Caucasian American volunteers. Nutr J 2009; 8: 49 .

61. Schwiertz A, Taras D, Schafer K, Beijer S, Bos NA, Donus C et al. Microbiota and SCFA in lean and overweight healthy subjects. Obesity (Silver Spring, Md.) 2010; 18: $190-5$.

62. Hu HJ, Park SG, Jang HB, Choi MG, Park KH, Kang JH et al. Obesity Alters the Microbial Community Profile in Korean Adolescents. PloS one 2015; 10: e0134333.

63. Fernandes J, Su W, Rahat-Rozenbloom S, Wolever TM, Comelli EM. Adiposity, gut microbiota and faecal short chain fatty acids are linked in adult humans. Nutrition \& diabetes 2014; 4: e121.

64. Yasir M, Angelakis E, Bibi F, Azhar EI, Bachar D, Lagier JC et al. Comparison of the gut microbiota of people in France and Saudi Arabia. Nutrition \& diabetes 2015; 5: e153.

65. Heinritz SN, Mosenthin R, Weiss E. Use of pigs as a potential model for research into dietary modulation of the human gut microbiota. Nutrition research reviews 2013; 26: 191-209.

66. Houpt TR, Anika SM, Houpt KA. Preabsorptive intestinal satiety controls of food intake in pigs. The American journal of physiology 1979; 236: R328-37.

67. Turnbaugh PJ, Backhed F, Fulton L, Gordon JI. Diet-induced obesity is linked to marked but reversible alterations in the mouse distal gut microbiome. Cell host \& microbe 2008; 3: 213-23.

68. Turnbaugh PJ, Ley RE, Mahowald MA, Magrini V, Mardis ER, Gordon JI. An obesity-associated gut microbiome with increased capacity for energy harvest. Nature 2006; 444: 1027-31

69. Alang N, Kelly CR. Weight gain after fecal microbiota transplantation. Open forum infectious diseases 2015; 2: ofv004. 
70. Vrieze A, Van Nood E, Holleman F, Salojarvi J, Kootte RS, Bartelsman JF et al. Transfer of intestinal microbiota from lean donors increases insulin sensitivity in individuals with metabolic syndrome. Gastroenterology 2012; 143: 913-6 e7.

71. Dridi B, Henry M, El Khechine A, Raoult D, Drancourt M. High prevalence of Methanobrevibacter smithii and Methanosphaera stadtmanae detected in the human gut using an improved DNA detection protocol. PloS one 2009; 4: e7063.

72. Wolever TM, Robb PA, Ter Wal P, Spadafora PG. Interaction between methaneproducing status and diet on serum acetate concentration in humans. The Journal of nutrition 1993; 123: 681-8.

73. Deppenmeier U. The unique biochemistry of methanogenesis. Prog Nucleic Acid Res Mol Biol 2002; 71: 223-83.

74. Fricke WF, Seedorf H, Henne A, Kruer M, Liesegang H, Hedderich R et al. The genome sequence of Methanosphaera stadtmanae reveals why this human intestinal archaeon is restricted to methanol and $\mathrm{H} 2$ for methane formation and ATP synthesis. Journal of bacteriology 2006; 188: 642-58.

75. Backhed F, Ding H, Wang T, Hooper LV, Koh GY, Nagy A et al. The gut microbiota as an environmental factor that regulates fat storage. Proceedings of the National Academy of Sciences of the United States of America 2004; 101: 15718-23.

76. Backhed F, Manchester JK, Semenkovich CF, Gordon JI. Mechanisms underlying the resistance to diet-induced obesity in germ-free mice. Proceedings of the National Academy of Sciences of the United States of America 2007; 104: 979-84.

77. Samuel BS, Shaito A, Motoike T, Rey FE, Backhed F, Manchester JK et al. Effects of the gut microbiota on host adiposity are modulated by the short-chain fatty-acid binding G protein-coupled receptor, Gpr41. Proceedings of the National Academy of Sciences of the United States of America 2008; 105: 16767-72.

78. Bjursell M, Admyre T, Goransson M, Marley AE, Smith DM, Oscarsson J et al. Improved glucose control and reduced body fat mass in free fatty acid receptor 2-deficient mice fed a high-fat diet. American journal of physiology. Endocrinology and metabolism 2011; 300: E211-20.

79. Cherbut C, Ferrier L, Roze C, Anini Y, Blottiere H, Lecannu G et al. Short-chain fatty acids modify colonic motility through nerves and polypeptide YY release in the rat. The American journal of physiology 1998; 275: G1415-22

80. Freeland KR, Wolever TM. Acute effects of intravenous and rectal acetate on glucagon-like peptide-1, peptide YY, ghrelin, adiponectin and tumour necrosis factor-alpha. The British journal of nutrition 2010; 103: 460-6.

81. Cani PD, Bibiloni R, Knauf C, Waget A, Neyrinck AM, Delzenne NM et al. Changes in gut microbiota control metabolic endotoxemia-induced inflammation in high-fat diet-induced obesity and diabetes in mice. Diabetes 2008; 57: 1470-81.

82. Cani PD, Delzenne NM. The role of the gut microbiota in energy metabolism and metabolic disease. Curr Pharm Des 2009; 15: 1546-58.
83. Brun P, Castagliuolo I, Di Leo V, Buda A, Pinzani M, Palu G et al. Increased intestinal permeability in obese mice: new evidence in the pathogenesis of nonalcoholic steatohepatitis. American journal of physiology. Gastrointestinal and liver physiology 2007; 292: G518-25.

84. Muccioli GG, Naslain D, Backhed F, Reigstad CS, Lambert DM, Delzenne NM et al. The endocannabinoid system links gut microbiota to adipogenesis. Molecular systems biology 2010; 6: 392

85. de La Serre CB, Ellis CL, Lee J, Hartman AL, Rutledge JC, Raybould HE Propensity to high-fat diet-induced obesity in rats is associated with changes in the gut microbiota and gut inflammation. American journal of physiology. Gastrointestinal and liver physiology 2010; 299: G440-8.

86. Amar J, Burcelin R, Ruidavets JB, Cani PD, Fauvel J, Alessi MC et al. Energy intake is associated with endotoxemia in apparently healthy men. The American journal of clinical nutrition 2008; 87: 1219-23.

87. Bastiaanssen JM, de Bie RA, Bastiaenen CH, Heuts A, Kroese ME, Essed GG et al. Etiology and prognosis of pregnancy-related pelvic girdle pain; design of a longitudinal study. BMC public health 2005; 5: 1.

88. Moreno-Indias I, Cardona F, Tinahones FJ, Queipo-Ortuno MI. Impact of the gut microbiota on the development of obesity and type 2 diabetes mellitus. Frontiers in microbiology 2014; 5: 190. 


\section{CHAPTER 2}

THE INTESTINAL MICROBIOTA COMPOSITION AND WEIGHT DEVELOPMENT IN CHILDREN: THE KOALA BIRTH COHORT STUDY 


\section{Abstract}

Objective To investigate whether the intestinal microbiota composition in early infancy is associated with subsequent weight development in children.

Methods Analyses were conducted within the KOALA Birth Cohort Study ( $\mathrm{n}=2834$ ). This cohort originates from two recruitments groups, pregnant women with a conventional lifestyle (no selection based on lifestyle) and pregnant women recruited through alternative channels (organic shops, anthroposophic clinicians/midwives, Steiner schools, and relevant magazines). From 909 one-month-old infants fecal samples were collected and analyzed by qPCR targeting bifidobacteria, Bacteroides fragilis-group Clostridium difficile, Escherichia coli, lactobacilli, and total bacteria counts. Between the ages of 1-10 years, parent-reported weight and height was collected at 7 time points Age- and gender-standardized Body Mass Index (BMI) z-scores were calculated. Data were analyzed using Generalized Estimating Equation.

Results Colonization with $B$. fragilis-group was borderline significantly associated with a higher BMI z-score of 0.15 (95\% CI: -0.02 to 0.31 ), in the conventional subcohort. After stratification for fiber intake $\left(\mathrm{p}_{\text {forinteraction }} 0.003\right)$, colonization with $B$. fragilis-group was associated with a 0.34 higher BMI z-score among children with a low fiber intake in this subcohort (95\% CI: 0.17 to 0.53 ). Higher counts among colonized children were positively associated with BMI z-score only in children within the conventional subcohort and a high fiber diet (BMI z-score 0.08 ; 95\% CI: 0.01 to 0.14 ), but inversely associated in children with a low fiber diet (BMI z-score -0.05 ; 95\% CI: -0.10 to 0.00 ), and in children recruited through alternative channels (BMI z-score $-0.10 ; 95 \% \mathrm{CI}$ : -0.17 to -0.03$)$. The other bacteria were not associated with BMI z-scores, regardless of subcohort.

Conclusion Using a targeted approach, we conclude that the intestinal microbiota, particularly the $B$. fragilis-group, is associated with childhood weight development. To identify the potential impact of additional bacterial taxa, further prospective studies applying an unconstrained in-depth characterization of the microbiota are needed.

\section{Introduction}

Overweight and obesity can have serious health consequences, including type 2 diabetes and cardiovascular diseases, which are major public health problems ${ }^{1}$. Not only in adults, but also in children, the prevalence of overweight and obesity is increasing ${ }^{2,3}$. The development of obesity is a complex process involving both genetic and environmental factors, such as an increased energy intake and reduced energy expenditure. However, these factors do not fully explain the increased obesity prevalence ${ }^{4,5}$.

Our human gut is colonized with a complex 100 trillion microbe cells, the intestinal microbiota. The intestinal microbiota composition varies between individuals; the development of the infant microbiota is mainly influenced by prenatal exposure: mode of delivery, type of infant feeding, and antibiotic use ${ }^{6}$. Recently, the intestinal microbiota has been identified as a potential determinant of obesity, both in animal and human studies. The study by Ley et al. published in 2005, showed for the first time that the intestinal microbiota differs between lean versus obese mice ${ }^{7}$. Obese mice harbor significantly less Bacteroidetes and more Firmicutes compared to their lean siblings ${ }^{7}$. Furthermore, colonization of germ-free mice with an intestinal microbiota of obese donor mice led to a significantly greater increase in fat deposition than colonization with an intestinal microbiota of lean donors ${ }^{8}$. A limited number of human studies, usually comparing obese with normal weight subjects in a cross-sectional design, have been conducted so far. In addition, the many different methods for characterization of the indigenous microbiota complicate the direct comparison of results between studies (summarized in Table 1). So far, studies have provided contradictory results: some demonstrated a reduced level of Bacteroidetes to be associated with obesity ${ }^{9-14}$, whereas others found the opposite ${ }^{15-17}$, or no association ${ }^{18-22}$. Specific bacterial and archeal genera or species have also been associated with obesity in humans, such as, the Lactobacillus $s p p^{10,22,23}$, bifidobacteria ${ }^{15,24,25}$, Escherichia coli ${ }^{25}$, and Methanobrevibacter smithii ${ }^{10,15}$

${ }^{23}$ (Table 1), but findings were not consistent between studies. To determine whether a different microbiota composition in early infancy is related to subsequent weight development, longitudinal cohort studies are needed. To our knowledge only four human observational studies investigated the relation between intestinal microbiota composition and weight development in a longitudinal manner ${ }^{25-29}$, two of which addressed microbiota in infancy with short term follow-up but not beyond infancy ${ }^{28}$, ${ }^{29}$ and two others addressed microbiota at ages 6-12 months and 3 months, in children with follow-up until 7 years and 10 years, respectively ${ }^{25-27}$ (Table 1).

Several mechanisms have been put forward to explain how the interaction between microbiota and host metabolism may contribute to obesity ${ }^{30,31}$. Certain species are able to digest dietary fiber, i.e. complex carbohydrates that cannot be degraded by human enzymes, thus yielding energy for microbial growth and end products such as short-chain fatty acids (SCFAs). The latter have profound effects on human metabolism because they can serve as energy substrates for the gut (butyrate) and peripheral tissues (acetate, 
propionate), modulate inflammation and wound healing, and act as vasodilators ${ }^{30,31}$ In addition, SCFAs can signal through G-protein-coupled receptors (GPRs), such as GPR41, on enteroendocrine cells, inducing the secretion of peptide $Y^{32,33}$.

The aim of this study was to investigate whether the intestinal microbiota composition in early infancy is associated with subsequent weight development during childhood. The fecal samples of 909 one-month-old infants were analyzed with quantitative polymerase chain reaction (qPCR) assays, to enumerate several bacterial groups and species and related to weight development up to the age of 10 years.

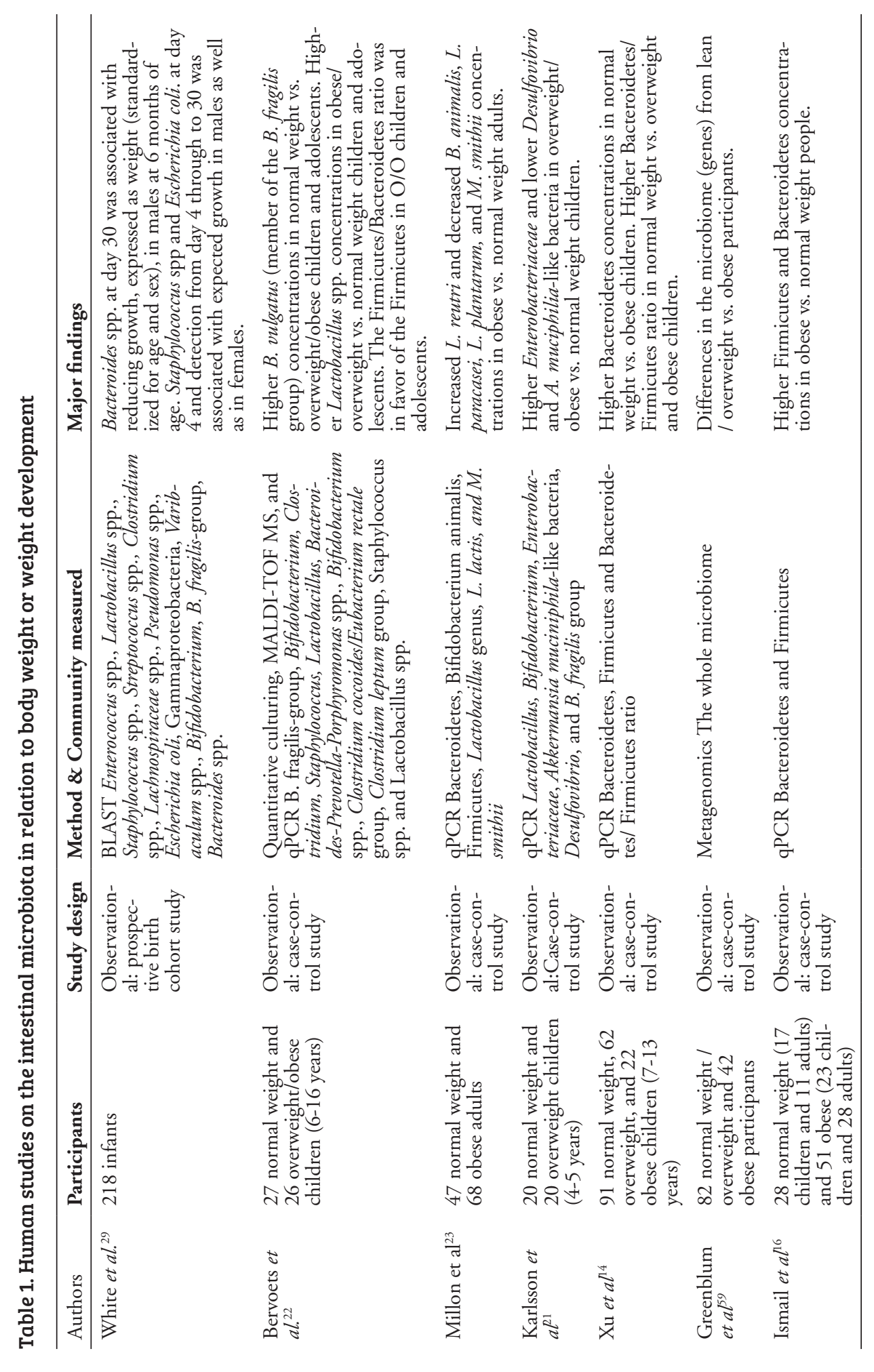



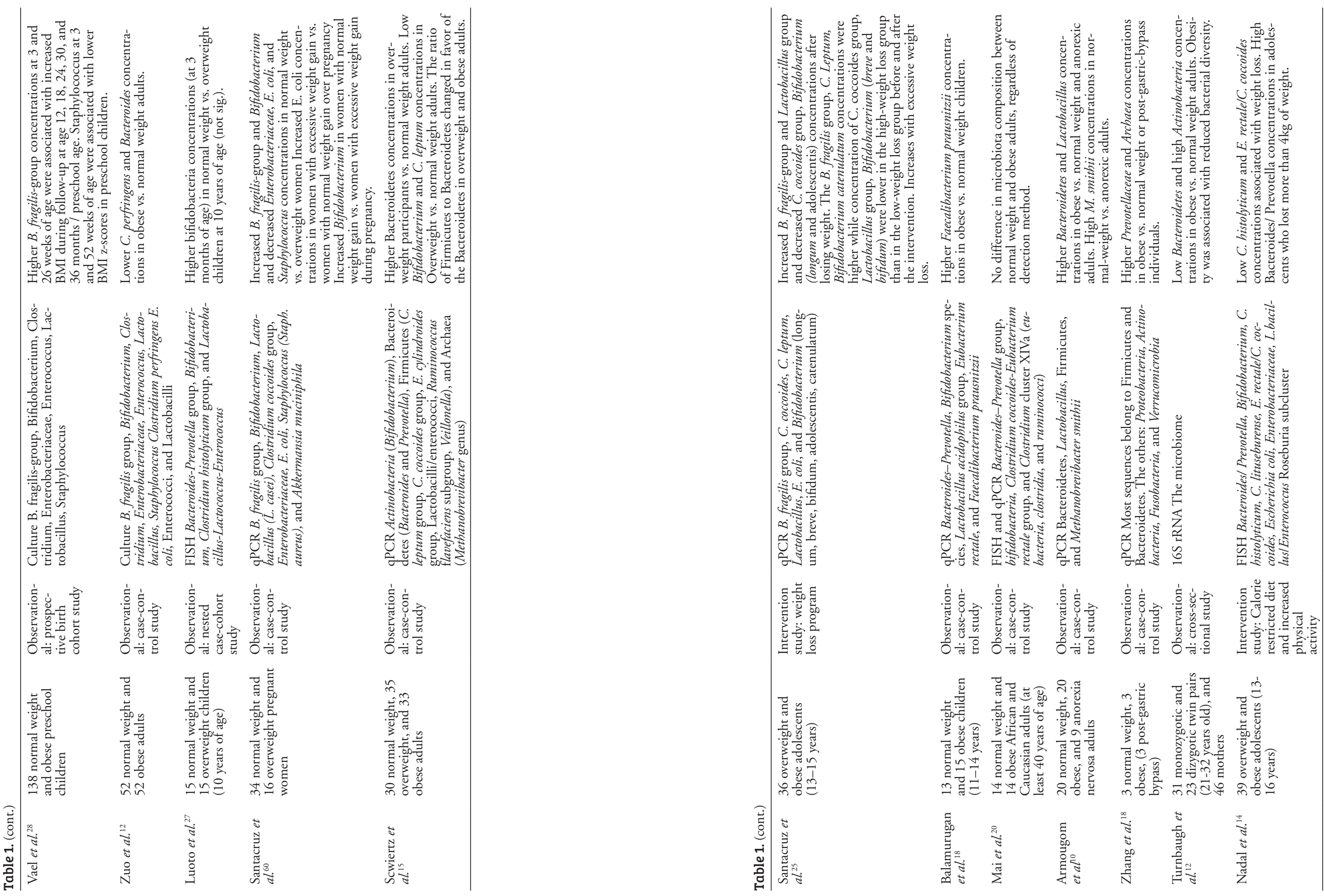


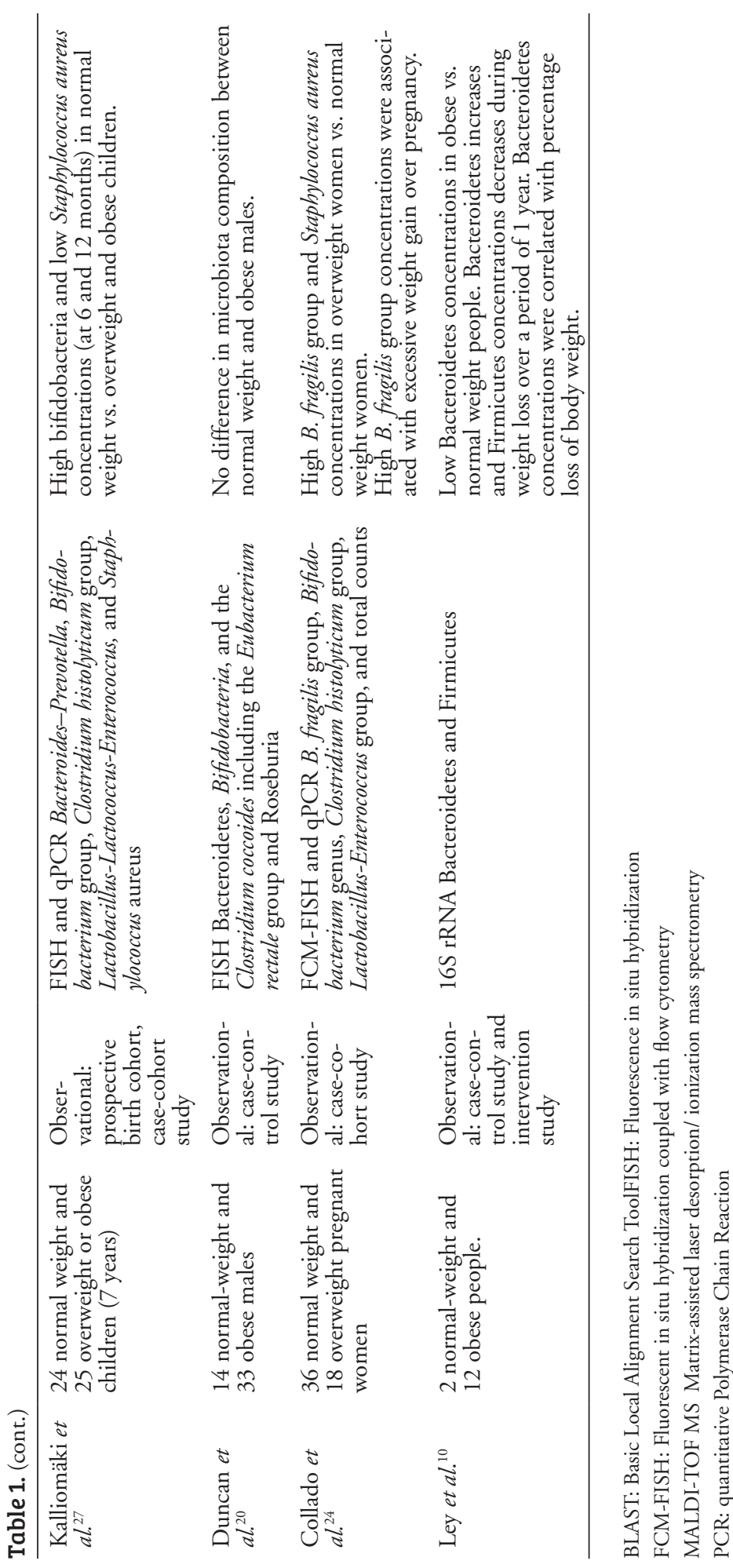

\section{Methods}

\section{Subjects and Study Design}

The current analyses were conducted within the KOALA Birth Cohort Study in the Netherlands. The design of the KOALA study has been described in detail elsewhere ${ }^{34}$. Briefly, this cohort originates from two recruitment groups, healthy pregnant women with a conventional lifestyle $(\mathrm{n}=2343)$ and pregnant women recruited through alternative channels $(\mathrm{n}=491)$. The women with a conventional lifestyle were retrieved from an on-going prospective pregnancy cohort study on pregnancy-related pelvic girdle pain in the Netherlands ${ }^{35}$. The second group of pregnant women were recruited through alternative channels, i.e. posters in organic food shops, anthroposophic doctors and midwives, anthroposophic under-five clinics, Rudolf Steiner schools, and magazines for special interest groups. This latter group of women was considered to have an alternative lifestyle, which could involve dietary habits (vegetarian, organic), child rearing practices, vaccination schemes and/or use of antibiotics. All participants were enrolled at 34 weeks of gestation.

Women recruited from January 2002 until December 2002 ( $n=1176)$ collected a fecal sample from their child approximately one month postpartum. Inclusion criteria for the present analyses were: availability of a fecal sample collected between 3 and 6 weeks of life, sufficient amount of feces ( $\geq 1 \mathrm{~g}$ ), and parental completion of the accompanying questionnaire (fecal collection questionnaire)

Exclusion criteria were: prematurity (infants born before 37 weeks of gestation), twins, congenital abnormalities related to growth (such as Down's syndrome, Turner syndrome, Fallot's tetralogy multiple disabilities), administration of antimicrobial agents before feces collection, and children without any BMI measurement (Figure 1). All parents signed the informed consent and the study was approved by the Medical Ethics Committee of Maastricht University Medical Center+ (Maastricht UMC+). 


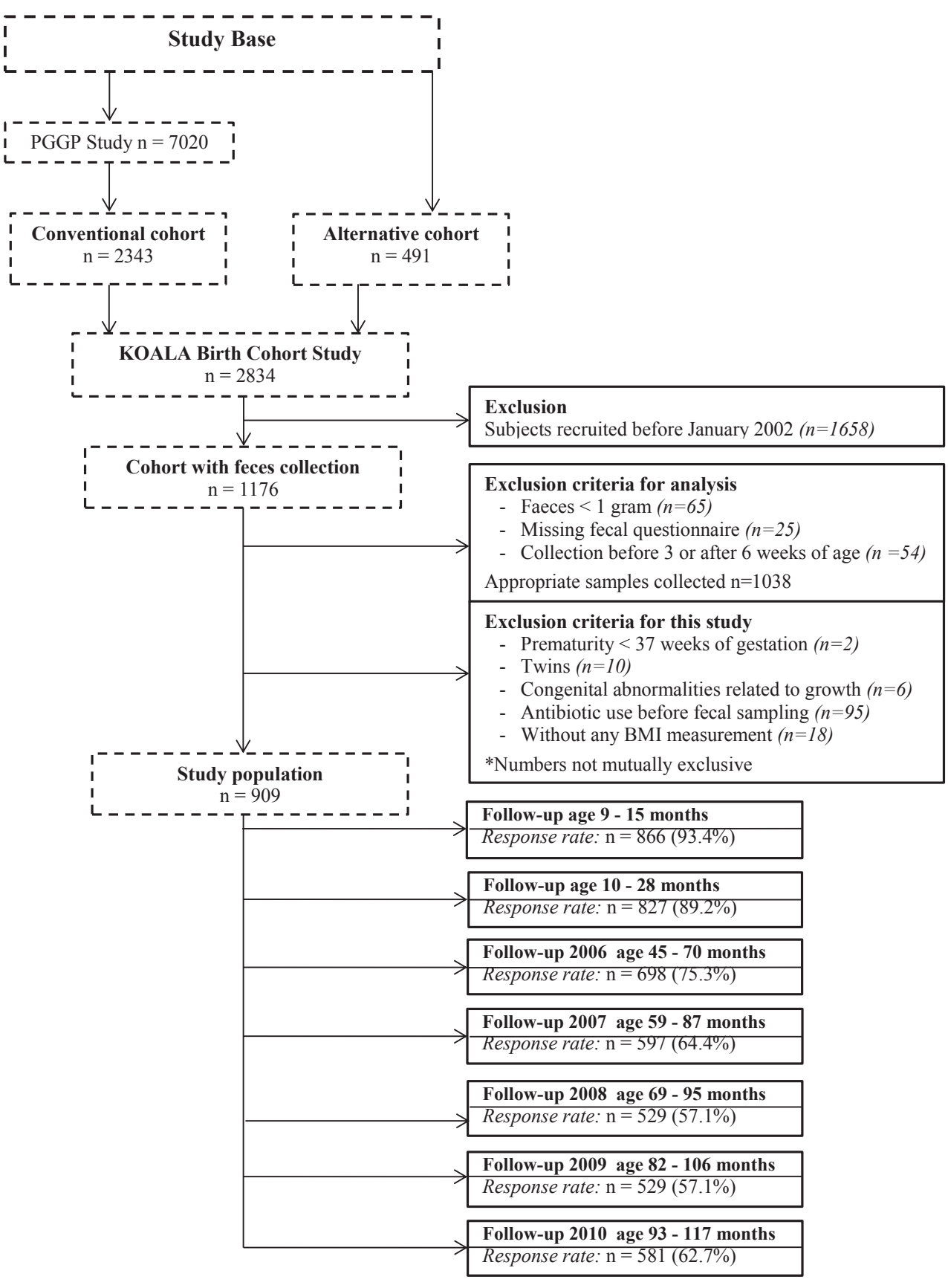

FIGURE 1. Flow chart of the study population. The KOALA Birth Cohort study included pregnant women with a conventional lifestyle (recruited from the on-going Pregnancyrelated Pelvic Girdle Pain study (PPGP)) or an alternative lifestyle (recruited from

'alternative' channels). Participants recruited from January 2002 onwards were asked to collect a fecal sample of their child. Reasons for exclusion with numbers, and response rates on the seven weight and height questionnaires are presented.

\section{Fecal collection and Microbial analysis}

Parents were asked to collect the feces of their child at one month postpartum. They received a feces tube with a spoon attached to the lid (Sarstedt, Nümbrecht, Germany), together with a sanitary napkin, an instruction form about the correct collection and sending procedure, and a brief questionnaire. Parents placed a sanitary napkin in the diaper to prevent absorption by the diaper; collection of the feces was done by spoon and deposited in the tube. The tube was sent to the Medical Microbiology department at Maastricht UMC+ by post as soon as possible. Transport time was minimized by asking the parents to collect the feces on a Monday, Tuesday or Wednesday, so that the samples did not remain in the mail over the weekend.

At the laboratory, fecal samples were 10-fold diluted in peptone-water (Oxoid CM009) containing $20 \% \mathrm{v} / \mathrm{v}$ glycerol (Merck, Darmstadt, Germany) and stored at $-20^{\circ} \mathrm{C}$ until analysis.

DNA extraction from the feces and the subsequent microbial analyses by means of real-time PCR assays has been described in detail elsewhere ${ }^{6}$. Briefly, the DNA was extracted by a combination of bead-beating and the QIAamp DNA Stool Mini Kit (Qiagen, Hilden, Germany). DNA from all fecal samples was subjected to real-time PCRs for quantification of bifidobacteria, Bacteroides fragilis group, Clostridium difficile, Escherichia coli, lactobacilli, and total bacteria based on 16S rDNA gene sequences. For detection of the bifidobacteria, C. diffcile, E. coli, and members of the bacteroides, the 5'-nuclease technique was used. For quantification of lactobacilli and total bacteria load, real-time detection of PCR products was conducted by means of SYBR Green I (Bio-Rad Laboratories, Hercules, CA). The validation of the real-time PCR assays has been described in detail elsewhere ${ }^{36-38} \cdot \log _{10}$ colony-forming units per gram $\left(\log _{10}\right.$ CFU/g) were calculated for each stool sample from the threshold cycle values by using the constructed standard curves. The prevalence of colonization was expressed as the percentage of infants colonized with a specific bacterial group or species. Since almost all infants were colonized with bifidobacteria, a cut-off value of $10.68 \log _{10} \mathrm{CFU} / \mathrm{g}$ (the median) was used to divide the population into those with a low or high abundance of the genus.

\section{Outcome variable}

Information on the child's weight, height and age at the time of measurements was collected using self-administered questionnaires. Parents were asked to report their child's body weight and height at 7 different time points. At the first and second time points, where the children had an average age \pm standard deviation (SD) of $11 \pm 1$ months and $22 \pm 3$ months, respectively, parents were asked to report the most recent weight and height measured at the child health clinic, and to also report the age (in months) at the time of these measurements. At the further follow-up time points, in 2006 (age $56 \pm 4$ months), 2007 (age $73 \pm 5$ months), 2008 (age $80 \pm 5$ months), 2009 
(age $92 \pm 5$ months), and 2010 (age $103 \pm 5$ months), parents were asked to measure weight (in kilograms specified to one decimal) and height (in centimeters) without shoes and clothes and to report the exact date of measurement. BMI (weight $/ h^{2}$ ight ${ }^{2}, \mathrm{~kg} / \mathrm{m}^{2}$ ) was standardized by recoding it into age- and gender specific BMI z-scores using data from the Dutch reference population ${ }^{39}$.

\section{Statistical analysis}

The characteristics of the participants are given as mean values \pm SD for continuous variables and as numbers and proportions for categorical variables. Missing values for continuous covariables were replaced with the mean (maternal pre-pregnancy BMI $n=2$, age at collection of fecal sample $\mathrm{n}=10$ ), and missing values for categorical covariables were classified as 'unknown' (place and mode of delivery $n=23$, maternal education of the mother $\mathrm{n}=10$ ).

Generalized Estimating Equation (GEE) models with unstructured correlation structure were used for analysis of the repeated BMI z-scores. The analyses included only one bacterial group or species at a time. When bacterial counts were used as an independent variable, only infants who were colonized with that specific bacterial group or species were included. The age of the child at the time of BMI measurement was included in all models as the time variable. We tested if the association between the intestinal microbiota composition and BMI z-scores differed with increasing age by including an interaction term in the GEE models. When the interaction term was significant ( $p$-value $<0.05$ ), we performed linear regression analyses for each BMI measurement separately. Participants were recruited through two different recruitment channels (representing a conventional or alternative lifestyle); we therefore tested for interaction between the intestinal microbiota and recruitment group. The interaction term was significant for C. difficile ( $\mathrm{p}$ 0.037) and B. fragilis-group (p 0.032); we therefore performed all analyses stratified for lifestyle.

First, unadjusted GEE analyses were performed to determine the association between colonization (yes/no) and bacterial counts $\left(\log _{10} \mathrm{CFU} / \mathrm{g}\right.$ ), and BMI z-scores. Second, adjusted GEE analyses were conducted that included potential confounders. If the potential confounder changed the regression coefficient of any of the main determinants by more than $10 \%$, it was consequently included in all models. The following variables were considered: infant gender (male, female), place and mode of delivery (vaginal delivery at home, vaginal delivery in hospital, artificial delivery in hospital, caesarean section in hospital), birth weight (grams), maternal pre-pregnancy BMI $\left(\mathrm{kg} / \mathrm{m}^{2}\right)$, age at collection of fecal sampling (in days), maternal smoking during pregnancy (number of cigarettes per day), type of infant feeding in the first month (exclusive breastfeeding, exclusive bottle-feeding, or a combination), duration of breastfeeding (months), education level of the mother (lower education, vocational education, higher general secondary/pre-university, or higher vocational/academic education), and total counts of bacteria. Finally, a third model additionally included the following dietary variables: total energy intake, energy percentage from fat, and energy percentage from protein. Dietary information was collected during a period of 4 weeks by a food frequency questionnaire (FFQ) administered at the age of 4 years. The questionnaire was specifically developed to assess children's energy intake and validated by using the doubly labeled water method ${ }^{40}$. The questionnaire consisted of 71 items, and, in addition, for 27 foods the specific types or brands consumed and preparation methods were asked. Parents reported their child's habitual food consumption by indicating the frequency of consumption ('never' to '6-7 days a week') and by specifying proportion sizes in natural units (e.g., pieces, slices), household units (e.g., glasses of spoons) or grams (e.g., grams of fish). Parents were asked to measure volume of the cups and glasses they used for the children. The average energy intake (kJ) and fiber intake (in grams per MJ) per day were calculated using the Netherlands Food Composition Table 2001 (NEVO) ${ }^{41}$. For the products that were not included in the NEVO 2001 table the nutritional values were provided by a dietician.

Fiber intake was considered as a potential effect-modifier. Information on dietary fiber intake at the age of 4 years was also obtained from the FFQ. To determine whether dietary fiber modified the associations between the intestinal microbiota and weight development, a test for interaction with fiber intake was conducted in both recruitment groups. If the interaction term was significant, the analysis was stratified by level of dietary fiber intake (above or below the median of $15.0 \mathrm{~g} /$ day).

Data analysis was performed using the SPSS statistical software package version 19.0 (SPSS Inc., Chicago, IL, USA). The unadjusted (crude) and adjusted (adj) regression coefficients with the corresponding $95 \%$ confidence interval (95\% CI) are presented. A p-value of $<0.05$ was considered statistically significant in all analyses.

\section{Results}

Of the 1176 collected fecal samples, the samples that were too small $(<1 \mathrm{~g})(n=65)$, were collected before the age of 3 weeks or after the age of 6 weeks $(n=54)$, or where the fecal questionnaire was missing $(n=25)$ were excluded. In total 1032 fecal samples were appropriate for microbial analysis ${ }^{6}$. After exclusion of premature infants $(n=2)$, twins $(n=10)$, children with congenital abnormalities related to growth $(n=6)$, children without any BMI measurement $(\mathrm{n}=18)$, and children who received antibiotics prior to fecal sampling $(\mathrm{n}=95)$, the study population consisted of 909 children (Fig 1). Table 2 shows the baseline characteristics of the KOALA cohort $(n=2834)$ and the study population ( $\mathrm{n}=909$ ). In general, the two groups were comparable, except that the study population had more participants with an alternative lifestyle, a higher level of maternal education, and longer duration of breastfeeding, but less mothers who smoked during pregnancy. These differences are mainly due to the period of fecal sampling, which coincided with recruitment of the alternative group. Almost all infants were colonized 
with bifidobacteria (98.6\%), followed by E. coli (88.2\%), and B. fragilis-group (81.2\%), whereas colonization with $C$. difficile (25.3\%) and lactobacilli (31.9\%) was less frequent (Table 2).

TABLE 2 Baseline characteristics of the KOALA Birth Cohort and the study population

\begin{tabular}{|c|c|c|}
\hline & $\begin{array}{l}\text { KOALA Birth } \\
\text { Cohort Study } \\
(\mathbf{n}=2834) \\
\end{array}$ & $\begin{array}{l}\text { Study population } \\
(\mathbf{n}=909)\end{array}$ \\
\hline \multicolumn{3}{|l|}{ Determinants } \\
\hline \multicolumn{3}{|l|}{ Prevalence of colonization with intestinal bacteria, $\mathrm{n}(\%)$} \\
\hline Bifidobacteria & - & 896 (98.6) \\
\hline Escherichia coli & - & $802(88.2)$ \\
\hline Clostridium difficile & - & $230(25.3)$ \\
\hline Bacteroides fragilis group & - & $738(81.2)$ \\
\hline Lactobacilli & - & $290(31.9)$ \\
\hline \multicolumn{3}{|c|}{ Counts of intestinal bacteria $\left(\log _{10} \mathrm{CFU} / \mathrm{g}\right)$, median (range $)^{\S}$} \\
\hline Bifidobacteria & - & $10.69(6.84-11.56)$ \\
\hline Escherichia coli & - & $9.30(5.91-10.79)$ \\
\hline Clostridium difficile & - & $5.40(2.70-9.57)$ \\
\hline Bacteroides fragilis group & - & $9.40(5.74-10.36)$ \\
\hline Lactobacilli & - & $8.66(7.92-10.73)$ \\
\hline Total count & - & $12.69(8.47-19.63)$ \\
\hline \multicolumn{3}{|l|}{ Covariables } \\
\hline Age sampling feces (days), (mean $\pm \mathrm{SD}$ ) & - & $31.7 \pm 3.3$ \\
\hline Recruitment group conventional & $2343(83 \%)$ & $618(68 \%)$ \\
\hline \multicolumn{3}{|l|}{ Maternal education * } \\
\hline Low & $289(10 \%)$ & $60(7 \%)$ \\
\hline Middle & $1060(38 \%)$ & $312(34 \%)$ \\
\hline High & $1341(48 \%)$ & $508(56 \%)$ \\
\hline Other & $108(4 \%)$ & $19(2 \%)$ \\
\hline Maternal pre-pregnancy BMI $\left(\mathrm{kg} / \mathrm{m}^{2}\right),($ mean $\pm \mathrm{SD})$ & $23.6 \pm 4.0$ & $23.3 \pm 3.6$ \\
\hline \multicolumn{3}{|l|}{ Maternal smoking during late pregnancy } \\
\hline Yes & $200(7 \%)$ & $27(3 \%)$ \\
\hline \multicolumn{3}{|l|}{ Gender } \\
\hline Boy & $1451(51 \%)$ & $454(50 \%)$ \\
\hline Birth weight, gram $($ mean $\pm S D)$ & $3500 \pm 512$ & $3562 \pm 467$ \\
\hline$<2500$ & $79(3 \%)$ & $12(1 \%)$ \\
\hline $2500-4500$ & $2663(95 \%)$ & $873(96 \%)$ \\
\hline$>4500$ & $70(3 \%)$ & $24(3 \%)$ \\
\hline \multicolumn{3}{|l|}{ Place and mode of delivery } \\
\hline Natural delivery at home & $1187(42 \%)$ & $432(48 \%)$ \\
\hline Natural delivery in hospital & $924(33 \%)$ & $301(33 \%)$ \\
\hline Artificial delivery at home ${ }^{\dagger}$ & & $2(0 \%)$ \\
\hline Artificial delivery in hospital ${ }^{\dagger}$ & $223(8 \%)$ & $66(7 \%)$ \\
\hline
\end{tabular}

Table 2. (cont.)

\begin{tabular}{|c|c|c|}
\hline Caesarean section in hospital & $311(11 \%)$ & $93(10 \%)$ \\
\hline Duration of breastfeeding, months (mean $\pm S D$ ) & $4.7 \pm 3.0$ & $5.9 \pm 4.5$ \\
\hline \multicolumn{3}{|l|}{ Type of infant feeding } \\
\hline Formula feeding from birth & $446(16 \%)$ & $113(12 \%)$ \\
\hline Combination of breast and formula feeding in first 3 month & $1185(42 \%)$ & $320(35 \%)$ \\
\hline Breastfeeding as the only milk feeding in first 3 months & $614(22 \%)$ & $241(26 \%)$ \\
\hline Breastfeeding as the only milk feeding in first 6 months & $562(20 \%)$ & $235(26 \%)$ \\
\hline \multicolumn{3}{|l|}{ Dietary factors } \\
\hline Total energy intake, kcal (mean $\pm \mathrm{SD}$ ) & $1466 \pm 305$ & $1445 \pm 298$ \\
\hline Energy percentage from fat, $\%$ (mean $\pm S D$ ) & $14.6 \pm 2.1$ & $14.4 \pm 2.1$ \\
\hline Energy percentage from protein, $\%($ mean $\pm S D)$ & $29.6 \pm 4.2$ & $29.4 \pm 4.3$ \\
\hline Energy percentage from carbohydrates, $\%$ (mean $\pm \mathrm{SD}$ ) & $55.8 \pm 5.0$ & $56.1 \pm 5.1$ \\
\hline Fiber, gram $($ mean $\pm S D)$ & $15.3 \pm 4.0$ & $15.4 \pm 4.1$ \\
\hline
\end{tabular}

Numbers do not always add up to the total because of missing data.

$\$$ Includes only children who were colonized with the specific bacteria group or species.

* Low: primary school, preparatory vocational or lower general secondary school, middle: vocational, higher general secondary or pre-university education, high: higher vocational or academic education.

$†$ Forceps or vacuum extraction

Neonatal colonization with $B$. fragilis-group in the conventional subcohort was associated with a statistically significant higher BMI z-score of 0.16 , compared to infants who were not colonized (Table 3). However, this did not remain significant after adjustment (Adj $0.11 ; 95 \%$ CI -0.05 to 0.26 ). Other bacterial groups or species were not associated with BMI z-scores in children in the conventional subcohort. In children, from the alternative subcohort (Table 4), a higher count of $B$. fragilis-group was associated with a significantly lower BMI z-score in both crude and adjusted models (Adj -0.07; 95\% CI -0.15 to 0.00$)$. Other bacterial groups or species were not associated with BMI z-scores in the alternative subcohort.

In the conventional subcohort, the interaction term between colonization with $B$. fragilis-group and fiber intake was significant (p 0.003). 

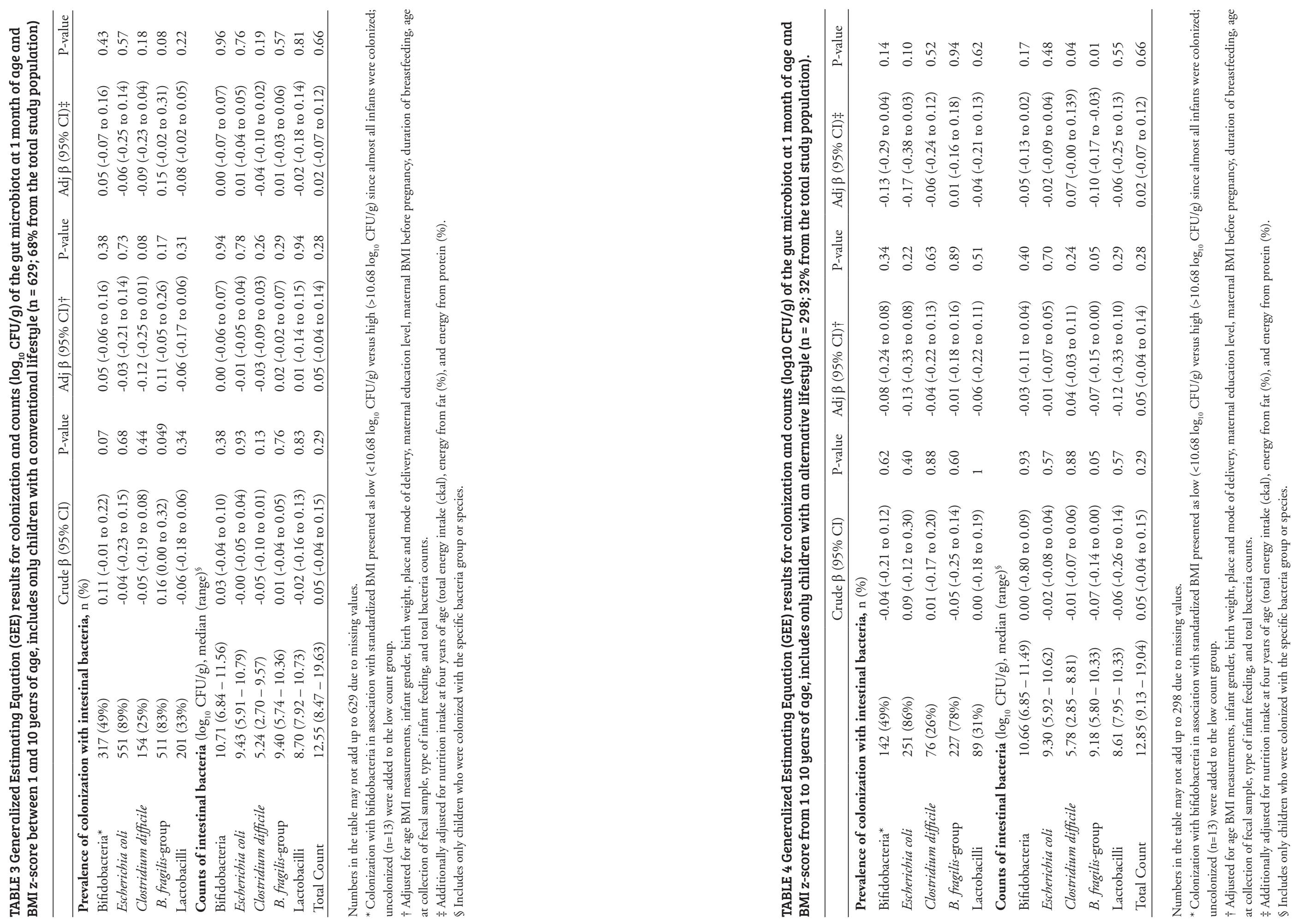
There was no significant interaction with fiber for any of the other bacteria. After stratification for fiber intake (Table 5), in children with a lower than median fiber intake ( $<15 \mathrm{~g} /$ day), colonization with $B$. fragilis-group was associated with a higher BMI z-score (Adj $\beta$ 0.34; 95\% CI 0.17 to 0.53), however higher counts of $B$. fragilis-group in colonized children was associated with a lower BMI z-score after adjustment for potential confounders (Adj $\beta$-0.05; 95\% CI -0.10 to 0.01). Furthermore, in children with a higher than median fiber intake ( $>15 \mathrm{~g} /$ day), colonization with $B$. fragilis-group was not associated with BMI z-scores, but a higher count of $B$. fragilis-group was associated with a higher BMI z-score (Adj $\beta$ 0.07; $95 \%$ CI 0.01 to 0.14 ). For all analyses, adding the dietary variables to the adjusted models (model 3 ) did not substantially alter the results.

Finally, we examined whether associations of bacterial groups and species with BMI z-scores changed over time (age of BMI measurement). Only for $C$. difficile the time interaction term was significant (p 0.002). Linear regression analysis showed that children in the conventional subcohort, who were colonized with $C$. difficile at one month postpartum, had a lower BMI z-score of -0.24 (Adj $\beta$ 0.24; 95\% CI -0.45 to $-0.03)$ at $103 \pm 5$ months of age. For the other time points, no significant effects were found (data not shown).

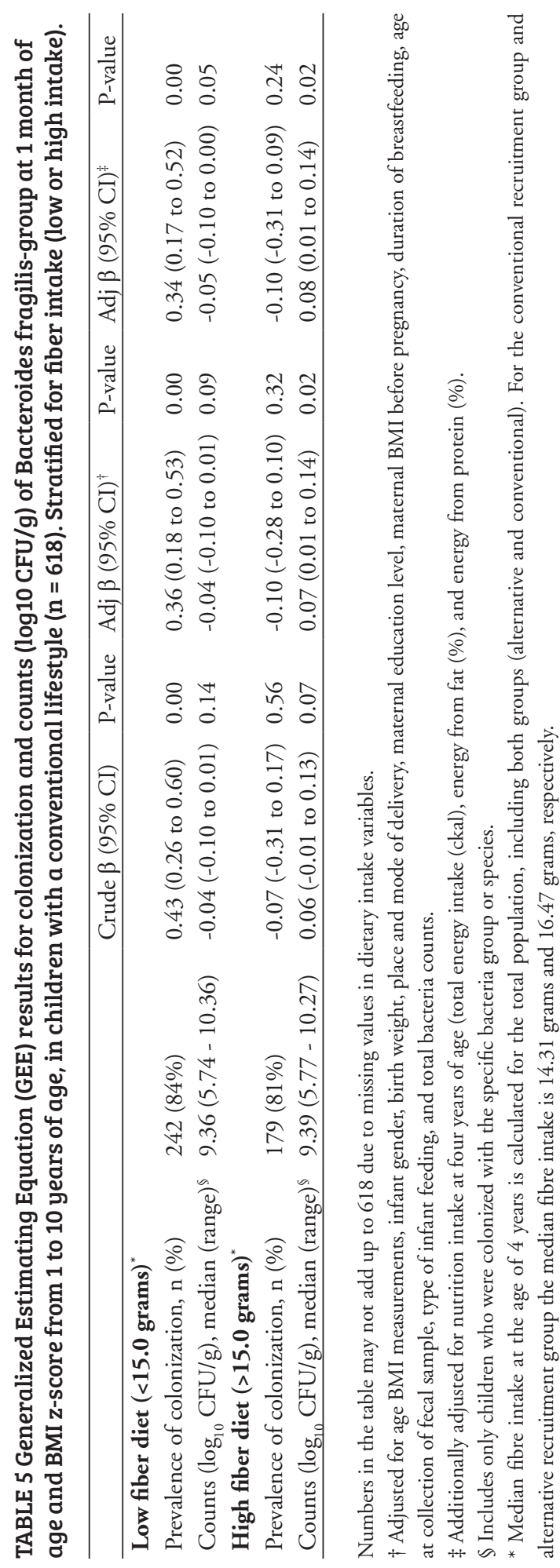




\section{Discussion}

The current study showed that colonization with B. fragilis-group at one month postpartum tended to be associated with a higher BMI in children up to 10 years of age, in particular among children in the conventional subcohort and a low fiber diet. In line with our results, Bäckhed et al. showed that host total body fat content increased after colonization of germ free mice with Bacteroides thetaiotaomicron, the most abundant member of the $B$. fragilis-group in the human gut ${ }^{42}$. These latter results were explained by the ability of Bacteroides thetaiotaomicron to ferment plant- or host-derived polysaccharides to SCFAs, in particular acetate. Acetate can serve as a source of energy for peripheral tissues, and is taken up by the liver and used as a substrate for lipogenesis and gluconeogenesis. Colonized mice have higher levels of liver triglycerides, which suppress the expression of fasting induced adipose factor (FIAF) and increases the storage of triglycerides in adipocytes ${ }^{30,31}$. Our results are furthermore in accordance with the observational study by Vael et al., who showed a positive association between B. fragilisgroup in the feces of 3- and 26-week old infants, and BMI z-score at preschool age (up to 36 months) $(n=138)^{28}$. In contrast to our study, White et al. showed that presence of Bacteroides spp. in 30-day old infants was associated with lower body weight z-scores at the age of 6 months in males $(n=108)$, but not in females ${ }^{29}$. However, these studies used traditional culture and a microarray respectively to assess the microbiota composition, caution is therefore required when comparing these results with our study. The role of fiber in children colonized with members of the $B$. fragilis-group is contradictory. Only in children with a low fiber diet $(<15 \mathrm{~g} /$ day) colonization with $B$. fragilis-group resulted in a higher BMI. In children with a high fiber diet colonization with $B$. fragilis-group did not influence BMI. A potential explanation for this loss of association between colonization with the B. fragilis-group and BMI in the high fiber consumers might be that consuming a high fiber diet at the age of 4 years might compensate for the effect that early B. fragilis-group colonization has on BMI.

Our results for higher counts of $B$. fragilis-group in children who are colonized, are less clear. Higher counts are positively associated with BMI only in children in the conventional subcohort and a high fiber diet, but inversely associated in children with a low fiber diet, and in children in the alternative subcohort. A plausible explanation might be a different composition of B. fragilis-group species between infants in the two different recruitments groups. The pregnant women recruited through alternative channels, might introduce a different lifestyle for their children promoting early colonization with other bacteroides species than in the conventional subgroup. Indeed, species within the $\mathrm{B}$. fragilis group might differentially affect weight development as suggested by Bervoets et al. who showed more B. fragilis in obese and more B. vulgatus in control subjects. Identification of bacteroides at the species level in future prospective studies is warranted to address whether a different species distribution actually precedes (over)weight development during childhood.
We are not aware of any previous human studies that investigated the interaction between bacteroides and dietary fiber intake. It is important to note that although we were able to study this interaction, collection of fecal samples (at 1 month) and dietary information (at 4 years) did not take place at the same time, and this is clearly a weakness of this study. Despite the high instability of the microbiota in infancy, it may be speculated that the presence of $B$. fragilis-group as pioneer species in the neonatal gut could be indicative for the subsequent persistence of these bacteria or other developmental processes towards an adult-like microbiota. Although, dietary information was only collected once, at the age of four years, we used a validated FFQ to determine the habitual dietary intake. The FFQ reflects the long-term dietary pattern and gives a much better estimate of habitual dietary intake than instruments such as food diaries and 24-hour recall. In addition, previous studies showed that dietary patterns stay relatively stable during childhood ${ }^{43,44}$. Furthermore, we observed that neonatal colonization with $C$. difficile was associated with a lower BMI at the age of $103 \pm 5$ months. Since, asymptomatic carriage of $C$. difficile is very common in the first years of life and a significant effect was only found in the children in the conventional subcohort, after adjustment of potential confounders, and merely in the last time point of BMI measurement (average age of 105 months), caution in drawing conclusions is required. Since we conducted several tests for the 5 different bacteria groups/species, a type I error due to multiple testing cannot be excluded. Therefore, further research is required to replicate our findings.

We did not find an association between bifidobacteria and BMI development. This is in contrast to the results from Kalliomäki and colleagues ${ }^{26}$, who found lower levels of bifidobacteria at 6 and 12 months of age in children with normal weight $(n=24)$ compared to overweight or obesity $(n=25)$ at 7 years of age. That study was the first to show an association between the intestinal microbiota composition and the development of overweight. We did not find an association between bifidobacteria and subsequent BMI in children. In our study, fecal samples were collected only at age 1 month when almost all children are colonized with high concentrations of bifidobacteria, which might mask a potential effect of bifidobacteria.

The prospective study design, a large study population, adjustment for the main determinants of the microbiota composition in early infancy (for example, place and mode of delivery, type of infant feeding in the first month), and repeated measurements of BMI on 7 occasions over a time period of 10 years are major strengths of our study. Nevertheless, the present study has also some limitations; one drawback is that only five bacterial groups and genera were measured, while others may also be involved in weight development in childhood ${ }^{45}$. Previous studies using extensive profiling of the neonatal gut microbiota, have however shown that the microbiota at this age is still very simple and dominated by the bacterial groups targeted in the present study ${ }^{46}$. Another drawback of this study was the timing of fecal sampling collection at 1 month of age. In early infancy, the gut microbiota composition is relatively unstable and its role in shaping the 
microbiota at a later age is to date unknown $\mathrm{n}^{47,48}$. This study only provides information on the role of the intestinal microbiota at early infancy. The measured species might actually indicate presence or absence of other unstudied co-occurring bacterial genera or species that influence weight development ${ }^{49}$. Another limitation relates to the time between collection of the fecal sampling by the parents and analyzing the samples in the laboratory, which was 1 day for the majority of samples. Even though the total amount of bacterial DNA, as well as the diversity of the microbiota may decrease significantly in such a time period, the similarities of the fecal samples processed directly and those processed after 24 hours remain high ${ }^{36}$. This applies also for the temperature at which the fecal samples are held in the first 24 hours after collection ${ }^{50}$.

Finally, in the present study, we made use of parent-reported body weight and height. Even though the procedure of measuring weight and height of their child was explained and numerous studies have demonstrated that self-reported questionnaires are a valid method to estimate body weight and height ${ }^{51,52}$, it is known that parents of children with a low BMI tend to overreport body weight, while parents of children with a high BMI tend to underreport body weight ${ }^{53,54}$. Recently we reported a similar underestimation in the KOALA study ${ }^{55}$. This implies that the association we observed between the intestinal microbiota and BMI may actually have been stronger than reported.

\section{Conclusion}

Our study indicates that presence of $B$. fragilis-group in early infancy tended to be associated with a higher BMI later in childhood. If causal, this may have important public health implications since children with an elevated BMI are more likely to remain overweight as adult $s^{56}$. Even a moderate increase in BMI over a long period of time has been shown to increase disease risk ${ }^{57}$. Some studies found that a reduction of $0.25 \mathrm{BMI}$ z-scores results in a small improvement in metabolic markers among obese adolescent $s^{58}$ and a reduction of $0.5 \mathrm{BMI} z$-scores leads to a major improvement ${ }^{59}$. Modification of the composition of the intestinal microbiota could contribute to the prevention of overweight and obesity.

\section{Acknowledgements}

We are grateful to the children and parents who participated in the KOALA Birth Cohort Study. The following sponsors contributed to data collection for the present study: Netherlands Organisation for Health Research and Development (ZonMw grant no. 2100.0090), Netherlands Asthma Foundation (grants no. 3.2.03.48 and no. 3.2.07.022), Netherlands Heart Foundation (grant no. 2008B112), Triodos Foundation, Phoenix Foundation, Raphaël Foundation, Iona Foundation, Foundation for the Advancement of Heilpedagogiek, Royal Friesland Foods (currently FrieslandCampina); Netherlands Sugar Foundation, and the Ministry of Economic affairs, all in the Netherlands. The sponsors had no influence on the analysis and reporting of the present study.

\section{References}

1. Bastien M, Poirier P, Lemieux I, Despres JP. Overview of epidemiology and contribution of obesity to cardiovascular disease. Prog Cardiovasc Dis 2014; 56(4): 369-81.

2. Lakshman R, Elks CE, Ong KK. Childhood obesity. Circulation 2012; 126(14): 1770-9.

3. Schonbeck Y, Talma H, van Dommelen P, Bakker B, Buitendijk SE, Hirasing RA et al. Increase in prevalence of overweight in Dutch children and adolescents: a comparison of nationwide growth studies in 1980, 1997 and 2009. PLoS One 2011; 6(11): e27608.

4. Raoult D. Obesity pandemics and the modification of digestive bacterial flora. European Journal of Clinical Microbiology and Infectious Diseases 2008; 27(8): 631634.

5. Farooqi S, O’Rahilly S. Genetics of obesity in humans. Endocrine Reviews 2006; 27(7): 710-718.

6. Penders J, Thijs C, Vink C, Stelma FF, Snijders B, Kummeling I et al. Factors influencing the composition of the intestinal microbiota in early infancy. Pediatrics 2006; 118(2): 511-21.

7. Ley RE, Backhed F, Turnbaugh P, Lozupone CA, Knight RD, Gordon JI. Obesity alters gut microbial ecology. Proc Natl Acad Sci U S A 2005; 102(31): 11070-5.

8. Turnbaugh PJ, Ley RE, Mahowald MA, Magrini V, Mardis ER, Gordon JI. An obesity-associated gut microbiome with increased capacity for energy harvest. Nature 2006; 444(7122): 1027-31.

9. Ley RE, Turnbaugh PJ, Klein S, Gordon JI. Microbial ecology: human gut microbes associated with obesity. Nature 2006; 444(7122): 1022-3.

10. Armougom F, Henry M, Vialettes B, Raccah D, Raoult D. Monitoring bacterial community of human gut microbiota reveals an increase in Lactobacillus in obese patients and Methanogens in anorexic patients. PLoS One 2009; 4(9): e7125.

11. Turnbaugh PJ, Hamady M, Yatsunenko T, Cantarel BL, Duncan A, Ley RE et al. A core gut microbiome in obese and lean twins. Nature 2009; 457(7228): 480-4.

12. Zuo HJ, Xie ZM, Zhang WW, Li YR, Wang W, Ding XB et al. Gut bacteria alteration in obese people and its relationship with gene polymorphism. World Journal of Gastroenterology 2011; 17(8): 1076-81.

13. Nadal I, Santacruz A, Marcos A, Warnberg J, Garagorri M, Moreno LA et al. Shifts in clostridia, bacteroides and immunoglobulin-coating fecal bacteria associated with weight loss in obese adolescents. International Journal of Obesity 2009; 33(7): 758-67.

14. Xu P, Li M, Zhang J, Zhang T. Correlation of intestinal microbiota with overweight and obesity in Kazakh school children. BMC Microbiol 2012; 12: 283. 
15. Schwiertz A, Taras D, Schafer K, Beijer S, Bos NA, Donus C et al. Microbiota and SCFA in lean and overweight healthy subjects. Obesity (Silver Spring) 2010; 18(1): $190-5$.

16. Abdallah Ismail N, Ragab SH, Abd Elbaky A, Shoeib AR, Alhosary Y, Fekry D. Frequency of Firmicutes and Bacteroidetes in gut microbiota in obese and normal weight Egyptian children and adults. Arch Med Sci 2011; 7(3): 501-7.

17. Zhang H, DiBaise JK, Zuccolo A, Kudrna D, Braidotti M, Yu Y et al. Human gut microbiota in obesity and after gastric bypass. Proc Natl Acad Sci U S A 2009; 106(7): 2365-70.

18. Balamurugan R, George G, Kabeerdoss J, Hepsiba J, Chandragunasekaran AM, Ramakrishna BS. Quantitative differences in intestinal Faecalibacterium prausnitzii in obese Indian children. The British journal of nutrition 2010; 103(3): 335-8.

19. Duncan SH, Lobley GE, Holtrop G, Ince J, Johnstone AM, Louis P et al. Human colonic microbiota associated with diet, obesity and weight loss. International Journal of Obesity 2008; 32(11): 1720-4.

20. Mai V, McCrary QM, Sinha R, Glei M. Associations between dietary habits and body mass index with gut microbiota composition and fecal water genotoxicity: An observational study in African American and Caucasian American volunteers. Nutr. J. 2009; 8(1).

21. Karlsson CL, Onnerfalt J, Xu J, Molin G, Ahrne S, Thorngren-Jerneck K. The microbiota of the gut in preschool children with normal and excessive body weight. Obesity 2012; 20(11): 2257-61.

22. Bervoets L, Van Hoorenbeeck K, Kortleven I, Van Noten C, Hens N, Vael C et al. Differences in gut microbiota composition between obese and lean children: a cross-sectional study. Gut Pathog 2013; 5(1): 10.

23. Million M, Maraninchi M, Henry M, Armougom F, Richet H, Carrieri P et al. Obesity-associated gut microbiota is enriched in Lactobacillus reuteri and depleted in Bifidobacterium animalis and Methanobrevibacter smithii. International Journal of Obesity 2012; 36(6): 817-25.

24. Collado MC, Isolauri E, Laitinen K, Salminen S. Distinct composition of gut microbiota during pregnancy in overweight and normal-weight women. Am J Clin Nutr 2008; 88(4): 894-9.

25. Santacruz A, Marcos A, Warnberg J, Marti A, Martin-Matillas M, Campoy C et al. Interplay between weight loss and gut microbiota composition in overweight adolescents. Obesity (Silver Spring) 2009; 17(10): 1906-15.

26. Kalliomaki M, Collado MC, Salminen S, Isolauri E. Early differences in fecal microbiota composition in children may predict overweight. American Journal of Clinical Nutrition 2008; 87(3): 534-8.

27. Luoto R, Kalliomaki M, Laitinen K, Delzenne NM, Cani PD, Salminen S et al. Initial dietary and microbiological environments deviate in normal-weight compared to overweight children at 10 years of age. J Pediatr Gastroenterol Nutr 2011; 52(1): 90-5.

28. Vael C, Verhulst SL, Nelen V, Goossens H, Desager KN. Intestinal microflora and body mass index during the first three years of life: an observational study. Gut Pathog 2011; 3(1): 8

29. White RA, Bjornholt JV, Baird DD, Midtvedt T, Harris JR, Pagano M et al. Novel Developmental Analyses Identify Longitudinal Patterns of Early Gut Microbiota that Affect Infant Growth. PLoS Comput Biol 2013; 9(5): e1003042.

30. Diamant M, Blaak EE, de Vos WM. Do nutrient-gut-microbiota interactions play a role in human obesity, insulin resistance and type 2 diabetes? Obes Rev 2011; 12(4): $272-81$.

31. Tremaroli V, Backhed F. Functional interactions between the gut microbiota and host metabolism. Nature 2012; 489(7415): 242-9.

32. Samuel BS, Shaito A, Motoike T, Rey FE, Backhed F, Manchester JK et al. Effects of the gut microbiota on host adiposity are modulated by the short-chain fattyacid binding G protein-coupled receptor, Gpr41. Proc Natl Acad Sci U S A 2008; 105(43): 16767-72.

33. Xiong Y, Miyamoto N, Shibata K, Valasek MA, Motoike T, Kedzierski RM et al. Short-chain fatty acids stimulate leptin production in adipocytes through the G protein-coupled receptor GPR41. Proc Natl Acad Sci U S A 2004; 101(4): 104550.

34. Kummeling I, Thijs C, Penders J, Snijders BEP, Stelma F, Reimerink J et al. Etiology of atopy in infancy: the KOALA Birth Cohort Study. Pediatr Allergy Immunol 2005; 16(8): 679-684

35. Bastiaanssen JM, de Bie RA, Bastiaenen CH, Heuts A, Kroese ME, Essed GG et al. Etiology and prognosis of pregnancy-related pelvic girdle pain; design of a longitudinal study. BMC public health 2005; 5: 1.

36. Ott SJ, Musfeldt M, Ullmann U, Hampe J, Schreiber S. Quantification of intestinal bacterial populations by real-time PCR with a universal primer set and minor groove binder probes: a global approach to the enteric flora. J Clin Microbiol 2004; 42(6): 2566-72.

37. Rinttila T, Kassinen A, Malinen E, Krogius L, Palva A. Development of an extensive set of $16 \mathrm{~S}$ rDNA-targeted primers for quantification of pathogenic and indigenous bacteria in faecal samples by real-time PCR. J Appl Microbiol 2004; 97(6): 116677. 
38. Nadkarni MA, Martin FE, Jacques NA, Hunter N. Determination of bacterial load by real-time PCR using a broad-range (universal) probe and primers set. Microbiology 2002; 148(1): 257-66.

39. Kwaliteitsinstituut voor Gezondheidszorg CBO. Diagnostiek en behandeling van obesitas bij volwassenen en kinderen, 2008.

40. Dutman AE, Stafleu A, Kruizinga A, Brants HA, Westerterp KR, Kistemaker C et $a l$. Validation of an FFQ and options for data processing using the doubly labelled water method in children. Public Health Nutr 2011; 14(3): 410-7.

41. Stichting Nederlands Voedingsstoffenbestand Nederlands voedingsstoffenbestad 2001 (Netherlands Food Composition Table 2001) 2001.

42. Backhed F, Ding H, Wang T, Hooper LV, Koh GY, Nagy A et al. The gut microbiota as an environmental factor that regulates fat storage. Proc Natl Acad Sci U S A 2004; 101(44): 15718-23.

43. Singer MR, Moore LL, Garrahie EJ, Ellison RC. The tracking of nutrient intake in young children: the Framingham Children's Study. Am J Public Health 1995; 85(12): 1673-7.

44. Bjelland M, Brantsaeter AL, Haugen M, Meltzer HM, Nystad W, Andersen LF. Changes and tracking of fruit, vegetables and sugar-sweetened beverages intake from 18 months to 7 years in the Norwegian Mother and Child Cohort Study. BMC public health 2013; 13: 793.

45. Kallus SJ, Brandt LJ. The intestinal microbiota and obesity. J Clin Gastroenterol 2012; 46(1): 16-24.

46. Azad MB, Konya T, Maughan H, Guttman DS, Field CJ, Chari RS et al. Gut microbiota of healthy Canadian infants: profiles by mode of delivery and infant diet at 4 months. Cmaj 2013; 185(5): 385-94.

47. Palmer C, Bik EM, DiGiulio DB, Relman DA, Brown PO. Development of the human infant intestinal microbiota. PLoS Biology 2007; 5(7): 1556-1573.

48. Eckburg PB, Bik EM, Bernstein CN, Purdom E, Dethlefsen L, Sargent M et al. Diversity of the human intestinal microbial flora. Science 2005; 308(5728 ): 1635 1638.

49. Rousseau C, Levenez F, Fouqueray C, Dore J, Collignon A, Lepage P. Clostridium difficile colonization in early infancy is accompanied by changes in intestinal microbiota composition. Journal of clinical microbiology 2011; 49(3): 858-65.

50. Cardona S, Eck A, Cassellas M, Gallart M, Alastrue C, Dore J et al. Storage conditions of intestinal microbiota matter in metagenomic analysis. BMC Microbiol 2012; 12: 158.

51. Spencer EA, Appleby PN, Davey GK, Key TJ. Validity of self-reported height and weight in 4808 EPIC-Oxford participants. Public Health Nutr 2002; 5(4): 561-5.
52. Nyholm M, Gullberg B, Merlo J, Lundqvist-Persson C, Rastam L, Lindblad U. The validity of obesity based on self-reported weight and height: Implications for population studies. Obesity (Silver Spring) 2007; 15(1): 197-208.

53. Scholtens S, Brunekreef B, Visscher TL, Smit HA, Kerkhof M, de Jongste JC et al. Reported versus measured body weight and height of 4-year-old children and the prevalence of overweight. Eur J Public Health 2007; 17(4): 369-74.

54. Shields M, Connor Gorber S, Janssen I, Tremblay MS. Obesity estimates for children based on parent-reported versus direct measures. Health Rep 2011; 22(3): 47-58

55. Timmermans SH, Mommers M, Gubbels JS, Kremers SP, Stafleu A, Stehouwer $\mathrm{CD}$ et al. Maternal smoking during pregnancy and childhood overweight and fat distribution: the KOALA Birth Cohort Study. Pediatr Obes 2013.

56. Singh AS, Mulder C, Twisk JW, van Mechelen W, Chinapaw MJ. Tracking of childhood overweight into adulthood: a systematic review of the literature. Obes Rev 2008; 9(5): 474-88.

57. Baker JL, Olsen LW, Sorensen TI. Childhood body-mass index and the risk of coronary heart disease in adulthood. $N$ Engl J Med 2007; 357(23): 2329-37.

58. Ford AL, Hunt LP, Cooper A, Shield JP. What reduction in BMI SDS is required in obese adolescents to improve body composition and cardiometabolic health? Arch Dis Child 2010; 95(4): 256-61.

59. Reinehr T, de Sousa G, Toschke AM, Andler W. Long-term follow-up of cardiovascular disease risk factors in children after an obesity intervention. American Journal of Clinical Nutrition 2006; 84(3): 490-6. 
CHAPTER 3

GUT MICROBIOTA AND BODY WEIGHT IN HEALTHY SCHOOL-AGED CHILDREN: THE KOALA BIRTH COHORT STUDY 


\section{ABSTRACT}

OBJECTIVE: To examine the association between intestinal microbiota composition and body weight in children at school age.

METHODS: Within the KOALA Birth Cohort Study faecal samples were collected, and height and weight were measured at age 6-7 years. Faecal microbiota composition of 295 children was determined using the Human Intestinal Tract Chip. Elastic net was used to select genus-like bacterial groups (amongst a total of 130) related to anthropometric outcomes (age- and sex- standardized weight and BMI z-scores, overweight defined as $\mathrm{BMI} \geq 85$ th percentile). Multiple linear and logistic regression were used to associate selected bacterial groups with anthropometric outcomes while adjusting for confounders. RESULTS: Prevotella melaninogenica et rel., Prevotella oralis et rel., Dialister and uncultured Clostridiales II (UCII) accounted for $26.1 \%$ of the variation in microbiota composition. The following bacterial groups were inversely associated with anthropometric outcomes: Akkermansia ( $\mathrm{p}=0.030$ for BMI; $\mathrm{p}=0.009$ for weight); Sutterella wadsworthia et rel. ( $\mathrm{p}=0.008$ for BMI; $\mathrm{p}=0.038$ for overweight); Bryantella formatexigens et rel. ( $\mathrm{p}=0.050$ for weight; $\mathrm{p}=0.027$ for overweight), and Burkholderia $(\mathrm{p}=0.017$ for weight). Streptococcus bovis et rel. was positively associated with overweight $(\mathrm{p}=0.013)$. Among bimodal bacterial groups, high abundance of UCII was inversely associated with all three outcomes $(\operatorname{adj} \beta-0.22$; $95 \% \mathrm{CI}-0.42$ to -0.02 for BMI and weight; adjOR $0.28 ; 95 \%$ CI 0.10 to 0.79 for overweight). High abundances of Prevotella melanogenica et rel. and Prevotella oralis et rel. were inversely associated with overweight (adjOR 0.21; 95\%CI 0.07 to 0.68 , and adjOR 0.20; 95\%CI 0.06 to 0.64 , respectively). Microbial diversity and richness, and Bacteroidetes:Firmicutes ratio were not significantly associated with any of the outcomes.

CONCLUSIONS: In the largest population-based study on childhood gut microbiota and body weight so far, we found both new and previously identified bacterial groups to be either positively or negatively associated with overweight. Further research should elucidate their role in energy metabolism.

\section{INTRODUCTION}

The worldwide prevalence of childhood overweight has been growing at an alarming rate during the past decades. Overweight children are highly prone to become overweight adults and are at high risk of developing comorbidities such as cardiovascular diseases, type 2 diabetes, stroke, metabolic syndrome, several types of cancer, and osteoarthritis. As such, the prevention and treatment of childhood overweight remains an important public health goal.

While excessive energy intake and insufficient physical activity are the main drivers of childhood overweight and obesity, recent research has suggested that other factors such as the gut microbiota may also be involved. ${ }^{2}$ The gut microbiota is highly diverse in composition and plays an important role in human physiology, metabolism, nutrition and immune function. ${ }^{3,4}$ Evidence from human and animal studies [reviewed in ${ }^{5}$ ] suggests that the gut microbiota may contribute to the development of overweight via mechanisms involving increased energy harvest ${ }^{6}$ regulation of host metabolism, ${ }^{7}$ and the activation of innate immunity. ${ }^{8,9}$ In humans, obesity has been associated with a reduced Bacteroidetes to Firmicutes (B:F) ratio in some studies, ${ }^{10-15}$ whereas others reported the opposite ${ }^{16-18}$ or no association at all. ${ }^{19-24}$ Associations between specific bacteria (e.g. Bacteroides fragilis, ${ }^{25}$ Bifidobacterium spp, Staphylococcus spp ${ }^{26}$ Akkermansia muciniphila ${ }^{27}$ and Faecalibacterium prausnitzii) ${ }^{20}$ or archaea (e.g. Methanobrevibacter smithii $^{28}$ and obesity in humans have also been reported, although the identified microbial groups vary greatly between studies. Furthermore, a lower gut microbial species and gene richness and diversity in overweight as compared to normal weight subjects has been shown in several but not all studies. ${ }^{10,27,29,30}$

These inconsistent findings might be attributable to the use of miscellaneous methods to assess the gut microbiota, often enumerating specific taxa rather than using broad $16 \mathrm{~S}$ rRNA gene surveys or metagenomics. Moreover, studies vary greatly in the populations considered, their designs, and the degree of control for potential confounding factors such as lifestyle and diet. In human observational studies, carefully controlled data analysis is essential. ${ }^{31}$ Perturbations in microbial diversity and community structure in adults with overweight and obesity may be partly due to long-term dietary habits or physiological changes in these subjects. ${ }^{30}$ As such, exploring the association between the gut microbiota and variation in BMI and weight in early life, prior to or close to the onset of overweight, might provide additional insights. We therefore aimed to investigate the relation between gut microbiota composition and body weight in a group of 295 well-characterized school-aged children. 


\section{MATERIALS AND METHODS}

\section{Subjects and study design}

The current study is conducted within the context of the KOALA Birth Cohort Study in the Netherlands. The design of the KOALA study has been described in detail elsewhere. ${ }^{32}$ Briefly, a total of 2834 pregnant women were recruited, at 34 weeks of gestation, from October 2000 until December 2002. Healthy pregnant women with a conventional lifestyle $(\mathrm{N}=2343)$ were recruited from an on-going cohort study on the aetiology of pregnancy-related pelvic girdle pain in the Netherlands. ${ }^{33}$ To enhance the contrast in lifestyle characteristics, an additional 491 pregnant women with alternative lifestyles with regards to dietary habits (organic food choice), child rearing practices, vaccination schemes and/or use of antibiotics, were recruited through organic food shops, anthroposophist doctors and midwives, Steiner schools and dedicated magazines ${ }^{32}$

A subgroup of 1,204 parents was asked for consent for a home visit for anthropometric measurements and to collect a single faecal sample from the child at the age of 6-7 years. This subgroup comprised of participants who had home visits for blood collection from the mother during pregnancy and/or the child at age 2 years, and who were still active participants (Supplementary Figure 1). Faecal samples were obtained for $n=669$ children. Exclusion criteria for the current study were: prematurity (infants born before 37 weeks of gestation), twins, abnormalities linked to growth (such as Down's syndrome, Turner syndrome, Fallot's tetralogy, multiple disabilities, and cystic fibrosis), faecal samples with transport times exceeding 3 days, or lack of data on dietary intake. A total of 295 children were finally included in the present study; all being Caucasians. Written informed consent was given by all parents, and the study was approved by the Medical Ethics Committee of Maastricht University and the National Ethical Committee for Medical Research.

\section{Data collection and outcome measures}

\section{Faecal collection}

Faecal samples of the children were collected by the parents at home upon receipt of a faeces tube with a spoon attached to the lid (Sarstedt, Nürmbrecht, Germany) together with instructions for collection. A faecal sample was collected and sent to the laboratory by mail. After arrival, samples were 10-fold diluted in peptone/water (Oxoid CM0009) containing $20 \%$ (vol $/ \mathrm{vol}$ ) glycerol (Merck, Darmstadt, Germany), and stored at $-80^{\circ} \mathrm{C}$ until further analysis.

\section{Faecal DNA isolation and microbiota profiling}

DNA isolation from faecal samples has been described in detail elsewhere. ${ }^{34}$ Briefly, DNA was isolated using a combination of Repeated-Bead-Beating (RBB) and column purification. DNA concentration and purity were assessed with a Nanodrop 1000 spectrophotometer (Thermo Fisher Scientific, Wilmington, USA). DNA was then stored at $-20^{\circ} \mathrm{C}$ pending microbial analysis, which was performed using a previously described and benchmarked ${ }^{35-37}$ custom made, phylogenetic microarray, the Human Intestinal Tract Chip (HITChip). ${ }^{36}$ After DNA extraction, the full-length $16 \mathrm{~S}$ rRNA gene was amplified, followed by in vitro transcription and labelling of the resultant RNA with Cy3 and Cy5 before hybridization to the array. ${ }^{36}$ Each sample was hybridized at least twice to ensure reproducibility, and raw signal intensities were normalised as previously described. ${ }^{38}$ For the data analysis, hybridization signals were summarized to 130 genuslike phylogenetic groups ( $>90 \% 16 \mathrm{~S}$ rRNA gene sequence similarity) referred to as species and relatives ('et rel.'). ${ }^{36}$ The $\log 10$-transformed signals were used as a proxy for bacterial abundance. B:F ratio was calculated by dividing total hybridisation signal intensities for Bacteroidetes by Firmicutes. Diversity of the microbiota was quantified using Shannon's diversity index based on non-logarithmic oligo-level signals as implemented by the $\mathrm{R}$ package vegan ${ }^{39}$ Probes were counted in each sample to measure richness, by using an $80 \%$ quantile threshold for detection.

\section{Anthropometric outcomes}

Height and weight were measured during home visits by trained research assistants at the age of 6-7 years, with the children wearing only their underwear. Height (in millimetres) was measured using a portable stadiometer (Leicester height measure) and weight (in grams rounded off to $100 \mathrm{~g}$ ) using a digital scale (HE-5, CAS Corp., East Rutherford, NJ, USA). BMI was calculated as weight divided by height squared. The BMI, weight and height measurements were then converted into age- and gender-specific z-scores using the children from the Dutch National Growth Study as the reference population. ${ }^{40}$ BMI $\mathrm{z}$-scores were used both as continuous and dichotomous outcomes: without overweight vs. with overweight (BMI z-score $\geq 1.04$, corresponding to the $85^{\text {th }}$ percentile). ${ }^{41}$

\section{Potential confounders}

At 14 and 34 weeks of gestation, pregnant women received questionnaires regarding, amongst others, family size, pre-pregnancy height and weight, and weight gain during pregnancy. Two weeks after childbirth, data was collected from obstetric reports, and questionnaires were completed by the mothers to obtain information on gestational age, birth weight and gender of the child. Food frequency questionnaires (FFQs) were filled out by the parents to report the dietary habits of their children at the age of $5.0 \pm 0.6$ years (mean \pm standard deviation $(S D)$ ). Included confounders are listed in Supplementary Table 1. 


\section{Statistical analysis}

Characteristics of the study population are presented as mean $\pm S D$ for continuous variables, and proportions for categorical variables. The microbiota profile, summarized into 130 genus-like phylogenetic groups was obtained for the 295 subjects. Using statistical software package Canoco $5,{ }^{42}$ redundancy analysis (RDA), a multivariate canonical ordination analysis method, was performed to determine how much variation in species composition was explained by the anthropometric outcomes and potential confounders.

\section{Selection of potentially relevant bacterial groups}

In order to prevent issues with multi-collinearity and multiple testing when performing regression analyses with large numbers of determinants, we first selected genus-like bacterial levels potentially associated with childhood (over)weight using the elastic net regularization proposed by Zou \& Hastie. ${ }^{43}$ Elastic net is a method that utilises the ridge $(\alpha=0)$ and lasso $(\alpha=1)$ penalties to perform both shrinkage and automatic variable selection simultaneously. It also addresses the problem of multi-collinearity by encouraging a grouping effect, where strong correlated genus-like bacterial levels are kept in the model. The data was divided at random into two parts: a training set with 197 observations, and a test set with 98 observations (Figure 1). Model fitting and tuning parameters $(\lambda$, and $s$ ) selection was done on the training set by performing a 10 -fold cross-validation. The first tuning parameter $(\lambda)$ plays a role in variable selection, whereas the second (s) captures correlated predictors at the same time. The chosen grid values were: $(0,0.01,0.1,1,10$, and 100$)$ for $\lambda$, and ( 0 to 1 dividing on a scale of 0.1$)$ for $s$ as previously suggested. ${ }^{43}$ The most parsimonious model was obtained using the combination of the two tuning parameters corresponding to the smallest mean-squared prediction error based on the cross-validations performed on the training set. Validation of the model performance was then performed by comparing the computed prediction mean squared error (for continuous outcomes) on both the training and test set. In the case of the binary outcome (overweight (yes/no)) validation of the performance of model prediction was done using area under the curve.

In addition, we a priori planned to examine the association between bacterial groups that exhibited a strong bimodal abundance distribution (calculated using potential analysis ${ }^{44}$ with the early warnings $\mathrm{R}$ package $\mathrm{e}^{45}$ ) and anthropometric outcomes. These bimodal bacterial groups were previously described Lahti et al. as potential tipping elements in the ecosystem, ${ }^{38}$ and might serve as indicators of the community state and its link with (over)weight. We selected bacterial groups that showed consistent evidence for multimodality with bootstrap support $\geq 68 \%$.

\section{Regression analysis}

First we performed unadjusted regression models (further referred to as Model 1) to analyse the association of each individual selected genus-like bacterial group (as identified by elastic net), bimodal bacterial groups (tipping elements), microbial richness and diversity, and B:F ratio, with the outcomes (linear regression for BMI and weight z-scores, logistic regression for overweight yes/no).

Second, we performed the same analyses while adjusting for potential confounders considered a priori (Model 2). We investigated whether the association between the intestinal microbiota composition and outcomes differed between the two different recruitment channels (alternative and conventional) by including a recruitment groupexposure interaction term in the models. This interaction was significant only for B:F ratio with regards to BMI and weight z-scores (data not shown).

Finally, we performed multiple regression models including all selected bacterial groups, the bimodal bacterial groups, and archaea (M. smithii (yes/no) and $M$. stadtmanae (yes/ no)) while adjusting for the potential confounders (Model 3). Archaea were added because in our previous study, ${ }^{28}$ the presence of archaea, specifically Methanobrevibacter smithii, was associated with childhood weight development.

Maternal weight gain during pregnancy was the only confounding variable with $\geq 5 \%$ missing values. Multiple imputations were done for this variable to assess whether results obtained from the imputed data deviated from the non-imputed. This was done using the Markov chain Monte Carlo (MCMC) method for multiple imputations. Results obtained from combined imputed datasets $(n=10)$ were comparable with those of the original non-imputed data, hence final analyses were done without imputation. Analyses were performed in R V.3.1.3 using the following packages: elastic net (for continuous outcomes) and glmnet (for binary outcomes), and SAS version 9.3 (SAS Institute, Cary NC). Significance level was set at $<0.05$. 


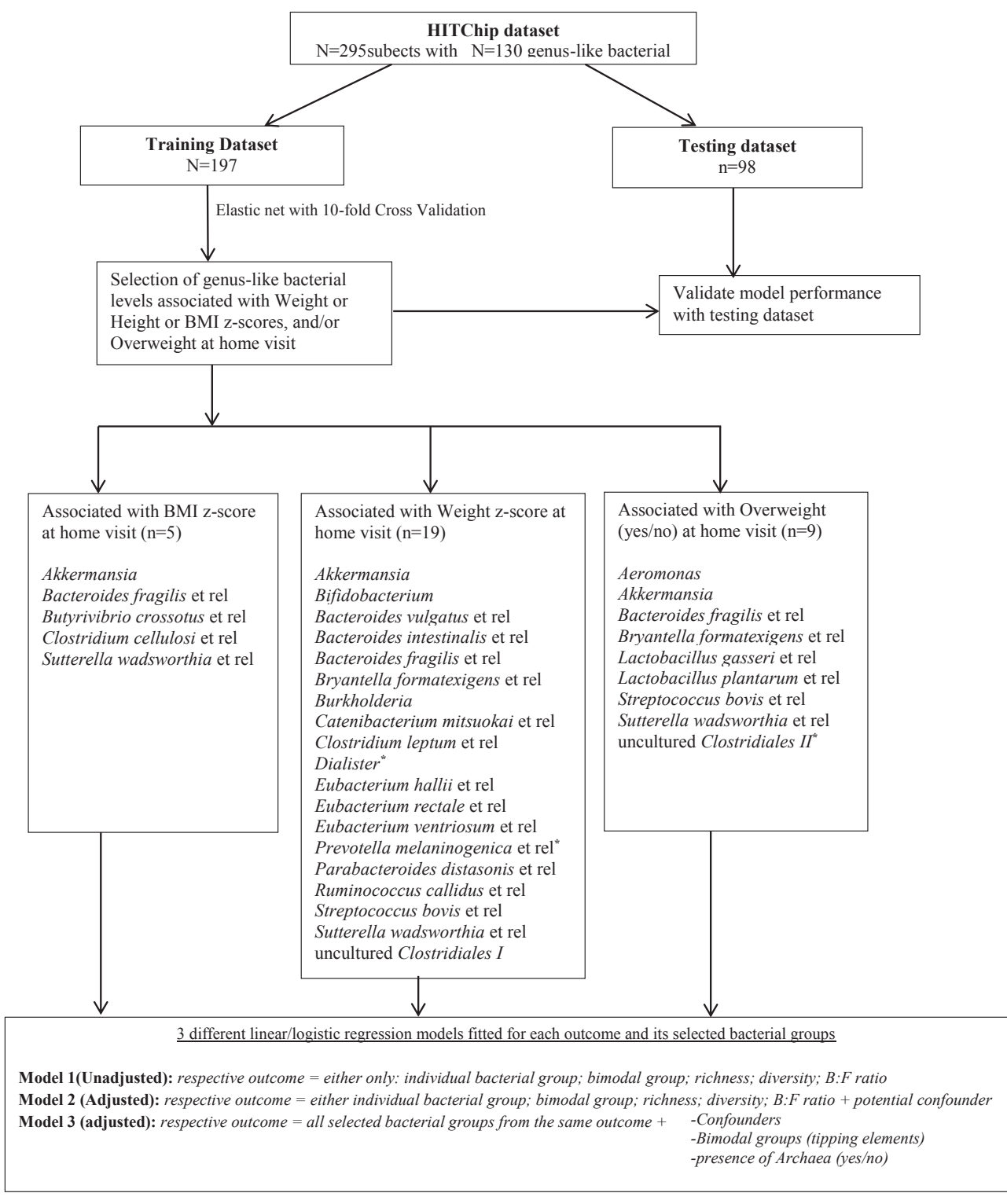

Figure 1: Schematic overview of the bacterial groups that were selected by elastic net for subsequent regression analysis.

*Genus-like bacterial groups identified as having a bimodal abundance distribution were analysed as dichotomous variables in the linear and logistic regression models.

\section{RESULTS}

General characteristics of the total KOALA population and of the current study population are presented in Table 1. A total of 295 subjects (148 (50.2\%) boys and 147 $(49.8 \%)$ girls) with a mean age of 7.4 years (SD 0.8) were eligible for the present study (Supplementary Figure 1). There were 27 (9.8\%) overweight children.

The gut microbiota of the children was dominated by Prevotella melaninogenica et rel., Bacteroides vulgatus et rel., Ruminococcus obeum et rel., Faecalibacterium prausnitzii et rel., and Bifidobacterium (Figure 2). RDA was performed to explore what percentage of variability of gut microbiota composition was explained by the anthropometric measures. The percentage of variability explained by each anthropometric measure under consideration was very low: $0.5 \%(\mathrm{p}=0.15), 0.6 \%(\mathrm{p}=0.06)$, and $0.5 \%(\mathrm{p}=0.09)$ by BMI z-scores, weight z-scores, and overweight, respectively (data not shown). We observed strong or moderate bootstrap support for a bimodal distribution in the abundance of Prevotella melaninogenica et rel., Prevotella oralis et rel., Dialister, and uncultured Clostridiales II (UCII), but not for Bacteroides fragilis et rel., and uncultured Clostridiales I (UCI). A distribution plot for each of the bacterial groups exhibiting bimodality (classified as low or high) and their cut-off or tipping points are illustrated in Supplementary Figure 3. 
Table 1. General characteristics of the KOALA Birth Cohort and the study population

\begin{tabular}{|c|c|c|}
\hline & $\begin{array}{l}\text { KOALA Birth Cohort } \\
\text { Study } \\
(\mathrm{N}=2834)^{\mathrm{a}} \\
\text { Mean } \pm \mathrm{SD}^{\mathrm{c}} \\
\end{array}$ & $\begin{array}{c}\text { Study Population } \\
(\mathrm{N}=295)^{\mathrm{b}} \\
\text { Mean } \pm \mathrm{SD}^{\mathrm{c}}\end{array}$ \\
\hline \multirow{2}{*}{\multicolumn{3}{|c|}{ Anthropometric data measured at home visit }} \\
\hline & & \\
\hline \multicolumn{3}{|l|}{ Overweight: n (\%) } \\
\hline yes & - & $27(9.8)$ \\
\hline no & - & $268(90.2)$ \\
\hline BMI z-scores & - & $-0.16 \pm 0.89$ \\
\hline Weight z-scores & - & $-0.20 \pm 0.96$ \\
\hline \multicolumn{3}{|c|}{ Time of last antibiotic course prior to home visit: $\mathrm{n}(\%)$} \\
\hline No antibiotic use in the previous year & - & $248(85.2)$ \\
\hline Greater than 4 weeks ago & - & $36(12.4)$ \\
\hline Less than 4 weeks ago & - & $7(2.4)$ \\
\hline Age at faecal sample collection (years) & - & $7.3 \pm 0.8$ \\
\hline Child's total physical activity (hrs/week) & - & $9.4 \pm 4.5$ \\
\hline \multicolumn{3}{|l|}{ Recruitment group } \\
\hline Conventional & $2343(82.7)$ & $218(73.9)$ \\
\hline Alternative & $491(11.3)$ & $77(26.1)$ \\
\hline \multicolumn{3}{|l|}{ Maternal educational level (n, \%) ${ }^{\mathrm{d}}$} \\
\hline Low & $289(10.7)$ & $21(7.2)$ \\
\hline Middle & $1060(39.4)$ & $113(38.8)$ \\
\hline High & $1341(49.9)$ & $157(54.0)$ \\
\hline Maternal pre-pregnancy weight $(\mathrm{Kg})$ & $67.7 \pm 13.1$ & $68.3 \pm 11.5$ \\
\hline Maternal weight gain in pregnancy $(\mathrm{Kg})$ & $14.3 \pm 5.1$ & $14.5 \pm 4.8$ \\
\hline \multicolumn{3}{|l|}{ Place and mode of delivery: $\mathrm{n}(\%)^{\mathrm{c}}$} \\
\hline Vaginal delivery at home & $1187(44.8)$ & $143(49.0)$ \\
\hline Vaginal delivery in the hospital & 1149 (43.4) & $120(41.1)$ \\
\hline Caesarean section in the hospital & $311(11.8)$ & $29(9.9)$ \\
\hline \multicolumn{3}{|l|}{ Maternal smoking in late pregnancy: $\mathrm{n}(\%)$} \\
\hline Yes & $200(7.1)$ & $12(4.1)$ \\
\hline No & $2634(92.9)$ & $283(95.9)$ \\
\hline Total Household size & $4.3 \pm 0.8$ & $4.3 \pm 0.8$ \\
\hline Gestational age & $39.8 \pm 5.0$ & $39.8 \pm 3.7$ \\
\hline Birth weight (g) & $3503 \pm 512$ & $3605 \pm 466$ \\
\hline Breastfeeding duration (months) & $4.7 \pm 3.0$ & $6.0 \pm 4.4$ \\
\hline \multicolumn{3}{|l|}{ Gender: n (\%) } \\
\hline Male & $1451(51.2)$ & $148(50.2)$ \\
\hline Female & 1376 (48.6) & $147(49.8)$ \\
\hline \multicolumn{3}{|l|}{ Child's dietary intake } \\
\hline Total energy intake $(\mathrm{KJ})$ & $6173 \pm 1285$ & $6180 \pm 1217$ \\
\hline$\%$ energy intake from fats & $29.6 \pm 4.2$ & $29.7 \pm 4.2$ \\
\hline$\%$ energy intake from carbohydrates & $55.8 \pm 5.0$ & $55.7 \pm 4.8$ \\
\hline Total fibre intake (g) & $15.3 \pm 4.0$ & $15.6 \pm 3.9$ \\
\hline
\end{tabular}

a,b Total may not sum up to 2834 and 295 respectively due to missings. cValues are mean (standard deviation), unless indicated otherwise.

'Low: primary school, preparatory vocational or lower general secondary school, Middle: vocational, higher general secondary and pre-university, High: higher vocational or academic.

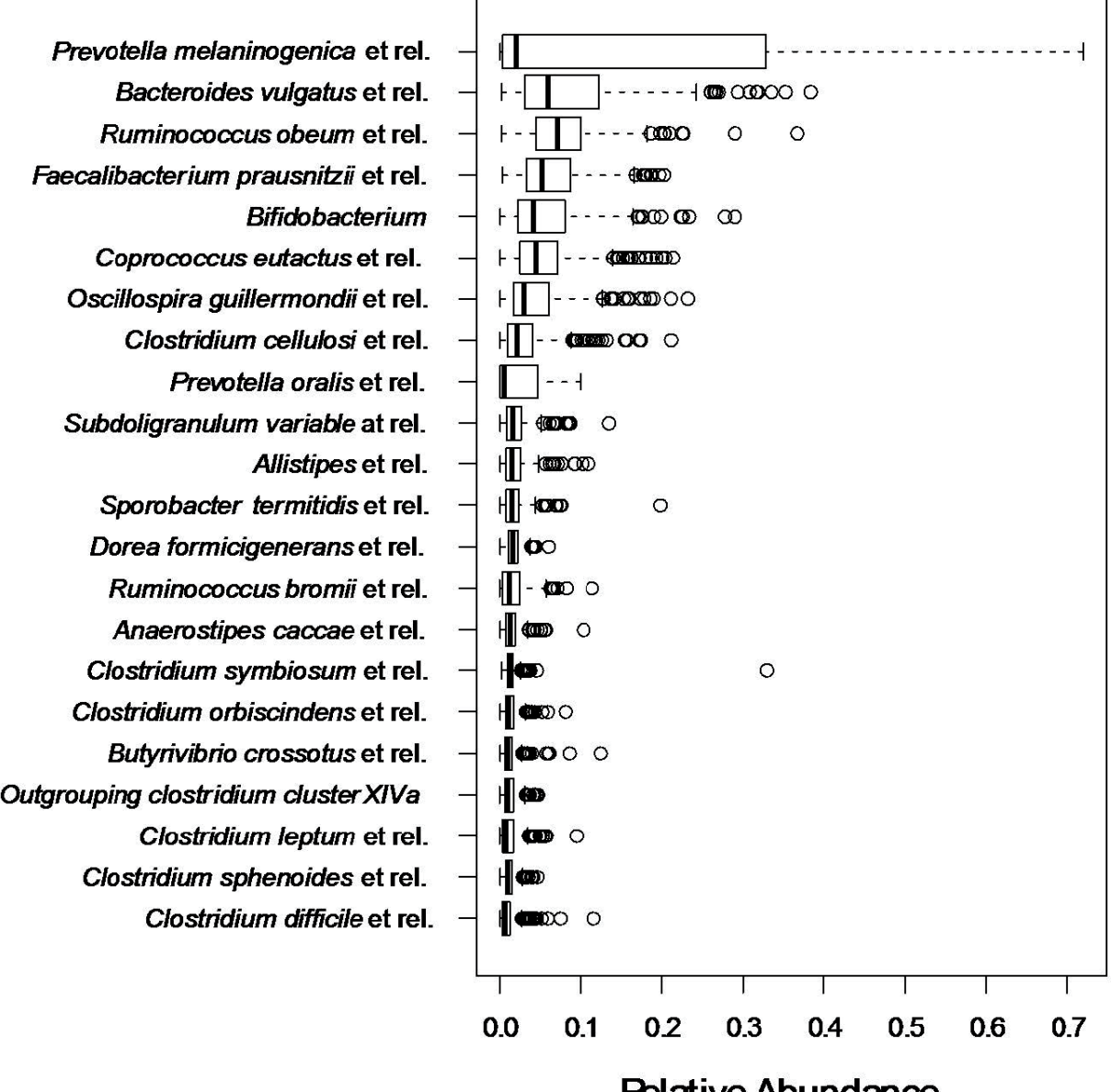

Relative Abundance

Figure 2: Boxplots representing the relative abundance of the 21 most abundant taxa (mean abundance $>1 \%$ ).

The cumulative abundance of the four bimodal groups accounted for $26.1 \%$ of the variation, with largest variation explained by Dialister, Prevotella oralis et rel. and melaninogenica et rel., and their co-correlating species (Figure 3). 


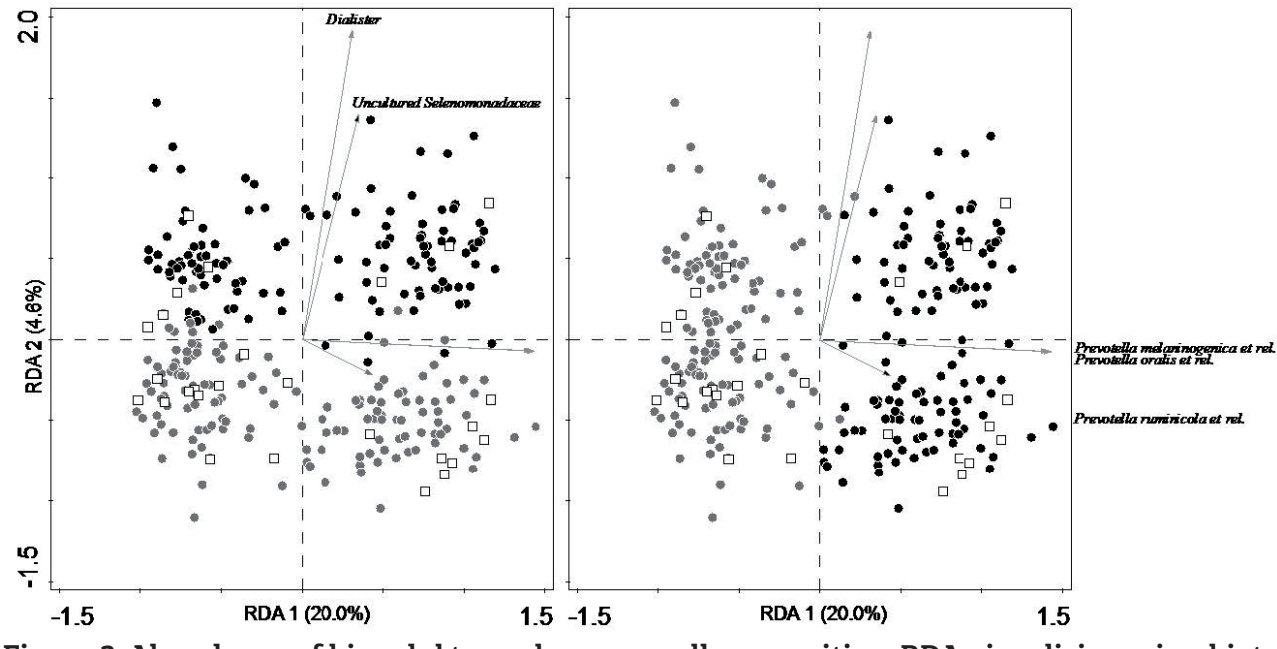

igure 3. Abundance of bimodal taxa shape overall composition. RDA visualising microbiota composition of all faecal samples ( $n=295$ ) coloured by high (black dots) and low (grey dots) abundance of Dialister (left panel), and Prevotella melaninogenica (right panel).

Overweight individuals are represented as squares. The direction of the arrows depicts the abundance of the bimodal bacterial groups as well as their co-correlating groups. Length of the arrows is a measure of fit for the species.

Considering the bimodal bacterial groups, a high abundance of UCII was inversely associated with BMI- and weight $\mathrm{z}$-score, $(\operatorname{adj} \beta-0.22 ; 95 \% \mathrm{CI}-0.42$ to -0.02 for both; Table 2) and overweight (adjOR $0.28 ; 95 \%$ CI 0.10 to 0.79 ; Table 3 ) in the adjusted analysis. Higher abundances of Prevotella melanoginica et rel. (adjOR $0.21 ; 95 \% \mathrm{CI} 0.07$ to 0.68 ) and Prevotella oralis et rel. (adjOR $0.20 ; 95 \% \mathrm{CI} 0.06$ to 0.64 ) were inversely associated with overweight (Table 3). Regarding microbial richness, diversity, and B:F ratio, we only found a borderline significant inverse association between microbial diversity and overweight in the unadjusted linear regression model. Overall, microbial richness and diversity and B:F ratio appeared not be associated with anthropometric outcomes in the childhood population studied.

We subsequently examined whether specific bacterial groups were associated with the anthropometric outcomes under study. Elastic net was applied to the 130 genuslike bacterial groups for each outcome measure separately. A total of 5, 19, and 9 weight-associated bacterial groups were identified as main effects with regards to BMI z-scores, weight z-scores, and overweight, respectively (Figure 1). The elastic net coefficient paths for these bacterial groups with respect to each outcome are presented in Supplementary Figures 2a-c. The selected bacterial groups were included as continuous variables in the regression models, except for Prevotella melanogenica et rel. and Dialister spp. (weight z-scores), and UCII (overweight) as they were already identified as having a bimodal abundance distribution and as such were analysed as dichotomous variables.

After adjusting for confounders (Table 2, Model 2), BMI z-score was inversely associated with Akkermansia ( $\mathrm{p}=0.030)$, and Sutterella wadsworthia et rel $(\mathrm{p}=0.008)$. Similar results were obtained from Model 3, which included all five pre-selected genus-like bacterial groups, other microbial groups (archaea, bimodal bacterial groups), and confounders (Supplementary Table 2). Weight z-scores were inversely associated with Akkermansia $(\mathrm{p}=0.009)$, Burkholderia $(\mathrm{p}=0.017)$, and Bryantella formatexigens et rel. (borderline significant; $\mathrm{p}=0.050$ ) after adjusting for confounders (Table 2, Model 2). In the model with all 19 pre-selected bacteria adjusted for confounders plus other microbial groups (supplementary Table 2, Model 3); only Akkermansia, and Bryantella formatexigen. remained inversely associated with weight z-scores. With regards to overweight, Sutterella wadsworthia et rel. $(\mathrm{p}=0.038)$, and Bryantella formatexigens et rel. $(\mathrm{p}=0.027)$, were inversely associated with overweight in the adjusted analyses. In contrast, Streptococcus bovis et rel. ( $\mathrm{p}=0.013)$ was positively associated with overweight. In the model with all nine pre-selected bacteria, other microbial groups, and confounders (Supplementary Table 2, Model 3), only Akkermansia remained significantly inversely associated with overweight. Overall, Akkermansia, Sutterella wadsworthia et rel., and Bryantella formatexigens et rel. were consistently associated with the three anthropometric outcomes, even after adjusting for the presence of other gut microbial groups and confounders. 

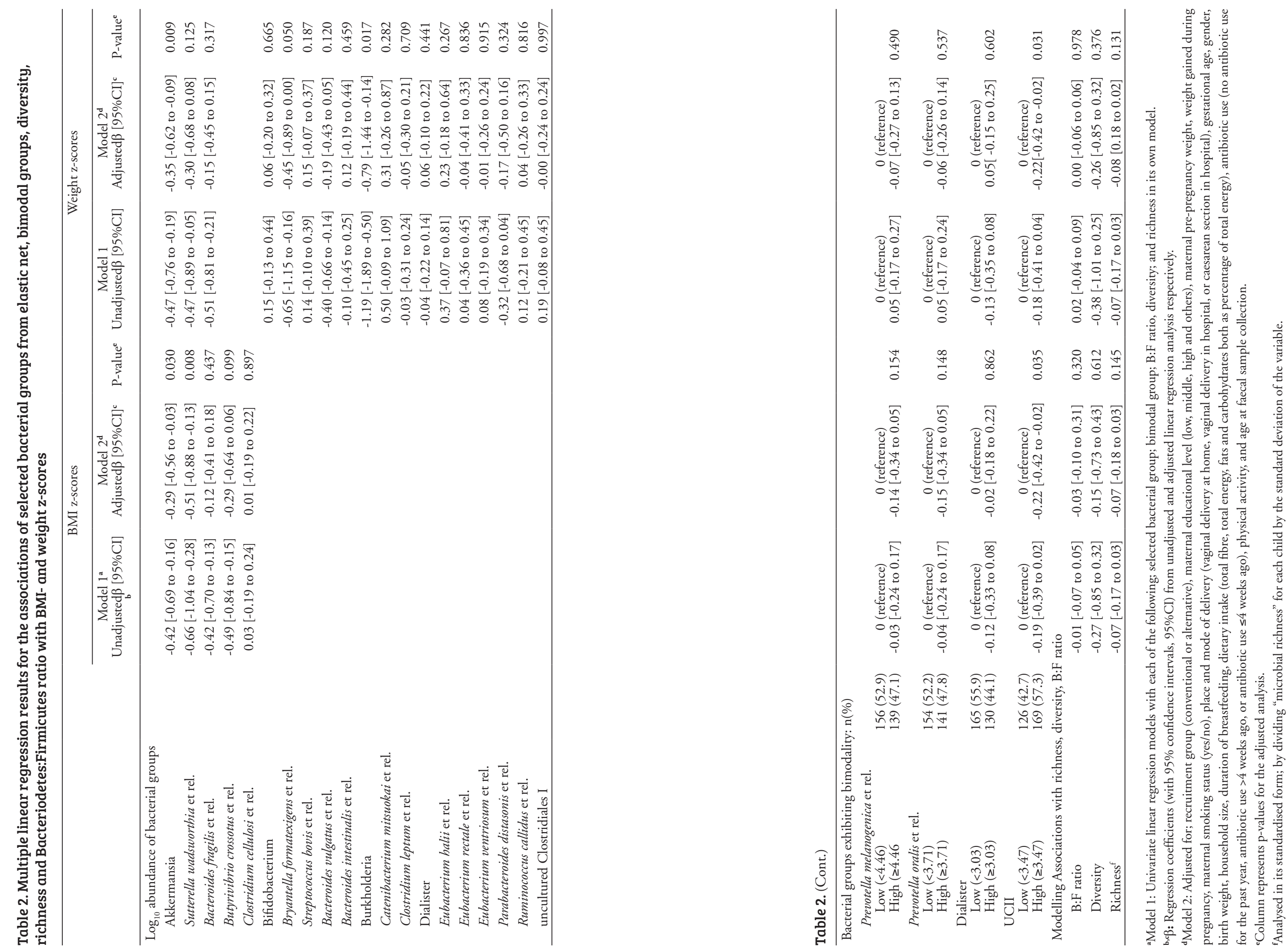

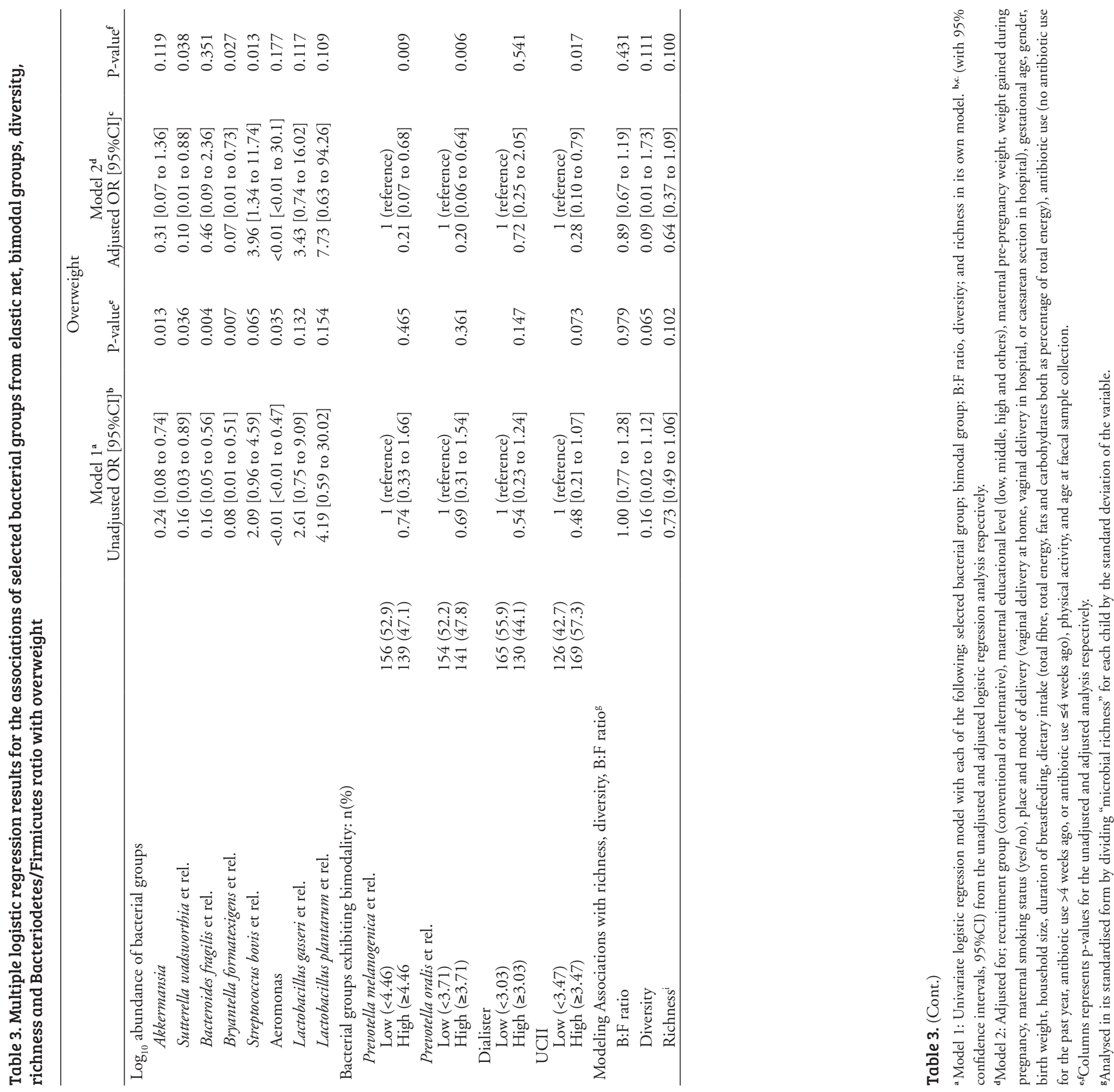


\section{DISCUSSION}

Within a population of 295 school-aged children participating in the KOALA-study, we examined the association between microbiota composition and overweight. So far, this is the largest population-based study on childhood gut microbiota in relation to body weight. Moreover, the extensive data on lifestyle and diet allowed us to carefully control for potential confounding factors. The anthropometric outcomes and potential confounders explained very little variation in the overall microbiota composition; however, the abundances of several specific bacterial groups were consistently linked to BMI-, weight z-scores, and overweight.

The gut microbiota of 6-7 year-old children is less well studied than that of adults, and it is still being debated whether the composition has reached a relatively stable, adultlike state soon after weaning ${ }^{46}$ or continues developing into teen years. ${ }^{47}$ An in-depth comparison with adults is beyond the scope of this paper, however, it is noteworthy that we observed several bimodal distributed bacterial groups as well as their co-correlating species that were previously reported to be present in healthy adults, ${ }^{38}$ including UCII, Prevotella spp. (P. oralis et rel. and $P$. melaninogenica et rel.) co-correlating with $P$. ruminicola et rel., and Dialister with uncultured Selenomodaceae. Lack of support for bimodality of UCI in our study is also in concordance with Lahti et al, ${ }^{38}$ who showed previously that UCI exhibits very clear shifting state probabilities associated with ageing, where the high abundant state was only observed above 40 years of age. Since the bootstrap support of bimodality for Bacteroides fragilis was only moderate in the study of Lahti et al., this bimodality might have been missed in our study due to the smaller sample size, age, health status, or other biological factors.

The abundance of the four bimodal groups explained $26.1 \%$ of the variation in species composition, compared to $<1 \%$ for each of the anthropometric outcomes. Therefore, we cannot confirm the often large-scale community shifts previously reported mainly from rodent studies. ${ }^{6,29}$ In this group of healthy children within a relatively normal weight range, weight and associated parameters therefore did not seem to be major drivers of overall microbial composition or vice versa. This is in line with observations from Hollister et al., who also found that BMI failed to account for a significant proportion of the variation in gut microbial composition and function of American children at age 7-12 years. ${ }^{47}$ The B:F ratio was not associated with weight-related outcomes in the present study. Although previous studies have reported a lower B:F ratio in individuals with overweight or obesity as compared to normal weight individuals, ${ }^{10-15}$ others studies found the opposite association, ${ }^{16-18}$ or analogous to our study, no association at all. ${ }^{19-24}$

A healthy gut microbial ecosystem is generally thought to be characterised by high microbial richness and diversity, presumed to indicate a more stable and resilient state of this ecosystem. ${ }^{48}$ A lower richness/diversity of the gut bacterial communities has been reported in subjects with obesity, and overweight compared to normal weight individuals. ${ }^{13,30,49}$ We also observed a tendency towards a lower gut microbial diversity in overweight compared to normal weight children. However, this association disappeared upon adjusting for confounders. This implies that differences in microbial diversity between obese and lean subjects, as observed in previous studies not comprehensively controlling for confounders may be overestimated. Altogether, our results confirm that the $\mathrm{B}: \mathrm{F}$ ratio and diversity appear not to be a general feature distinguishing the normal and overweight human gut microbiota across populations. ${ }^{50}$

Although we did not find a significant association with the overall microbial community composition, we did observe associations between the anthropometric outcomes and the contrasting alternative stable states of specific bacterial groups that could potentially act as tipping elements of the whole gut microbial ecosystem. We could confirm the observation by Lahti et al. (2014) that UCII was inversely associated with BMI. We found an inverse association with BMI- and weight $\mathrm{z}$-scores, and with overweight. Likewise, higher abundances of $P$. oralis et rel. and $P$. melaninogenica et rel., were inversely associated overweight even after adjusting for other microbial groups that were also associated with overweight, but not with the other outcomes. In addition, using the elastic net statistical method of variable selection, ${ }^{43}$ we identified several bacterial groups, of which Akkermansia, Bryantella formatexigens et rel. and Sutterella wadsworthia et rel. were consistently associated with all three anthropometric outcomes. The inverse association between Akkermansia abundance and body weight is consistent with previous studies both in mice and humans. ${ }^{27,51-53}$ Although the precise mechanism through which Akkermansia influences host metabolism has not yet been fully elucidated, studies in mice have demonstrated that it is involved in the reduction of metabolic endotoxemia, which is characteristic of obesity and associated metabolic disorders, through the restoration of gut barrier function..$^{54}$ Bryantella formatexigens et rel. has been shown to ferment glucose to acetate in the presence of high formate concentration $s^{55}$ and the production of acetate can result in appetite suppression, ${ }^{56}$ suggesting a mechanism by which these bacteria might be linked to lower weight. Sutterella wadsworthia et rel. has been suggested to a play a role in autism spectrum disorder in children, ${ }^{57}$ but its role in overweight development has not been reported before.

The strengths of this study compared to previous cross-sectional studies on the gut microbiota and childhood overweight are; its large sample size in combination with a broad and high resolution interrogation of the whole gut microbial community, and extensive adjustment for important confounding variables (especially diet and physical activity). This allowed us to select bacterial groups (out of a total of 130) that were associated with weight-related outcomes, without an a priori constraint on the target 
species. In addition, our study is one of the first to examine the association between microbiota composition and body weight in a population of mostly lean, healthy children. Previous studies focused on extreme categories of lean and obese individuals. As a consequence, differences in microbiota composition might be less prominent in our study as compared to these previous studies, but it provides insight in the role of the gut microbiota in the normal developing child.

A limitation of the present study was the transport time for faecal samples, which ranged from less than 1 to 3 days at ambient to room temperature. This might have affected the measurable diversity and structure of the bacterial communities. However, several previous studies have shown that the microbial diversity and composition of faecal samples is much more affected by inter-individual differences and biases in molecular techniques rather than differences in short-term storage conditions, including storage for up to 2 weeks at room temperature. ${ }^{58,59}$ Furthermore, we could only assess the associations of the bacterial groups with weight outcomes at one time point, and as a result causality could not be established. However, only a few longitudinal studies have been published so far in this field. ${ }^{25,60}$ Hence, large longitudinal cohort studies that characterise the gut microbiota at multiple time points and collect detailed data on important confounding variables (e.g. mode of delivery, diet, and physical activity) are needed to obtain an in-depth knowledge of the relation between gut microbiota dynamics and childhood weight development. The ongoing follow-up of the children in our study facilitates a future longitudinal investigation of our findings taking into account these important confounding factors.

In conclusion, weight-related outcomes failed to explain much of the observed variation in gut microbiota composition in our cohort of healthy children, suggesting that at least in this group of individuals, weight-related parameters (BMI and weight z-scores, and overweight) are not major drivers of microbial composition in the gut. Nonetheless, several specific bacterial taxa appeared to be consistently associated with weight-related outcomes. These include several bacteria that have previously been linked to weightrelated outcomes (Akkermansia, UCII), as well as species that have not previously been linked to (over)weight such as Sutterella wadsworthia et rel. and Bryantella formatexigens et rel. In this regard, more detailed information on their functional role in energy metabolism will help to establish their importance for weight development. Our results provide new avenues with regards to bacteria in the gut of humans in relation to the increasing trend of overweight worldwide.

Funding source: This study was funded by TI Food and Nutrition, public private partnership in food and nutrition research. The mission is to contribute to optimum human nutrition, food safety and sustainable food production and to increase the competitiveness of food industry. Partners are key players in the global food industry, leading research institutes, universities and medical centres. Additional funding for data collection was received by: Netherlands Organisation for Health Research and Development (grant 2100.0090), Netherlands Asthma Foundation (grants 3.2.03.48, 3.2.07.022), Netherlands Heart Foundation (grant 2008B112), Triodos Foundation, Phoenix Foundation, Raphaël Foundation, Iona Foundation, Foundation for the Advancement of Heilpedagogiek, Royal Friesland Foods (currently FrieslandCampina); Netherlands Sugar Foundation, and the Ministry of Economic affairs. The sponsors had no influence on the analysis and reporting of this study.

\section{ACKNOWLEDGMENTS}

This study was funded by TI Food and Nutrition, public private partnership in food and nutrition research. The mission is to contribute to optimum human nutrition, food safety and sustainable food production and to ease the competitiveness of food industry. Partners are key players in the global food industry, leading research institutes, universities and medical centres. Dr. Sacha van Hijum of the Center for Molecular and Biomolecular Informatics, Radboud UMC, Nijmegen, and NIZO food research, Ede, the Netherlands is gratefully acknowledged for his input during statistical analysis of the data. 


\section{REFERENCES}

1. Sahoo K, Sahoo B, Choudhury AK, Sofi NY, Kumar R, Bhadoria AS. Childhood obesity: Causes and consequences. J Family Med Prim Care 2015; 4: 187-192.

2. D'Aversa F, Tortora A, Ianiro G, Ponziani FR, Annicchiarico BE, Gasbarrini A. Gut microbiota and metabolic syndrome. Intern Emerg Med 2013; 8 Suppl 1: S11-15.

3. Eckburg PB, Bik EM, Bernstein CN, Purdom E, Dethlefsen L, Sargent M et al. Diversity of the human intestinal microbial flora. Science 2005; 308: 1635-1638.

4. Tap J, Mondot S, Levenez F, Pelletier E, Caron C, Furet JP et al. Towards the human intestinal microbiota phylogenetic core. Environ Microbiol 2009; 11: 2574-2584.

5. Koleva PT, Bridgman SL, Kozyrskyj AL. The infant gut microbiome: Evidence for obesity risk and dietary intervention. Nutrients 2015; 7: 2237-2260.

6. Turnbaugh PJ, Ley RE, Mahowald MA, Magrini V, Mardis ER, Gordon JI. An obesity-associated gut microbiome with increased capacity for energy harvest. Nature 2006; 444: 1027-1031.

7. Joyce SA, MacSharry J, Casey PG, Kinsella M, Murphy EF, Shanahan F et al. Regulation of host weight gain and lipid metabolism by bacterial bile acid modification in the gut. Proc Natl Acad Sci US A 2014; 111: 7421-7426.

8. Cani PD, Bibiloni R, Knauf C, Waget A, Neyrinck AM, Delzenne NM et al. Changes in gut microbiota control metabolic endotoxemia-induced inflammation in high-fat diet-induced obesity and diabetes in mice. Diabetes 2008; 57: 1470 1481 .

9. Cani PD, Amar J, Iglesias MA, Poggi M, Knauf C, Bastelica D et al. Metabolic endotoxemia initiates obesity and insulin resistance. Diabetes 2007; 56: 17611772 .

10. Turnbaugh PJ, Hamady M, Yatsunenko T, Cantarel BL, Duncan A, Ley RE et al. A core gut microbiome in obese and lean twins. Nature 2009; 457: 480-484.

11. Bervoets L, Van Hoorenbeeck K, Kortleven I, Van Noten C, Hens N, Vael C et al. Differences in gut microbiota composition between obese and lean children: A cross-sectional study. Gut Pathog 2013; 5: 10.

12. Zuo HJ, Xie ZM, Zhang WW, Li YR, Wang W, Ding XB et al. Gut bacteria alteration in obese people and its relationship with gene polymorphism. World J Gastroenterol 2011; 17: 1076-1081.

13. Verdam FJ, Fuentes S, de Jonge C, Zoetendal EG, Erbil R, Greve JW et al. Human intestinal microbiota composition is associated with local and systemic inflammation in obesity. Obesity (Silver Spring) 2013; 21: E607-615.

14. Ley RE, Turnbaugh PJ, Klein S, Gordon JI. Microbial ecology: Human gut microbes associated with obesity. Nature 2006; 444: 1022-1023.
15. Kasai C, Sugimoto K, Moritani I, Tanaka J, Oya Y, Inoue H et al. Comparison of the gut microbiota composition between obese and non-obese individuals in a japanese population, as analyzed by terminal restriction fragment length polymorphism and next-generation sequencing. BMC Gastroenterol 2015; 15: 100.

16. Zhang H, DiBaise JK, Zuccolo A, Kudrna D, Braidotti M, Yu Y et al. Human gut microbiota in obesity and after gastric bypass. Proc Natl Acad Sci US A 2009; 106: 2365-2370.

17. Xu P, Li M, Zhang J, Zhang T. Correlation of intestinal microbiota with overweight and obesity in kazakh school children. BMC Microbiol 2012; 12: 283.

18. Armougom F, Henry M, Vialettes B, Raccah D, Raoult D. Monitoring bacterial community of human gut microbiota reveals an increase in lactobacillus in obese patients and methanogens in anorexic patients. PLoS One 2009; 4: e7125.

19. Duncan SH, Lobley GE, Holtrop G, Ince J, Johnstone AM, Louis P et al. Human colonic microbiota associated with diet, obesity and weight loss. Int J Obes (Lond) 2008; 32: 1720-1724.

20. Balamurugan R, George G, Kabeerdoss J, Hepsiba J, Chandragunasekaran AM, Ramakrishna BS. Quantitative differences in intestinal faecalibacterium prausnitzii in obese indian children. Br J Nutr 2010; 103: 335-338.

21. Mai V, McCrary QM, Sinha R, Glei M. Associations between dietary habits and body mass index with gut microbiota composition and fecal water genotoxicity: An observational study in african american and caucasian american volunteers. Nutr J 2009; 8: 49.

22. Schwiertz A, Taras D, Schafer K, Beijer S, Bos NA, Donus C et al. Microbiota and scfa in lean and overweight healthy subjects. Obesity (Silver Spring) 2010; 18: 190195.

23. Hu HJ, Park SG, Jang HB, Choi MG, Park KH, Kang JH et al. Obesity alters the microbial community profile in korean adolescents. PLoS One 2015; 10: e0134333.

24. Fernandes J, Su W, Rahat-Rozenbloom S, Wolever TM, Comelli EM. Adiposity, gut microbiota and faecal short chain fatty acids are linked in adult humans. Nutr Diabetes 2014; 4: e121.

25. Scheepers LE, Penders J, Mbakwa CA, Thijs C, Mommers M, Arts IC. The intestinal microbiota composition and weight development in children: The koala birth cohort study. Int J Obes (Lond) 2015; 39: 16-25.

26. Kalliomaki M, Collado MC, Salminen S, Isolauri E. Early differences in fecal microbiota composition in children may predict overweight. Am J Clin Nutr 2008; 87: 534-538. 
27. Karlsson CL, Onnerfalt J, Xu J, Molin G, Ahrne S, Thorngren-Jerneck K. The microbiota of the gut in preschool children with normal and excessive body weight. Obesity (Silver Spring) 2012; 20: 2257-2261.

28. Mbakwa CA, Penders J, Savelkoul PH, Thijs C, Dagnelie PC, Mommers M et al. Gut colonization with methanobrevibacter smithii is associated with childhood weight development. Obesity (Silver Spring) 2015.

29. Turnbaugh PJ, Backhed F, Fulton L, Gordon JI. Diet-induced obesity is linked to marked but reversible alterations in the mouse distal gut microbiome. Cell Host Microbe 2008; 3: 213-223.

30. Le Chatelier E, Nielsen T, Qin J, Prifti E, Hildebrand F, Falony G et al. Richness of human gut microbiome correlates with metabolic markers. Nature 2013; 500: 541-546.

31. Hermes GD, Zoetendal EG, Smidt H. Molecular ecological tools to decipher the role of our microbial mass in obesity. Benef Microbes 2015; 6: 61-81.

32. Kummeling I, Thijs C, Penders J, Snijders BE, Stelma F, Reimerink J et al. Etiology of atopy in infancy: The koala birth cohort study. Pediatr Allergy Immunol 2005; 16: 679-684.

33. Bastiaanssen JM, de Bie RA, Bastiaenen CH, Heuts A, Kroese ME, Essed GG et al. Etiology and prognosis of pregnancy-related pelvic girdle pain; design of a longitudinal study. BMC Public Health 2005; 5: 1.

34. Salonen A, Nikkila J, Jalanka-Tuovinen J, Immonen O, Rajilic-Stojanovic M, Kekkonen RA et al. Comparative analysis of fecal DNA extraction methods with phylogenetic microarray: Effective recovery of bacterial and archaeal DNA using mechanical cell lysis. J Microbiol Methods 2010; 81: 127-134.

35. Jalanka-Tuovinen J, Salonen A, Nikkila J, Immonen O, Kekkonen R, Lahti L et al. Intestinal microbiota in healthy adults: Temporal analysis reveals individual and common core and relation to intestinal symptoms. PLoS One 2011; 6: e23035.

36. Rajilic-Stojanovic M, Heilig HG, Molenaar D, Kajander K, Surakka A, Smidt H et al. Development and application of the human intestinal tract chip, a phylogenetic microarray: Analysis of universally conserved phylotypes in the abundant microbiota of young and elderly adults. Environ Microbiol 2009; 11: 1736-1751.

37. Claesson MJ, O'Sullivan O, Wang Q, Nikkila J, Marchesi JR, Smidt H et al. Comparative analysis of pyrosequencing and a phylogenetic microarray for exploring microbial community structures in the human distal intestine. PLoS One 2009; 4: e6669.

38. Lahti L, Salojarvi J, Salonen A, Scheffer M, de Vos WM. Tipping elements in the human intestinal ecosystem. Nat Commun 2014; 5: 4344.

39. Jari Oksanen F, Kindt R, Legendre P, Minchin PR, O'Hara R, Simpson GL et al. Vegan: Community ecology package. R package version 2.0-10. In, 2013.
40. Fredriks AM, van Buuren S, Wit JM, Verloove-Vanhorick SP. Body index measurements in 1996-7 compared with 1980. Arch Dis Child 2000; 82: 107-112.

41. Ogden CL, Flegal KM. Changes in terminology for childhood overweight and obesity. Natl Health Stat Report 2010: 1-5.

42. Šmilauer P, Lepš J. Multivariate analysis of ecological data using canoco 5, Cambridge University Press, 2014.

43. Zou H, Hastie T. Regularization and variable selection via the elastic net. Journal of the Royal Statistical Society: Series B (Statistical Methodology) 2005; 67: 301-320.

44. Livina VN, Kwasniok F, Lenton TM. Potential analysis reveals changing number of climate states during the last 60 kyr. Climate of the Past 2010; 6: 77-82.

45. Dakos V, Carpenter SR, Brock WA, Ellison AM, Guttal V, Ives AR et al. Methods for detecting early warnings of critical transitions in time series illustrated using simulated ecological data. PLoS One 2012; 7: e41010.

46. Koenig JE, Spor A, Scalfone N, Fricker AD, Stombaugh J, Knight R et al. Succession of microbial consortia in the developing infant gut microbiome. Proc Natl Acad Sci U S A 2011; 108 Suppl 1: 4578-4585.

47. Hollister EB, Riehle K, Luna RA, Weidler EM, Rubio-Gonzales M, Mistretta TA et al. Structure and function of the healthy pre-adolescent pediatric gut microbiome. Microbiome 2015; 3: 36.

48. Lozupone CA, Stombaugh JI, Gordon JI, Jansson JK, Knight R. Diversity, stability and resilience of the human gut microbiota. Nature 2012; 489: 220-230.

49. Yasir M, Angelakis E, Bibi F, Azhar EI, Bachar D, Lagier JC et al. Comparison of the gut microbiota of people in france and saudi arabia. Nutr Diabetes 2015; 5: e153.

50. Walters WA, Xu Z, Knight R. Meta-analyses of human gut microbes associated with obesity and ibd. FEBS Lett 2014; 588: 4223-4233.

51. Everard A, Lazarevic V, Derrien M, Girard M, Muccioli GG, Neyrinck AM et al. Responses of gut microbiota and glucose and lipid metabolism to prebiotics in genetic obese and diet-induced leptin-resistant mice. Diabetes 2011; 60: 27752786.

52. Remely M, Hippe B, Geretschlaeger I, Stegmayer S, Hoefinger I, Haslberger A. Increased gut microbiota diversity and abundance of faecalibacterium prausnitzii and akkermansia after fasting: A pilot study. Wien Klin Wochenschr 2015.

53. Santacruz A, Collado MC, Garcia-Valdes L, Segura MT, Martin-Lagos JA, Anjos $\mathrm{T}$ et al. Gut microbiota composition is associated with body weight, weight gain and biochemical parameters in pregnant women. Br J Nutr 2010; 104: 83-92.

54. Everard A, Belzer C, Geurts L, Ouwerkerk JP, Druart C, Bindels LB et al. Crosstalk between akkermansia muciniphila and intestinal epithelium controls dietinduced obesity. Proc Natl Acad Sci U S A 2013; 110: 9066-9071. 
55. Wolin MJ, Miller TL, Collins MD, Lawson PA. Formate-dependent growth and homoacetogenic fermentation by a bacterium from human feces: Description of bryantella formatexigens gen. Nov., sp. Nov. Appl Environ Microbiol 2003; 69: 6321-6326.

56. Frost G, Sleeth ML, Sahuri-Arisoylu M, Lizarbe B, Cerdan S, Brody L et al. The short-chain fatty acid acetate reduces appetite via a central homeostatic mechanism. Nat Commun 2014; 5: 3611.

57. Wang L, Christophersen CT, Sorich MJ, Gerber JP, Angley MT, Conlon MA. Increased abundance of sutterella spp. And ruminococcus torques in feces of children with autism spectrum disorder. Mol Autism 2013; 4: 42.

58. Lauber CL, Zhou N, Gordon JI, Knight R, Fierer N. Effect of storage conditions on the assessment of bacterial community structure in soil and human-associated samples. FEMS Microbiol Lett 2010; 307: 80-86.

59. Tedjo DI, Jonkers DM, Savelkoul PH, Masclee AA, van Best N, Pierik MJ et al. The effect of sampling and storage on the fecal microbiota composition in healthy and diseased subjects. PLoS One 2015; 10: e0126685.

60. Vael C, Verhulst SL, Nelen V, Goossens H, Desager KN. Intestinal microflora and body mass index during the first three years of life: An observational study. Gut Pathog 2011; 3: 8.

\section{SUPPLEMENTAL MATERIAL}

Supplementary Table 1. List of potential confounding variables

\begin{tabular}{|c|c|}
\hline Potential confounders & Variable description/label \\
\hline Recruitment group & $\begin{array}{l}\text { Categorical } \\
\bullet 0 \text { - alternative } \\
\cdot 1 \text { - conventional }\end{array}$ \\
\hline Maternal educational level & $\begin{array}{l}\text { Categorical } \\
\cdot 0 \text { - lower education } \\
\cdot 1 \text { - vocational education } \\
\cdot 2 \text { - higher general secondary/pre-university } \\
\cdot 3 \text { - higher vocational/academic education }\end{array}$ \\
\hline Maternal pre-pregnancy weight & Continuous \\
\hline Weight gained during pregnancy & Continuous \\
\hline Maternal smoking status & $\begin{array}{c}\text { Categorical } \\
\bullet 0 \text { - no } \\
\cdot 1-\text { yes }\end{array}$ \\
\hline Place and mode of delivery & $\begin{array}{l}\text { Categorical } \\
\cdot 0 \text { - vaginal delivery at home } \\
\cdot 1 \text { - vaginal delivery in hospital } \\
\cdot 2 \text { - caesarean section in hospital }\end{array}$ \\
\hline Gestational age & Continuous \\
\hline Gender & $\begin{array}{l}\text { Categorical } \\
\cdot 0 \text { - male } \\
\cdot 1 \text { - female }\end{array}$ \\
\hline Birth weight & Continuous \\
\hline Household size & Continuous \\
\hline Duration of breastfeeding & Continuous \\
\hline \multicolumn{2}{|l|}{ Child's dietary intake } \\
\hline Total energy intake $(\mathrm{KJ})$ & Continuous \\
\hline$\%$ energy intake from fats & Continuous \\
\hline$\%$ energy intake from carbohydrates & Continuous \\
\hline Time of last antibiotic course prior to home visit & $\begin{array}{l}\text { Categorical } \\
\bullet 0 \text { - no antibiotic use in the previous year } \\
\cdot 1 \text { - greater than } 4 \text { weeks ago } \\
\cdot 2 \text { - less than } 4 \text { weeks ago }\end{array}$ \\
\hline Physical activity & Continuous \\
\hline Age at faecal sample collection (years) & Continuous \\
\hline
\end{tabular}

All zero values were treated as reference category for each categorical variable. 

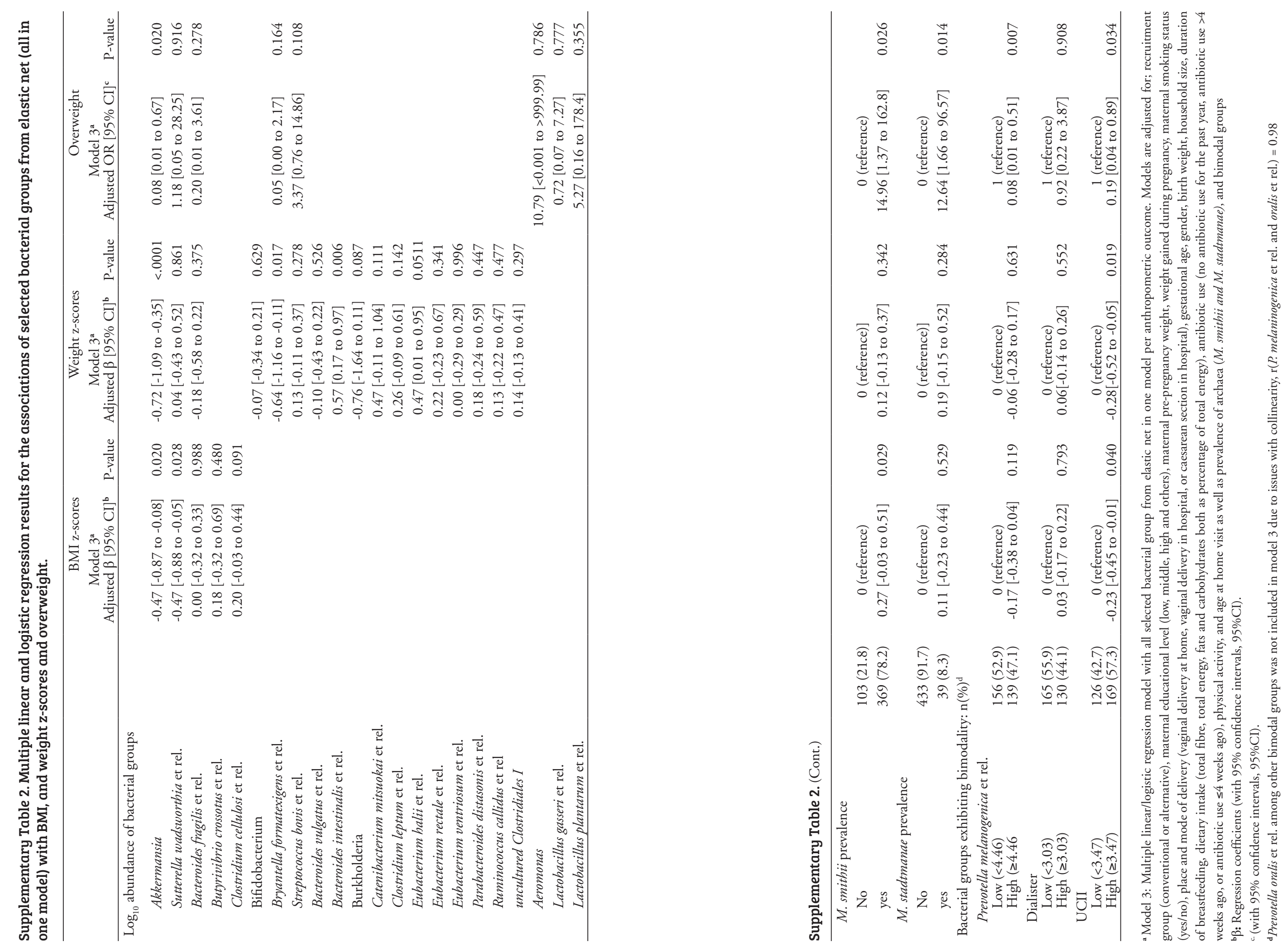


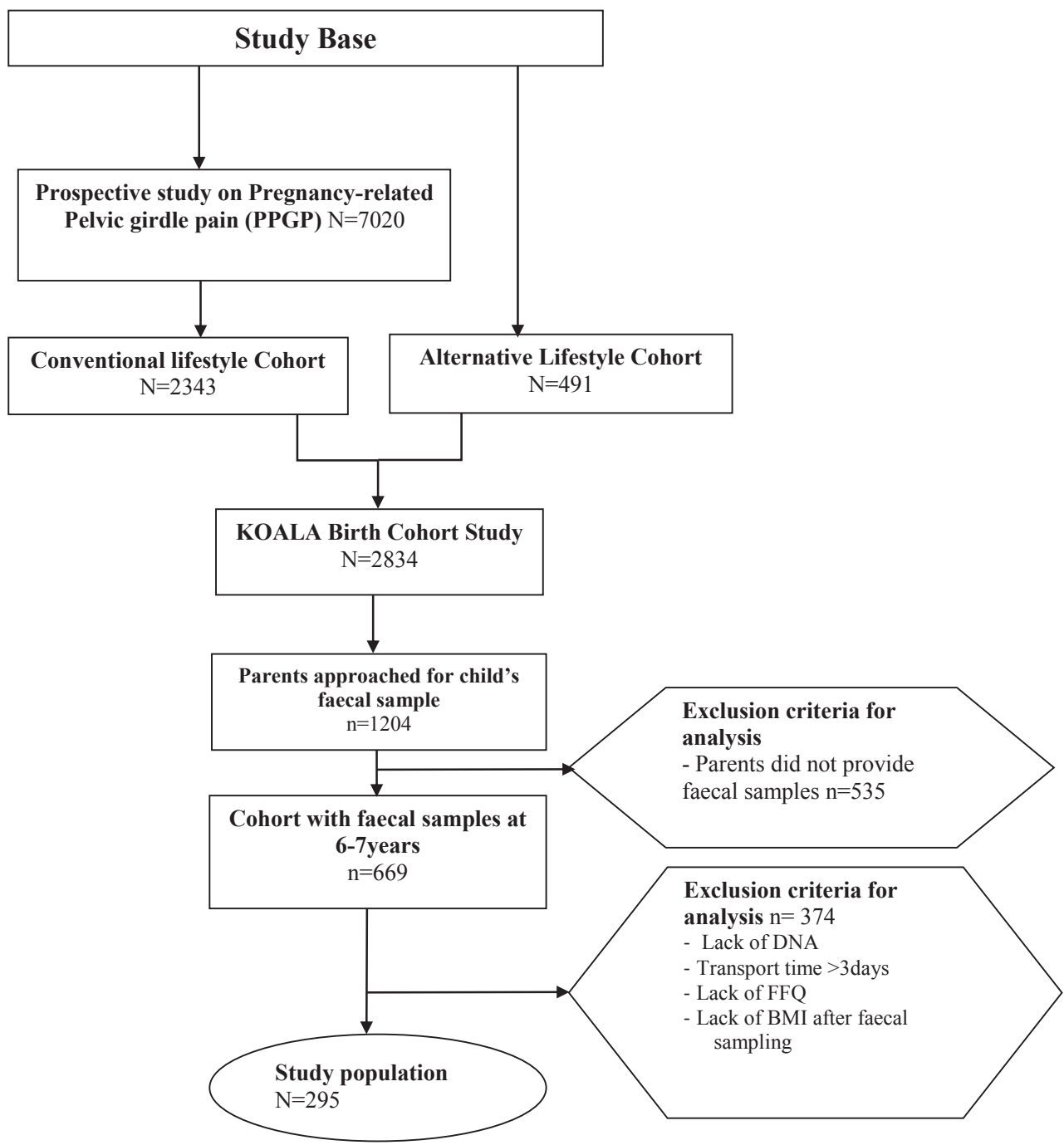

Supplementary Figure 1. Flow chart illustrating how the present study population of 295 children was obtained from the initial KOALA cohort of 2834 healthy pregnant women. a

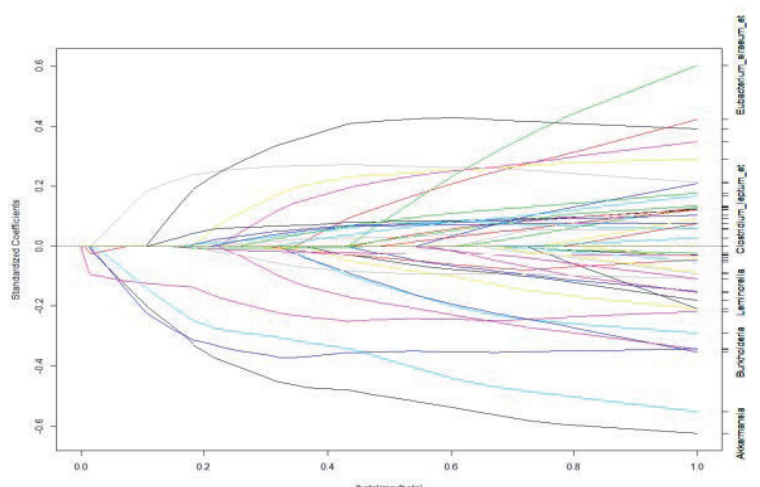

b
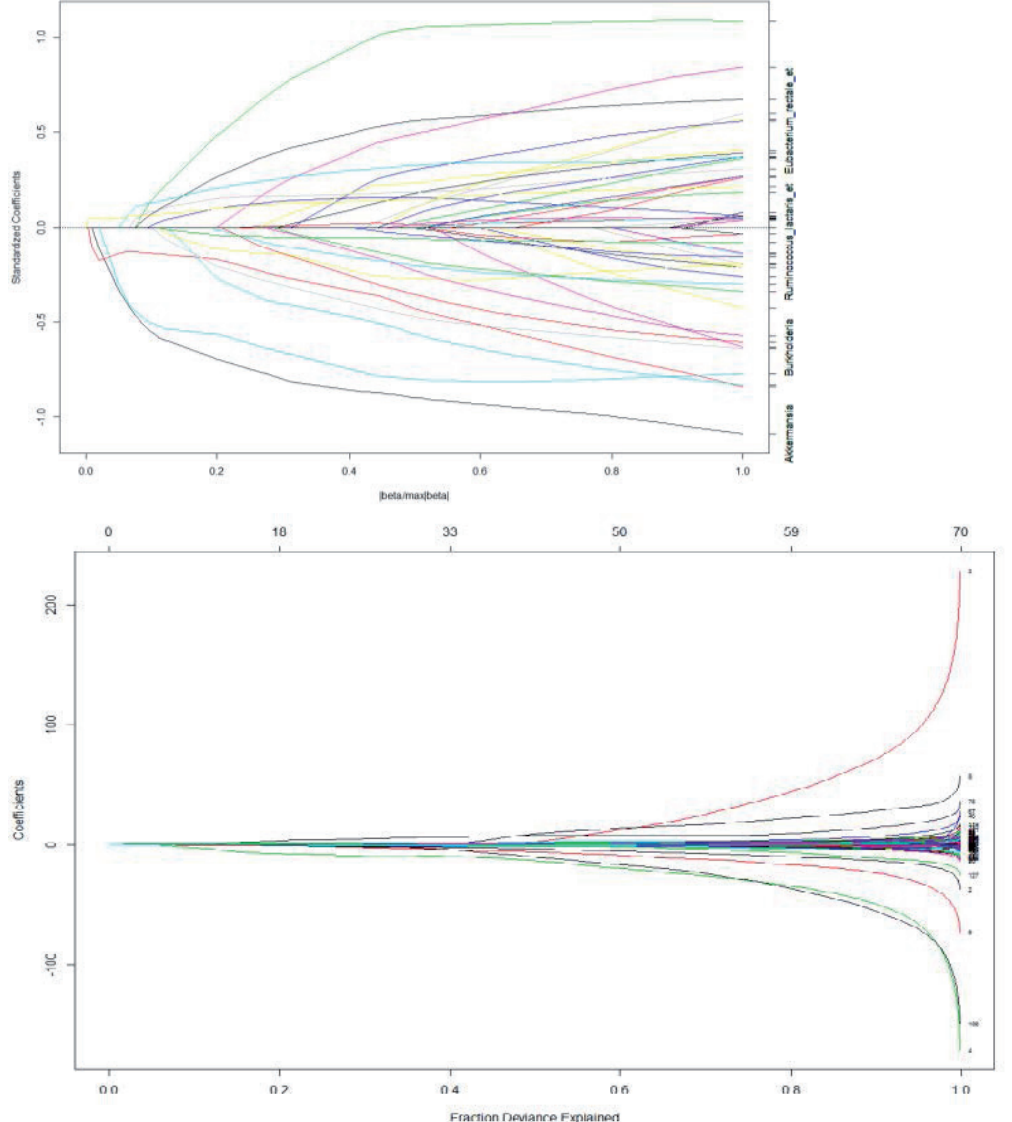

Supplementary Figure 2. Coefficient paths for the elastic net regression models applied to the gut microbiota data. (a) Elastic net regression estimates for BMI z-scores with the optimal lambda value $(\lambda=0.1)$ as obtained from ten-fold cross-validation parameters and $s=0.1$ on the horizontal axis. Selected bacterial groups with non-zero coefficients are the lines that fall below the cut-off value $s=0.1(n=5)$; (b) elastic net regression coefficients for weight $z$-scores with tuning parameters $(\lambda=0.01$ and $s=0.2$ ) coefficients below $s=0$. $(n=19)$; (c) elastic net regression coefficients for overweight with tuning parameters $(\lambda=0.01$ and $s=0.1)$ with non-zero coefficients below $s=0.1(n=9)$. 

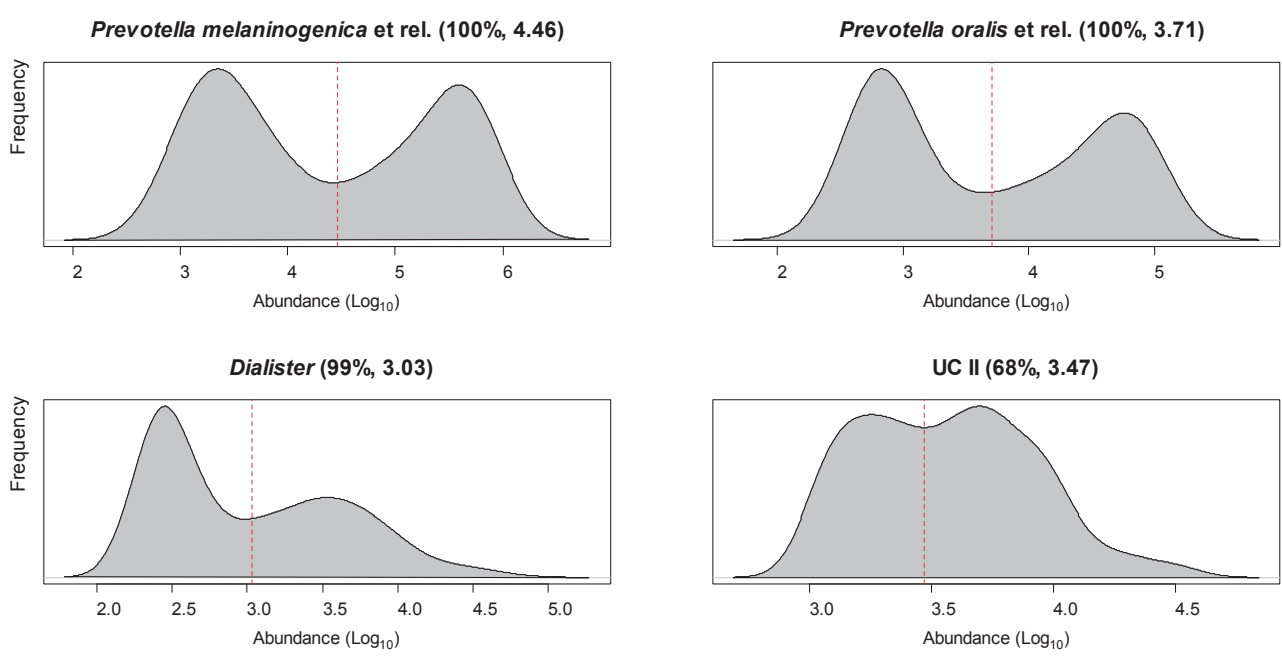

Supplementary Figure 3. Logarithmic abundance distributions of the four bacterial groups that exhibited a bimodal abundance across the gut microbiota of 295 children.

High and low abundance states are separated by a dashed red line. Proportion of children

with high levels of bimodal bacterial groups; $47.1 \%, 47.8 \%, 44.1 \%$ and $57.3 \%$ for Prevotella

melanogenica et rel., Prevotella oralis et rel., Dialister and UCII respectively. UC II refers to

the Uncultured Clostridiales II.

\section{CHAPTER 4}

\section{COLONISATION OF THE GUT WITH THE ARCHAEON METHANOBREVIBACTER SMITHII IS ASSOCIATED WITH CHILDHOOD WEIGHT DEVELOPMENT.}




\section{Abstract}

Objective: To prospectively investigate the presence and counts of archaea in faeces of 472 children in association with weight development from 6-10 years of age.

Methods: Within the KOALA Birth Cohort Study, a single faecal sample from each child was analysed by qPCR to quantify archaea (Methanobrevibacter smithii, Methanosphera stadtmanae). Anthropometric outcomes (overweight (BMI $\geq 85$ th percentile), age- and sex-standardized BMI, weight, and height z-scores) were repeatedly measured at ages $($ mean $\pm S D)$ of $6.2 \pm 0.5,6.8 \pm 0.5,7.8 \pm 0.5$, and $8.8 \pm 0.5$ years. Generalized Estimating Equations was used for statistical analysis while controlling for confounders.

Results: M. smithii colonization was associated with an increased risk of overweight (adjusted odds ratio $(\mathrm{OR})=2.69$; 95\%CI 0.96-7.54) from 6-10 years of age. Children with high levels ( $>7 \log _{10}$ copies/g faeces) of this archaeon were at highest risk for overweight $(\mathrm{OR}=3.27 ; 95 \% \mathrm{CI}$ 1.09-9.83). Moreover, M. smithii colonization was associated with higher weight $z$-scores $(\operatorname{adj} \beta 0.18 ; 95 \% \mathrm{CI} 0.00-0.36)$, but not with height. For BMI z-scores, the interaction $(\mathrm{P}=0.008)$ between $M$. smithii and age, was statistically significant, implying children colonized with M. smithii had increasing BMI z-scores with age.

Conclusion: Presence and higher counts of M. smithii in the gut of children is associated with higher weight z-scores, higher BMI z-scores and overweight.

\section{Introduction}

Salonen, 2010 \#98\}Over the past decades childhood overweight and obesity have reached epidemic proportions in most industrialized countries. ${ }^{1}$ Since 1980 , there has been a two to three fold increase in childhood overweight and four to six fold increase in obesity in the Netherlands. ${ }^{2}$ Eventually, children with overweight or obesity are more likely to become obese adults, ${ }^{3,4}$ leading to increased risk for chronic diseases, including cardiovascular disease, hypertension, type 2 diabetes mellitus and premature mortality. ${ }^{2}$ Moreover, once obesity is established, it is difficult to reverse through interventions. ${ }^{5}$ Recently, a role of the gut microbiota has been put forward. The human gut microbiota is a complex, densely populated ecosystem, mainly consisting of bacteria. ${ }^{6}$ Besides the many bacterial species, the human gut contains several archaeal species, which are considered to play a crucial role in the metabolic capacity of the human gut microbiota. To date, only three distinct species within the group of methanogenic archaea have been isolated from human faeces, Methanobrevibacter smithii, ${ }^{7}$ Methanospaera stadtmanae ${ }^{8}$ and Methanomassilicoccus luminyesis. ${ }^{9}$ In children from 1 to 10 years of age, the prevalence of these methanogenic species have been found in, $88 \%, 11 \%$ and $1 \%$ of the children respectively. ${ }^{10}$

Methanogens use hydrogen, a by-product of bacterial fermentation, to produce methane. The removal of hydrogen accelerates the bacterial fermentation of polysaccharides and carbohydrates, leading to the more efficient production of short-chain fatty acids which can serve as an additional energy source for the host. ${ }^{11-15}$

Several studies, both in animal models and humans have suggested a potential role for archaea, specifically $M$. smithii, in the development of overweight/obesity. Using a mouse model, Samuel and colleagues, illustrated that colonization with M. smithii leads to increased utilization of dietary fibre and increased adiposity. ${ }^{16}$ Another study revealed a significant increase in M. smithii in mice fed with high-fat chow compared to those fed with normal chow. ${ }^{17}$ Only few studies have addressed the relationship between archaea and host energy balance in humans. In a small study including 9 human participants, Zhang et al. ${ }^{18}$ detected significantly higher numbers of $\mathrm{H}_{2}$-utilizing methanogenic archaea in obese individuals compared to normal-weight as well as post-gastric-bypass individuals. In contrast, other studies have reported lower amounts of M. smithii in obese compared to lean individuals. ${ }^{19}, 20$ These results demonstrate that more research is needed to unde\{Altschul, $1997 \# 87\}$ rstand the role of archaea in obesity. ${ }^{20}$ Most of the studies reporting a positive association between methanogenic archaea and obesity were based on breath methane measurements. A study among 58 obese subjects showed a significantly higher BMI among breath methane-positive as compared to methanenegative subjects. ${ }^{21}$ Moreover, in a large study among 792 subjects the presence of both hydrogen and methane on breath testing was associated with a higher BMI and percent body fat. ${ }^{22}$ Breath methane measurements alone may however underestimate the number of participants with methanogenic archaea due to the lower sensitivity 
(62\%) as compared to molecular detection of methanogens in stools. ${ }^{23,}{ }^{24}$ Moreover, the main evidence originates from animal studies and the limited number of human studies that used faecal samples had small sample sizes hence low power to detect a significant association, and a cross-sectional design. Lastly, none of these studies has been performed in children.

Therefore, we aimed to investigate whether the presence and counts of archaea in the faecal samples of 472 children at school age is associated with childhood weight development from 6 to 10 years of age.

\section{Methods}

\section{Study design}

The present study was conducted within the prospective KOALA Birth Cohort Study, in the Netherlands. The design of this study has been described in detail elsewhere. ${ }^{25} \mathrm{~A}$ total of 2834 pregnant women were recruited, at 34 weeks of gestation, from October 2000 until December 2002. Healthy pregnant women with a conventional lifestyle (n 2343) were retrieved from an on-going cohort study on the aetiology of pregnancyrelated pelvic girdle pain in the Netherlands. An additional 491 pregnant women with alternative lifestyles were recruited through organic food shops, anthroposophist doctors and midwives, Steiner schools and dedicated magazines. This latter group of women was considered to have an alternative lifestyle that could involve dietary habits (vegetarian, organic food choice), child rearing practices, vaccination schemes and/or use of antibiotics. Exclusion criteria for the present study were: prematurity $(<37$ weeks of gestation), twins, abnormalities linked to growth (such as Down's syndrome, Turner syndrome, Fallot's tetralogy, multiple disabilities, and cystic fibrosis), and faecal samples whose transport time was greater than 4 days. All children included in this study were Caucasians. Informed consent was given by all parents, and the study was approved by the Medical Ethics Committee of Maastricht University and the National Ethical Committee for Medical Research.

\section{Data collection and longitudinal outcome measures}

At 14 and 34 weeks of gestation, pregnant women received questionnaires collecting data on amongst others family size, pre-pregnancy height and weight, and weight gain during pregnancy. Two weeks after childbirth, data was collected from obstetric reports and questionnaires were completed by the mothers to obtain data on gestational age, birth weight and gender of the child. Food frequency questionnaires were filled out by the parents to report the dietary habits of their children at the age (mean \pm standard deviation $(\mathrm{SD}))$ of $5.0 \pm 0.6$ years.
Parent-reported weight and height of children was repeatedly assessed by mailing followup questionnaires to the parents in 2007, 2008, 2009 and 2010. This corresponds to longitudinal assessment of the children's' height and weight at the ages (mean $\pm \mathrm{SD}$ ) of $6.2 \pm 0.5,6.8 \pm 0.5,7.8 \pm 0.5$, and $8.8 \pm 0.5$ years respectively.

BMI was computed as weight divided by height squared $\left(\mathrm{kg} / \mathrm{m}^{2}\right)$. The BMI, weight and height measurements were then converted into age- and gender-specific z-scores using the Dutch National growth study ${ }^{26}$ as the reference population. BMI z-scores were used both as continuous and dichotomous outcomes. Dichotomisation into normal weight vs. overweight was based upon a cut-off of a $\mathrm{z}$-score ${ }^{3} 1.04$, equivalent to BMI z-scores $385^{\text {th }}$ percentile standardized for age and gender. ${ }^{27}$

\section{Faecal sample collection}

A subgroup of this cohort $(n=1204)$, i.e. the participants who were visited at home for blood collection from the mother during pregnancy and/or the child at age 2 years, and were still active participants at child's age of 6-7 years (Figure 1), was asked to collect a single faecal sample from their children at school age. Faeces collection tubes with spoon attached to their lids (Sarstedt, Nümbrecht, Germany) together with collection instructions were sent to the parents of participating children. A faecal sample was collected and sent to the laboratory by mail. Upon arrival in the laboratory, faecal samples were 10-fold diluted in peptone/water (Oxoid CM0009) containing 20\% (vol/ vol) glycerol (Merck, Darmstadt, Germany) and stored at $-80^{\circ} \mathrm{C}$ until further analysis. 


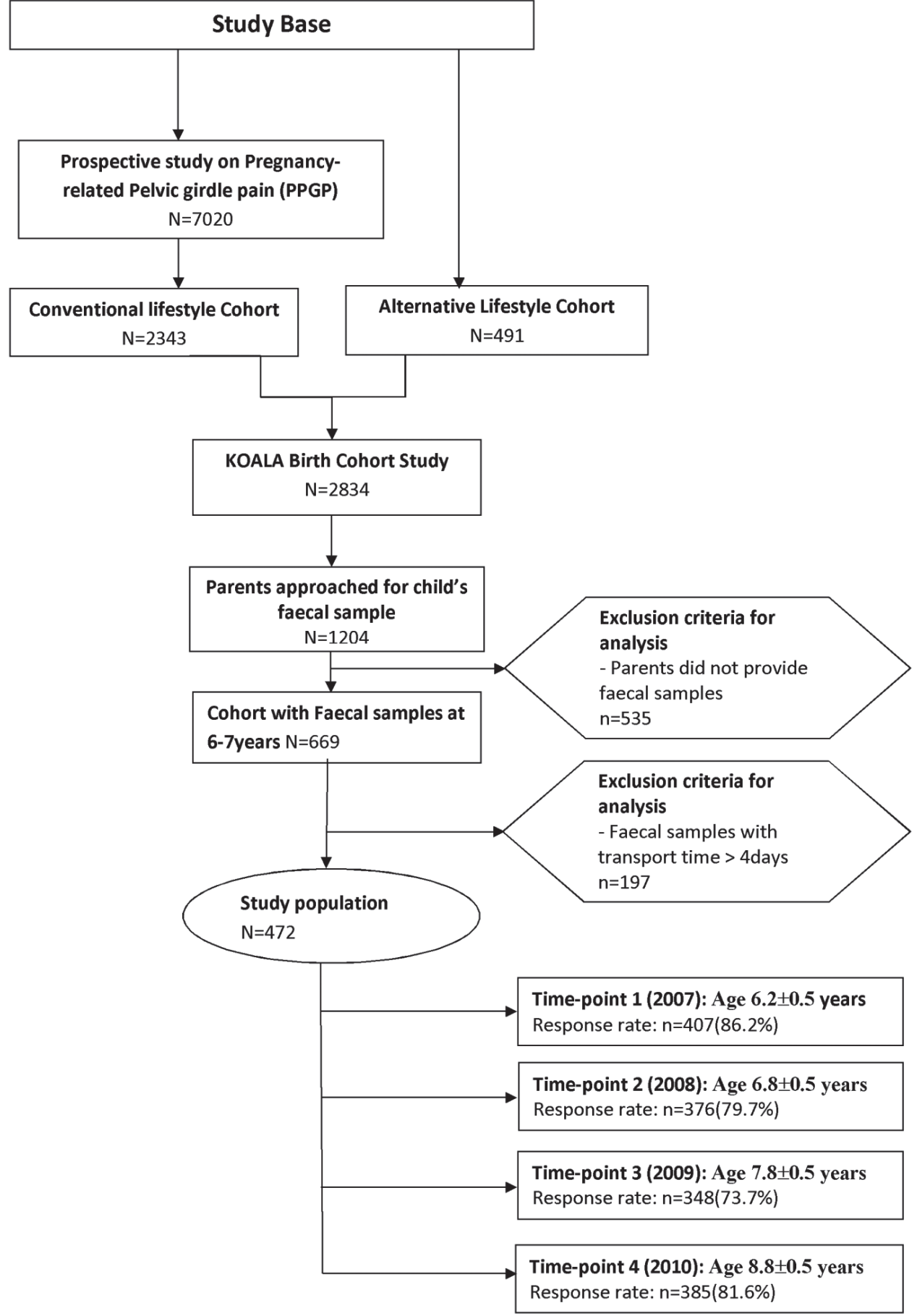

Figure 1. Flow chart illustrating how the present study population of 472 children was obtained from the initial KOALA cohort of 2834 healthy pregnant women.

\section{Faecal DNA isolation and Real-time quantitative PCR}

DNA isolation from faecal samples has been described in detail elsewhere. ${ }^{28}$ In brief, the DNA was isolated using a combination of Repeated-Bead-Beading (RBB) plus column purification method. Concentration and purity of the DNA were assessed with a Nanodrop 1000 spectrophotometer (Thermo Fisher Scientific, Wilmington, USA).

DNA from all faecal samples was subjected to 5'-nuclease based real-time PCR assays for the enumeration of $M$. smithii and $M$. stadtmanae (primers and probes are listed in Table 1). For both M. smithii and M. stadtmanae, amplifications were conducted in a total volume of $25 \mu \mathrm{L}$, containing $1 \times$ Absolute qPCR Mix (ABgene, Hamburg, Germany), $200 \mathrm{nM}$ of forward and reverse primers, $200 \mathrm{nM}$ TaqMan probe, and $2 \mu \mathrm{L}$ of tenfold diluted target DNA. The amplification $\left(2\right.$ minutes at $50^{\circ} \mathrm{C}, 10$ minutes at $95^{\circ} \mathrm{C}$, and 42 cycles of 15 seconds at $95^{\circ} \mathrm{C}$ and 1 minute at $60^{\circ} \mathrm{C}$ ) and detection were conducted with an Applied Biosystems Prism 7900 sequence detection system (Applied Biosystems).

Table 1. Real-time PCR primers and probe sequences for detecting M. smithii and $M$. stadtmanae $16 \mathrm{~S}$ rRNA

\begin{tabular}{llll}
\hline $\begin{array}{l}\text { Target organisms } \\
\text { (amplicon size) }\end{array}$ & Primer/probe & Sequence (5'-3') & $\mathrm{T}_{\mathrm{m}}\left({ }^{\circ} \mathrm{C}\right)$ \\
\hline M. smithii (123 bp) & Forward primer & 5'-CCGGGTATCTAATCCGGTTC-3' & 63.0 \\
& Reverse primer & 5'-CTCCCAGGGTAGAGGTGAAA-3' & 64.0 \\
& Probe & 5'-CCGTCAGAATCGTTCCAGTCAG-3' & 61.0 \\
M. stadtmanae (97 bp) & Forward primer & 5'-AGGAGCGACAGCAGAATGAT-3' & 64.0 \\
& Reverse primer & 5'-CAGGACGCTTCACAGTACGA-3' & 65.0 \\
& Probe & 5'-TGAGAGGAGGTGCATGGCCG-3' & 71.0 \\
\hline
\end{tabular}

${ }^{2}$ Reference for information in table; Dridi et al., (2009) ${ }^{8}$

Quantification of M. smithii and M. stadtmanae was achieved by using a quantification plasmid containing the target sequences. Plasmid constructs containing the sequence of interest were created as positive controls (see supplemental material S1 and Figure S1(a) and (b) for standard curves). The lower limits of detection were 3.81 and 4.82 $\log 10$ copies/g faeces for $M$. smithii and $M$. stadtmanae respectively. In the present study faecal samples were sent by mail and transport time varied from 0 to 4 days. However, the proportion of positive samples as well as the concentration of archaea did not significantly differ between samples according to transport time (Chi-square test, p-value $>0.05)$ 


\section{Statistical analyses}

Characteristics of the children are presented as mean $\pm \mathrm{SD}$ or median (range) for continuous variables, and proportions for categorical variables. We used Generalized Estimating Equations (GEE) with autoregressive correlation structure to analyse the association between archaea and childhood BMI, weight, and height (as z-scores for continuous outcomes) and overweight status over time (as binary outcome) including all available parent-reported repeated measurements up to 10 years of age. For each of these outcomes we examined the effects of colonisation with either M. smithii or $M$. stadtmanae (yes/no) and the counts of each of these species. For M. smithii, we constructed a variable accounting for the tri-modal distribution of the counts (uncolonised, low levels (3.5 to $7 \log 10$ copies/g faeces), high levels ( $>7 \log 10$ copies/g faeces)) observed (Figure 2). To evaluate whether increasing levels of the counts of $M$. smithii were associated with higher BMI z-scores, Cochran Armitage trend test was performed for this exposureoutcome combination.

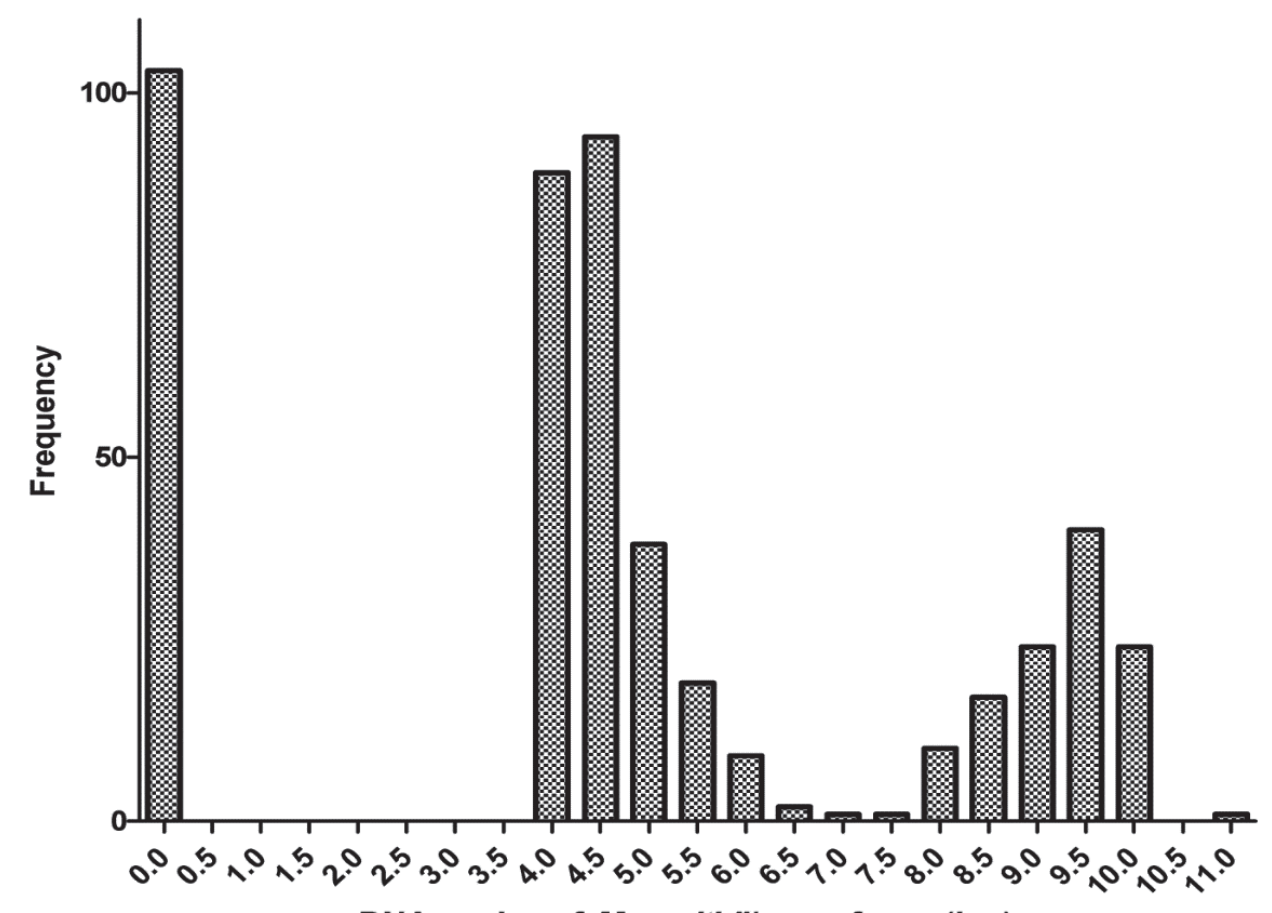

DNA copies of $M$. smithiilgram feces $(\mathrm{log})$

Figure 2. Histogram showing the tri-modal distribution of counts (Log10 DNA copies/ gfaeces) for M. smithii.
To investigate whether results differed across ages, we tested for statistical interaction between the main independent variables and age of the child at the time of outcome measurement as a continuous variable. The interaction term was statistically significant only for M. smithii prevalence (yes/no) with BMI z-scores as the outcome (interaction $\mathrm{p}=0.008$ ); hence an age-stratified analysis was performed for this association.

Potential confounders considered for inclusion in the model were: recruitment group (conventional or alternative), maternal pre-pregnancy weight, maternal pre-pregnancy height, maternal educational level (lower education, vocational education, higher general secondary/pre-university, or higher vocational/academic education), weight gained during pregnancy, place and mode of delivery (vaginal delivery at home, vaginal delivery in hospital, or caesarean section in hospital), gestational age, birth weight, household size, antibiotic use (no antibiotics in past year, antibiotic use $>4$ weeks ago, or antibiotic use $\leq 4$ weeks ago), physical activity, gender, and child's dietary intake (total fibre, total energy, fats and carbohydrates both as percentage of total energy). Variables that changed parameter estimates of the main independent variable by more than $10 \%$ were included in the final models. All children $(\mathrm{N}=472)$ were included in the unadjusted analyses and a total of 406 (86\%) children was included in the adjusted analyses. The latter was due to missing values in some confounders, ranging from $1.3 \%$ missing values for mode of delivery and antibiotic use to $6.1 \%$ for physical activity. We checked whether results obtained following multiple imputations deviated from the results obtained without imputation. Multiple imputations were done using all four repeated measurements for BMI z-scores, weight z-scores and height z-scores variables including confounders with missing values. As results from combined imputed datasets $(n=10)$ were comparable with those of the original non-imputed data, we performed the final analyses without imputation.

The following statistical software was used: SAS version 9.3 and SPSS version 21.0 (SPSS Inc., Chicago, IL, USA). A pre-selected significance level of 0.05 was used.

\section{Results}

A total of 472 faecal samples were eligible for analysis (Figure 1). M. smithii was present in $369(78.2 \%)$, and M. stadtmanae in 39 (8.3\%) of the 472 children (Table 2). From all these children, at least one anthropometric measurement was available. At time-point 1 (start of follow-up) anthropometric data were available for 407 out of the 472 children, and $6.9 \%(28 / 407)$ of the children were overweight (Table 3). At this same time point, the percentage overweight among children colonized with $M$. smithii was $7.6 \%$ compared to $4.4 \%$ for children not colonized with $M$. smithii. While the percentage overweight among children colonized with $M$. stadtmanae, was $6.2 \%$ compared to $6.9 \%$ among children not colonized with this archaeon. For the subsequent follow-up time-points anthropometric data were available for respectively 376,348 and 385 out of 472 children. 


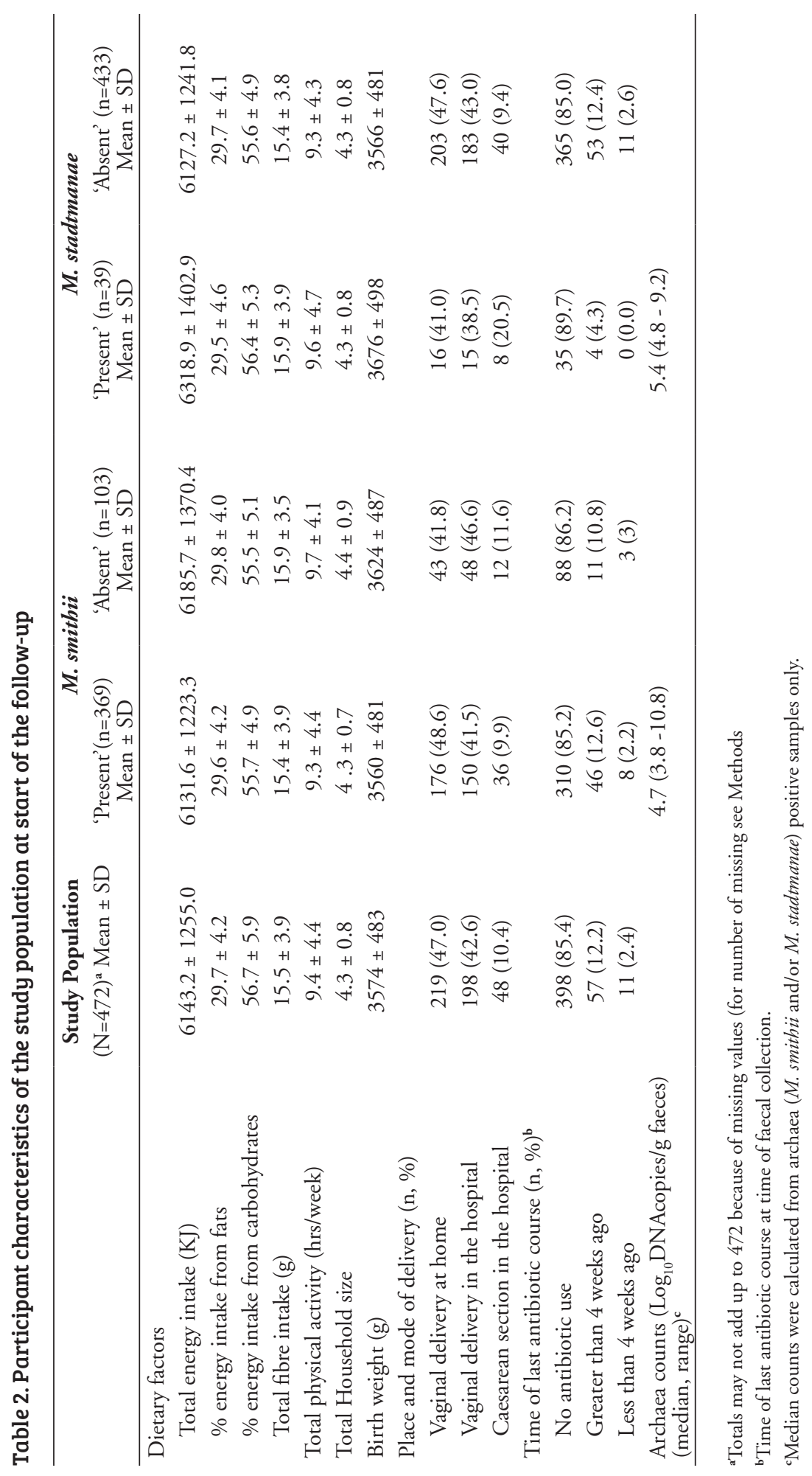

Table 3. Anthropometric measures of the study population at the four different follow-up time points

\begin{tabular}{lcccc}
\hline & $\begin{array}{c}\text { Time-point 1 } \\
(2007) \\
\text { Mean } \pm \text { SD }\end{array}$ & $\begin{array}{c}\text { Time-point 2 } \\
(2008) \\
\text { Mean } \pm \text { SD }\end{array}$ & $\begin{array}{c}\text { Time-point 3 } \\
(2009) \\
\text { Mean } \pm \text { SD }\end{array}$ & $\begin{array}{c}\text { Time-point 4 } \\
(2010) \\
\text { Mean } \pm \text { SD }\end{array}$ \\
\hline $\begin{array}{l}\text { Children with anthropometric } \\
\text { data (n, \%) }\end{array}$ & $407(86.2)$ & $376(79.7)$ & $348(73.7)$ & $385(81.6)$ \\
$\quad$ Age (years) & & & & \\
$\quad \begin{array}{l}\text { Overweight (n, \%) } \\
\text { yes }\end{array}$ & $6.2 \pm 0.5$ & $6.8 \pm 0.5$ & $7.8 \pm 0.5$ & $8.8 \pm 0.5$ \\
$\quad$ no & $28(6.9)$ & $22(5.9)$ & $31(8.9)$ & $41(10.7)$ \\
BMI z-scores & $379(93.1)$ & $354(94.1)$ & $317(91.1)$ & $344(89.3)$ \\
$\quad$ Weight z-scores & $-0.33 \pm 0.95$ & $-0.37 \pm 0.90$ & $-0.26 \pm 0.97$ & $-0.22 \pm 0.96$ \\
$\quad$ Height z-scores & $-0.37 \pm 0.95$ & $-0.35 \pm 0.96$ & $-0.27 \pm 0.98$ & $-0.19 \pm 0.91$ \\
& $-0.05 \pm 0.96$ & $-0.10 \pm 0.98$ & $-0.09 \pm 0.96$ & $0.08 \pm 0.90$ \\
\hline
\end{tabular}

Unadjusted and adjusted associations between the presence, counts and levels of counts of M. smithii and M. stadtmanae and the different outcome variables are presented in Table 4 (for overweight as binary outcome) and Table 5 (for BMI, weight and height z-scores as continuous outcomes). In the unadjusted analyses we found no statistically significant association between the presence/counts of archaea and overweight status. Upon adjusting for confounders, children that were colonized with $M$. smithii were at increased risk of being overweight (adjusted odds ratio $(\mathrm{OR})=2.69$; 95\% CI 0.96 7.54). Children with a low level of counts (3.5 to $7 \log 10$ copies/g faeces) of $M$. smithii were twice more likely to be overweight compared to children without this archaeon, although this association was not significant $(\mathrm{OR}$ adjused $=2.40 ; 95 \% \mathrm{CI} 0.83-6.95)$. Children having a high level of counts ( $>7 \log 10$ copies/g faeces) of $M$. smithii were three times more likely to be overweight $(\mathrm{OR}=3.27$; 95\%CI $1.09-9.83)$. P for trend across these levels (none, low and high) of $M$. smithii and overweight status approached significance (Cochran Armitage $\mathrm{p}=0.066$ ). Analyses on the counts of $M$. smithii as a continuous variable also showed that, a $\log 10$ increase in the counts of $M$. smithii was associated with a $10 \%$ increased risk of overweight $\left(\mathrm{OR}_{\text {adjused }}=1.10 ; 95 \% \mathrm{CI} 1.00-1.21\right)$ No statistically significant association between $M$. stadtmanae, neither for presence nor counts, and overweight status was found.

Regarding BMI z-score as a continuous outcome variable, we found a statistically significant interaction between the presence of $M$. smithii and age (p-value=0.008), implying, colonisation with $M$. smithii was associated with an increasing BMI z-score as age increased (Figure 3). However, differences at individual time (age) points after stratifying for age did not reach statistical significance (data not shown). 


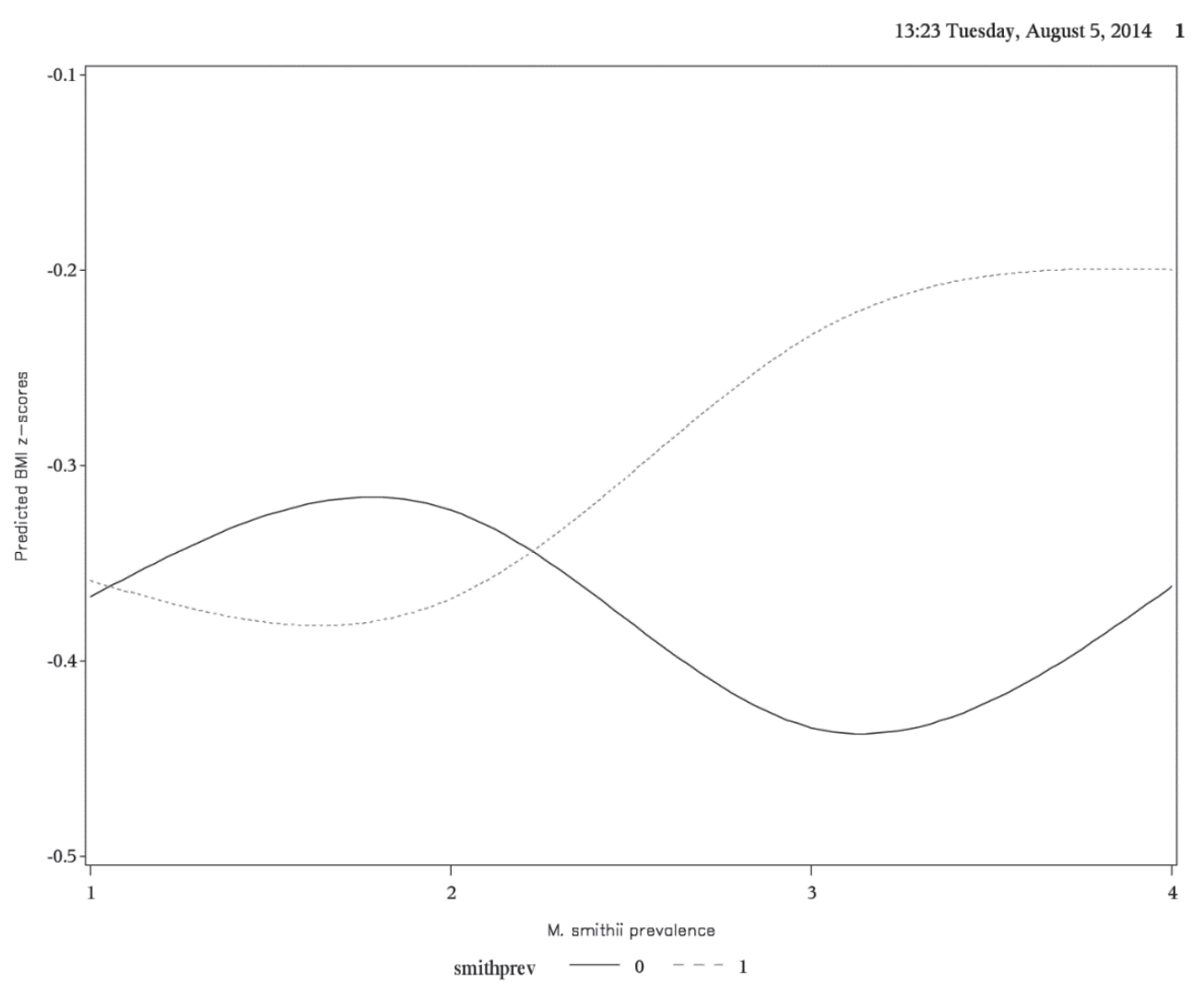

Figure 3. An interaction plot for the association of M. smithii prevalence and BMI z-scores across ages. The horizontal axis is the grouped ages at which different outcomes were measured. The are indexed in the variable time as follows (ages (mean \pm SD) $6.2 \pm 0.5$, $6.8 \pm 0.5,7.8 \pm 0.5$, and $8.8 \pm 0.5$ years as time 1 , time 2 , time 3 and time 4 respectively); the $6.8 \pm 0.5,7.8 \pm 0.5$, and $8.8 \pm 0.5$ years as time 1 , time 2 , time 3 and time 4 respectively); the
vertical axis are the predicted BMI $z$-scores for each child at different time points obtained vertical axis are the predicted BMI z-scores for each child at different time points obt prevalence groups (smooth line for uncolonised and dotted line for colonized). The smooth curves were obtained using spline interpolation.

Unadjusted analyses for the associations between the presence and counts of $M$. smithit and $M$. stadtmanae with weight $\mathrm{z}$-scores as a continuous variable were not statistically significant. In the adjusted analyses, the presence of $M$. smithii in children was statistically significantly associated with higher weight $z$-scores $(\operatorname{adj} \beta 0.18$; 95\% CI 0.00 0.36) compared to children without this archaeon. In addition, low and high levels of M. smithii in children were also associated with higher weight z-scores compared to uncolonised children, although this only approached statistical significance (low: adj $\beta$ $0.18 ; 95 \%$ CI -0.01 to 0.36 and high: adj $\beta 0.20 ; 95 \%$ CI -0.01 to 0.40 ; Table 5). The $\mathrm{P}$ for trend across these levels (none, low and high) of counts of $M$. smithii approached significance in association with increasing weight $\mathrm{z}$-scores ( $\mathrm{p}$ for trend=0.09).
There was no statistically significant association of $M$. smithii with height z-scores. For M. stadtmanae, there were no statistically significant associations with any of the four outcomes (Table $4 \& 5$ ) neither for presence or the counts of $M$. stadtmanae.

Table 4. GEE results showing association of overweight (yes/no) from 6 to 10 years of age with the prevalence of colonisation and counts ( Log $_{10}$ DNAcopies $/ g$ faeces) of archaea species in the gut microbiota at 6-7 yrs of age ${ }^{a}$

\begin{tabular}{|c|c|c|c|c|}
\hline & $\mathrm{n}$ & Crude OR $[95 \% \mathrm{CI}]^{\mathrm{b}}$ & Adjusted OR $[95 \% \mathrm{CI}]^{\mathrm{c}}$ & P-value ${ }^{\mathrm{d}}$ \\
\hline \multicolumn{5}{|l|}{ Overweight (No/Yes) } \\
\hline \multicolumn{5}{|l|}{ M. smithii prevalence } \\
\hline No & 103 & 1.00 [reference] & 1.00 [reference] & \\
\hline Yes & 369 & $1.75[0.77$ to 3.96$]$ & $2.69[0.96$ to 7.54$]$ & 0.059 \\
\hline \multicolumn{5}{|l|}{ M. smithii count levels } \\
\hline None & 103 & 1.00 [reference] & 1.00 [reference] & \\
\hline Low ( $\leq 7 \log _{10}$ DNAcopies/g faeces $)$ & 251 & $1.64[0.69$ to 3.86$]$ & $2.40[0.83$ to 6.95$]$ & 0.108 \\
\hline $\operatorname{High}\left(\geq 7 \log _{10}\right.$ DNAcopies/g faeces) & 118 & $1.97[0.80$ to 4.85$]$ & $3.27[1.09$ to 9.83$]$ & 0.035 \\
\hline \multicolumn{5}{|l|}{ M. stadtmanae prevalence } \\
\hline No & 433 & 1.00 [reference] & 1.00 [reference] & \\
\hline Yes & 39 & $1.20[0.46$ to 3.13$]$ & $1.14[0.53$ to 3.90$]$ & 0.483 \\
\hline \multicolumn{5}{|l|}{$\begin{array}{l}\text { Counts of archaeal species (Log10D- } \\
\text { NAcopies/g faeces)e, median (range) }\end{array}$} \\
\hline M. smithii & & $1.05[0.97$ to 1.34$]$ & $1.10[1.00$ to 1.21$]$ & 0.047 \\
\hline M. stadtmanae & & $1.06[0.92$ to 1.22$]$ & $1.08[0.94$ to 1.25$]$ & 0.265 \\
\hline
\end{tabular}

${ }^{\mathrm{a}} \mathrm{GEE}=$ Generalised Estimating Equations

${ }^{\mathrm{b}}$ Sample size used for crude analysis $\mathrm{N}=472$; $\mathrm{OR}=$

c Sample size for adjusted analysis $\mathrm{N}=428$ and $\mathrm{N}=406$ for $M$. smithii and $M$. stadtmanae respectively due to missing values. Confounders in the final adjusted model for M. smithii: household size, place and mode of delivery, birth weight, dietary intake (total fibre intake, total percentage energy intake, percentage energy intake for fats and carbohydrates), antibiotic use and physical activity; and for M. stadtmanae: household size, place and mode of delivery, birth weight, nutritional intake (total fibre intake, total percentage energy intake, percentage energy intake for fats and carbohydrates), physical activity, maternal level of education (low, middle and high), and weight gain during pregnancy

aColumn represents $\mathrm{p}$-values for the adjusted analysis

GEE analysis was done using archaea (M. smithii and/or M. Stadtmanae) positive samples only. 
Table 5: GEE results showing association of different continuous outcomes (BMI, weight and height z-scores) from 6 to 10 years of age with the prevalence of colonisation and counts ( $\log _{10}$ DNAcopies/g faeces) of archaea species in the gut microbiota at 6-7 yrs of age ${ }^{a}$

\begin{tabular}{|c|c|c|c|c|}
\hline \multicolumn{5}{|c|}{ Adjusted $\beta[95 \% \mathrm{CI}]^{\mathrm{c}} \quad \mathrm{P}$-value $\mathrm{d}^{\mathrm{d}}$} \\
\hline BMI z-scores ${ }^{e}$ & & & & \\
\hline \multicolumn{5}{|l|}{ M. smithii count levels } \\
\hline None & 103 & 0 [reference] & 0 [reference] & \\
\hline Low ( $<7$ Log10DNAcopies/g faeces) & 251 & $0.07[-0.12$ to 0.27$]$ & $0.10[-0.09$ to 0.29$]$ & 0.286 \\
\hline High (>7 Log10DNAcopies/g faeces) & 118 & $0.09[-0.14$ to 0.32$]$ & $0.14[-0.07$ to 0.38$]$ & 0.194 \\
\hline \multicolumn{5}{|l|}{ M. stadtmanae prevalence } \\
\hline No & 433 & 0 [reference] & 0 [reference] & \\
\hline Yes & 39 & $0.04[-0.26$ to 0.34$]$ & $0.15[-0.17$ to 0.46$]$ & 0.358 \\
\hline \multicolumn{5}{|c|}{ Counts of Archaeal species ( $\log _{10}$ DNAcopies/g faeces), median (range) ${ }^{\mathrm{f}}$} \\
\hline M. smithii & & $0.00[-0.02$ to 0.03$]$ & $0.01[-0.01$ to 0.03$]$ & 0.436 \\
\hline M. stadtmanae & & $0.02[-0.02$ to 0.06$]$ & $0.03[-0.01$ to 0.07$]$ & 0.186 \\
\hline \multicolumn{5}{|l|}{ Weight z-score } \\
\hline \multicolumn{5}{|l|}{ M. smithii prevalence } \\
\hline No & 103 & 0 [reference] & 0 [reference] & \\
\hline Yes & 369 & $0.13[-0.06$ to 0.31$]$ & $0.18[0.00$ to 0.36$]$ & 0.046 \\
\hline \multicolumn{5}{|l|}{ M. smithii count levels } \\
\hline None & 103 & 0 [reference] & 0 [reference] & \\
\hline Low $(<7 \log 10 \Gamma$ & 251 & $0.12[-0.08$ & $0.18[-0.01$ to 0.36$]$ & 0.071 \\
\hline High (>7 Log10DNAcop & 118 & $0.15[-0.08$ to 0.38$]$ & $0.20[-0.02$ to 0.40$]$ & 0.077 \\
\hline \multicolumn{5}{|l|}{ M. stadtmanae prevalence } \\
\hline No & 433 & 0 [refere & 0 [refer & \\
\hline Yes & 39 & $0.16[-0.15$ to 0.48$]$ & $0.15[-0.16$ to 0.46$]$ & 0.335 \\
\hline \multicolumn{5}{|c|}{ Counts of archaeal species ( $\log _{10}$ DNAcopies/g faeces), median (range) } \\
\hline M. smithii & & $0.01[-0.01$ to 0.04$]$ & $0.01[-0.01$ to 0.04$]$ & 0.228 \\
\hline M. stadtmanae & & $0.04[-0.01$ to 0.08$]$ & $0.03[-0.01$ to 0.08$]$ & 0.107 \\
\hline \multicolumn{5}{|l|}{ Height z-scores } \\
\hline \multicolumn{5}{|l|}{ M. smithii prevalence } \\
\hline No & 103 & 0 [reference & 0 [reference] & \\
\hline Yes & 369 & $0.09[-0.09$ to 0.27$]$ & $0.13[-0.05$ to 0.31$]$ & 0.170 \\
\hline \multicolumn{5}{|l|}{ M. smithii count levels } \\
\hline None & 103 & 0 [refer & 0 [re & \\
\hline Low ( $<7$ Log10DNAcopies/g faece & 251 & $0.10[-0.10$ to 0.29$]$ & $0.14[-0.05$ to 0.34$]$ & 0.134 \\
\hline High ( $>7 \log 10$ DNAcop & 118 & $0.07[-0.16$ to 0.29$]$ & $0.07[-0.13$ to 0.29$]$ & 0.477 \\
\hline \multicolumn{5}{|l|}{ M. stadtmanae Prevalence } \\
\hline No & 433 & 0 [reference] & 0 [reference] & \\
\hline & 39 & $0.15[-0.16$ to 0.46$]$ & $0.06[-0.27$ to 0.39$]$ & 0.726 \\
\hline \multicolumn{5}{|c|}{ Counts of Archaeal species ( $\log _{10}$ DNAcopies/g faeces), median (range) } \\
\hline M. smithii & & $0.01[-0.02$ to 0.03$]$ & $0.01[-0.02$ to 0.03$]$ & 0.708 \\
\hline M. stadtmanae & & $0.03[-0.01$ to 0.08$]$ & $0.02[-0.02$ to 0.07$]$ & 0.369 \\
\hline
\end{tabular}

GEE = Generalised Estimating Equations

Sample size used for crude analysis $\mathrm{N}=472$

Sample size for adjusted analysis $\mathrm{N}=428$ and $\mathrm{N}=406$ for $M$. smithii and $M$. stadtmanae respectively due to missing values. Confounders in the final adjusted model for M. smitthi: household size, place and mode of delivery, birth weigh dietary intake (total fibre intake, total percentage energy intake, percentage energy intake for fats and carbohydrates), anticic use and physic physical activity, maternal level of education (low, middle and high), and weight gain during pregnancy

"Column represents p-values for the adjusted analysis

'Model with M. smithii prevalence as main determinant in association with BMI z-score not presented due to significan interaction with age.

GEE analysis was done using archaea (M. smithii and/or M. Stadtmanae) positive samples only.

\section{Discussion}

This prospective cohort study is the first to demonstrate that the presence as well as the counts of methanogenic archaea, specifically M. smithii, in the gut of children at school age is associated with more overweight and higher weight $\mathrm{z}$-scores. We also found that the strength of the association between colonization with $M$. smithii and BMI z-scores increased with age from 6 to 10 years.

Several previous studies ${ }^{16,18}$ supported the hypothesis that archaea (M. smithii) contribute to energy harvesting and hence weight development. Samuel and Gordon, $2006,{ }^{16}$ observed that $M$. smithii played a critical role in facilitating an increased capacity of $B$. thetaiotaomicron to digest polyfructose-containing glycans leading to increased production of short-chain fatty acids (SCFAs) and total liver triglycerides in mice. Mice colonized with $B$. thetaiotaomicron and Desulfovibrio piger instead of $M$. smithii, did not show such an effect, highlighting the key role of $M$. smithii in promoting polysaccharide degradation and formation of SCFAs. It should however be noted that animal studies often show that increased fermentable fiber intake is associated with reduced body weight gain and/or adiposity, which may also depend on the animals phenotype ${ }^{29}$ likely due to differences in microbial fermentation capacity. A potential mechanism whereby methanogens may affect energy extraction and subsequently lead to overweight is through signalling of the $\mathrm{G}$ protein-coupled receptor Gpr41, for which SCFAs serve as ligands. Gpr41 expressed in the intestine and adipocytes stimulates the expression of the adipokine leptin and the intestinal peptide tyrosine-tyrosine (peptide-YY), which both influences energy metabolism and appetite level. ${ }^{17}$ Although, our results were in line with the above studies, other studies showed conflicting results compared to ours. Million et al. ${ }^{30}$ found that the gut microbiota of obese humans is depleted in $M$. smithii. Two studies also reported that $M$. smithii was negatively correlated with BMI. ${ }^{19}$ ${ }^{31}$ Fernandes et al. ${ }^{23}$ found that archaea presence was not associated with increased BMI. Armougom et al. ${ }^{20}$ did not find a difference in the abundance of $M$. smithii in obese compared to normal weight individuals. Differences in the methods and designs, such as techniques to detect methanogens, sample sizes, geographical settings, and dietary habits of the participants might all contribute to these different findings. Moreover, our study differs compared to most previous studies with respect to participants' weight status, which is in the normal range for the majority of subjects, and their young age. We collected faeces from the children at an age where stability of the gut microbiota is believed to be achieved and may be comparable to the adult microbiota. A number of studies revealed that the childhood microbiota has evolved into an adult-like configuration by the age of 2 to 3 years. ${ }^{32-34}$ Little is known whether the levels of archaea present in children are comparable to adults and studies have not yet been done on children above 3 years.

The large sample size and longitudinal design are major strengths of the present study. Questionnaires were repeatedly collected during the developmental stages of the 
children, yielding vast information on anthropometric data over time. The presence of detailed and prospective information on background factors enabled the adjustments of many confounders, including physical activity and diet. Results showed an independent association of archaea with weight outcomes, regardless of such confounding factors.

Our study also has some limitations. Repeated weight and height measurements in our study were parent-reported. A study by Scholtens et al., showed that this may lead to both an underestimation of the children's weight and an overestimation of their height, resulting in a lower BMI and lower prevalence of overweight. ${ }^{35}$ Another study showed the opposite, that is, an overestimation of weight implying more overweight in parent-reported information. ${ }^{36} \mathrm{~A}$ validation study using data from the KOALA Birth Cohort Study, found an underestimation of overweight was found with parent-reported data compared to data collected during home visits. ${ }^{37}$ Based on this, it is likely that anthropometric measurements by well-trained persons may lead to stronger associations between BMI and archaea. This may have resulted in an underestimation of the true associations.

Faecal samples of the children were collected only at one time point. We assumed that the colonization with archaea in the children is relatively constant over time. Indeed, previous studies have shown that the quantities of M. smithii in human faeces remained constant over time ${ }^{38}$ This trend of stability of $M$. smithii has also been reported over a 13 -month period using faecal specimens from two individuals. ${ }^{39}$ Additionally, a comparative analysis of the genome of $M$. smithii and its transcriptome and metabolome in gnotobiotic mice in the absence and presence of $B$. thetaiotaomicron indicated that $M$. smithii survives in the intestinal tract of the gnotobiotic mice through different survival and colonization mechanisms despite the presence of its competitors for substrates. ${ }^{40}$ However, future studies are warranted in which faecal samples are collected at different time points of anthropometric measurements to accurately assess the change of archaea prevalence or counts in an individual over time. This could further establish changes in the archaeal microbiota due to different physiological, pathological, and iatrogenic (e.g., administration of certain antibiotics) conditions over time.

In conclusion, this study demonstrates that the presence as well as the higher counts of M. smithii in the gut of children at school age is associated with overweight, higher weight, and BMI z-scores from 6 to 10 years of age. This finding further supports the role of the methanogenic archaea in obesity after controlling for diet and physical activity which are the main factors associated with obesity. As such, manipulating the intestinal (archaeal) microbiota represents a potential strategy to apply together with dietary restrictions and exercise in the control of obesity. So far, little is known about the factors that determine archaea colonization in the gut. This indicates a pressing need for further research on these determinants of archaeal colonization which may be used to control colonization of the gut by archaea in the future.
Funding source: This study was funded by TI Food and Nutrition, public private partnership in food and nutrition research. The mission is to contribute to optimum human nutrition, food safety and sustainable food production and to increase the competitiveness of food industry. Partners are key players in the global food industry, leading research institutes, universities and medical centres.

Additional funding for data collection was received by: Netherlands Organisation for Health Research and Development (grant 2100.0090), Netherlands Asthma Foundation (grants 3.2.03.48, 3.2.07.022), Netherlands Heart Foundation (grant 2008B112), Triodos Foundation, Phoenix Foundation, Raphaël Foundation, Iona Foundation, Foundation for the Advancement of Heilpedagogiek, Royal Friesland Foods (currently FrieslandCampina); Netherlands Sugar Foundation, and the Ministry of Economic affairs. The sponsors had no influence on the analysis and reporting of this study.

\section{Acknowledgments}

This study was funded by TI Food and Nutrition, public private partnership in food and nutrition research. The mission is to contribute to optimum human nutrition, food safety and sustainable food production and to increase the competitiveness of food industry. Partners are key players in the global food industry, leading research institutes, universities and medical centres. 


\section{References}

1 Candeias V, Armstrong TP, Xuereb GC. Diet and physical activity in schools: perspectives from the implementation of the WHO global strategy on diet, physical activity and health. Can J Public Health. 2010; 101 Suppl 2: S28-30.

2 Schonbeck Y, Talma H, van Dommelen P, Bakker B, Buitendijk SE, Hirasing $\mathrm{RA}$, et al. Increase in prevalence of overweight in Dutch children and adolescents: a comparison of nationwide growth studies in 1980, 1997 and 2009. PloS one. 2011; 6: e27608.

3 Singh AS, Mulder C, Twisk JW, van Mechelen W, Chinapaw MJ. Tracking of childhood overweight into adulthood: a systematic review of the literature. Obes Rev. 2008; 9: 474-88.

4 Whitaker RC, Wright JA, Pepe MS, Seidel KD, Dietz WH. Predicting obesity in young adulthood from childhood and parental obesity. N Engl J Med. 1997; 337: 869-73.

5 Oude Luttikhuis H, Baur L, Jansen H, Shrewsbury VA, O’Malley C, Stolk RP, et al. Interventions for treating obesity in children. The Cochrane database of systematic reviews. 2009: CD001872.

6 Tilg H, Kaser A. Gut microbiome, obesity, and metabolic dysfunction. J Clin Invest. 2011; 121: 2126-32.

7 Miller TL, Wolin MJ, Conway de Macario E, Macario AJ. Isolation of Methanobrevibacter smithii from human feces. Applied and environmental microbiology. 1982; 43: 227-32.

8 Miller TL, Wolin MJ. Methanosphaera stadtmaniae gen. nov., sp. nov.: a species that forms methane by reducing methanol with hydrogen. Arch Microbiol. 1985; 141: 116-22.

9 Dridi B, Fardeau ML, Ollivier B, Raoult D, Drancourt M. Methanomassiliicoccus luminyensis gen. nov., sp. nov., a methanogenic archaeon isolated from human faeces. International journal of systematic and evolutionary microbiology. 2012; 62: 1902-7.

10 Dridi B, Henry M, Richet H, Raoult D, Drancourt M. Age-related prevalence of Methanomassiliicoccus luminyensis in the human gut microbiome. APMIS. 2012; 120: 773-7.

11 Dridi B, Henry M, El Khechine A, Raoult D, Drancourt M. High prevalence of Methanobrevibacter smithii and Methanosphaera stadtmanae detected in the human gut using an improved DNA detection protocol. PloS one. 2009; 4: e7063.

12 Wolever TM, Robb PA, Ter Wal P, Spadafora PG. Interaction between methaneproducing status and diet on serum acetate concentration in humans. J Nutr. 1993; 123: 681-8.
13 Turnbaugh PJ, Ley RE, Mahowald MA, Magrini V, Mardis ER, Gordon JI. An obesity-associated gut microbiome with increased capacity for energy harvest. Nature. 2006; 444: 1027-31.

14 Deppenmeier U. The unique biochemistry of methanogenesis. Prog Nucleic Acid Res Mol Biol. 2002; 71: 223-83.

15 Fricke WF, Seedorf H, Henne A, Kruer M, Liesegang H, Hedderich R, et al. The genome sequence of Methanosphaera stadtmanae reveals why this human intestinal archaeon is restricted to methanol and $\mathrm{H} 2$ for methane formation and ATP synthesis. Journal of bacteriology. 2006; 188: 642-58.

16 Samuel BS, Gordon JI. A humanized gnotobiotic mouse model of host-archaealbacterial mutualism. Proceedings of the National Academy of Sciences of the United States of America. 2006; 103: 10011-6.

17 Mathur R, Kim G, Morales W, Sung J, Rooks E, Pokkunuri V, et al. Intestinal Methanobrevibacter smithii but not total bacteria is related to diet-induced weight gain in rats. Obesity (Silver Spring, Md). 2013; 21: 748-54.

18 Zhang H, DiBaise JK, Zuccolo A, Kudrna D, Braidotti M, Yu Y, et al. Human gut microbiota in obesity and after gastric bypass. Proceedings of the National Academy of Sciences of the United States of America. 2009; 106: 2365-70.

19 Million M, Angelakis E, Maraninchi M, Henry M, Giorgi R, Valero R, et al. Correlation between body mass index and gut concentrations of Lactobacillus reuteri, Bifidobacterium animalis, Methanobrevibacter smithii and Escherichia coli. International journal of obesity (2005). 2013; 37: 1460-6.

20 Armougom F, Henry M, Vialettes B, Raccah D, Raoult D. Monitoring bacterial community of human gut microbiota reveals an increase in Lactobacillus in obese patients and Methanogens in anorexic patients. PloS one. 2009; 4: e7125.

21 Basseri RJ, Basseri B, Pimentel M, Chong K, Youdim A, Low K, et al. Intestinal methane production in obese individuals is associated with a higher body mass index. Gastroenterol Hepatol (N Y). 2012; 8: 22-8.

22 Mathur R, Amichai M, Chua KS, Mirocha J, Barlow GM, Pimentel M. Methane and hydrogen positivity on breath test is associated with greater body mass index and body fat. J Clin Endocrinol Metab. 2013; 98: E698-702.

23 Fernandes J, Wang A, Su W, Rozenbloom SR, Taibi A, Comelli EM, et al. Age, dietary fiber, breath methane, and fecal short chain fatty acids are interrelated in Archaea-positive humans. J Nutr. 2013; 143: 1269-75.

24 Kim G, Deepinder F, Morales W, Hwang L, Weitsman S, Chang C, et al. Methanobrevibacter smithii is the predominant methanogen in patients with constipation-predominant IBS and methane on breath. Digestive diseases and sciences. 2012; 57: 3213-8. 
25 Kummeling I, Thijs C, Penders J, Snijders BE, Stelma F, Reimerink J, et al. Etiology of atopy in infancy: the KOALA Birth Cohort Study. Pediatr Allergy Immunol. 2005; 16: 679-84

26 Fredriks AM, van Buuren S, Wit JM, Verloove-Vanhorick SP. Body index measurements in 1996-7 compared with 1980. Arch Dis Child. 2000; 82: 107-12.

27 Ogden CL, Flegal KM. Changes in terminology for childhood overweight and obesity. Natl Health Stat Report. 2010: 1-5.

28 Salonen A, Nikkila J, Jalanka-Tuovinen J, Immonen O, Rajilic-Stojanovic M, Kekkonen RA, et al. Comparative analysis of fecal DNA extraction methods with phylogenetic microarray: effective recovery of bacterial and archaeal DNA using mechanical cell lysis. J Microbiol Methods. 2010; 81: 127-34.

29 Everard A, Belzer C, Geurts L, Ouwerkerk JP, Druart C, Bindels LB, et al. Crosstalk between Akkermansia muciniphila and intestinal epithelium controls dietinduced obesity. Proceedings of the National Academy of Sciences of the United States of America. 2013; 110: 9066-71.

30 Million M, Maraninchi M, Henry M, Armougom F, Richet H, Carrieri P, et al. Obesity-associated gut microbiota is enriched in Lactobacillus reuteri and depleted in Bifidobacterium animalis and Methanobrevibacter smithii. International journal of obesity (2005). 2012; 36: 817-25.

31 Schwiertz A, Taras D, Schafer K, Beijer S, Bos NA, Donus C, et al. Microbiota and SCFA in lean and overweight healthy subjects. Obesity (Silver Spring, Md). 2010; 18: 190-5.

32 Yatsunenko T, Rey FE, Manary MJ, Trehan I, Dominguez-Bello MG, Contreras M, et al. Human gut microbiome viewed across age and geography. Nature. 2012; 486: $222-7$.

33 Koenig JE, Spor A, Scalfone N, Fricker AD, Stombaugh J, Knight R, et al. Succession of microbial consortia in the developing infant gut microbiome. Proceedings of the National Academy of Sciences of the United States of America. 2011; 108 Suppl 1: 4578-85.

34 Palmer C, Bik EM, DiGiulio DB, Relman DA, Brown PO. Development of the human infant intestinal microbiota. PLoS Biol. 2007; 5: e177.

35 Scholtens S, Brunekreef B, Visscher TL, Smit HA, Kerkhof M, de Jongste JC, et al. Reported versus measured body weight and height of 4-year-old children and the prevalence of overweight. European journal of public health. 2007; 17: 369-74.

36 Dubois L, Girad M. Accuracy of maternal reports of pre-schoolers' weights and heights as estimates of BMI values. International journal of epidemiology. 2007; 36: $132-8$.

37 Timmermans SH, Mommers M, Gubbels JS, Kremers SP, Stafleu A, Stehouwer CD, et al. Maternal smoking during pregnancy and childhood overweight and fat distribution: the KOALA Birth Cohort Study. Pediatr Obes. 2014; 9: e14-25.
38 Conway de Macario E, Macario AJ. Methanogenic archaea in health and disease: a novel paradigm of microbial pathogenesis. Int J Med Microbiol. 2009; 299: 99108.

39 Miller TL, Wolin MJ. Stability of Methanobrevibacter smithii populations in the microbial flora excreted from the human large bowel. Applied and environmental microbiology. 1983; 45: 317-8.

40 Samuel BS, Hansen EE, Manchester JK, Coutinho PM, Henrissat B, Fulton R et al. Genomic and metabolic adaptations of Methanobrevibacter smithii to the human gut. Proceedings of the National Academy of Sciences of the United States of America. 2007; 104: 10643-8. 


\section{SUPPLEMENTAL MATERIAL}

Supplemental information S1: Information on plasmid construction for positive controls (found in materials and methods section)

Samples positive for M. smithii and M. stadtmanae were used as template in PCR reactions for generating positive controls for each of the targets. Each of the specific PCR products was purified using the QIAquick PCR Purification Kit (Qiagen, Hilden, Germany), ligated into the pGEM®-T Easy Vector according to the manufacturer's instructions (Promega, Madison, USA) and subsequently transformed into chemically competent E. coli K12 DH10 (Top10, Invitrogen), which were grown overnight on agar plates containing ampicillin, isopropyl $\beta$-D-1-thiogalactopyranoside (IPTG) and 5 -bromo-4-chloro-indolyl- $\beta$-D-galactopyranoside (X-gal). Colonies containing the desired construct, as observed by blue/white screening, were subsequently transferred to culture tubes. After overnight culture, plasmids were isolated and sequences between EcoRI restriction sites were determined. Serial dilutions of plasmids with the correct insert were then used for the construction of standard curves.

Samples with threshold cycle $(\mathrm{Ct})$-values $<40$ for $M$. smithii and $<35$ for $M$. stadtmanae were considered positive. $\log _{10}$ DNA copies for a given archaeal species per gram of wet weight faeces was calculated for each stool sample from the Ct-values using the constructed standard curves.

To confirm the specificity of both assays, PCR products of a random selection of positive samples were sequenced. Upon BLAST search, all sequences matched between 99 $100 \%$ to target species, confirming specificity of the assays.
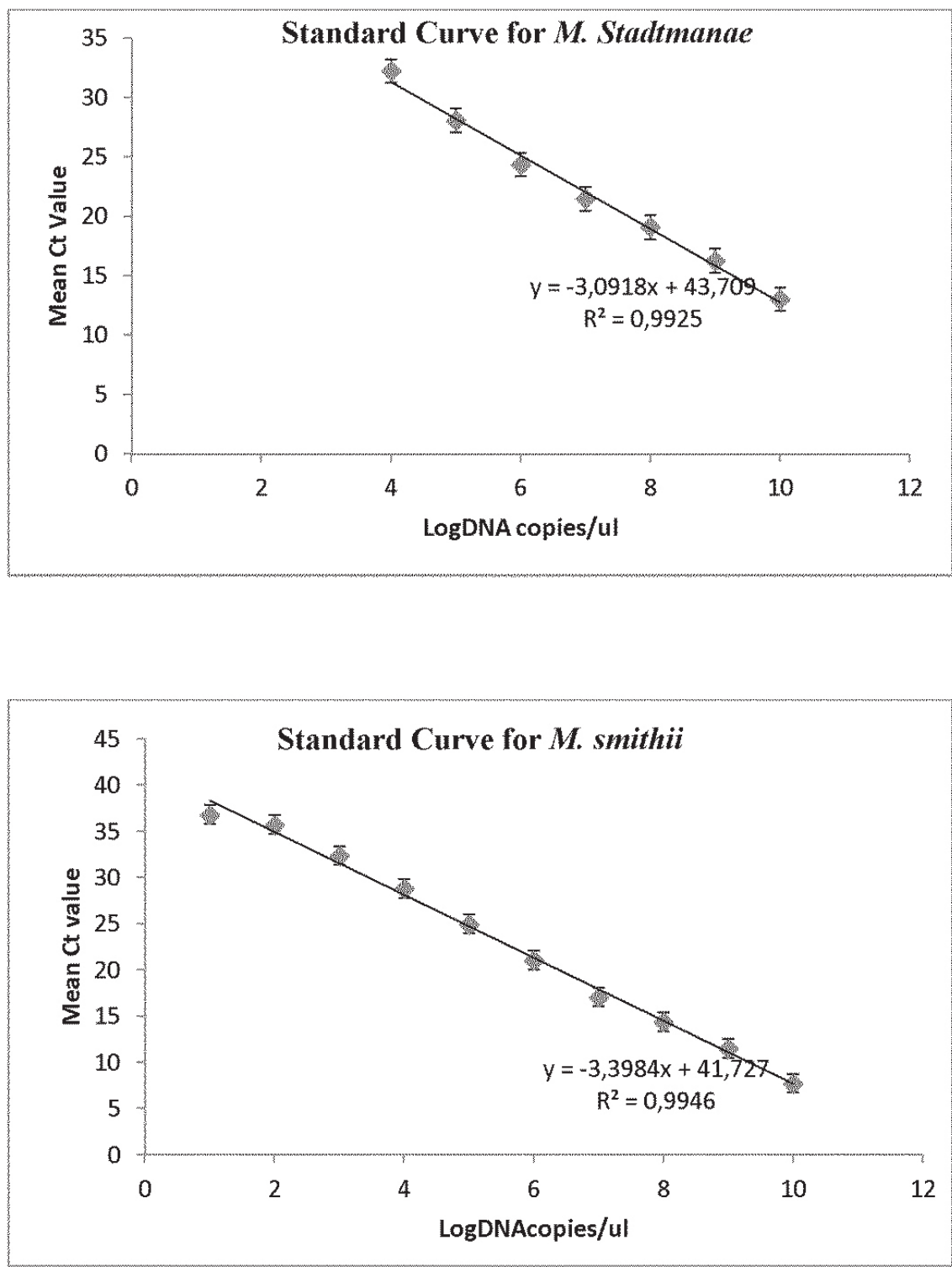

Figure S1 (a) and (b). Standard curves for qPCR assays of; (a) M. stadtmanae, and (b) M. smithii. Ten-fold serial dilutions of the faecal DNA of M. stadtmanae, and M. smithii were used to prepare the standard curves and it showed amplification efficiencies of 1.10 and 0.97 respectively, with both $\mathrm{R}^{2}=0.99$. 


\section{CHAPTER 5}

EARLY LIFE ANTIBIOTIC EXPOSURE AND WEIGHT DEVELOPMENT IN CHILDREN 


\section{Abstract}

Objective: To examine the timing, frequency and type of antibiotic exposure during the first 10 years of life in association with (over)weight across this period in a cohort of 979 children.

Methods: Within the KOALA Birth Cohort Study, antibiotic exposure was obtained from General Practitioners. Anthropometric outcomes (age- and sex-standardized BMI, weight, and height z-scores, and overweight) were repeatedly measured at seven timepoints during the first ten years of life. Generalized estimating equations was used for statistical analysis.

Results: After adjusting for confounders, children exposed to one course of antibiotics compared to none in the first six months of life had increased weight- (adj $0.24 ; 95 \% \mathrm{Cl}$ $0.03-0.44$ ) and height (adj 0.23; 95\%CI: 0.0002-0.46) z-scores while exposure to $\geq 2$ courses during the second year of life was associated with both increased weight (adj 0.34; 95\%CI 0.07-0.60), and height z-scores (adj 0.29; 95\%CI -0.003-0.59). Exposure later in life was not associated with anthropometric outcomes. Associations with weight z-scores were mainly driven by exposure to broad- ( $\geq 2$ courses: adj $0.11 ; 95 \% \mathrm{CI}$ 0.003-0.22) and narrow-spectrum -lactams (one course: adj 0.18 ; 95\%CI 0.005-0.35) during the follow-up period. Antibiotics use was not associated with BMI z-scores and overweight.

Conclusions: Repeated exposure to antibiotics early in life, especially -lactams, is associated with increased weight and height, thereby indicating that early antibiotic exposure might contribute to the rise in childhood obesity. If causality can be established in future studies, this further highlights the need for restrictive antibiotic use and avoidance of prescriptions when there is minimal clinical benefit.

\section{Introduction}

The discovery of antibiotics in the 1940s has played an important role in the treatmen of bacterial infections leading to a substantial reduction in human morbidity and mortality. ${ }^{1}$ The optimal rate of prescribing antibiotics to patients has recently become a source of concern due to the fact that over-prescription of antibiotics is a threat to public health in terms of costs, increasing antibiotic resistance and frequent side effects. ${ }^{2-4}$ The increase in the overuse of broad-spectrum antibiotics in conditions that could be treated with narrow-spectrum agents has also been reported. ${ }^{5}$ Despite a decreasing trend in antibiotic use among children, it is still the age group with the highest consumption of antibiotics. Among children, approximately $70 \%$ of antibiotics are prescribed for upper respiratory infections $s^{6,7}$ and a large part of these prescriptions are considered unnecessary. ${ }^{8}$

Antibiotics have been linked to both short- as well as long-term perturbations of the actively developing infant gut microbiota. This may have a profound impact on human health and disease throughout life, as changes in the gut microbiota during this period may disrupt metabolic and immune development. ${ }^{9}$ The important metabolic role of the human gut microbiota, which includes extracting energy from otherwise indigestible dietary compounds, highlights the importance of elucidating the impact of antibiotic use on childhood weight development. Several studies have shown that antimicrobial agents can alter the gastrointestinal microbial diversity and community structure, ${ }^{10-12}$ which in turn can lead to modulation of host metabolism, ${ }^{13-15}$ hence resulting in an effect on body weight. ${ }^{9,16}$

The growth promoting effect of antibiotics was first observed in the 1950s where domesticated mammalian and avian species were routinely administered sub-therapeutic doses of antibiotics to accelerate their weight gain for marketing purposes. ${ }^{17-20}$ Previous studies in humans have shown that early-life exposure to antibiotics may affect weight development in children. ${ }^{21-26}$ The differential effects of various antibiotic classes as well as the importance of the timing of exposure on childhood weight development still remain largely unanswered. ${ }^{27}$ Moreover, the majority of previous studies was of cross-sectional design or, if longitudinal, did not address the transitional evolution of childhood (over) weight over an extended period of time.

The aim of the present study is to evaluate the impact of antibiotic exposure from birth until the age of 10 years on height and weight development of Dutch children participating in the KOALA Birth Cohort Study. The study focuses on the influence of timing of antibiotic exposure, type of antibiotics used, and the number of courses a child was exposed to. 


\section{Materials and Methods}

Subjects and study design

The current study was conducted within the KOALA Birth Cohort Study, an ongoing cohort study in the Netherlands. The design of the KOALA study has been described in detail elsewhere. ${ }^{28}$ Briefly, from October 2000 until December 2002, a total of 3030 pregnant women were recruited at 34 weeks of gestation. Pregnant women with a conventional lifestyle $(\mathrm{n}=2512)$ were recruited from an ongoing prospective cohort study on pregnancy-related pelvic girdle pain in the Netherlands. ${ }^{29}$ A second group of pregnant women $(\mathrm{n}=518)$ with alternative lifestyles with regards to dietary habits (organic food choice), child rearing practices, vaccination schemes and/or use of antibiotics was recruited through alternative channels, organic food shops, Steiner schools, magazines and anthroposophic doctors and midwives. Over time, data was collected using questionnaires, during home visits, and by clinical/laboratory examinations. A subgroup of 1,793 parents (out of 2,313 asked) gave informed consent to obtain information regarding their child's medication use from General Practitioner (GP) records. In 2014, a postal questionnaire was sent to GPs to retrieve this information. Finally, 529 out of the 744 contacted GPs provided information on medication used for a total of 1,171 children. After excluding premature children $(<37$ weeks of gestation, $\mathrm{n}=28$ ), twins $(\mathrm{n}=16)$, children with congenital abnormalities related to growth (e.g Down's syndrome, cystic fibrosis, Turner syndrome, and Fallot's tetralogy, $\mathrm{n}=12$ ) as well as children without detailed information on antibiotic use $(\mathrm{n}=136)$, a total sample size of 979 children was eligible for further analysis (Figure I).

All children in this study were Caucasians. The study was approved by the Medical Ethics Committee of the Maastricht University Medical Center, the Netherlands.

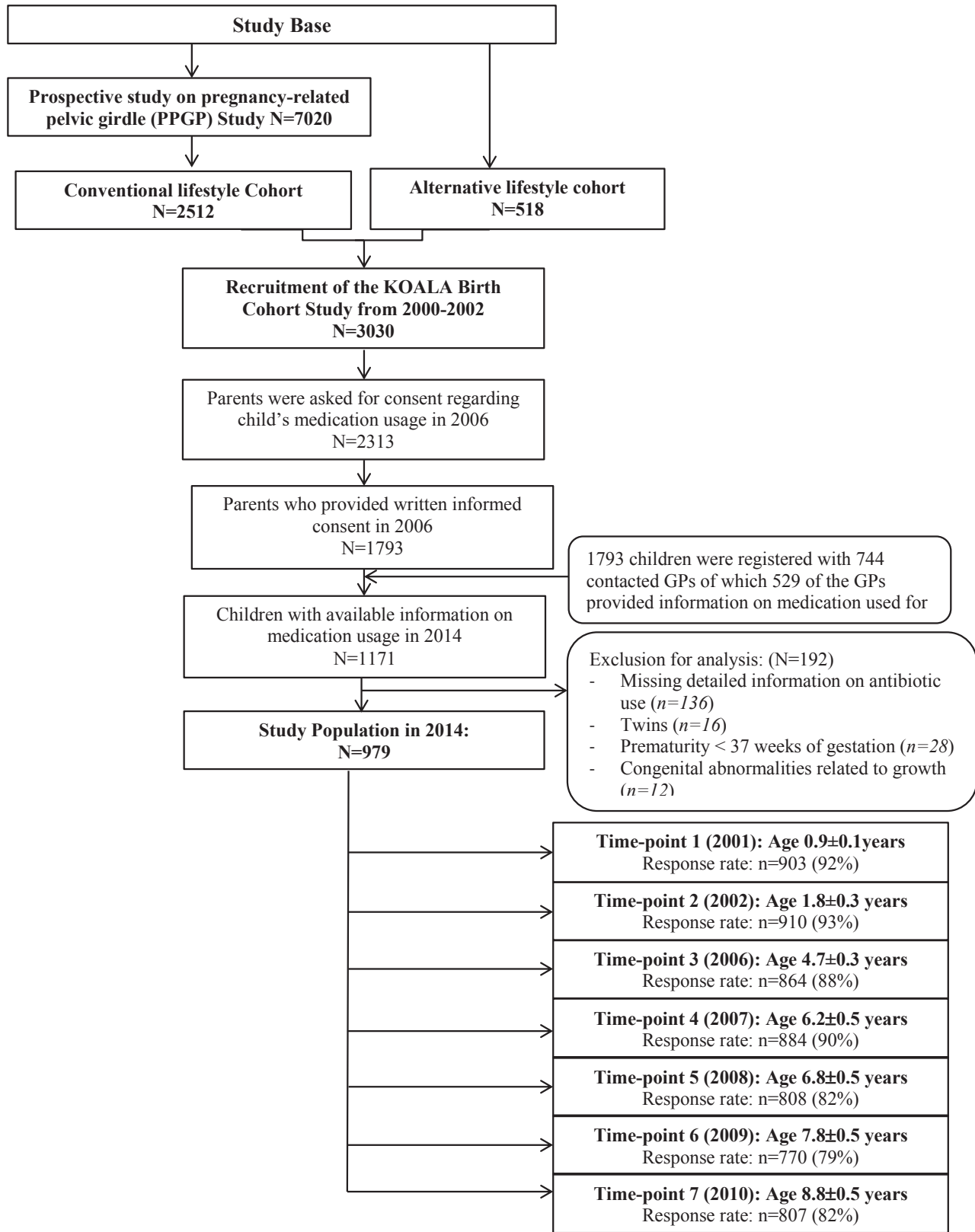

Figure I. Flow chart illustrating how the present study population of 979 children was obtained 
Antibiotic use

The questionnaires sent to GPs amongst others referred to exposure of the child to ora antibiotics over its lifetime, i.e. "Did the child ever use antibiotics" and "If yes, could you give the generic drug name and date of each prescription." In addition, GPs were also asked to attach the entire medication history (including generic drug name, and date of prescription) of the child from birth onwards. Both sources of information were used to determine the antibiotic use of each child. We did not collect information on antibiotics administered in hospitals.

The number of courses of antibiotics prescribed to children in the first 10 years of life was analyzed as a categorical variable (none, $1,2-3$, and $\geq 4$ courses). Separate variables were subsequently created to examine antibiotic exposure at different ages (first six (0-6) months), second six (6-12) months, second (1-2 years), and above the second (>2 years) year of life), and to examine the effects of different types of antibiotics prescribed (broadspectrum (BS) $\beta$-lactams (amoxicillin, cephalosporin), narrow-spectrum (NS) -lactams (flucloxacillin, pheneticillin, phenoxymethylpenicillin), macrolides (erythromycin, clarithromycin, azithromycin), antimetabolites (co-trimoxazol, trimethoprim), and others (nitrofurantoin, metronidazol, gentamicin, and tetracycline)). Within these variables, the number of antibiotic courses (none, 1 , and $\geq 2$ courses) was associated with anthropometric outcomes.

\section{Data collection and longitudinal outcome measures}

Pregnant women received questionnaires at 14 and 34 weeks of gestation, collecting data on pre-pregnancy weight, weight gain during pregnancy, maternal education and family size. Data from obstetric reports and questionnaires completed by the mothers were obtained two weeks after childbirth, with data on gestational age, birth weight, gender mode and place of delivery, smoking during pregnancy and gestational hypertension or diabetes. At the children's age of (mean \pm standard deviation (SD) $5.0 \pm 0.6$ years, food frequency questionnaires (FFQ) were filled out by the parents to report the dietary habits and physical activity of their children. The FFQ was developed and validated with the doubly labelled water method to measure energy intake at age 4-6 years. ${ }^{30}$

Information on the child's weight, height and age at the time of measurement was collected via self-administered questionnaires at seven different points in time. At the first two follow-up time points, when the children had attained the age $($ mean $\pm S D)$ of $0.9 \pm 0.1$ and $1.8 \pm 0.3$ years, parents were asked to report the most recent height and weight measurements including age at measurement (in months) at the Baby Welfare clinics. At the other five follow-up points, questionnaires were sent to the parents in which they were asked to measure and report the child's height $(\mathrm{cm})$ and weight $(\mathrm{kg}$, specified to one decimal) without clothes or shoes at ages (mean \pm SD) of $4.7 \pm 0.3,6.2 \pm 0.5,6.8 \pm 0.5$, $7.8 \pm 0.5$, and $8.8 \pm 0.5$ years respectively. Body Mass Index $\left(B M I=\right.$ weight $/$ height $^{2}$ in $\mathrm{kg} /$ $\mathrm{m}^{2}$ ), height and weight measurements were standardized by recoding them into ageand gender-specific z-scores using the Dutch Growth Study ${ }^{31}$ as a reference population. BMI z-scores were used as continuous outcomes as well as dichotomized into "not overweight" vs. "overweight" based upon a cut-off z-score $\geq 1.04$ (BMI z-score agreeing with the 85 th percentile) standardized for age and gender. ${ }^{32}$

\section{Statistical analysis}

Summary statistics of exposure variables and characteristics of the study population for children who were exposed and not exposed to antibiotics are presented as mean ${ }_{ \pm} \mathrm{SD}$ for continuous variables, and numbers and percentages for categorical variables. Generalized estimating equations (GEE) models with an autoregressive correlation structure were used to analyze the association between antibiotic use and the 7 repeated BMI z-scores, weight z-scores, height z-scores (as continuous outcomes), and overweight status over time (as a binary outcome). The age of the child at the time of weight and height measurement was included in all models as the time variable. We investigated whether the association between the main exposures and outcomes differed over time and also if this association differed between recruitment groups (alternative and conventional), and gender. This was done by entering a time-exposure, a recruitment group-exposure, and a gender-exposure interaction term, respectively, in all models. In none of the models were these interactions statistically significant $(\mathrm{p}>0.05)$. The following a priori potentia confounders ${ }^{33-35}$ were included in all adjusted (multivariable) models: recruitment group (conventional or alternative), household size, maternal education (low (primary, preparatory vocational or lower general secondary schools), middle (vocational, higher general secondary or pre-university education), high (higher vocational or academic education), or other), maternal pre-pregnancy weight, maternal pregnancy weight gain, smoking during pregnancy, gestational diabetes, gestational hypertension, mode and place of delivery (vaginal delivery at home, vaginal delivery in hospital, or caesarean section in hospital), gender, birth weight, gestational age, duration of breastfeeding, child's dietary intake (total fiber, total energy, fats and carbohydrates both as percentage of total energy), and child's physical activity.

Due to loss to follow-up and incompletely filled out questionnaires, missing values in some confounders occurred. To obtain an unbiased and statistically more powerful analysis $^{36}$ we imputed these confounders. We used a Markov Chain Monte Carlo (MCMC) method for multiple imputations in SAS to impute missing values: ranging from $0.004 \%$ missing values for duration of breastfeeding to $0.1 \%$ for household size. Missing values in categorical confounders were imputed by adding a 'missing' category. We then performed GEE analyses on the combined imputed datasets $(n=10)$ while averaging all parameter estimates for each variable. ${ }^{37,38}$ Results from the combined imputed datasets were comparable to those of the original non-imputed data; hence final results were reported from the imputed data. 
Data analysis was performed using statistical software packages SAS 9.3 and SPSS 21.0 (SPSS Inc., Chicago, IL, USA). A pre-selected significance level of $\mathrm{p}$-value $<0.05$ was considered in all analyses.

\section{Results}

From the cohort of 1,171 children with information on antibiotic use, a total of 979 children were eligible for analysis (Figure I). Participant characteristics of the current study population and the entire KOALA cohort are presented in Table I. In general, the KOALA cohort and the present study population were comparable, although the proportion of mothers with a high education level as well as home-born children appeared to be slightly higher, and the duration of breastfeeding appeared to be longer in the present study population.
Table I. Participant characteristics of the present study population and the total KOALA Birth Cohort Study at start of the follow-up

\begin{tabular}{|c|c|c|c|c|}
\hline Covariates & $\begin{array}{l}\text { KOALA Birth } \\
\text { Cohort Study } \\
(\mathrm{N}=3030) \\
\text { Mean } \pm \text { SD } \\
\end{array}$ & $\begin{array}{c}\text { Study } \\
\text { Population } \\
(\mathrm{N}=979)^{\mathbf{a}} \\
\text { Mean } \pm \mathrm{SD}\end{array}$ & $\begin{array}{c}\text { Exposed } \\
(\mathrm{n}=613) \\
\text { Mean } \pm \mathrm{SD}\end{array}$ & $\begin{array}{l}\text { Unexposed } \\
(\mathrm{n}=366) \\
\text { Mean } \pm \mathrm{SD})\end{array}$ \\
\hline \multicolumn{5}{|l|}{ Recruitment group (n (\%)) } \\
\hline Conventional & $2512(81.9)$ & $801(81.8)$ & $534(87.1)$ & $267(73.0)$ \\
\hline $\begin{array}{l}\text { Maternal education }(\mathrm{n}(\%))^{\mathbf{b}} \\
\text { Low } \\
\text { Middle } \\
\text { High } \\
\text { Other }\end{array}$ & $\begin{array}{c}289(9.5) \\
1062(35.0) \\
1343(44.3) \\
108(3.6)\end{array}$ & $\begin{array}{c}73(7.5) \\
345(35.2) \\
521(53.2) \\
30(3.1)\end{array}$ & $\begin{array}{c}54(8.8) \\
234(38.2) \\
300(48.9) \\
18(2.9)\end{array}$ & $\begin{aligned} 19 & (5.2) \\
111 & (30.3) \\
221 & (60.4) \\
12 & (3.3)\end{aligned}$ \\
\hline \multicolumn{5}{|c|}{ Maternal smoking during pregnancy (n (\%)) } \\
\hline Maternal pre-pregnancy weight $(\mathrm{kg})$ & $67.8 \pm 13.1$ & $68.0 \pm 12.5$ & $68.4 \pm 12.6$ & $67.4 \pm 12.2$ \\
\hline Maternal pregnancy weight gain $(\mathrm{kg})$ & $14.3 \pm 5.1$ & $14.0 \pm 5.0$ & $14.1 \pm 5.0$ & $13.9 \pm 4.9$ \\
\hline $\begin{array}{l}\text { Gestational diabetes (n (\%)) } \\
\text { yes }\end{array}$ & $19(0.6)$ & $7(0.7)$ & $7(1.1)$ & $0(0.0)$ \\
\hline $\begin{array}{l}\text { Gestational hypertension } \\
\text { yes }\end{array}$ & $118(3.9)$ & $48(4.9)$ & $31(5.1)$ & $17(4.6)$ \\
\hline $\begin{array}{l}\text { Mode and place of delivery (n (\%)) } \\
\text { Vaginally at home } \\
\text { Vaginally in hospital } \\
\text { Caesarean section at hospital }\end{array}$ & $\begin{array}{c}1194(39.4) \\
1149(37.9) \\
311(10.3)\end{array}$ & $\begin{array}{l}451(46.1) \\
395(40.3) \\
107(10.9)\end{array}$ & $\begin{array}{c}270(44.0) \\
253(41.3) \\
70(11.4)\end{array}$ & $\begin{array}{c}181(49.5) \\
142(38.8) \\
37(10.1)\end{array}$ \\
\hline $\begin{array}{l}\text { Gender }(\mathrm{n}(\%)) \\
\text { Boy }\end{array}$ & $1543(50.9)$ & $490(50.1)$ & $314(51.2)$ & $176(48.1)$ \\
\hline Birthweight (g) & $3504 \pm 512.4$ & $3551.3 \pm 454.7$ & $3547 \pm 456$ & $3557 \pm 453$ \\
\hline Gestational age (weeks) & $39.8 \pm 5.0$ & $39.8 \pm 3.0$ & $39.8 \pm 3.7$ & $39.8 \pm 1.2$ \\
\hline Duration of breastfeeding (months) & $4.9 \pm 4.6$ & $5.4 \pm 0.1$ & $4.9 \pm 4.1$ & $6.4 \pm 4.4$ \\
\hline Dietal & & & & \\
\hline $\begin{array}{l}\text { Total energy intake }(\mathrm{kJ}) \\
\% \text { energy intake from protein } \\
\% \text { energy intake from carbohydrates } \\
\text { Fiber }(\mathrm{g})\end{array}$ & $\begin{array}{c}6173 \pm 1249 \\
14.6 \pm 2.1 \\
55.8 \pm 5.0 \\
15.3 \pm 4.0\end{array}$ & $\begin{array}{c}6181 \pm 1277 \\
14.6 \pm 2.0 \\
55.8 \pm 4.9 \\
15.3 \pm 3.8\end{array}$ & $\begin{array}{c}6186 \pm 1245 \\
14.6 \pm 2.0 \\
55.8 \pm 4.9 \\
15.0 \pm 3.7\end{array}$ & $\begin{array}{c}6173 \pm 1330 \\
14.5 \pm 2.0 \\
55.7 \pm 4.9 \\
15.7 \pm 4.0\end{array}$ \\
\hline Household size & $4.3 \pm 0.8$ & $4.3 \pm 0.8$ & $4.2 \pm 0.7$ & $4.4 \pm 0.8$ \\
\hline Physical activity (hrs/week) & $9.5 \pm 4.5$ & $9.3 \pm 4.3$ & $9.3 \pm 4.4$ & $9.1 \pm 4.0$ \\
\hline
\end{tabular}

Totals may not add up to 979 because of missing values (see number of missing values in methods section) Maternal education - Low: primary school, preparatory vocational or lower general secondary school, middle: vocational, higher general secondary or pre-university education, high: higher vocational or academic education. 
Of the 979 children, $613(62.6 \%)$ children were exposed to at least one antibiotic course during follow-up (Table II). Of these 613 children, 127 (13.0\%) received four or more courses of antibiotics over the entire follow-up period, while $64(7.0 \%)$ and $102(11.7 \%)$ were exposed to antibiotics before the age of 6 and 6-12 months respectively. The majority of children, $531(54.5 \%)$ were exposed to BS $\beta$-lactams, whereas macrolides $(168 ; 17.2 \%)$, NS $\beta$-lactams $(72 ; 7.4 \%)$, antimetabolites (37; $3.8 \%)$, and other antibiotics $(24 ; 2.4 \%)$ were used less frequently. All children had at least one anthropometric measurement available during follow-up (Table III). At timepoint 1 (beginning of follow-up) anthropometric data were available for 896 out of the 979 children, with $15.1 \%$ of the children being overweight. For subsequent follow-up time-points anthropometric data were available for $900,848,820,757,709$, and 768 children, respectively.

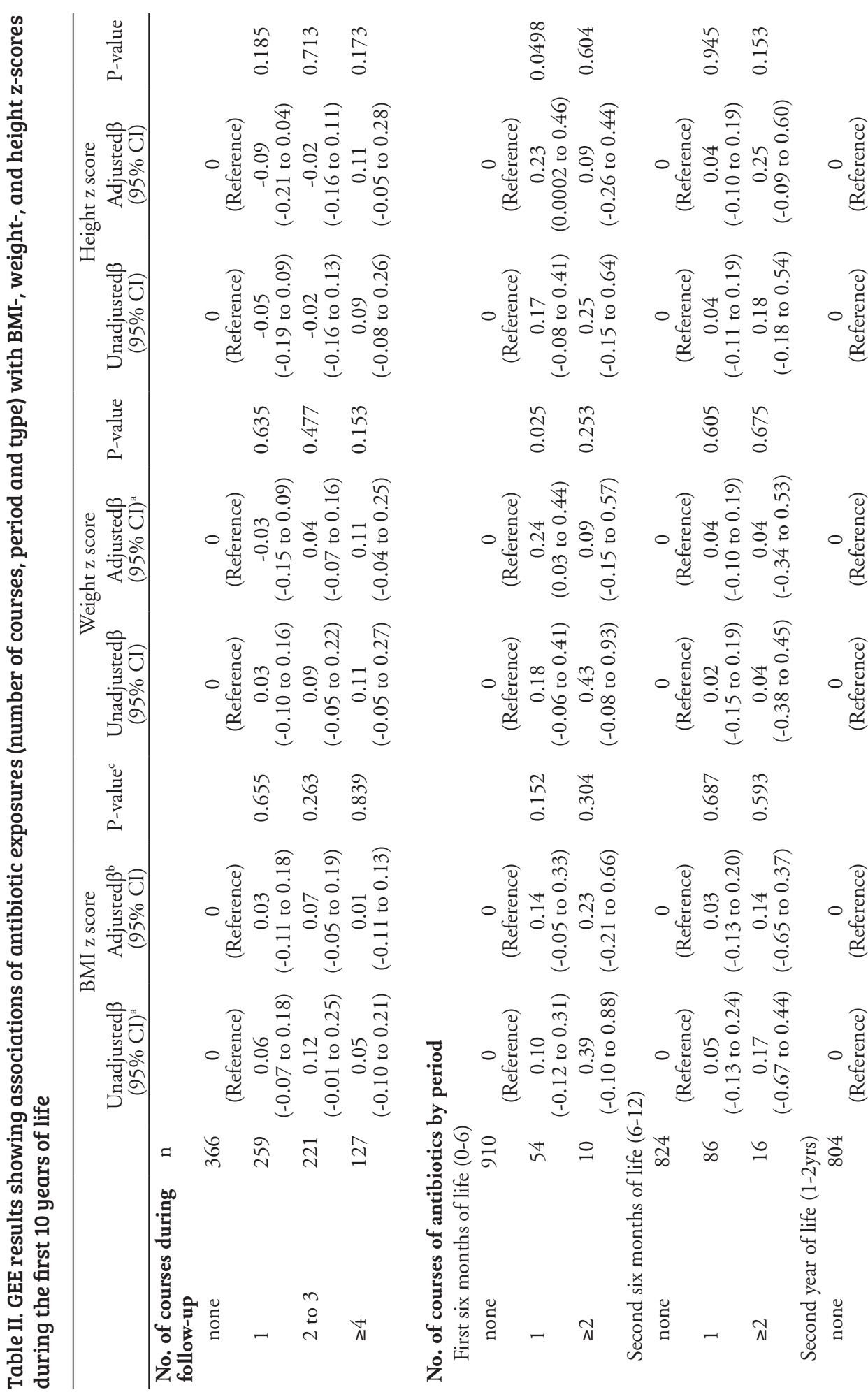



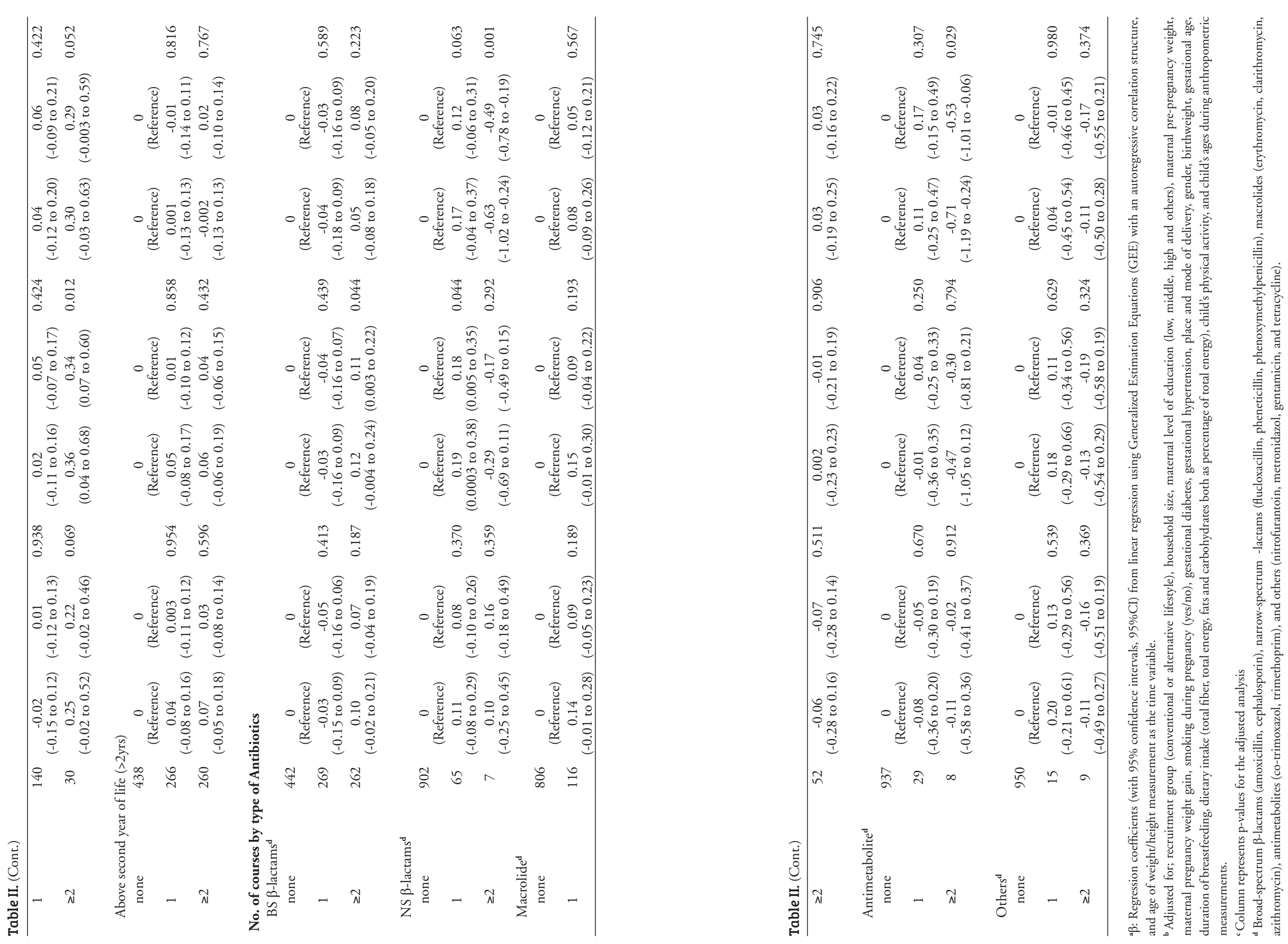


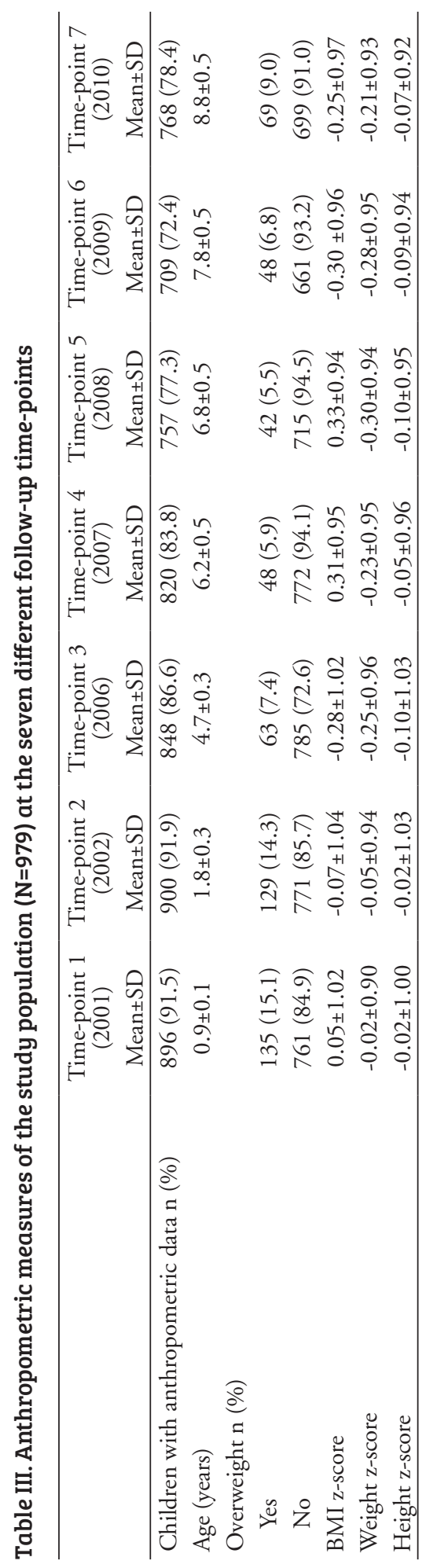

When analyzing the number of courses of antibiotics children were exposed to during the entire follow-up period, neither the crude nor adjusted models showed significant associations with BMI-, weight-, height z-scores (Table II) or overweight (Table IV, Supplemental).

When we subsequently examined antibiotic exposure at different ages, children exposed to a single course of antibiotics in the first 6 months of life had higher weight z-scores $(\operatorname{adj} \beta$ 0.24; $95 \% \mathrm{CI}: 0.03$ to 0.44$)$ and higher height $\mathrm{z}$-scores $(\operatorname{adj} \beta$ 0.23; 95\%CI: 0.0002 to 0.46 ). We found no association for exposure to a single course of antibiotics in the second 6 months of life with any of the outcomes. Due to the small group sizes for exposure to $\geq 2$ course of antibiotics in the first 6 and second 6 months of life we did not find an association with any of the outcomes, although effect sizes were fairly comparable to the group exposed to $\geq 2$ courses of antibiotics in the second year of life. This can be confirmed by the fact that, grouping exposure in the first and second 6 months of life into exposure in the first year of life, the exposure to $\geq 2$ courses of antibiotics was significantly associated with higher height z-scores. (adjb 0.25 ; 95\%CI 0.04 to 0.46 ). Children exposed to $\geq 2$ courses of antibiotics in second year of life had higher BMI-, weight-, and height z-scores compared to children not exposed to antibiotics (Table II). These associations in second year of life reached significance with higher weight $\mathrm{z}$-scores (adjb 0.34; 95\%CI: 0.07 to 0.60) while borderline significant associations were observed for BMI (adjb 0.22; 95\%CI: -0.02 to 0.46 ) and height z-scores (adjb 0.29; 95\%CI: -0.003 to 0.59 ). No clear associations were observed for risk of being overweight in any of the age periods (Table IV; Supplemental).

With regards to the number of courses of specific types of antibiotics, we found that exposure to $\geq 2$ courses of $\mathrm{BS} \beta$-lactams over the entire follow-up period was associated with significantly increased weight-z-sores (Adj $\beta 0.11 ; 95 \% \mathrm{CI} 0.00$ to 0.22 ), while this was not the case for children exposed to only one single course of BS $\beta$-lactams (Table II). In addition, a single course of NS $\beta$-lactams during follow-up was associated with higher weight z-scores ( $\operatorname{adj} \beta$ 0.18; 95\%CI: 0.00 to 0.35 ) and borderline significantly with higher height $z$-scores $(\operatorname{adj} \beta$ 0.12; 95\%CI: -0.06 to 0.31$)$, compared to children not exposed to NS $\beta$-lactams during the course of the follow-up. In contrast to these observations, exposure to $\geq 2$ courses of NS $\beta$-lactam antibiotics was inversely associated with height z-scores (adj $\beta-0.49$; 95\%CI -0.78 to -0.19 ), but the number of children that had been prescribed multiple courses of NS $\beta$-lactams was very small $(n=7)$. The same was true for children exposed to $\geq 2$ courses of antimetabolites ( $\operatorname{adj} \beta-0.53 ; 95 \% \mathrm{CI}$ -1.01 to $-0.06 ; n=8)$. No associations were found for macrolides and other antibiotics (metronidazol, nitrofurantoin, gentamicin and tetracycline) with BMI-, weight-, and height z-scores. Furthermore, no significant associations were found for any of the specific antibiotics with risk of overweight (Table IV; online). 


\section{Discussion}

Within the context of the longitudinal KOALA-study we examined childhood exposure to antibiotics (with regards to the timing, type and number of courses) as reported by the children's GPs over an extensive follow-up period from birth up to the age of 10 years. Our study demonstrates that antibiotic exposure in early childhood is associated with higher weight and height z-scores in children up to 10 years of age, independent of other determinants of growth in childhood. Exposure to a single course of antibiotics before 6 months and exposure to multiple courses of antibiotics between 1-2 years showed the most pronounced associations with height and weight z-scores. Also, $\beta$-lactams over the entire follow-up period was associated with increasing weight z-scores.

Several studies examined the association between parent-reported antibiotic exposures during infancy in relation to BMI or overweight in childhood. ${ }^{24-26}$ Although these studies reported an association between antibiotic exposure and increased weight, these associations were sometimes only found in subgroups. Murphy et al. ${ }^{25}$, only found an association between antibiotic exposure and increased weight in boys but not in girls, while Asjlev et al. found this association only to be apparent in children from normal weight mothers. ${ }^{26}$ An important limitation of studies using parent-reported antibiotic exposure is their inability to distinguish between different types of antibiotics or to examine the effect of the number of antibiotic courses children were exposed to.

Two large GP and prescription registry-based cohort studies examined the association between antibiotic exposure within the first two years of life and BMI in early childhood. ${ }^{21,23}$ These studies were able to elegantly take into account the timing, number of prescriptions and the type of antibiotics, while they did not have the possibility to control for confounding factors such as habitual diet or physical activity. Both studies showed that antibiotic exposure was associated with increased (over)weight, which appeared to be most pronounced for exposure to macrolides ${ }^{21}$ and broad-spectrum antibiotics ${ }^{23}$ respectively.

A recent study by Azad et al, investigated antibiotic exposure in the first year of life, as retrieved from prescription records, in association with overweight and adiposity at the ages of 9 and 12 years within the context of the Canadian study of Asthma, Genes and the Environment (SAGE). According to their findings, infants receiving antibiotics in the first year of life were more likely to develop overweight and have higher central adiposity in later childhood compared to unexposed infants. These associations only remained statistically significant in boys but not in girls after stratifying for gender. ${ }^{22}$ Several previous studies indicated the existence of gender differences in the association between antibiotic exposure and the anthropometric outcomes. ${ }^{21,22,25}$ However, in our study we did not find a statistical significant interaction between antibiotic exposure and gender in association with these anthropometric outcomes.
In contrast to these previous studies we were able to take antibiotic exposure over a longer period of time (up to the age of 10 years) into account. We however found that exposure to antibiotics in the first two years of life, but not exposure over the entire follow-up period was associated with weight-related outcomes. A single course of antibiotics in the first 6 months of life was already significantly associated with increased weight- and height z-scores. This is consistent with the results of Transande et al, who found that antibiotic exposure in the first 6 months of life (but not exposure from 6-14 months) was consistently associated with increased body mass at 10,20 and 38 months of age respectively and overweight at 38 months. ${ }^{2}$ We however also found that multiple courses of antibiotics during the second year of life was associated with increased weightand height $\mathrm{z}$-scores. This could indicate that repeated antibiotic-induced microbial perturbations are required to demonstrate an effect on weight development at the age when the microbiome starts to become more resilient.

Altogether, our findings support the hypothesis that the time-window in which antibiotics can influence weight development appears to be within the first two years of life. In a study using a mouse model to mimic pediatric antibiotic use, it was indeed shown that therapeutic antibiotic administration accelerates total mass growth and progressively changes the microbiome composition and function depending on the number of courses and type of antibiotic. ${ }^{39}$

Consistent with the findings of Bailey et al. ${ }^{23}$, in which antibiotic exposure was also assessed using medical records obtained from GPs, we found that exposure to b-lactam especially repeated exposure to BS -lactams is associated with increased weight z-scores. This association was also seen for exposure to a single course of NS -lactams but not for repeated exposure to NS -lactams. However, there were only a few children ( $n=7)$ who were repeatedly exposed to NS -lactams, hence the lack of statistical power to detect associations with regards to weight $\mathrm{z}$-scores.

Among previous studies conducted with regards to exposure to antibiotics and weight development, only one recent study investigated the association of antibiotic exposure with height. ${ }^{21}$ Consistent with our findings they reported an increase in height in children exposed to antibiotics (especially penicillins) in the first two years of life as compared to unexposed children. Additionally, we found that repeated exposure to both NS -lactams and antimetabolite antibiotics was associated with decreased height z-scores. However, since only a few children were prescribed multiple courses of these antibiotics ( $n=7$ and $n=8$, respectively), these findings may be due to chance. Furthermore, little is known regarding the associations of b-lactam antibiotics, and antimetabolites with anthropometric outcomes hence further studies may be required to replicate these findings. 
Although the underlying mechanisms through which antibiotics mediate growth promotion is not yet completely understood, it is generally accepted that antibioticinduced perturbations of the gut microbiota contributes to these growth-promoting effects. ${ }^{15} \mathrm{~A}$ study in germ-free mice receiving microbiota transplants of murine donors receiving low-dose antibiotics showed an increase in fat mass whereas this was not observed in germ-free mice receiving fecal transplants from donors without antibiotic exposure. ${ }^{9}$ This transferability of the growth promotion phenotype indicates that, rather than the antibiotics themselves, the antibiotic-induced microbial perturbations play a causal role. In addition, some studies also showed that the effects on both growth promotion and the ability to convert food calories into body mass was greater for animals exposed to antibiotics earlier in life compared to those exposed in later life. ${ }^{19,40}$ Thi might explain why antibiotic exposure during early-life has more pronounced effects on weight development than exposure in later childhood, since the infant microbiota is more susceptible to antibiotic-induced perturbations as compared to the more resilient adult-like microbiota that establishes around the age of 2 to 3 years. ${ }^{40-42}$

A major strength of our study is that multiple questionnaires were sent over the years, which led to comprehensive data on background information enabling the adjustment for many determinants of growth development in infancy. Additionally, we had 7 occasions of outcome measurements over a time period of 10 years, which were together modeled taking into account the correlations between the repeated outcome measures within each subject. Moreover, reliable data on antibiotic exposure (including timing, type and number of courses) of the children were also available over the entire follow-up period as retrieved from GP records.

As a consequence of the detailed and longitudinal characterization of the participating children, the sample size is not as large as several previous studies where information on antibiotic exposure was obtained during the first ${ }^{25,26}$ and the second ${ }^{21,23,24}$ years of life. Although our data on antibiotic use was derived from detailed information on prescribed medication in primary healthcare, we did not have information on antibiotics prescribed in the hospital and whether the antibiotics prescribed were actually taken by the children. However, in the Netherlands, as in most other developed countries, the vast majority of antibiotics for childhood infections including infections of the respiratory tract, urinary tract and skin are prescribed in primary care. ${ }^{43}$ As such, underestimation of antibiotic exposure is limited. Another potential limitation is the potential bias introduced by the fact that weight and height measurements were parent-reported. Even though the procedure of measuring weight and height was explained in detail to the parents beforehand, parents may tend to over-report body weight in children with a low BMI and under-report weight in children with a high BMI hence lower prevalence of overweight. ${ }^{44}$ An underestimation of overweight with parent-reported data compared to data collected during home visits was also reported by a validation study of the KOALA Birth Cohort Study. ${ }^{45}$ This may have resulted in an underestimation of the true associations as we saw weak associations with BMI z-scores and none with overweight. This lack of associations between antibiotic use and overweight might be due to the low prevalence of overweight children in our study population and consequently the limited statistical power. To control for dietary factors, dietary information was collected only once at the age of 5 years using a FFQ. Yet, FFQs are specifically designed to reflect a long-term dietary pattern and give a good estimate of habitual dietary intake. Moreover, previous studies have shown a relatively stable dietary pattern during childhood. ${ }^{46}$ Lastly, our study population consisted entirely of Dutch Caucasian children hence results might not be generalizable to children with another ethnic or racial background.

We did not take the indication for which antibiotics were prescribed into account and therefore confounding-by-indication cannot be completely ruled out. ${ }^{47}$ Confoundingby-indication occurs when the indication for which the antibiotics are prescribed, rather than the antibiotics themselves, are causally related to weight development. However, this is unlikely to explain our results, as multiple infectious episodes in early infancy are more likely associated with decreased rather than increased weight. ${ }^{48}$

In conclusion, our study among Dutch Caucasian children supports previous evidence that repeated childhood exposure (in terms of number of courses) to antibiotics, especially BS -lactams, leads to perturbations of the gut microbiota and subsequent weight development in children. Our findings imply that exposure below 2 years of age is a critical time in which antibiotics influence the gut microbiota and thus metabolism as we saw that antibiotic exposure above 2 years of age has little effect on growth development over time. Given the high antibiotic prescription rates in early childhood and the growing pandemic of overweight and obesity in western children, further research is needed to identify long-term implications in adulthood, and to determine the exact mechanisms of this association.

\section{Acknowledgments}

Funding source: This study was funded by TI Food and Nutrition, public private partnership in food and nutrition research. The mission is to contribute to optimum human nutrition, food safety and sustainable food production and to increase the competitiveness of food industry. Partners are key players in the global food industry, leading research institutes, universities and medical centers. Additional funding for data collection was received from: BBMRI-NL, a Research Infrastructure financed by the Dutch government (NWO 184.021.007), Netherlands Organization for Health Research and Development (grant 2100.0090), Netherlands Asthma Foundation (grants 3.2.03.48, 3.2.07.022), Netherlands Heart Foundation (grant 2008B112), Triodos Foundation, Phoenix Foundation, Raphaël Foundation, Iona Foundation, Foundation for the Advancement of Heilpedagogiek, Royal Friesland Foods (currently 
FrieslandCampina); Netherlands Sugar Foundation, and the Ministry of Economic affairs. The sponsors had no influence on the analysis and reporting of this study.

\section{References}

1. Jayachandran S, Lleras-Muney A, Smith K. Modern medicine and the 20th century decline in mortality: Evidence of the impact of sulfa drugs (Working Paper 15089). Cambridge, MA: National Bureau of Economic Research; 2009.

2. Ball P, Baquero F, Cars O, File T, Garau J, Klugman K, et al. Antibiotic therapy of community respiratory tract infections: strategies for optimal outcomes and minimized resistance emergence. J Antimicrob Chemother. 2002;49:31-40.

3. Wise R. The relentless rise of resistance? J Antimicrob Chemother. 2004;54:30610.

4. Hicks LA, Chien YW, Taylor TH, Jr., Haber M, Klugman KP. Outpatient antibiotic prescribing and nonsusceptible Streptococcus pneumoniae in the United States, 1996-2003. Clin Infect Dis. 2011;53:631-9.

5. Hersh AL, Jackson MA, Hicks LA. Principles of judicious antibiotic prescribing for upper respiratory tract infections in pediatrics. Pediatrics. 2013;132:1146-54.

6. Majeed A, Moser K. Age- and sex-specific antibiotic prescribing patterns in general practice in England and Wales in 1996. Br J Gen Pract. 1999;49:735-6.

7. Finkelstein JA, Metlay JP, Davis RL, Rifas-Shiman SL, Dowell SF, Platt R. Antimicrobial use in defined populations of infants and young children. Arch Pediatr Adolesc Med. 2000;154:395-400.

8. Pichichero ME. Dynamics of antibiotic prescribing for children. JAMA. 2002;287:3133-5.

9. Cox LM, Yamanishi S, Sohn J, Alekseyenko AV, Leung JM, Cho I, et al. Altering the intestinal microbiota during a critical developmental window has lasting metabolic consequences. Cell. 2014;158:705-21.

10. Penders J, Thijs C, Vink C, Stelma FF, Snijders B, Kummeling I, et al. Factors influencing the composition of the intestinal microbiota in early infancy. Pediatrics. 2006;118:511-21.

11. Jernberg C, Lofmark S, Edlund C, Jansson JK. Long-term impacts of antibiotic exposure on the human intestinal microbiota. Microbiology. 2010;156:3216-23.

12. Jakobsson HE, Jernberg C, Andersson AF, Sjolund-Karlsson M, Jansson JK, Engstrand L. Short-term antibiotic treatment has differing long-term impacts on the human throat and gut microbiome. PLoS One. 2010;5:e9836.

13. Backhed F, Ding H, Wang T, Hooper LV, Koh GY, Nagy A, et al. The gu microbiota as an environmental factor that regulates fat storage. Proc Natl Acad Sci U S A. 2004;101:15718-23.

14. Turnbaugh PJ, Ley RE, Mahowald MA, Magrini V, Mardis ER, Gordon JI. An obesity-associated gut microbiome with increased capacity for energy harvest. Nature. 2006;444:1027-31.

15. Ley RE, Backhed F, Turnbaugh P, Lozupone CA, Knight RD, Gordon JI. Obesity alters gut microbial ecology. Proc Natl Acad Sci U S A. 2005;102:11070-5. 
16. Cho I, Yamanishi S, Cox L, Methe BA, Zavadil J, Li K, et al. Antibiotics in early life alter the murine colonic microbiome and adiposity. Nature. 2012;488:621-6.

17. Lassiter C. Antibiotics as growth stimulants for dairy cattle: a review. Journal of Dairy Science. 1955;38:1102-38.

18. Cromwell GL. Why and how antibiotics are used in swine production. Anim Biotechnol. 2002;13:7-27.

19. Gaskins HR, Collier CT, Anderson DB. Antibiotics as growth promotants: mode of action. Anim Biotechnol. 2002;13:29-42.

20. Libby DA, Schaible PJ. Observations on growth responses to antibiotics and arsonic acids in poultry feeds. Science. 1955;121:733-4.

21. Saari A, Virta LJ, Sankilampi U, Dunkel L, Saxen H. Antibiotic exposure in infancy and risk of being overweight in the first 24 months of life. Pediatrics. 2015;135:617-26.

22. Azad MB, Bridgman SL, Becker AB, Kozyrskyj AL. Infant antibiotic exposure and the development of childhood overweight and central adiposity. Int J Obes (Lond). 2014;38:1290-8.

23. Bailey LC, Forrest CB, Zhang P, Richards TM, Livshits A, DeRusso PA Association of antibiotics in infancy with early childhood obesity. JAMA Pediatr. 2014;168:1063-9.

24. Trasande L, Blustein J, Liu M, Corwin E, Cox LM, Blaser MJ. Infant antibiotic exposures and early-life body mass. Int J Obes (Lond). 2013;37:16-23.

25. Murphy R, Stewart AW, Braithwaite I, Beasley R, Hancox RJ, Mitchell EA. Antibiotic treatment during infancy and increased body mass index in boys: an international cross-sectional study. Int J Obes (Lond). 2014;38:1115-9.

26. Ajslev TA, Andersen CS, Gamborg M, Sorensen TI, Jess T. Childhood overweight after establishment of the gut microbiota: the role of delivery mode, pre-pregnancy weight and early administration of antibiotics. Int J Obes (Lond). 2011;35:522-9.

27. Cox LM, Blaser MJ. Antibiotics in early life and obesity. Nat Rev Endocrinol. 2014.

28. Kummeling I, Thijs C, Penders J, Snijders BE, Stelma F, Reimerink J, et al. Etiology of atopy in infancy: the KOALA Birth Cohort Study. Pediatr Allergy Immunol. 2005;16:679-84

29. Bastiaanssen JM, de Bie RA, Bastiaenen CH, Heuts A, Kroese ME, Essed GG, et al. Etiology and prognosis of pregnancy-related pelvic girdle pain; design of a longitudinal study. BMC Public Health. 2005;5:1.

30. Dutman AE, Stafleu A, Kruizinga A, Brants HA, Westerterp KR, Kistemaker C, et al. Validation of an FFQ and options for data processing using the doubly labelled water method in children. Public Health Nutr. 2011;14:410-7.
31. Oude Luttikhuis HG, Verkade HJ, Sauer PJ, Stolk RP. [Guideline 'Diagnosis and treatment of obesity in adults and children']. Ned Tijdschr Geneeskd. 2008; 152:2749-50; author reply 50.

32. Cole TJ, Bellizzi MC, Flegal KM, Dietz WH. Establishing a standard definition for child overweight and obesity worldwide: international survey. BMJ. 2000;320:1240-3

33. Weng SF, Redsell SA, Swift JA, Yang M, Glazebrook CP. Systematic review and meta-analyses of risk factors for childhood overweight identifiable during infancy. Arch Dis Child. 2012;97:1019-26.

34. Kleiser C, Schaffrath Rosario A, Mensink GB, Prinz-Langenohl R, Kurth BM. Potential determinants of obesity among children and adolescents in Germany: results from the cross-sectional KiGGS Study. BMC Public Health. 2009;9:46.

35. Reilly JJ, Armstrong J, Dorosty AR, Emmett PM, Ness A, Rogers I, et al. Early life risk factors for obesity in childhood: cohort study. BMJ. 2005;330:1357.

36. Sterne JA, White IR, Carlin JB, Spratt M, Royston P, Kenward MG, et al. Multiple imputation for missing data in epidemiological and clinical research: potential and pitfalls. BMJ. 2009;338:b2393.

37. Schafer JL. Analysis of Incomplete Multivariate Data. London: Chapman \& Hall 1997.

38. Rubin DB. Multiple imputation for nonresponse in surveys. New York: Wiley; 1987.

39. Nobel YR, Cox LM, Kirigin FF, Bokulich NA, Yamanishi S, Teitler I, et al. Metabolic and metagenomic outcomes from early-life pulsed antibiotic treatment. Nat Commun. 2015;6:7486.

40. Palmer C, Bik EM, DiGiulio DB, Relman DA, Brown PO. Development of the human infant intestinal microbiota. PLoS Biol. 2007;5:e177.

41. Yatsunenko T, Rey FE, Manary MJ, Trehan I, Dominguez-Bello MG, Contreras $\mathrm{M}$, et al. Human gut microbiome viewed across age and geography. Nature. 2012;486:222-7.

42. Koenig JE, Spor A, Scalfone N, Fricker AD, Stombaugh J, Knight R, et al. Succession of microbial consortia in the developing infant gut microbiome. Proc Natl Acad Sci U S A. 2011;108 Suppl 1:4578-85.

43. de Bont EG, van Loo IH, Dukers-Muijrers NH, Hoebe CJ, Bruggeman CA, Dinant GJ, et al. Oral and topical antibiotic prescriptions for children in general practice. Arch Dis Child. 2013;98:228-31.

44. Scholtens S, Brunekreef B, Visscher TL, Smit HA, Kerkhof M, de Jongste JC, et al. Reported versus measured body weight and height of 4-year-old children and the prevalence of overweight. Eur J Public Health. 2007;17:369-74. 
45. Timmermans SH, Mommers M, Gubbels JS, Kremers SP, Stafleu A, Stehouwer $\mathrm{CD}$, et al. Maternal smoking during pregnancy and childhood overweight and fat distribution: the KOALA Birth Cohort Study. Pediatr Obes. 2014;9:e14-25.

46. Singer MR, Moore LL, Garrahie EJ, Ellison RC. The tracking of nutrient intake in young children: the Framingham Children's Study. Am J Public Health. 1995;85:1673-7.

47. Kummeling I, Thijs C. Reverse causation and confounding-by-indication: do they or do they not explain the association between childhood antibiotic treatment and subsequent development of respiratory illness? Clin Exp Allergy. 2008;38:124951.

48. Dewey KG, Mayers DR. Early child growth: how do nutrition and infection interact? Matern Child Nutr. 2011;7 Suppl 3:129-42.
Table IV. GEE results showing associations of antibiotic exposures (number of courses, type, and period) with the risk of being overweight during the first 10 years of life

\begin{tabular}{|c|c|c|c|c|c|}
\hline & & \multicolumn{4}{|c|}{ Overweight } \\
\hline & & $\begin{array}{l}\text { Unadjusted } \mathrm{OR}^{\mathrm{a}} \\
(95 \% \mathrm{CI})\end{array}$ & P-value & $\begin{array}{l}\text { Adjusted OR }{ }^{\mathrm{b}} \\
(95 \% \mathrm{CI})\end{array}$ & P-value ${ }^{c}$ \\
\hline \multicolumn{6}{|c|}{ Number of courses during follow-up $n$} \\
\hline none & 366 & 1 (Reference) & & 1 (Reference) & \\
\hline 1 & 259 & $1.22(0.85$ to 1.75$)$ & 0.275 & 1.09 (0.76 to 1.57$)$ & 0.640 \\
\hline 2 to 3 & 221 & $1.26(0.88$ to 1.80$)$ & 0.209 & $1.13(0.79$ to 1.63$)$ & 0.506 \\
\hline$\geq 4$ & 127 & $1.13(0.72$ to 1.79$)$ & 0.598 & $1.03(0.66$ to 1.60$)$ & 0.891 \\
\hline \multicolumn{6}{|c|}{ No. of courses of antibiotics by age period } \\
\hline \multicolumn{6}{|c|}{ First 6 months of life } \\
\hline none & 910 & 1 (Reference) & & 1 (Reference) & \\
\hline 1 & 54 & $1.23(0.79$ to 1.91$)$ & 0.252 & $1.21(0.78$ to 1.87$)$ & 0.396 \\
\hline$\geq 2$ & 10 & $1.13(0.39$ to 3.29$)$ & 0.843 & $1.19(0.38$ to 3.74$)$ & 0.762 \\
\hline \multicolumn{6}{|c|}{ 6-12 months of life } \\
\hline none & 872 & 1 (Reference) & & 1 (Reference) & \\
\hline 1 & 86 & $1.34(0.81$ to 2.20$)$ & 0.361 & 1.40 (0.81 to 2.42$)$ & 0.223 \\
\hline$\geq 2$ & 16 & $1.15(0.29$ to 4.54$)$ & 0.821 & $0.83(0.26$ to 2.67$)$ & 0.754 \\
\hline \multicolumn{6}{|c|}{ Second year of life (1-2yrs) } \\
\hline none & 804 & 1 (Reference) & & 1 (Reference) & \\
\hline 1 & 140 & $0.88(0.58$ to 1.33$)$ & 0.536 & 0.96 (0.63 to 1.46$)$ & 0.859 \\
\hline$\geq 2$ & 30 & $1.25(0.66$ to 2.37$)$ & 0.488 & $1.14(0.61$ to 2.13$)$ & 0.676 \\
\hline \multicolumn{6}{|c|}{ Above second year of life (>2yrs) } \\
\hline none & 438 & 1 (Reference) & & 1 (Reference) & \\
\hline 1 & 266 & $1.33(0.95$ to 1.85$)$ & 0.092 & 1.21 (0.87 to 1.70$)$ & 0.263 \\
\hline$\geq 2$ & 260 & $1.14(0.81$ to 1.60$)$ & 0.464 & $1.02(0.73$ to 1.43$)$ & 0.890 \\
\hline \multicolumn{6}{|c|}{$\begin{array}{l}\text { No. of courses by type of antibiotic } \\
\text { No. of observations }=5661\end{array}$} \\
\hline \multicolumn{6}{|c|}{ BS $\beta$-lactams ${ }^{\mathrm{d}}$} \\
\hline none & 437 & 1 (Reference) & & 1 (Reference) & \\
\hline 1 & 269 & $1.02(0.73$ to 1.44$)$ & 0.892 & $0.95(0.68$ to 1.34$)$ & 0.790 \\
\hline$\geq 2$ & 262 & $1.28(0.92$ to 1.78$)$ & 0.148 & $1.20(0.86$ to 1.67$)$ & 0.278 \\
\hline \multicolumn{6}{|c|}{ NS $\beta$-lactams ${ }^{d}$} \\
\hline none & 902 & 1 (Reference) & & 1 (Reference) & \\
\hline 1 & 65 & $1.03(0.59$ to 1.79$)$ & 0.918 & $1.00(0.57$ to 1.76$)$ & 0.986 \\
\hline$\geq 2$ & 7 & 0.32 (0.05 to 2.14$)$ & 0.240 & 0.41 (0.06 to 2.63$)$ & 0.347 \\
\hline \multicolumn{6}{|c|}{ Macrolide $^{\mathrm{d}}$} \\
\hline none & 806 & 1 (Reference) & & 1 (Reference) & \\
\hline 1 & 116 & $1.39(0.97$ to 2.00$)$ & 0.073 & 1.29 (0.89 to 1.86$)$ & 0.178 \\
\hline$\geq 2$ & 52 & 0.74 (0.42 to 1.32$)$ & 0.309 & 0.64 (0.35 to 1.16$)$ & 0.140 \\
\hline
\end{tabular}


Table IV. (Cont.)

\begin{tabular}{lccccc}
\hline $\begin{array}{l}\text { Antimetabolites } \\
\text { none }\end{array}$ & 937 & 1 (Reference) & & 1 (Reference) & \\
1 & 29 & $0.82(0.33$ to 2.05$)$ & 0.674 & $0.83(0.33$ to 2.11$)$ & 0.699 \\
$\geq 2$ & 8 & $0.69(0.19$ to 2.51$)$ & 0.569 & $0.67(0.19$ to 2.31$)$ & 0.524 \\
& & & & & \\
Others $^{\mathrm{d}}$ & & & & & \\
none & & 1 (Reference) & & 1 (Reference) & \\
1 & 15 & $1.65(0.55$ to 5.02$)$ & 0.374 & 1.62 (0.52 to 5.06$)$ & 0.407 \\
$\geq 2$ & 9 & $0.57(0.20$ to 1.68$)$ & 0.310 & $0.50(0.21$ to 1.20$)$ & 0.119 \\
\hline
\end{tabular}

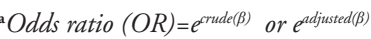

bAdjusted for; recruitment group (conventional or alternative lifestyle), household size, maternal level of education (low, middle, high and others), maternal pre-pregnancy weight, maternal pregnancy weight gain, smoking during pregnancy (yes/no), gestational diabetes, gestational hypertension, place and mode of delivery, gender, birthweight, gestational (yes/no), gestational diabetes, gestational hypertension, place and mode of delivery, gender, birthweight, gestational
age, duration of breastfeeding, dietary intake (total fiber, total energy, fats and carbohydrates both as percentage of total nergy), child's physical activity, and child's ages during anthropometric measurements.

Column represents p-values for the adjusted analysis

"Broad-spectrum $\beta$-lactams (amoxicillin, cephalosporin), narrow-spectrum $\beta$-lactams (flucloxacillin, pheneticillin, phenoxymethylpenicillin), macrolides (erythromycin, clarithromycin, azithromycin), antimetabolites (co-trimoxazo, trimethoprim), and others (nitrofurantoin, metronidazol, gentamicin, and tetracycline).

\section{CHAPTER 6}

REDUCTION OF HIGH DIMENSIONAL DATA OF THE GUT MICROBIOTA IN RELATION TO BMI Z-SCORE TRAJECTORIES: THE KOALA BIRTH COHORT STUDY

Catherine A. Mbakwa, John Penders, Valéria Lima Passos, Sacha A. F. T. van Hijum, Gerben D. A. Hermes, Carel Thijs, Pieter C. Dagnelie, Monique Mommers,

Erwin G. Zoetendal, Hauke Smidt, and Ilja C.W. Arts 


\section{Abstract}

Objective: The present study aimed to identify developmental trajectories of BMI z-scores in healthy children from 6-10 years of age; evaluate the relation of the trajectories with established risk factors of childhood overweight; and finally reduce the high dimensional data of the gut microbiota in association with the trajectories.

Methods: A total of 295 Dutch children from the KOALA Birth Cohort Study were included in this study. Group-based trajectory modelling (GBTM), a method that facilitates the identification of distinct longitudinal developmental patterns was applied to BMI z-scores measured over four time points. Multinomial logistic regression (MLR) was used to investigate the association between established risk factors of overweight (total energy intake (KJ), total physical activity (hours/week)) and the trajectories, while univariate MLR and Random Forest (RF) were used as methods for data reduction.

Results: Four distinct BMI z-score trajectories were identified: (i) underweight (15.6\% of the children), (ii) low-normal weight $(44.1 \%)$, (iii) high-normal weight $(34.3 \%)$ and (iv) overweight $(6.1 \%)$. BMI as measured by trained research assistants at baseline was positively associated with the BMI trajectories $(\mathrm{P}=<0.0001)$. An increase in total energy intake was associated with a higher likelihood of falling into the overweight trajectory $(\mathrm{P}=0.026)$ while an increase in total physical activity was associated with a lower likelihood of falling into both the underweight $(\mathrm{P}=0.002)$ and low-normal weight $(\mathrm{P}=0.047)$ trajectories. An increase in bacterial diversity was associated with a lower likelihood of falling into both the underweight (adjOR 0.09; 95\%CI 0.01 to 0.64 ) and overweight (adjOR 0.06 ; 95\%CI 0.00 to 0.84 ) trajectories. Data reduction by means of univariate MLR led to the identification of 10 bacterial groups that were associated with the trajectories (FDR corrected $\mathrm{p}<0.25$ ). RF was unable to classify the trajectories in association with the gut microbiota with regards to our data.

Conclusion: The present study illustrates how the identification of unique patterns of childhood growth development by means of GBTM might be used to study the role of the microbiome in weight development within the context of longitudinal studies.

\section{Introduction}

Over the past decade, the evidence for a role of the gut microbiota in childhood overweight has been rapidly increasing. ${ }^{1}$ The human gut microbiota is a complex community, consisting of approximately 100 trillion bacteria belonging to hundreds of different species, next to numerous viruses, archaea, fungi and protozoa. ${ }^{2}$ The composition of the gut microbiota also varies significantly between individuals. ${ }^{3}$ The high diversity and dimensionality of data from this ecosystem complicates the identification of relevant microbial candidates that may be associated with childhood overweight and in addition impedes drawing valid biological inferences. Further complications arise when weight fluctuations which differ within and between children during childhood development need to be taken into consideration. Hence, the application of statistical approaches for data reduction and variable selection with regards to repeatedly measured multinomial dependent variables could help in tackling this challenge.

Previous studies conducted so far [reviewed $\left.\mathrm{in}^{4}\right]$ on the association between the gut microbiota and weight development mainly used traditional methods such as linear and logistic regressions to link the presence and abundance of a variety of microbial taxa to childhood overweight at fixed time points (cross-sectional studies). However, childhood height and weight development is pulsatile, in which periods of rapid growth ("growth spurts") are separated by periods of no measurable growth. The few longitudinal studies that have taken such fluctuations into account considered associations between microbiota and weight gain (increases in BMI) over a defined period of follow-up using generalised linear mixed models for longitudinal data. ${ }^{5-7}$ This approach assumes that the children form a homogenous group without considering the fact that there may be distinct patterns of weight development during childhood.

A number of studies have been performed identifying distinct BMI trajectories in children using group-based trajectory modelling (GBTM). ${ }^{8-10}$ GBTM, a model-based clustering method (a person-centred approach) was developed to identify groups of individuals following a similar developmental pattern of a certain entity in a longitudinal setting. ${ }^{11,12}$ Using this approach, researchers are able to understand how life-course experiences unfold at the individual level, hence clustering individuals with similar developmental patterns. The growth trajectories created in previous studies were used to investigate their associations with antenatal and postnatal risk factors ${ }^{8-10}$.

So far no study has been performed to associate high dimensional data, such as comprehensive measures of the gut microbiota, to childhood weight developmental trajectories. Altogether, to examine the association between the gut microbiota and childhood weight development, a combination of statistical methods is required that can capture the heterogeneity in growth patterns during childhood, and enable the 
reduction of the high dimensional microbial data to a limited number of bacteria candidates that are potentially associated with these trajectories. Using data of children from the KOALA Birth Cohort Study with anthropometrics measured repeatedly from 6 to 10 years of age, we sought to: 1) identify developmental patterns of BMI z-scores (also known as latent trajectories); 2) validate these trajectories with variables known to be associated with overweight; and 3) use existing statistical methods for variable selection/reduction (univariate logistic regression, and Random Forest (RF)) to identify bacterial groups of the gut microbiota associated with these trajectories.

\section{Methods}

\section{Study design and participants}

Data were obtained from the prospective KOALA Birth Cohort Study in the Netherlands, whose design has been described in detail elsewhere. ${ }^{13}$ Briefly, a total of 2,834 pregnant women were recruited, at 34 weeks of gestation, from October 2000 until December 2002. A subgroup of 1,204 parents was asked for consent for a home visit for anthropometric measurements and to collect a single faecal sample from the child at the age of 6-7 years. This subgroup comprised of participants who had home visits for blood collection from the mother during pregnancy and/or the child at age 2 years, and who were still active participants (Figure 1). Faecal samples were obtained from 669 children. Exclusion criteria for the current study were: prematurity (infants born before 37 weeks of gestation), twins, abnormalities linked to growth (such as Down's syndrome, Turner syndrome, Fallot's tetralogy, multiple disabilities, and cystic fibrosis), faecal samples with transport times exceeding 3 days, or lack of data on dietary intake. A total of 295 children that met these criteria were included in the present study; all being Caucasians. Written informed consent was given by all parents, and the study was approved by the Medical Ethics Committee of Maastricht University and the National Ethical Committee for Medical Research.

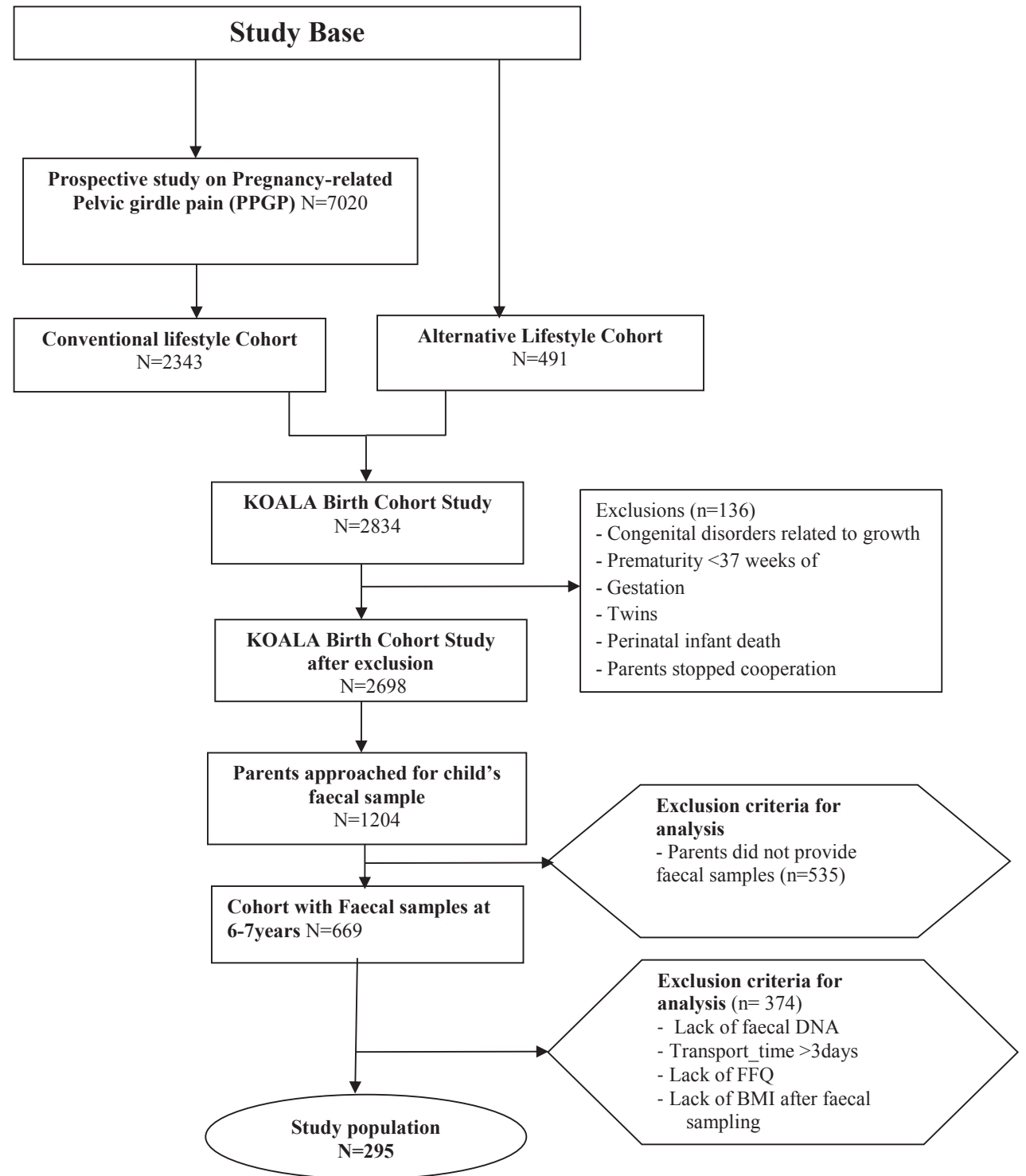

Figure 1: Flowchart of the study population 


\section{Data collection and outcome measures}

\section{Faecal sample collection}

Parents collected faecal samples of their children using faeces tubes with spoons attached to their lids (Sarstedt, Nümbrecht, Germany). Samples collected were mailed to the laboratory, 10-fold diluted in peptone/water (Oxoid CM0009) containing 20\% (vol/ vol) glycerol (Merck, Darmstadt, Germany) upon arrival, and stored at $-80^{\circ} \mathrm{C}$ until further analysis.

\section{Microbiota profiling}

Faecal DNA isolation has been described in detail elsewhere. ${ }^{14,15}$ Briefly, faecal DNA from 295 faecal samples was isolated using a combination of Repeated-Bead-Beating (RBB) plus column purification method. A Nanodrop 1000 spectrophotometer (Thermo Fisher Scientific, Wilmington, USA) was used to determine DNA concentration and purity. Faecal DNA was then stored at $-20^{\circ} \mathrm{C}$ pending microbial analyses. The intestinal microbiota composition was assessed using the Human Intestinal Tract Chip (HITChip). ${ }^{16}$ This is a phylogenetic profiling DNA microarray containing over 4,800 probes and targeting the V1 and V6 hypervariable regions of 16S rRNA gene. The array detects over 1,033 species-like bacterial phylotypes (>98\% 16S rRNA gene sequence similarity) that represent the majority of the bacterial diversity of the human intestinal tract. ${ }^{16}$ The full-length $16 \mathrm{~S}$ rRNA gene was amplified after DNA extraction, followed by in vitro transcription and labelling of the resultant RNA with Cy3 and Cy5 before hybridization to the array. Each sample was hybridized in duplicate to ensure reproducibility, and raw signal intensities were normalised as previously described. ${ }^{17}$ For the data analysis, hybridization signals were summarized to 130 genus-like phylogenetic groups (>90\% 16S rRNA gene sequence similarity) referred to as species and relatives, the latter being shortened as 'et rel.. ${ }^{16}$ A list of these 130 genus-like levels has been reported elsewhere. ${ }^{17}$ The $\log 10$-transformed signals were used as a proxy for bacterial logarithmic abundance. Diversity of the microbiota was quantified using Shannon's diversity index based on non-logarithmic oligo-level signals as implemented by the $\mathrm{R}$ package vegan ${ }^{18}$ while richness was obtained by counting the total number of probes in each sample using an $80 \%$ quantile threshold for detection.

\section{Anthropometric measures}

Height (in $\mathrm{cm}$ ) without wearing shoes and clothes, and weight (in $\mathrm{kg}$ ) of the children at ages $($ mean $\pm S D)$ of $6.0 \pm 0.3,6.8 \pm 0.2,7.7 \pm 0.3$, and $8.8 \pm 0.4$ years were reported by their parents through the use of self-administered questionnaires. These ages at BMI measurements will further be referred to as time-points 1-4, respectively. For each time-point BMI was calculated as weight divided by height squared $\left(\mathrm{kg} / \mathrm{m}^{2}\right)$. BMI measurements were then converted into age- and gender-specific z-scores using the
Dutch National growth study ${ }^{19}$ as the reference population. The BMI z-scores were subsequently used as input for the Group-Based Trajectory Modelling.

In a subgroup of children ( $\mathrm{n}=712$ ) including the 295 children in this present study, height, and weight, were also measured during home visits by trained research assistants at the age of 6-7 years, with the children wearing only their underwear. Height was measured with a portable stadiometer (Leicester height measure), and weight was measured with a digital scale (HE-5, CAS Corp., East Rutherford, NJ, USA) and recorded in millimetres and grams (rounded off to $100 \mathrm{~g}$ ), respectively. The height and weight measurements during the home-visits were also converted into BMI z-scores, but were not used for the Group-Based Trajectory Modelling.

\section{Other measures}

Physical activity: When the child was between 4-5 years of age, parents were asked to fill out a questionnaire about the physical activity level of their child during the last 4 weeks. The questions included: "How many times a week does your child exercise in school or a sports club?" and "How many days a week does your child play outside?" They could respond by indicating either of the following "never or less than 1 day a week," "1 day a week," "2 days a week," "3 days a week," "4 days a week," and "5 days a week or more." Furthermore, the duration of these activities was asked. The number of hours of physical activity per week was calculated from these answers.

Total energy intake: The average energy intake $(\mathrm{kJ})$ per day at 4-5 years of age was obtained through the use of Food Frequency Questionnaires (FFQ) specifically developed to assess children's energy intake and validated by using the doubly labelled water method. The questionnaire consisted of 71 items and, in addition, for 27 foods the specific types or brands consumed and preparation methods were asked. Parents reported their child's habitual food consumption by indicating the frequency of consumption ("never" to "6-7 days a week") and by specifying proportion sizes in natural units (for example, pieces, slices), household units (for example, glasses of spoons) or grams (for example, grams of fish). Additionally, parents were asked to measure the volumes of the cups and glasses they used for the children. The average energy intake $(\mathrm{kJ})$ per day was calculated with the aid of the Netherlands Food Composition Table 2001 (NEVO). ${ }^{20}$ A dietician provided nutritional values for the products that were not included in the NEVO 2001 table.

\section{Statistical Analysis}

Statistical analyses involved a series of sequential steps summarized in the flow-diagram (Figure 2). Briefly, the first part concerned the identification of BMI developmental trajectories with GBTM. The second part aimed at linking the extracted latent trajectories to established risk factors of childhood overweight (total energy intake (KJ), total physical activity (hours/week)) and BMI measured by trained research nurses 
during home visit at baseline (6-7 years of age). Methods for variable selection and reduction (univariate multinomial baseline-category logistic regression and random forest) were then used to reduce the high dimensional data of the gut microbiota at 6-7 years of age while linking it to the BMI developmental trajectories.

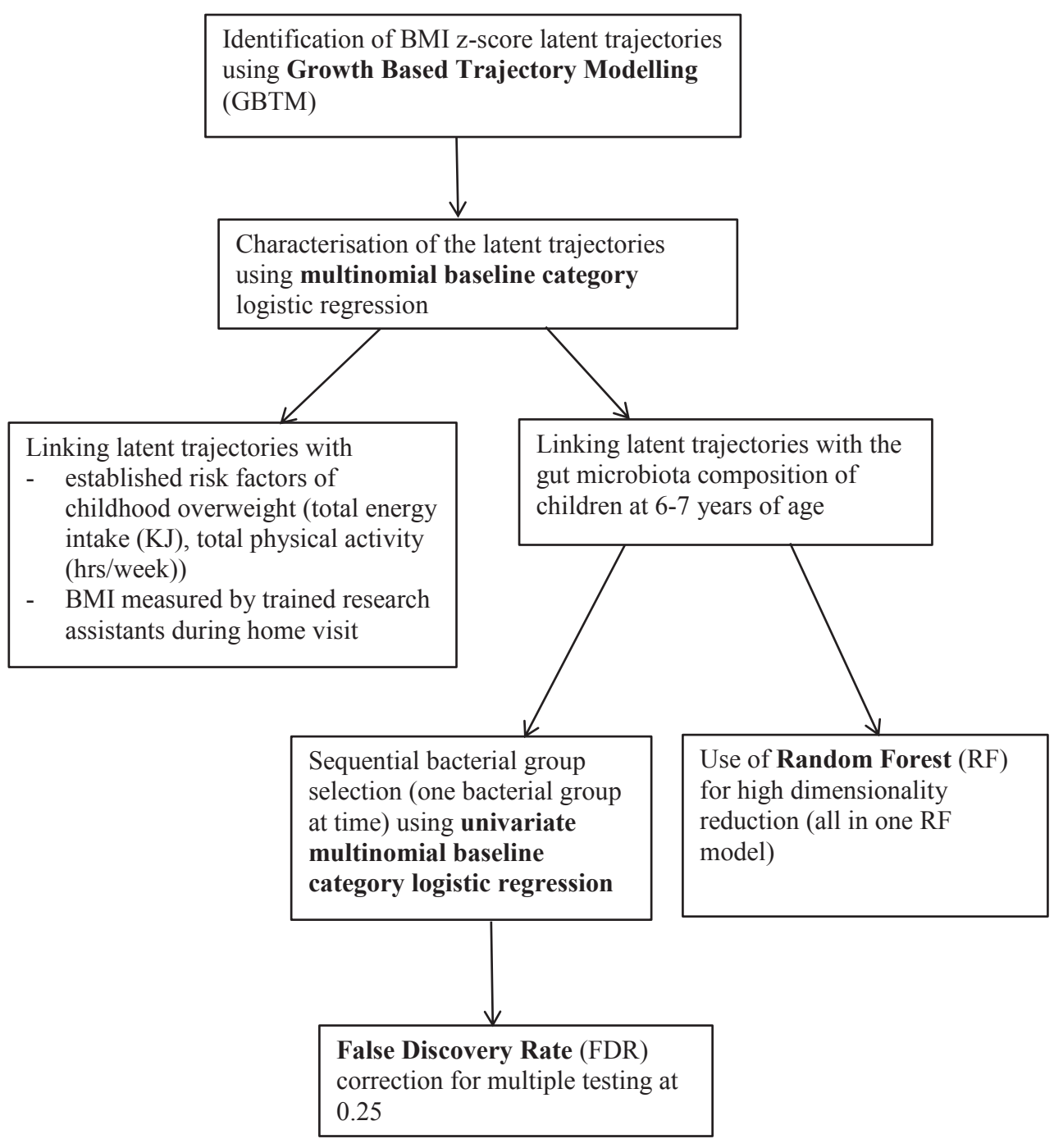

Figure 2. Schematic overview of methods used for statistical analysis in this present study

\section{Group-Based Trajectory Modelling (GBTM)}

Distinctive BMI z-score developmental trajectory patterns across time-point 1 to timepoint 4 were identified by fitting a group-based trajectory model also known as latent class growth analysis or semi-parametric finite mixture modelling (shown in Figure 2) ${ }^{21}$ using PROC TRAJ in SAS. ${ }^{22,23}$ This analytical method was developed to identify groups of individuals following a similar pattern of a certain characteristic during a defined follow-up period. Compared to the traditional latent growth curve modelling which assumes the random parameters to be normally distributed, group-based trajectory modelling assumes a number of discrete underlying groups in the population with each having its own estimated population prevalence, intercept (starting BMI z-scores value) and slope (i.e. the change of BMI z-scores across time points). ${ }^{21}$ Model selection followed a two-step approach: first the number of latent trajectories was established (class-enumeration), and then the order of the polynomials affecting the trajectories' level and shape was determined (given 4 time-points, polynomials up to cubic order were considered). ${ }^{12,21}$ To assess class-enumeration we employed a supportive R-code that compiles several fit-indices for several models with different number of latent classes into automated graphical displays (Fit-criteria Assessment Plots - F-CAP). ${ }^{24}$ Modeladequacy indices ${ }^{11}$ were the Bayesian Information Criterion (BIC), Akaike Information Criterion (AIC), the average posterior probability of assignment (APPA), odds of correct classification (OCC), mismatch between estimated and assigned group probabilities, standard deviation of group membership probabilities (SD-GMP), and the percentage of individuals estimated to be assigned to the smallest latent group. For the latter, a cutoff point of $1 \%$ was applied.

After obtaining the most appropriate number of trajectories, we carried out stratified analysis by gender by applying the final model to both strata. They were similar in their trajectory shapes but differed in their trajectory group proportions. Hence, due to the small sample size and to increase power, further analysis was performed without stratifying for gender. After determining the number of latent trajectories, children were assigned to one of the uncovered latent classes, based on the maximum posterior probability of assignment. ${ }^{21}$ This latent trajectory classification was used as the outcome for subsequent model validation. Multinomial baseline-category logistic regression models were fitted to examine whether the latent trajectories corresponded with established risk factors for childhood overweight (physical activity, total energy intake, and BMI z-scores measured at home visit). In addition, several studies have indicated a lower richness/diversity of the gut bacterial communities in subjects with obesity and overweight compared to normal weight individuals. ${ }^{25-27}$ We therefore examined the association between microbial richness and diversity and BMI z-score trajectories. 


\section{Random forest}

Random Forest (RF), a supervised machine learning technique which is well-suited for large data sets with many features, ${ }^{28}$ was used to identify bacterial groups that differentiate gut microbiota composition in children at age 6-7 years with regards to the four BMI z-scores trajectories generated. RF in principle allows determining nonlinear relationships and combinatorial relations of bacterial groups (e.g. a combination of two bacterial groups better separates classes than either bacterial group on its own) with the four BMI z-score trajectories. RF implemented in the statistical programming $\mathrm{R}$ package, randomFores $\mathrm{t}^{29}$ was used as described earlier ${ }^{30}$ where a classification forest was trained with 500 decision trees each. By default, RF trains a particular tree based on $63 \%$ of the samples and uses the remaining $37 \%$ of the samples to determine its classification accuracy. In this study, implementation of RF feature elimination allowed removing features irrelevant or even confusing to the classification to (i) reduce the number of features and (ii) potentially reduce the classification error of the dataset with reduced numbers of features.

\section{Multinomial baseline-category logistic regression}

To compare the performance of RF in identifying potential bacterial groups among the 130 that can potentially discriminate between the different classes of the trajectories, we performed a univariate analysis of each microbial group. This was done by fitting a univariate multinomial logistic regression model to obtain p-values for each bacterial group. To correct for multiple testing (adjusting p-values for the number of hypothesis tests performed), we applied the false discovery rate (FDR) approach of BenjaminiHochberg using PROC MULTEST in SAS. ${ }^{31}$ In order not to miss out important microbial groups which could be associated with the trajectory groups we decided to consider a 25\% (0.25) FDR for the adjusted p-values. ${ }^{32}$ This is because more traditional levels such as 0.05 can fail in identifying relevant microbial groups in exploratory analyses such as these. ${ }^{33}$

Except for RF, all analyses were conducted using SAS V.9.3 (SAS Institute, Cary, North Carolina, USA). The statistical significance level was set to $\alpha<0.05$.

\section{Results}

A total of 295 children were eligible for analysis (Figure 1). Characteristics of the study population and across the different trajectories are presented as means and standard deviation (SD) for continuous variables or as absolute numbers and percentages for categorical variables (Table 1). In the present study, BMI z-score measurements were available for $212(72 \%)$ children at time-point 1, 190 (64\%) at time-point 2, $224(76 \%)$ at time-point 3 and $245(83 \%)$ at time-point 4 . The model fit statistics for GBTM to identify the optimal number of distinct trajectories of BMI z-scores in the present study
Fit-Criteria Assessment Plots

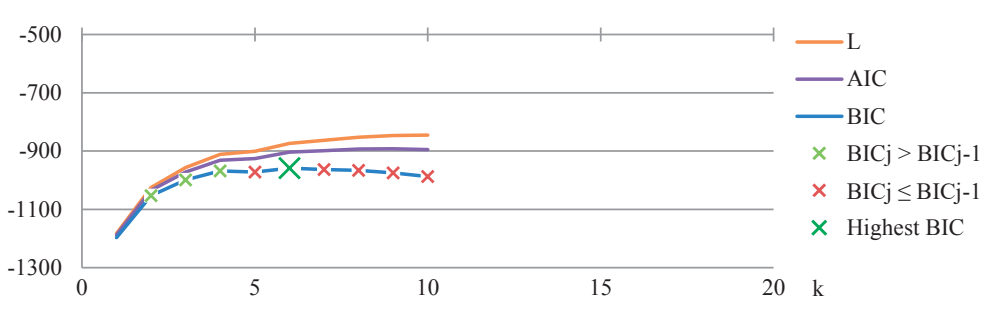

Akaike's information criterion, Bayesian information criterion and Likelihood

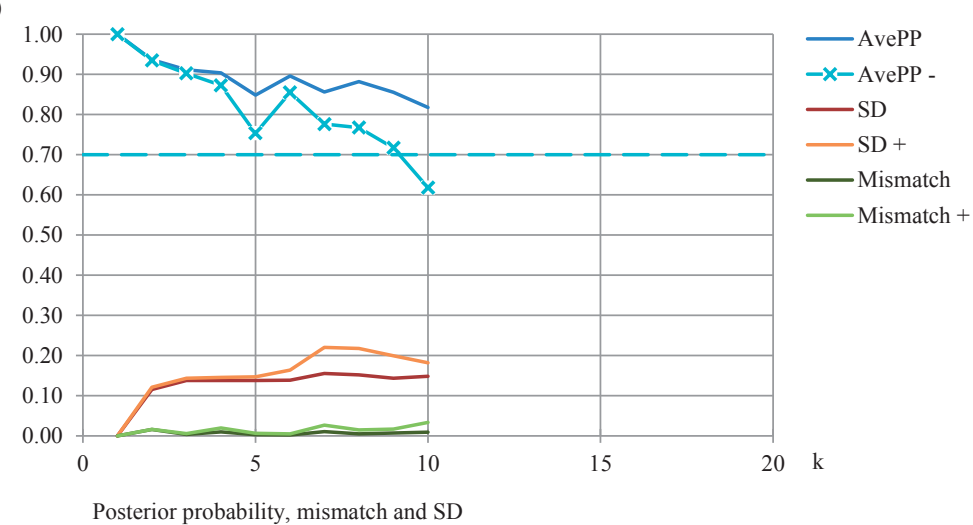

c)

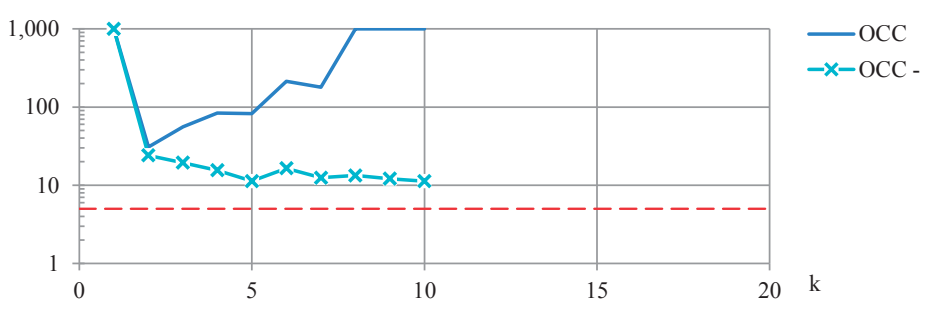

Odds of correct classification

d)

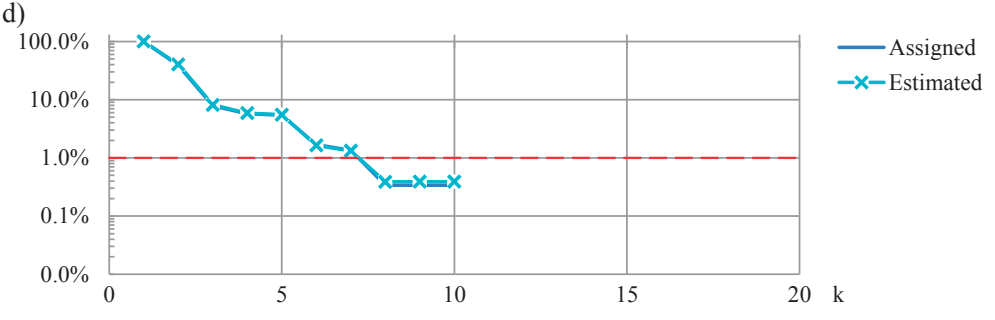

Percentage of individuals belonging to the smallest group

Figure 3. From a to d; AIC, BIC (calculated as; BIC $=\log (\mathrm{L})-\mathrm{p} \cdot \log (\mathrm{N}))$ and L (a); APPA, mismatch and SD (b); OCC (c) and percentage of individuals estimated to be assigned to the smallest group (d). Ten models for BMI $\mathrm{z}$-score developmental pattern were fitted ( $\mathrm{x}$-axis). The number of latent groups, $\mathrm{k}=4$ was selected. 
are presented in Figure 3 (a to d). According to the BIC criterion, which is the most commonly applied, the best-fit model was the one with six trajectories (Supplementary Figure 1). However, in order to obtain a reasonable number of children in each trajectory group and to improve the power for subsequent analysis, we decided to use the more parsimonious four-group trajectory model. The four group model also performed well on the other model adequacy indices: the (minimum) APPA of the latent groups was 0.80 (Figure 3b), well above the acceptability threshold of 0.70 , and OCC was above 10 (Figure 3c), again much larger than the acceptability threshold of 5 . The proportion of individuals belonging to the smallest group among the trajectory groups is illustrated in Figure 3d.

Based on the highest posterior probability of assignment, children were classified into one of these four groups ( $n=46,15.5 \%$ for the first trajectory group; $n=130,44.1 \%$ for the second group; $\mathrm{n}=101,34.4 \%$ for the third group; and $\mathrm{n}=18$, and $6.1 \%$ for the fourth group (Figure 4)). In labelling the trajectories, the following cut-offs were considered as z-scores; underweight (BMI z-scores<-1.64), healthy or normal weight (BMI z-scores 1.64 and 1.03 ), and overweight (BMI $z$-scores $\geq 1.04$ ). These cut-offs correspond to respectively the $<5^{\text {th }}$ percentile, $5^{\text {th }}$ to $85^{\text {th }}$ percentiles, and $\geq 85^{\text {th }}$ percentile, respectively, of the World Health Organisation reference population. ${ }^{34}$ Trajectory 1 consisted of children who were underweight over the entire follow-up period; hence this group was labelled as "underweight". The BMI z-score values for trajectories 2 and 3 during the period of follow-up were all within the normal range for healthy weight with a BMI range between -1.64 and 1.04; hence these groups were labelled as, "low-normal weight" and "high-normal weight" groups, respectively. Finally, the fourth trajectory group represents children who consistently had BMI z-scores above the cut-off for overweight throughout the follow-up period and was therefore characterized as the "overweight" group.

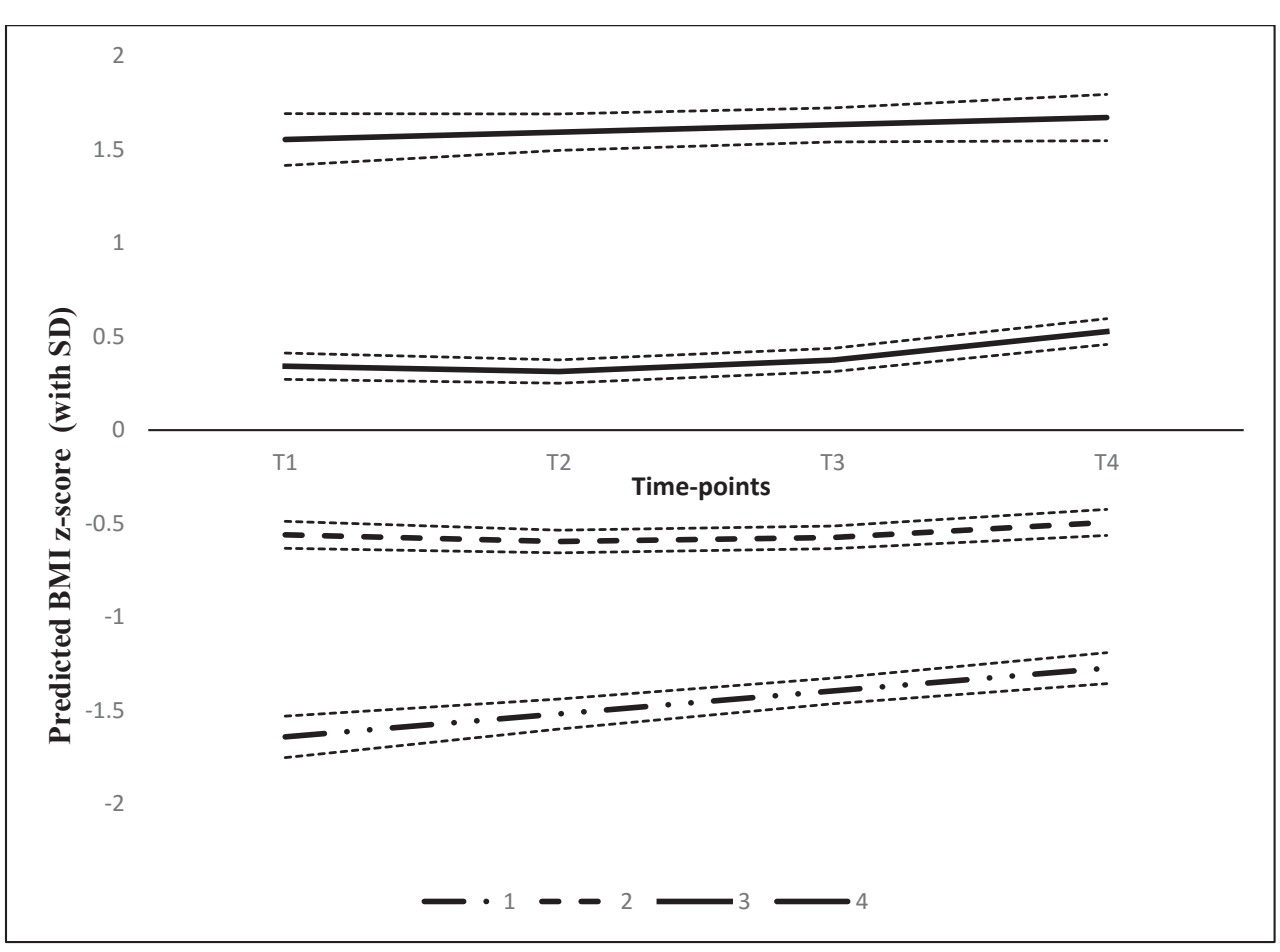

\begin{tabular}{|c|c|c|c|c|}
\hline \multirow[b]{2}{*}{$\begin{array}{l}\text { Trajectories: } \\
\text { Size (\%) }\end{array}$} & \multicolumn{4}{|c|}{ Time-point } \\
\hline & $\begin{array}{c}\mathrm{T} 1 \\
\text { Observed mean } \\
\pm \mathrm{SD}^{*}\end{array}$ & $\begin{array}{c}\mathrm{T} 2 \\
\text { Observed mean } \\
\pm \mathrm{SD}^{*}\end{array}$ & $\begin{array}{c}\mathrm{T} 3 \\
\text { Observed mean } \\
\pm \mathrm{SD}^{*}\end{array}$ & $\begin{array}{c}\mathrm{T} 4 \\
\text { Observed mean } \\
\pm \mathrm{SD}^{*}\end{array}$ \\
\hline 1: 146 (15.5) & $-1.63 \pm 0.66$ & $-1.60 \pm 0.53$ & $-1.43 \pm 0.61$ & $-1.27 \pm 0.67$ \\
\hline 2: 130 (44.1) & $-0.56 \pm 0.44$ & $-0.57 \pm 0.41$ & $-0.57 \pm 0.49$ & $-0.51 \pm 0.43$ \\
\hline 3: 101 (34.3) & $0.35 \pm 0.47$ & $0.35 \pm 0.50$ & $0.36 \pm 0.50$ & $0.57 \pm 0.45$ \\
\hline 4: 18 (6.1) & $1.72 \pm 0.51$ & $1.51 \pm 0.48$ & $1.67 \pm 0.47$ & $1.72 \pm 0.28$ \\
\hline
\end{tabular}

Figure 4: BMI z-scores trajectories over 4 time periods. 1= underweight; 2 = Low normal weight group; 3 = High normal weight group; and $4=$ overweight. Dotted lines below and above each trajectory line represent the lower and high $95 \%$ confidence bands respectively.
abeighted

Means and SDs for trajectories at each time point calculated from the raw (original) data 
As compared to the other trajectories, the overweight group appeared to have more male children (Table 1). Birthweight of the children appeared to increase across the four trajectories. Mothers from the two normal-weight trajectories appeared to be more often highly educated compared to the underweight and overweight group. As expected, the average BMI based upon height and weight measurements by trained research assistants around the time of faecal sampling corresponded to the respective, questionnairebased, latent trajectories (Table 1). Total physical activity was lower in children in the

\section{Table 1. Baseline characteristics of study participants in the present study across} trajectories

\begin{tabular}{|c|c|c|c|c|c|}
\hline & $\begin{array}{c}\text { Study popu- } \\
\text { lation } \\
\mathrm{N}=295^{\mathrm{a}} \\
\text { Mean } \pm \mathrm{SD}^{\mathrm{b}}\end{array}$ & $\begin{array}{l}\text { Underweight } \\
\text { trajectory } \\
N=46 \\
\text { Mean } \pm S D^{b}\end{array}$ & $\begin{array}{c}\text { Low-normal } \\
\text { trajectory } \\
N=130 \\
\text { Mean } \pm S^{b}\end{array}$ & $\begin{array}{l}\text { High-normal } \\
\text { trajectory } \\
\mathrm{N}=101 \\
\text { Mean } \pm \mathbf{S D}^{\mathrm{b}}\end{array}$ & $\begin{array}{c}\text { Overweight } \\
\text { Trajectory } \\
N=18 \\
\text { Mean } \pm S D^{b}\end{array}$ \\
\hline \multicolumn{6}{|l|}{ Gender: n (\%) } \\
\hline Male & $148(50.2)$ & $21(45.7)$ & $70(53.8)$ & 45 (44.6) & $11(61.1)$ \\
\hline Female & $147(49.8)$ & $25(54.3)$ & $60(46.2)$ & $56(55.4)$ & $7(38.9)$ \\
\hline \multicolumn{6}{|l|}{$\begin{array}{l}\text { Maternal educational } \\
\text { level: } \mathrm{n}(\%)\end{array}$} \\
\hline Low & $21(7.2)$ & $2(4.8)$ & $8(6.3)$ & $11(11.0)$ & $0(0.0)$ \\
\hline Middle & $113(38.8)$ & $18(42.9)$ & $50(39.4)$ & $36(36.0)$ & $9(60.0)$ \\
\hline High & $157(54.0)$ & $22(52.4)$ & $69(54.3)$ & $53(53.0)$ & $6(40.0)$ \\
\hline Birth weight (g) & $3605 \pm 466$ & $3337 \pm 441$ & $3583 \pm 447$ & $3728 \pm 492$ & $3761 \pm 443$ \\
\hline \multicolumn{6}{|l|}{$\begin{array}{l}\text { Variables used for validat- } \\
\text { ing trajectories }\end{array}$} \\
\hline BMI z-score at home visit & $-0.2 \pm 0.9$ & $-1.1 \pm 0.5$ & $-0.5 \pm 0.5$ & $0.4 \pm 0.6$ & $1.7 \pm 0.5$ \\
\hline Total energy intake (KJ) & $6180 \pm 1217$ & $6040 \pm 1261$ & $6018 \pm 1191$ & $6310 \pm 1170$ & $7046 \pm 1220$ \\
\hline $\begin{array}{l}\text { Total physical activity } \\
\text { (hrs/week) }\end{array}$ & $9.4 \pm 4.5$ & $7.8 \pm 3.6$ & $9.2 \pm 4.4$ & $10.4 \pm 4.7$ & $9.6 \pm 4.8$ \\
\hline $\begin{array}{l}\text { Age at faecal sample } \\
\text { collection (months) }\end{array}$ & $87.9 \pm 9.6$ & $86.9 \pm 7.6$ & $90.0 \pm 10.1$ & $86.6 \pm 9.6$ & $90.4 \pm 8.9$ \\
\hline \multicolumn{6}{|l|}{ Exposure Variables } \\
\hline Richness & $6.2 \pm 1.0$ & $5.8 \pm 1.3$ & $6.4 \pm 1.0$ & $6.2 \pm 0.9$ & $5.8 \pm 0.8$ \\
\hline Diversity & $5.9 \pm 0.2$ & $5.8 \pm 0.3$ & $5.9 \pm 0.2$ & $5.9 \pm 0.1$ & $5.8 \pm 0.2$ \\
\hline \multicolumn{6}{|l|}{$\begin{array}{l}\text { Time of last antibiotic } \\
\text { course prior to home visit: } \\
\mathrm{n}(\%)\end{array}$} \\
\hline $\begin{array}{l}\text { No antibiotic use in the } \\
\text { previous year }\end{array}$ & $248(85.2)$ & $36(80.0)$ & $118(90.8)$ & $81(81.8)$ & $13(72.2)$ \\
\hline Greater than 4 weeks ago & $36(12.4)$ & $6(13.3)$ & $11(8.4)$ & $15(15.2)$ & $4(22.2)$ \\
\hline Less than 4 weeks ago & $7(2.4)$ & $3(6.7)$ & $1(0.8)$ & $3(3.0)$ & $1(5.6)$ \\
\hline
\end{tabular}

underweight group. In the overweight group, total energy intake was higher compared to the other three trajectories (Table 1). The distributions of BMI at home-visit, total physical activity and energy intake across the 4 trajectories are further illustrated in Supplementary Figure $2(\mathrm{a}-\mathrm{c})$.

Associations between these three variables with childhood BMI z-score trajectories are presented in Table 2. Taking the high-normal weight trajectory group as the reference group, an increase in BMI z-scores measured at baseline during home visit as well as an increase in physical activity were both associated with a lower likelihood of falling into the underweight ( $\mathrm{p}=<0.0001$ for BMI $\mathrm{z}$-score and $\mathrm{p}=0.002$ for physical activity) or low-normal weight trajectories $(\mathrm{p}=<0.0001$ and $\mathrm{p}=0.047$, respectively, Table 2). As expected, an increase in total energy intake was associated with a lower likelihood of falling into the underweight and low-normal weight group compared to the highnormal weight reference group. This only approached borderline significance for the low-normal weight group $(\mathrm{p}=0.066)$. An increase in BMI measured at home visit as well as an increase in total energy intake was associated with a higher likelihood of falling in the overweight trajectory $(\mathrm{p}=<0.0001$, and 0.026 , respectively).

Considering variables characterising the gut microbiota, an increase in bacterial diversity was associated with a substantially lower likelihood of being in either the underweight (adjOR 0.09; 95\%CI 0.01 to 0.64 ) or in the overweight trajectory (adjOR 0.06; 95\%CI 0.00 to 0.84 ) (Table 2). An increase in bacterial richness was associated with a slightly lower likelihood of being in the underweight trajectory (borderline: adjOR $0.71 ; 95 \% \mathrm{CI}$ 0.50 to 1.01 ) compared to the high-normal weight trajectory. Altogether this indicates that both children in the underweight and overweight trajectories are characterised by a lower microbial diversity. 
Table 2: Multinomial (baseline category) logistic regression results for the association of overweight-related factors, bacterial richness and diversity with BMI z-score trajectories

\begin{tabular}{|c|c|c|c|}
\hline & Trajectory group & OR $[95 \% \mathrm{CI}]^{*}$ & P-value \\
\hline \multicolumn{4}{|l|}{ Validation parameter } \\
\hline BMI z-scores at home visit & $\begin{array}{l}\text { Underweight } \\
\text { Low-normal weight } \\
\text { High-normal weight } \\
\text { Overweight }\end{array}$ & $\begin{array}{c}0.002[<0.001 \text { to } 0.01] \\
0.02[0.01 \text { to } 0.05] \\
1 \text { (reference) } \\
62.97[10.29 \text { to } 385.53]\end{array}$ & $\begin{array}{l}<.0001 \\
<.0001 \\
<.0001\end{array}$ \\
\hline Total energy intake $(\mathrm{KJ} / \text { day })^{\mathrm{r}}$ & $\begin{array}{c}\text { Underweight } \\
\text { Low-normal weight } \\
\text { High-normal weight } \\
\text { Overweight }\end{array}$ & $\begin{array}{c}0.30[0.05 \text { to } 1.95] \\
0.28[0.07 \text { to } 1.09] \\
1 \text { (reference) } \\
18.59[1.41 \text { to } 244.74]\end{array}$ & $\begin{array}{l}0.212 \\
0.066 \\
0.026\end{array}$ \\
\hline Total physical activity (hrs/week) & $\begin{array}{c}\text { Underweight } \\
\text { Low-normal weight } \\
\text { High-normal weight } \\
\text { Overweight }\end{array}$ & $\begin{array}{c}0.87[0.79 \text { to } 0.95] \\
0.94[0.89 \text { to } 1.00] \\
1 \text { (reference) } \\
0.96[0.86 \text { to } 1.07]\end{array}$ & $\begin{array}{l}0.002 \\
0.047 \\
0.481\end{array}$ \\
\hline \multicolumn{4}{|l|}{ Exposure variables } \\
\hline Diversity & $\begin{array}{c}\text { Underweight } \\
\text { Low-normal weight } \\
\text { High-normal weight } \\
\text { Overweight }\end{array}$ & $\begin{array}{c}0.09[0.01 \text { to } 0.64] \\
1.92[0.37 \text { to } 10.05] \\
1 \text { (reference) } \\
0.06[0.005 \text { to } 0.84]\end{array}$ & $\begin{array}{l}0.016 \\
0.438 \\
0.036\end{array}$ \\
\hline Richness $^{\Psi}$ & $\begin{array}{c}\text { Underweight } \\
\text { Low-normal weight } \\
\text { High-normal weight } \\
\text { Overweight }\end{array}$ & $\begin{array}{c}0.71[0.50 \text { to } 1.01] \\
1.22[0.93 \text { to } 1.60] \\
1 \text { (reference) } \\
0.71[0.41 \text { to } 1.17] \\
\end{array}$ & $\begin{array}{l}0.055 \\
0.150 \\
0.179 \\
\end{array}$ \\
\hline
\end{tabular}

Odds ratio $\left((O R)=e^{(\beta)}\right)$ with $95 \%$ confidence intervals $(95 \% \mathrm{CI})$ from multinomial logistic regression analysis. For independent variables measured on the continuous scale ORs should be interpreted as, per unit increase in the independent variable.

${ }^{r}$ Analyzed in its standardised form by dividing "Total energy intake" for each child by the standard deviation of the variable

"Analysed in its standardised form by dividing "microbial richness" for each child by the standard deviation of the variable.

After performing univariate multinomial regression analysis to select bacterial groups (amongst 130) that were associated with the four trajectories, we obtained 17 bacteria groups for which the association was statistically significant. Upon controlling for multiple testing using FDR with a cut-off of less than 0.25 only 10 microbial groups (Burkholderia, Sutterella wadsworthia et rel., Eubacterium hallii et rel., Clostridium nexile et rel., Butyrivibrio crossotus et rel., Bacteroides vulgatus et rel., Bacteroides fragilis et rel., Lachnospira pectinoschiza et rel., Clostridium orbiscindens et rel., and Prevotella tannerae et rel., Table 3) out of the 17 remained statistically significant. The direction of the associations is illustrated in Supplementary Table 1.
Table 3. Bacterial groups that remained statistically significantly associated with BMI z-score trajectories after FDR correction*

\begin{tabular}{lcc}
\hline Genus-like level bacterial group & Raw p-value & FDR adjusted P-value \\
\hline Bacteroides fragilis et rel. & 0.0070 & 0.1221 \\
Bacteroides vulgatus et rel. & 0.0069 & 0.1221 \\
Burkholderia & 0.0017 & 0.1056 \\
Butyrivibrio crossotus et rel. & 0.0055 & 0.1221 \\
Clostridium nexile et rel. & 0.0045 & 0.1221 \\
Clostridium orbiscindens et rel. & 0.0110 & 0.1613 \\
Eubacterium hallii et rel. & 0.0024 & 0.1056 \\
Lachnospira pectinoschiza et rel. & 0.0074 & 0.1221 \\
Prevotella tannerae et rel. & 0.0150 & 0.1980 \\
Sutterella wadsworthia et rel. & 0.0019 & 0.1056 \\
\hline
\end{tabular}

Sutterella wadsworthia et rel.

0.0019

* No point estimates available as this is just an overall association summed over the four trajectories. Hence only a p-value is obtained indicating the presence of an association with at least one of the trajectories.

In order to determine microbial taxa (potentially non-linear or combinatorial) that were associated with the four trajectories, we additionally applied the RF machine learning technique. The four latent trajectories were used as classes and the microbial taxa as features. Unfortunately, the average classification error (out of bag error over 100 separate $\mathrm{RF}$ analyses) for this dataset, even after feature elimination, was on average 59.2\%. Due to this high percentage of error, we did not continue with RF analysis of this dataset. 


\section{Discussion}

The heterogeneity in weight development during childhood poses a challenge for researchers to identify and characterise regular or irregular patterns of BMI fluctuations in population-based studies and to relate these patterns to different risk factors in life. Using GBTM, we identified four (latent) subgroups of distinct developmental courses for BMI z-scores measured in children from 6-10 years of age within the KOALA Birth Cohort Study in the Netherlands. These BMI z-score trajectories were characterised as underweight, low-normal weight, high-normal weight, and overweight. Latent trajectories were also found to be associated with the established risk factors of childhood overweight including, physical activity and total energy intake.

The general patterns and number of trajectories identified in our study were consistent with results of several previous studies on populations with a similar age range. ${ }^{35,36}$ Likewise a recent review on BMI trajectories reported the existence of four latent subgroups characterised by high and low trajectories, both relatively stable over time, showing that the group of developmental patterns of BMI differed more in level (different onset between groups) than in shape ${ }^{37}$ Trajectories identified in a previous study using the same statistical methodology revealed that the changes in the developmental patterns only occurred between the ages of 1 and 4 years while no directional changes in patterns occurred between 4 to 10 years of age. ${ }^{10}$ All together the empirical evidence suggest that growth patterns (both in intercept and slope) are more heterogeneous in studies performed before six years of age as compared to studies performed in children above the age of 6 years. Therefore, early infancy (from birth to $1-5$ years) could be considered as the most critical period to monitor childhood weight development.

We found that children with high microbial diversity at baseline had a substantially lower likelihood of belonging to the underweight as well as the overweight trajectories, whereas a borderline significantly lower microbial richness was observed for the underweight children. A healthy gut microbial ecosystem is generally thought to be characterised by high microbial richness and diversity, presumed to indicate a more stable and resilient state of this ecosystem. ${ }^{38}$ A lower richness/diversity of the gut bacterial communities has been reported in malnourished children ${ }^{39}$, subjects with obesity, and overweight as compared to normal weight individuals. ${ }^{25,26}$ Our study is therefore in accordance with previous studies, implying that reported associations of microbial diversity and richness with weight status are also observed when growth trajectories in a population of healthy children are being used.

We are not aware of any previous human study that has attempted to investigate the association between the gut microbiota composition and BMI z-score trajectories in children. We used Random Forests, a supervised machine learning technique, which is a particularly powerful classifier that can exploit non-linear relationships and complex dependencies between bacterial groups. ${ }^{28,29}$ In addition, several studies have shown that RF is very efficient in handling multinomial dependent variables. ${ }^{40-42}$ However, RF failed to identify bacterial candidates of the gut microbiota that could differentiate the four different trajectories. The performance of RF was compared with another classification method known as univariate multinomial baseline-category logit model while controlling for multiple testing using a $25 \%$ FDR. Using this statistical method, we identified ten bacterial groups that were associated with the trajectory groups. Why RF was unable to identify bacterial groups that could differentiate between the trajectories might be due to the fact that our data was unbalanced. The majority of children were allocated to the low-normal and high-normal weight trajectories, whereas the overweight trajectory consisted of only a very small number of children. In such a case, RF tends to train the data in favour of the two normal weight trajectories that include the majority of subjects. Univariate analyses on the other hand consider each bacterial group separately, ignoring any correlations that may exist between bacterial groups, and making use of the entire dataset (i.e. data is not separated into a training and test set). In this explorative study, where we used a relatively lenient FDR cut-off of 0.25 , univariate analysis gave us a list of ten potentially interesting bacterial groups, whereas RF did not.

One of the strengths of the current study is that weight development of a population of healthy children was monitored over time. The availability of variables related to BMI such as physical activity, total energy intake, and BMI z-scores measured by trained nurses during home visit enabled us to evaluate the validity of the generated trajectories. Finally, the use of GBTM to generate different patterns of weight development in children provided a deeper insight into distinct patterns of childhood weight development over a defined period between 6-10 years of age. The identified latent trajectories convey the heterogeneous nature of BMI z-score over time, facilitating their clinical interpretation while relating them to the gut microbiota composition. These trajectories are not real, fixed entities, and should not be interpreted as such (fallacy of reification), but rather as longitudinal features of the data.

Some of the limitations in our study include the relatively small sample size and number of repeated measures over time (only 4 time points) and the fact that the gut microbiota composition of children was only available at a single time-point (baseline). Moreover, for simplicity, we opted for the classify-analyse strategy when linking the identified latent trajectories to the microbiota: first children were classified into one of the extracted trajectories (based on the maximum posterior probability of assignment) and the classes were subsequently treated deterministic in further inferential analyses. 
In conclusion, we identified a total of four BMI z-score trajectories across the ages of 6 to 10 years using GBTM. With this study we illustrated how the identification of unique patterns of childhood growth development by means of GBTM might be used to study the role of the microbiome in weight development within the context of longitudinal studies. This may aid other researchers within this research field to implement such methods.

\section{References}

1. Kotzampassi K, Giamarellos-Bourboulis EJ, Stavrou G. Obesity as a consequence of gut bacteria and diet interactions. ISRN obesity 2014; 2014: 651895.

2. Rodriguez JM, Murphy K, Stanton C, Ross RP, Kober OI, Juge N et al. The composition of the gut microbiota throughout life, with an emphasis on early life. Microbial ecology in health and disease 2015; 26: 26050.

3. Arumugam M, Raes J, Pelletier E, Le Paslier D, Yamada T, Mende DR et al. Enterotypes of the human gut microbiome. Nature 2011; 473: 174-80.

4. Koleva PT, Bridgman SL, Kozyrskyj AL. The infant gut microbiome: evidence for obesity risk and dietary intervention. Nutrients 2015; 7: 2237-60.

5. Vael C, Verhulst SL, Nelen V, Goossens H, Desager KN. Intestinal microflora and body mass index during the first three years of life: an observational study. Gut pathogens 2011; 3: 8 .

6. White RA, Bjornholt JV, Baird DD, Midtvedt T, Harris JR, Pagano M et al. Novel developmental analyses identify longitudinal patterns of early gut microbiota that affect infant growth. PLoS computational biology 2013; 9: e1003042.

7. Scheepers LE, Penders J, Mbakwa CA, Thijs C, Mommers M, Arts IC. The intestinal microbiota composition and weight development in children: the KOALA Birth Cohort Study. International journal of obesity (2005) 2015; 39: $16-$ 25.

8. van Rossem L, Wijga AH, Brunekreef B, de Jongste JC, Kerkhof M, Postma DS et al. Overweight in infancy: which pre- and perinatal factors determine overweight persistence or reduction? A birth cohort followed for 11 years. Annals of nutrition \& metabolism 2014; 65: 211-9.

9. Giles LC, Whitrow MJ, Davies MJ, Davies CE, Rumbold AR, Moore VM. Growth trajectories in early childhood, their relationship with antenatal and postnatal factors, and development of obesity by age 9 years: results from an Australian birth cohort study. International journal of obesity (2005) 2015; 39: 1049-56.

10. Ziyab AH, Karmaus W, Kurukulaaratchy RJ, Zhang H, Arshad SH. Developmental trajectories of Body Mass Index from infancy to 18 years of age: prenatal determinants and health consequences. Journal of epidemiology and community health 2014; 68: 934-41.

11. Nagin D. Group-based modeling of development, Harvard University Press, 2005.

12. Nagin DS, Odgers CL. Group-based trajectory modeling in clinical research. Annual Review of Clinical Psychology 2010; 6: 109-138.

13. Kummeling I, Thijs C, Penders J, Snijders BE, Stelma F, Reimerink J et al. Etiology of atopy in infancy: the KOALA Birth Cohort Study. Pediatric allergy and immunology : official publication of the European Society of Pediatric Allergy and Immunology 2005; 16: 679-84. 
14. Zoetendal EG, Heilig HG, Klaassens ES, Booijink CC, Kleerebezem M, Smidt H et al. Isolation of DNA from bacterial samples of the human gastrointestinal tract. Nat Protoc 2006; 1: 870-3.

15. Salonen A, Nikkila J, Jalanka-Tuovinen J, Immonen O, Rajilic-Stojanovic M, Kekkonen RA et al. Comparative analysis of fecal DNA extraction methods with phylogenetic microarray: effective recovery of bacterial and archaeal DNA using mechanical cell lysis. J Microbiol Methods 2010; 81: 127-34.

16. Rajilic-Stojanovic M, Heilig HG, Molenaar D, Kajander K, Surakka A, Smidt H et al. Development and application of the human intestinal tract chip, a phylogenetic microarray: analysis of universally conserved phylotypes in the abundant microbiota of young and elderly adults. Environmental microbiology 2009; 11: 1736-51.

17. Lahti L, Salojarvi J, Salonen A, Scheffer M, de Vos WM. Tipping elements in the human intestinal ecosystem. Nature communications 2014; 5: 4344.

18. Jari Oksanen F, Kindt R, Legendre P, Minchin PR, O'Hara R, Simpson GL et al. vegan: Community Ecology Package. R package version 2.0-10. In, 2013.

19. Fredriks AM, van Buuren S, Wit JM, Verloove-Vanhorick SP. Body index measurements in 1996-7 compared with 1980. Archives of disease in childhood 2000; 82: 107-12.

20. Voedingsstoffenbestand SN. Nederlands voedingsstoffenbestand 2001 (Netherlands Food Composition Table 2001). Den Haag, the Netherlands: Voedingscentrum 2001.

21. Nagin DS. Analyzing developmental trajectories: a semiparametric, group-based approach. Psychological methods 1999; 4: 139.

22. Jones BL, Nagin DS, Roeder K. A SAS procedure based on mixture models for estimating developmental trajectories. Sociological methods \& research 2001; 29: 374-393.

23. Jones BL, Nagin DS. Advances in group-based trajectory modeling and an SAS procedure for estimating them. Sociological Methods \& Research 2007; 35: $542-$ 571.

24. Klijn SL, Weijenberg MP, Lemmens P, van den Brandt PA, Lima Passos V. Introducing the fit-criteria assessment plot - A visualisation tool to assist class enumeration in group-based trajectory modelling. Statistical methods in medical research 2015.

25. Le Chatelier E, Nielsen T, Qin J, Prifti E, Hildebrand F, Falony G et al. Richness of human gut microbiome correlates with metabolic markers. Nature 2013; 500: 541-6.

26. Verdam FJ, Fuentes S, de Jonge C, Zoetendal EG, Erbil R, Greve JW et al. Human intestinal microbiota composition is associated with local and systemic inflammation in obesity. Obesity (Silver Spring, Md.) 2013; 21: E607-15.
27. Yasir M, Angelakis E, Bibi F, Azhar EI, Bachar D, Lagier JC et al. Comparison of the gut microbiota of people in France and Saudi Arabia. Nutrition \& diabetes 2015; 5: e153.

28. Breiman L. Random forests. Machine learning 2001; 45: 5-32.

29. Liaw A, Wiener M. Classification and regression by randomForest. $R$ news 2002; 2: $18-22$.

30. Bayjanov JR, Molenaar D, Tzeneva V, Siezen RJ, van Hijum SA. PhenoLink--a web-tool for linking phenotype to $\sim$ omics data for bacteria: application to genetrait matching for Lactobacillus plantarum strains. BMC genomics 2012; 13: 170.

31. Benjamini Y, Hochberg Y. Controlling the false discovery rate: a practical and powerful approach to multiple testing. Journal of the Royal Statistical Society. Series $B$ (Methodological) 1995: 289-300.

32. Hosmer DW, Lemeshow S. Applied regression analysis. New York, John Willey 1989.

33. Mickey RM, Greenland S. The impact of confounder selection criteria on effect estimation. American journal of epidemiology 1989; 129: 125-37.

34. Barlow SE. Expert committee recommendations regarding the prevention, assessment, and treatment of child and adolescent overweight and obesity: summary report. Pediatrics 2007; 120 Suppl 4: S164-92.

35. Magee CA, Caputi P, Iverson DC. Identification of distinct body mass index trajectories in Australian children. Pediatric obesity 2013; 8: 189-98.

36. Carter MA, Dubois L, Tremblay MS, Taljaard M, Jones BL. Trajectories of childhood weight gain: the relative importance of local environment versus individual social and early life factors. PloS one 2012; 7: e47065.

37. Hejazi S, Dahinten S, Ratner P, Marshall S. Developmental trajectories of weight status in childhood and adolescence. Global Perspectives on Childhood Obesity. Elsevier: London, UK 2011: 21-30.

38. Lozupone CA, Stombaugh JI, Gordon JI, Jansson JK, Knight R. Diversity, stability and resilience of the human gut microbiota. Nature 2012; 489: 220-30.

39. Monira S, Nakamura S, Gotoh K, Izutsu K, Watanabe H, Alam NH et al. Gut microbiota of healthy and malnourished children in bangladesh. Frontiers in microbiology 2011; 2: 228.

40. Maroco J, Silva D, Rodrigues A, Guerreiro M, Santana I, de Mendonca A Data mining methods in the prediction of Dementia: A real-data comparison of the accuracy, sensitivity and specificity of linear discriminant analysis, logistic regression, neural networks, support vector machines, classification trees and random forests. BMC research notes 2011; 4: 299.

41. Chen X, Wang M, Zhang $H$. The use of classification trees for bioinformatics. Wiley interdisciplinary reviews. Data mining and knowledge discovery 2011; 1: 5563. 
42. Calle ML, Urrea V, Boulesteix AL, Malats N. AUC-RF: a new strategy for genomic profiling with random forest. Human heredity 2011; 72: 121-32.

43. Breiman L, Chen C, Liaw A. Using random forest to learn imbalanced data. J. of Machine Learning Research 2004.

44. Ruiz A, Villa N. Storms prediction: Logistic regression vs random forest for unbalanced data. arXiv preprint arXiv:0804.0650 2008.

\section{SUPPLEMENTARY MATERIAL}

Supplementary Table 1. Associations of ten bacterial groups obtained from univariate multinomial logistic regression with BMI trajectories

\begin{tabular}{lcccc}
\hline Bacterial group & Underweight & $\begin{array}{c}\text { Low-normal } \\
\text { weight }\end{array}$ & $\begin{array}{c}\text { High-normal } \\
\text { weight }^{\text {§ }}\end{array}$ & Overweight \\
Bacteroides fragilis et rel. & 0,36 & 0,40 & 0,00 & $-2,57^{*}$ \\
Bacteroides vulgatus et rel. & $-0,34$ & 0,34 & 0,00 & $-1,64^{*}$ \\
Burkhoderia & $2,89^{*}$ & 0,42 & 0,00 & $-5,76^{*}$ \\
Butyrivibrio crossotus et rel. & $-0,35$ & $1,33^{*}$ & 0,00 & $-0,85$ \\
Clostridium nexile et rel. & $-1,91^{*}$ & 0,35 & 0,00 & $-0,02$ \\
Clostridium orbicindens et rel. & $-2,42^{*}$ & $-0,45$ & 0,00 & $-1,02$ \\
Eubacteriun hallii et rel & $-2,56^{*}$ & $-0,35$ & 0,00 & 1,09 \\
Lachnospira pectinoschiza et rel. & $-0,85$ & $1,13^{*}$ & 0,00 & $-0,22$ \\
Prevotella tannerae et rel & $-0,23$ & 0,67 & 0,00 & $-2,05^{*}$ \\
Sutterella wadsworthia et rel. & $2,38^{*}$ & 0,95 & 0,00 & $-1,36$ \\
\hline
\end{tabular}

*Bacterial group significantly associated with each BMI z-score trajectory

Indicates reference category (high-normal weight) with log-odds $\beta$ estimates $=0$

Red colour indicates negative associations

Green colour indicates positive associations 


\section{BMI z-scores Trajectories}

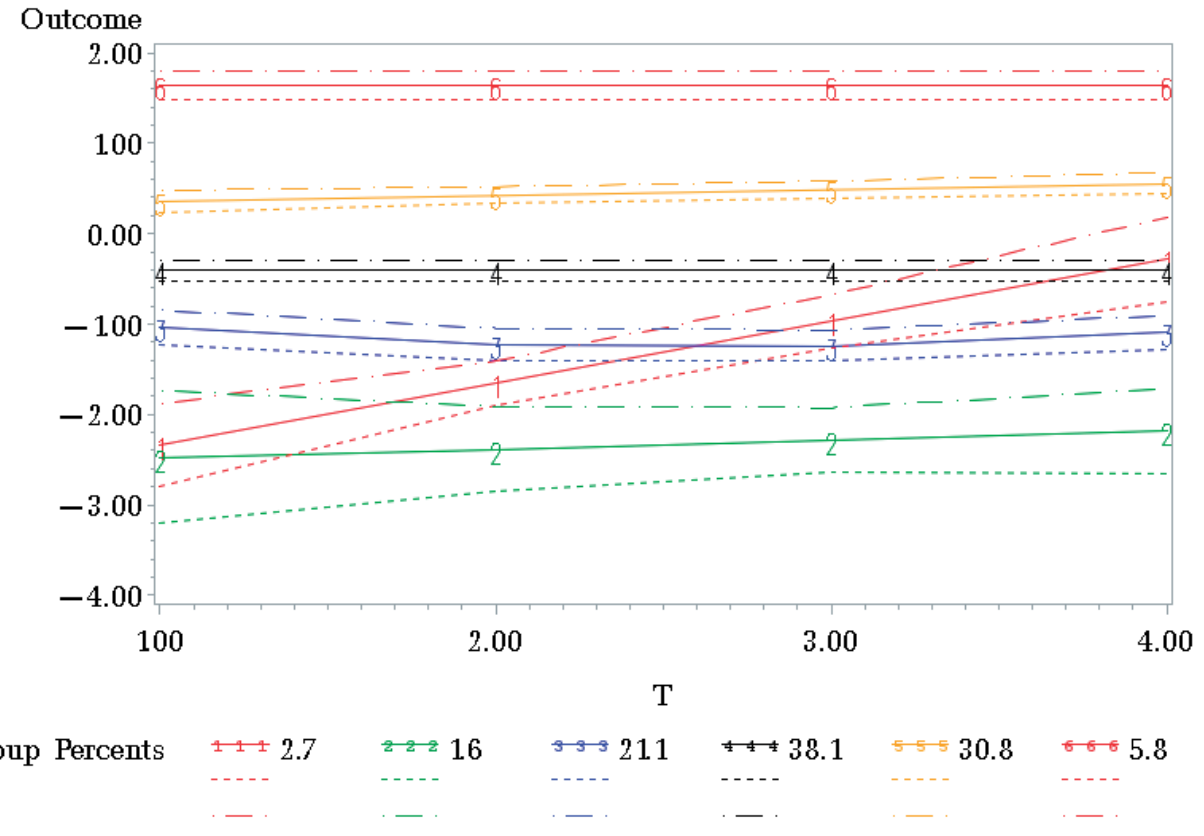

Supplementary Figure 1. Six BMI z-score trajectories
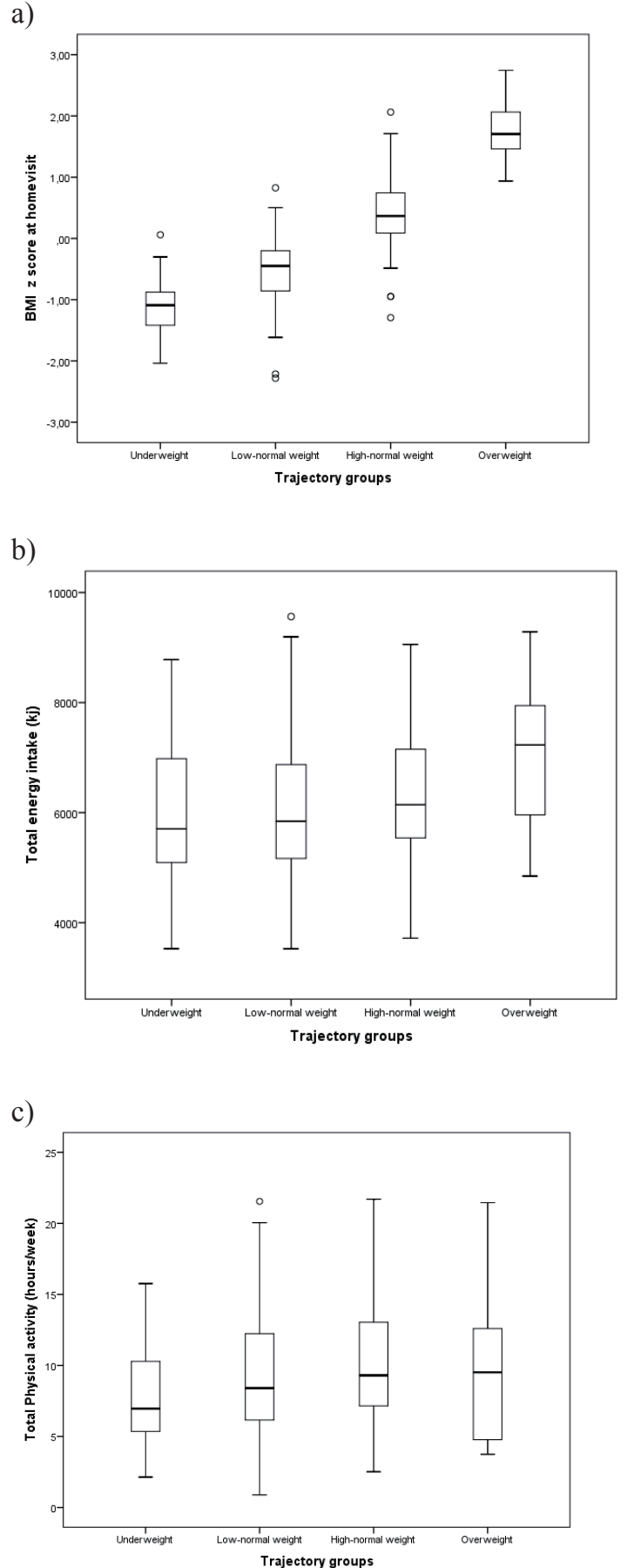

Supplementary Figure 2 Boxplots displaying the distribution of; a) BMI measured by trained research assistants b) total energy intake c) total physical activity across BMI $\mathrm{z}$-score trajectory groups with means $\pm \mathrm{SDs}$, and outlier points. 


\section{CHAPTER 7}

SUMMARY AND GENERAL DISCUSSION 
The main aims of this thesis were to: 1) examine associations between the gut microbiota composition and childhood (over)weight development; 2) examine the impact of childhood exposure to oral antibiotics and (over)weight development; and 3) address the methodological challenge of reducing high dimensional data of the gut microbiota in relation to latent BMI z-scores trajectories. To address these aims, a combination of advanced molecular microbial methods, a well-designed prospective epidemiological study and state-of-the-art biostatistical methods were used. A schematic overview of the main findings in this thesis is presented in Figure 1.

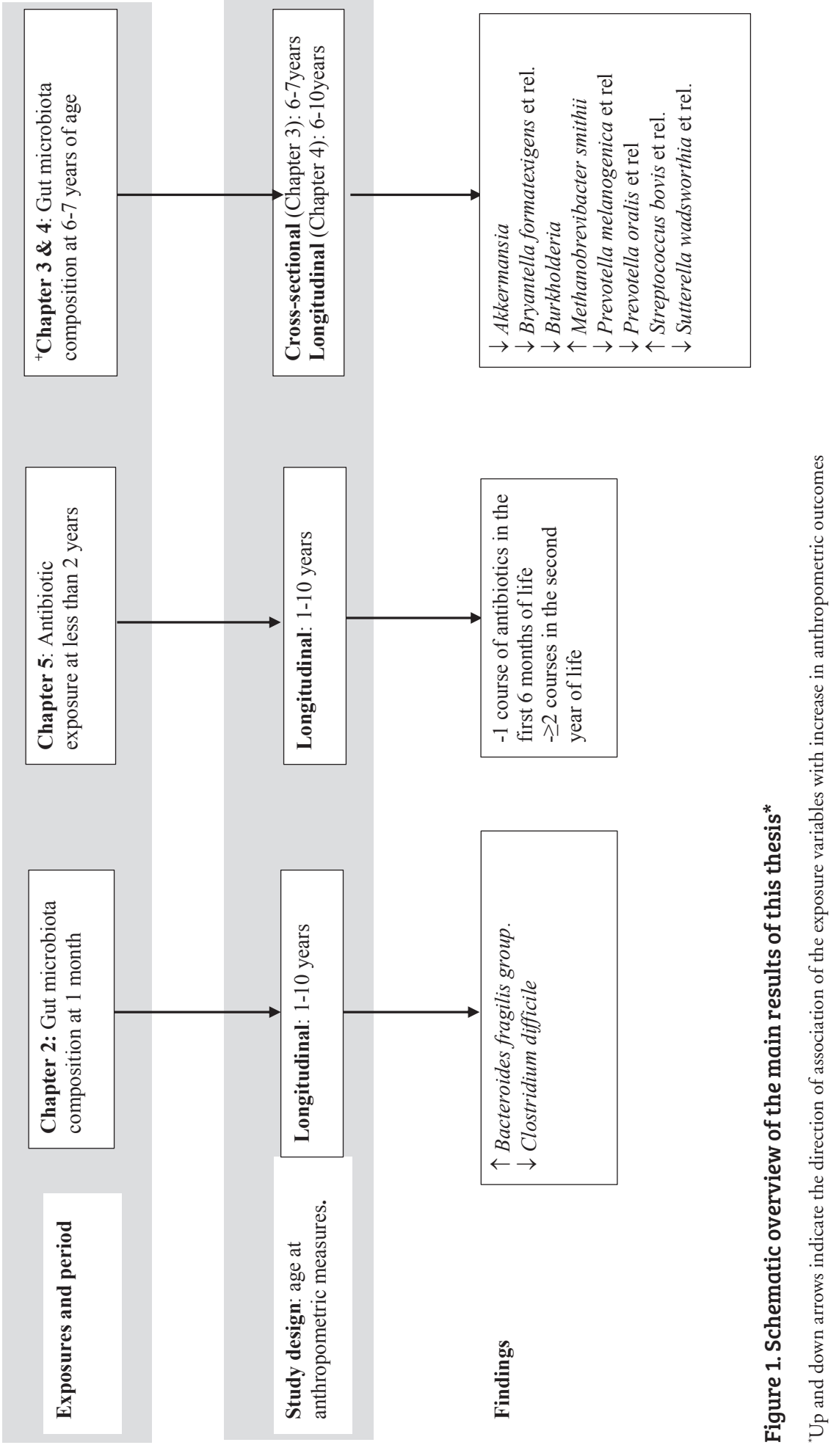




\section{Summary}

In Chapter 2, the association between the intestinal microbiota composition at 1 month of age and childhood weight development, measured repeatedly between the ages of 1 and 10 years, was investigated using data from the KOALA Birth Cohort Study. This cohort consists of two recruitment groups, a group with a conventional lifestyle was recruited from an ongoing prospective cohort study on pregnancy-related pelvic girdle pain (conventional recruitment group) and a second group was recruited through alternative channels, organic food shops, Steiner schools, magazines and anthroposophic doctors and midwives (alternative recruitment group). We found that gut colonization with Bacteriodes fragilis group at one month postpartum in the conventional recruitment group was significantly associated with a higher BMI z-score, but only among infants with a low fibre intake. $B$. fragilis counts in children that were colonized were positively associated with BMI z-score in children from the conventional recruitment group with a high-fibre diet, but negatively among those with a low fibre intake and among children from the alternative recruitment group.

The early infant gut microbiota is susceptible to changes by a number of environmental factors such as mode of delivery, type of infant feeding and antibiotic use. ${ }^{1-4}$ At $2-3$ years of age, an adult-like intestinal microbiota composition is established ${ }^{5-8}$, although maturation of the microbiota may still continue for several years. In Chapter 3, using the HITChip, we comprehensively characterised the gut microbiota composition of children at age 6-7 years, when its composition is assumed to be more resilient. We then investigated the association between the gut microbiota composition at this age in relation to the anthropometric outcomes BMI z-score weight z-score, and overweight. Using Redundancy Data Analysis (RDA), we found that part of the variation in the gut microbiota composition of these children was accounted for by the cumulative abundance of Prevotella melaninogenica et rel., Prevotella oralis et rel., Dialister, and Uncultured clostridiales II (UCII). The anthropometric outcomes and potential confounders explained very little of the variation in the overall microbiota composition. However, the abundances of several specific bacterial groups were associated with the anthropometric outcomes BMI, weight, and overweight. Akkermansia, and Bryantella formatexigens et rel. were found to be consistently associated with all three anthropometric outcomes while Sutterella wadsworthia et rel. was negatively associated with BMI and overweight. With regards to bacterial groups exhibiting a bimodal distribution, higher abundance of UCII was found to be inversely associated with all three outcomes under study while higher abundance of Prevotella (melaninogenica et rel. and oralis et rel.) was inversely associated with overweight.

Taken together, Chapter $\mathbf{2}$ and 3, demonstrate that specific bacterial groups of the gut microbiota are associated with childhood overweight. In chapter 2 only a total of 5 bacterial genera and species were considered whereas in chapter 3 we used the HITChip to carry out an in-depth characterisation of the gut microbiota composition identifying 130 genus-like bacterial groups. Even though both studies considered B. fragilis (at the genus level) in association to childhood over(weight) development, we only found associations for $B$. fragilis group in faecal samples collected at 1 month of age, and these associations were dependent on the level of fibre intake. Due to differences in age at faecal sampling, study design (longitudinal versus cross-sectional), and method of microbial identification, results are not directly comparable. Moreover, Bervoets et al. ${ }^{9}$ suggested that different species within the $B$. fragilis group might be responsible for the seemingly contradictory associations with weight development by showing that more $B$. fragilis was present in individuals suffering from obesity and more $B$. vulgatus in control subjects. Differences in the species composition of the $B$. fragilis group could explain both the opposite findings for the two recruitment groups at the age of 1 month, as well as the absence of an association at school-age.

Considering the fact that, next to bacteria, other microbial groups within the intestinal tract might influence host metabolism and energy balance, in Chapter 4 we examined the presence of archaea (M. smithii and M. stadtmanae) in the faecal samples of 472 children at age 6-7 years in association with childhood weight development. M. smithii, the dominant archaeal species in the human gut, was associated with higher weight z-scores and an increased likelihood of being overweight, with children harbouring the highest levels of this archaeon being at the highest risk. The biological interaction between archaea and bacteria was not investigated. A study by Samuel and Gordon, $2006,{ }^{10}$ actually showed that $M$. smithii played a critical role in facilitating an increased capacity of $B$. thetaiotaomicron to digest polyfructose-containing glycans leading to increased production of short-chain fatty acids (SCFAs) and total liver triglycerides in mice. Mice colonized with B. thetaiotaomicron and Desulfovibrio piger instead of $M$. smithii did not show such an effect. These biological interactions have not yet been investigated in humans and therefore should be considered for future studies.

Antibiotics have been reported as one of the factors affecting the composition of the gut microbiota ${ }^{11-13}$ and have also been reported to be associated with childhood overweight $^{14-17}$. In Chapter 5, we investigated the timing, frequency and type of antibiotic exposure during the first 10 years of life in association with (over)weight across this period in 979 children participating in the KOALA Birth Cohort Study. We found that exposure to a single course of antibiotics in the first 6 months of life, as well as $\geq 2$ courses during the first two years of life were associated with increased weight and height $\mathrm{z}$-scores. These associations were stronger for exposure to -lactam antibiotics. We found no associations between antibiotic exposure beyond the second year of life and childhood weight development. This indicates that early childhood is a critical period where exposure to antibiotics may have most pronounced effects on 
childhood overweight, possibly mediated by microbial perturbations. Our findings support existing evidence from previous studies ${ }^{14-17}$ that early exposure to antibiotics is associated with childhood (over)weight development. Our study is one of the first largescale prospective studies that included information on the timing, frequency and type of antibiotic used during the first 10 years of life, in relation to anthropometric outcomes measured repeatedly over this entire follow-up period.

In the above-mentioned longitudinal studies, we investigated associations of microbial or antibiotic exposures with BMI over time while ignoring the fact that there may be distinct developmental patterns of growth between children. In Chapter 6, we aimed to identify such developmental patterns. Using Group-based trajectory modelling (GBTM), we identified 4 distinct latent BMI z-score trajectories in our study population. Latent trajectories were found to be associated with established risk factors of childhood overweight, including physical activity and total energy intake. Using statistical methods to reduce the high dimensional data of the gut microbiota in relation to these latent trajectories, we identified ten bacterial groups that were associated with the trajectories. This shows that GBTM can be used to summarize complex developmental patterns of children into a single multi-category variable, which facilitates the reduction of high dimensional data in relation to this.

\section{Methodological considerations}

Reliability of faecal samples

Due to the relative ease and non-invasiveness of stool collection, most of the studies on the intestinal microbiota, including ours, have been performed using this sample type. It can be debated whether stool samples are the best sample type to gain insight into the intestinal microbiota since the microbial profile of faeces is substantially different from that of the mucosa, which itself can vary along the length of the gastrointestinal tract. ${ }^{18}$ However, colonic biopsies are more difficult to obtain, which makes collection of biopsies not feasible within the context of large-scale epidemiological studies, especially when involving children. Moreover, patients are required to take laxatives before colonoscopy which may also significantly alter the gut microbiota composition. ${ }^{19}$ It can be assumed that despite all activities that go on along the passage of the intestinal tract, most viable as well as nonviable commensal intestinal bacteria will still be detectable in faeces with molecular methods. However, it is unlikely that analysing microbiota composition in faeces is representative of all important intestinal micro-organisms. Hence, using faeces represents a limitation of most studies on the gut microbiota even though at this point faeces remain the only reliable sample in large non-invasive studies. ${ }^{20}$
Collection and processing of faecal samples

In order to minimise bias and transport time of faecal samples, detailed instructions were sent to parents directing them on how to collect their child's faeces. Upon collection, faecal samples were sent to the laboratory by mail. Issues arise because anaerobic conditions are not maintained during faecal sample collection, transportation and laboratory analysis. This may have led to increased proliferation of certain types of microbes whereas others, especially strictly anaerobes, might die during the course of sample transportation and handling. ${ }^{21}$ However, it is likely that the impact of sample handling and transport on the composition of the samples is less pronounced when molecular methods are used instead of traditional culture techniques, as the non-viable bacteria will still be detected. ${ }^{22}$ It can however not be ruled out that the potential overgrowth of some bacterial species and suppression of others, as well as degradation of bacterial DNA due to transportation could have influenced our results. ${ }^{23}$ In our study the transport time for faecal samples ranged from 1 to 3 days at ambient to room temperature. Several previous studies have shown that the microbial diversity and composition of faecal samples is much more affected by inter-individual differences and biases in molecular techniques rather than differences in short-term storage conditions, including storage for up to 2 weeks at room temperature. ${ }^{24,25}$ The method used for DNA extraction can also introduce bias as samples may contain both organisms that are more easily disrupted, such as gramnegative species, and those that are more difficult to lyse, such as gram-positive species, mycobacteria, and spores. ${ }^{26}$ We have minimised the potential effect of this bias by using a widely used and validated protocol that combines both mechanical and enzymatic disruption. ${ }^{27}$

\section{Temporal variations in microbiota composition}

The studies presented in this thesis were based upon characterization of the faecal microbiota at the ages of respectively 1 month and 6-7 years of age. It is well-known that the microbiota in neonates is highly dynamic. By only examining the microbiota at a single time-point during infancy, some potential associations between the gut microbiota and weight development might have gone undetected. By the age of 2-3 years an adult-like microbiota has established. ${ }^{5-8}$ Hence, at age 6-7 years the microbiome becomes more adult-like with a more stable composition, although the composition might still be affected by bacterial infections, antibiotic treatment, as well as changes in lifestyle and dietary patterns ${ }^{4}$ over time.

Validity of outcome measures

We used sex- and age-standardised BMI as a measure of adiposity classification. BMI is not only determined by body fat mass but also by lean mass, and therefore may misclassify children into the overweight category when actually they are not overly fat. However, several studies have indicated a positive correlation between BMI and body 
fatness. The World Health Organisation (WHO) also recommends BMI as the most useful population level measure of overweight and obesity. ${ }^{28}$ Together this justifies the use of BMI in our study as a measure to track childhood (over)weight development.

The repeated weight and height measurements used in our longitudinal analysis were parent-reported. A validation study using data from the KOALA Birth Cohort Study, found an underestimation of overweight with parent-reported data compared to data collected during home visits. ${ }^{37}$ This so-called differential misclassification, where the rate of misclassification depends on BMI, with more misclassification for overweight and obese individuals, may have led to both and under- or overestimation of the true associations in our studies. However, the fact that we had repeated measurements might have partially off-sets this drawback.

\section{Study design}

The current thesis contains both cross-sectional and longitudinal analyses. Longitudinal studies take into account associations between gut microbiota and weight development over a defined period of follow-up and have been considered to provide better evidence of causality than cross-sectional studies. ${ }^{29}$ The majority of previous studies on the role of the gut microbiota on (over)weight were of cross-sectional design or, if longitudinal, did not address the transitional evolution of childhood (over)weight over an extended period of time. The longitudinal study design therefore is one of the major strength of our studies. In addition, this thesis contains the first study that has used GBTM to generate longitudinal childhood growth patterns (BMI z-score trajectories) while associating them to gut microbiota composition. However, longitudinal studies have their own limitations, such as loss-to-follow up that leads to a reduction in sample size and hence decreases the statistical power to detect associations. In our study, loss-tofollow up rates was lowest among children from parents with a higher economic status and with a healthier lifestyle, implying that most of the drop-outs were the unhealthier children, which might have resulted in a smaller chance of finding associations.

Observational studies usually generate information on associations and not on causal relations. We therefore cannot rule out the fact that reverse causation might have occurred, particularly in the cross-sectional analyses on the gut microbiota and childhood body weight at the age of 6-7 years. Evidence for a causal role of the gut microbiota in overweight development comes mostly from animal studies, while a few human studies provide some evidence of causality by means of the effects of gut microbiota transplantation. ${ }^{30,31}$ With this in mind, evidence from previous studies and findings from this thesis further strengthens the hypothesis that the gut microbiota influences childhood over (weight) development.
Generalizability

Our study population consisted entirely of Dutch Caucasian children hence results might not be generalizable to children with another ethnic or racial background. Indeed, the gut microbiota composition has been shown to vary between populations from different geographic regions and racial backgrounds. ${ }^{5,32}$ It is however, unclear whether ethnicity or racial background has a direct impact on the gut microbiome since most of these variations between populations seem to be caused by differences in dietary habits. Nevertheless, there is a great need for similar studies in other regions of the world.

\section{Future perspectives/recommendations}

Several studies have reported associations between the gut microbiota and childhood overweight but till date, there is a lack of consensus in the findings between these studies. These inconsistent findings might, at least to some extent, be explained by differences in experimental techniques (DNA isolation, microbial identification) that affect the observed composition of the human microbiome. When multiple studies across the world are being carried out on large-scale cohorts while utilizing the same methods of DNA isolation and comprehensive microbial identification, this may likely clarify some of the present uncertainties.

In addition, most of the studies performed so far have been case-control studies. Such studies are important in actually providing the initial step in investigating if there is an association between the gut microbiota and overweight. However, causality cannot be established with such studies. Prospective studies or birth cohorts with multiple followup time-points from birth throughout infancy and childhood, and with faecal samples obtained at the same time of anthropometric outcomes will enable us to monitor the composition of the microbiome and its association to weight development. Some human intervention studies involving the transplantation of gut microbiota obtained from healthy donors to diseased recipients have already been carried out. ${ }^{30,31}$ Such studies could be used to investigate if effects of the microbiota are causal. However, such studies also have their drawbacks in that it carries the risk of transferring either unknown or undetectable pathogens. A recently reported type of faecal transplantation known as synthetic faecal transplantation seems to overcome the limitations of the direct or native faecal transplantation. Synthetic faecal transplantation utilises microbial strains from the faeces of a healthy donor that has been cultured and transplants these strains into an unhealthy recipient. ${ }^{33,34}$ Future studies, could therefore implement this method of faecal transplantation in place of the native faecal transplantation to investigate the causa effect of the gut microbiota on childhood over (weight) development.

Such studies should be extended to the different continents of the world to enable us to have a deeper insight into whether effects are similar in different geographic and ethnic populations. In addition, the studies should be able to carry out a high interrogation of the gut microbiota composition up to the species level and hence advanced statistica 
methodology for high dimensional data reduction and longitudinal data analysis are needed. The investigation of biological interactions between different microbial groups and the joint effect of these interactions on childhood weight development may further add meaning to the existing evidence.

Above all, it is important to mention that this is still a very new area of research which so far has revealed new leads as to how the gut microbial composition relates to different aspects of human health especially childhood obesity. Akkermansia has consistently been reported by previous studies and our study as being inversely associated with body weight in both mice ${ }^{35}$ and humans. ${ }^{36,37}$ Methanogenic archaea (specifically M. smithii) are also a group of gastrointestinal microorganisms that have been found to be positively associated with body weight. Further studies (e.g. trials) in which Akkermansia are being used as probiotics and animal studies which involve the administration of only archaea or archaea in combination with other microbes that compete with archaea for hydrogen are warranted. This will enable us to further confirm if the associations between Akkermansia, methanogenic archaea and weight development are causal. We also identified bacterial groups that have not been previously reported to be associated with childhood overweight such as Sutterella wadsworthia et rel. and Bryantella formatexigens. This will require the performance of mechanistic studies for such bacterial group to actually investigate their mechanisms involved in weight development. Future studies should aim at identifying what are beneficial ("good") and non-beneficial ("bad") microbes for an ideal gut microbial ecosystem for the human health.

As research in this field is ongoing, we hope that our findings and those of others will help in providing unique solutions to the growing epidemic of childhood obesity. To achieve this aim, the gut microbiota should be studied together and in interaction with established risk factors of overweight such as diet and physical activity.

\section{References}

1. Penders J, Thijs C, van den Brandt PA, Kummeling I, Snijders B, Stelma F et al. Gut microbiota composition and development of atopic manifestations in infancy: the KOALA Birth Cohort Study. Gut 2007; 56: 661-7.

2. Jandhyala SM, Talukdar R, Subramanyam C, Vuyyuru H, Sasikala M, Nageshwar Reddy D. Role of the normal gut microbiota. World journal of gastroenterology : WJG 2015; 21: 8787-803.

3. Penders J, Thijs C, Vink C, Stelma FF, Snijders B, Kummeling I et al. Factors influencing the composition of the intestinal microbiota in early infancy. Pediatrics 2006; 118: 511-21.

4. Rodriguez JM, Murphy K, Stanton C, Ross RP, Kober OI, Juge N et al. The composition of the gut microbiota throughout life, with an emphasis on early life. Microbial ecology in health and disease 2015; 26: 26050.

5. Yatsunenko T, Rey FE, Manary MJ, Trehan I, Dominguez-Bello MG, Contreras $\mathrm{M}$ et al. Human gut microbiome viewed across age and geography. Nature 2012; 486: $222-7$.

6. Koenig JE, Spor A, Scalfone N, Fricker AD, Stombaugh J, Knight R et al. Succession of microbial consortia in the developing infant gut microbiome. Proceedings of the National Academy of Sciences of the United States of America 2011; 108 Suppl 1: 4578-85.

7. Palmer C, Bik EM, DiGiulio DB, Relman DA, Brown PO. Development of the human infant intestinal microbiota. PLoS biology 2007; 5: e177.

8. Hollister EB, Riehle K, Luna RA, Weidler EM, Rubio-Gonzales M, Mistretta TA et al. Structure and function of the healthy pre-adolescent pediatric gut microbiome. Microbiome 2015; 3: 36.

9. Bervoets L, Van Hoorenbeeck K, Kortleven I, Van Noten C, Hens N, Vael C et al. Differences in gut microbiota composition between obese and lean children: a cross-sectional study. Gut pathogens 2013; 5: 10.

10. Samuel BS, Gordon JI. A humanized gnotobiotic mouse model of host-archaealbacterial mutualism. Proceedings of the National Academy of Sciences of the United States of America 2006; 103: 10011-6.

11. Jernberg C, Lofmark S, Edlund C, Jansson JK. Long-term ecological impacts of antibiotic administration on the human intestinal microbiota. The ISME journal 2007; 1: 56-66.

12. Jakobsson HE, Jernberg C, Andersson AF, Sjolund-Karlsson M, Jansson JK, Engstrand L. Short-term antibiotic treatment has differing long-term impacts on the human throat and gut microbiome. PloS one 2010; 5: e9836.

13. Dethlefsen L, Relman DA. Incomplete recovery and individualized responses of the human distal gut microbiota to repeated antibiotic perturbation. Proceedings of 
the National Academy of Sciences of the United States of America 2011; 108 Suppl 1: 4554-61.

14. Bailey LC, Forrest CB, Zhang P, Richards TM, Livshits A, DeRusso PA. Association of antibiotics in infancy with early childhood obesity. JAMA pediatrics $2014 ; \mathbf{1 6 8}$ 1063-9.

15. Ajslev TA, Andersen CS, Gamborg M, Sorensen TI, Jess T. Childhood overweight after establishment of the gut microbiota: the role of delivery mode, pre-pregnancy weight and early administration of antibiotics. International journal of obesity (2005) 2011; 35: 522-9.

16. Saari A, Virta LJ, Sankilampi U, Dunkel L, Saxen H. Antibiotic exposure in infancy and risk of being overweight in the first 24 months of life. Pediatrics 2015; 135: 617-26.

17. Trasande L, Blustein J, Liu M, Corwin E, Cox LM, Blaser MJ. Infant antibiotic exposures and early-life body mass. International journal of obesity (2005) 2013; 37: 16-23.

18. Harrell L, Wang Y, Antonopoulos D, Young V, Lichtenstein L, Huang Y et al. Standard colonic lavage alters the natural state of mucosal-associated microbiota in the human colon. PloS one 2012; 7: e32545.

19. Stearns JC, Lynch MD, Senadheera DB, Tenenbaum HC, Goldberg MB, Cvitkovitch DG et al. Bacterial biogeography of the human digestive tract. Scientific reports $2011 ; 1: 170$.

20. Mai V, Morris JG, Jr. Colonic bacterial flora: changing understandings in the molecular age. The Journal of nutrition 2004; 134: 459-64.

21. Ignys I, Szachta P, Galecka M, Schmidt M, Pazgrat-Patan M. Methods of analysis of gut microorganism--actual state of knowledge. Annals of agricultural and environmental medicine : AAEM 2014; 21: 799-803.

22. Otlewska A, Adamiak J, Gutarowska B. Application of molecular techniques for the assessment of microorganism diversity on cultural heritage objects. Acta biochimica Polonica 2014; 61: 217-25.

23. Ott SJ, Musfeldt M, Timmis KN, Hampe J, Wenderoth DF, Schreiber S. In vitro alterations of intestinal bacterial microbiota in fecal samples during storage. Diagnostic microbiology and infectious disease 2004; 50: 237-45.

24. Lauber CL, Zhou N, Gordon JI, Knight R, Fierer N. Effect of storage conditions on the assessment of bacterial community structure in soil and human-associated samples. FEMS Microbiol Lett 2010; 307: 80-6.

25. Tedjo DI, Jonkers DM, Savelkoul PH, Masclee AA, van Best N, Pierik MJ et al. The effect of sampling and storage on the fecal microbiota composition in healthy and diseased subjects. PloS one 2015; 10: e0126685.
26. Kaser M, Ruf MT, Hauser J, Marsollier L, Pluschke G. Optimized method for preparation of DNA from pathogenic and environmental mycobacteria. Applied and environmental microbiology 2009; 75: 414-8.

27. Salonen A, Nikkila J, Jalanka-Tuovinen J, Immonen O, Rajilic-Stojanovic M, Kekkonen RA et al. Comparative analysis of fecal DNA extraction methods with phylogenetic microarray: effective recovery of bacterial and archaeal DNA using mechanical cell lysis. J Microbiol Methods 2010; 81: 127-34.

28. Organization WH. Obesity and overweight. Fact sheet no. 311, May 2012. Retrieved from WHO website 2012.

29. Hill AB. The environment and disease: association or causation? Journal of the Royal Society of Medicine 2015; 108: 32-37.

30. Vrieze A, Van Nood E, Holleman F, Salojarvi J, Kootte RS, Bartelsman JF et al. Transfer of intestinal microbiota from lean donors increases insulin sensitivity in individuals with metabolic syndrome. Gastroenterology 2012; 143: 913-6 e7.

31. Alang N, Kelly CR. Weight gain after fecal microbiota transplantation. Open forum infectious diseases 2015; 2: ofv004.

32. De Filippo C, Cavalieri D, Di Paola M, Ramazzotti M, Poullet JB, Massart S et al. Impact of diet in shaping gut microbiota revealed by a comparative study in children from Europe and rural Africa. Proceedings of the National Academy of Sciences of the United States of America 2010; 107: 14691-6.

33. Petrof EO, Gloor GB, Vanner SJ, Weese SJ, Carter D, Daigneault MC et al. Stoo substitute transplant therapy for the eradication of Clostridium difficile infection: 'RePOOPulating' the gut. Microbiome 2013; 1: 3.

34. Allen-Vercoe E, Reid G, Viner N, Gloor GB, Hota S, Kim P et al. A Canadian Working Group report on fecal microbial therapy: microbial ecosystems therapeutics. Canadian journal of gastroenterology = Journal canadien de gastroenterologie 2012; 26: 457-62.

35. Everard A, Lazarevic V, Derrien M, Girard M, Muccioli GG, Neyrinck AM et al. Responses of gut microbiota and glucose and lipid metabolism to prebiotics in genetic obese and diet-induced leptin-resistant mice. Diabetes 2011; 60: 2775-86

36. Remely M, Hippe B, Geretschlaeger I, Stegmayer S, Hoefinger I, Haslberger A Increased gut microbiota diversity and abundance of Faecalibacterium prausnitzi and Akkermansia after fasting: a pilot study. Wiener klinische Wochenschrift 2015.

37. Santacruz A, Marcos A, Warnberg J, Marti A, Martin-Matillas M, Campoy C et al. Interplay between weight loss and gut microbiota composition in overweight adolescents. Obesity (Silver Spring, Md.) 2009; 17: 1906-15. 


\section{VALORISATION}


The purpose of research is obtaining results that can be put into use to help the society. This implies that the results of studies should have implications for policy and project implementation. In other words, this is known as valorisation, which can be fully defined as: "The process of value-creation out of knowledge, by making this knowledge suitable and available for economic or societal utilisation". ${ }^{1}$ The commercialisation of knowledge by generating patents and license contracts is an example of economic utilisation while societal utilisation involves making knowledge generated from research findings available to the population, policy makers and public organisations.

The studies presented in this thesis were aimed at: 1) examining associations between the gut microbiota composition and childhood (over)weight development; 2) examining the impact of childhood exposure to oral antibiotics on (over)weight development; and 3 ) addressing the methodological challenge of reducing high dimensional data of the gut microbiota in relation to latent BMI z-score trajectories. We showed that both the gut microbiota composition and early exposure to antibiotics were associated with childhood (over)weight development. However, due to their observational nature, studies in this thesis only yield associations and not causal relationships. Therefore, in this chapter, I will present some recommendations with regards to the findings obtained during my $\mathrm{PhD}$ project and how these findings can be applied to overcome this problem. This may aid in the prevention of overweight/obesity in children who are in the process of developing this and in the treatment of children already suffering from overweight/ obesity.

A large percentage of the population is already aware of some of the factors that are known to be associated with obesity, but few individuals are aware of the millions of micro-organisms present in our gastrointestinal tract and their relation with health. Moreover, most results obtained from research are not accessible to the public but mostly found in databases that can only be obtained through subscription. In our study, the population of interest were children hence our targeted audience are parents, general practitioners, and especially paediatricians. In my opinion the first move will be to inform parents on the importance of the gut microbiota on childhood health, including its potential association with childhood obesity. Creating awareness of the importance of the gut microbiota in health will go a long way to help parents improve the lifestyle of their children.

We showed that early exposure to antibiotics was associated with childhood weight development. In addition, antibiotics have been reported to have a perturbative effect on the composition of the gut microbiota and lead to an increase of bacterial strains that are resistant to antibiotics. The major concern will be to minimise the prescription of antibiotics to children suffering from viral self-limiting respiratory tract infections. The Netherlands has been known internationally for its leading role in increasing awareness about antibiotic use, by implementing restrictive antibiotic prescription guidelines. Meanwhile a lot still has to be done in other countries to achieve this aim e.g. southern European, Asian, and developing countries, and the United States of America. ${ }^{2,3}$ Therefore, strict guidelines for the prescription of antibiotics should be established and in countries with already established guidelines, adherence of GP's to the guidelines should be monitored for adequate antibiotic prescription. However, these guidelines are mainly based on antimicrobial susceptibility and resistance. In addition to existing cartoons to create awareness for antibiotic resistance (e.g. the Luke and Lucey cartoon "Auntie biotica"), cartoons demonstrating the negative impact of antibiotics that have direct impact on the patients such as the perturbation of the microbiota and associated effects on weight could be produced to help deliver the message to parents or the society.

To help prevent the overuse of antibiotics and their potential detrimental health effects, medical doctors should restrict the prescription of antibiotics according to the national guidelines. They should be able to educate their patients (especially parents) on the disadvantages of antibiotics and with the help of the public health sector, produce cards/flyers containing this information and share them. In this regards, this will help create awareness of antibiotics usage especially in children and will prevent them from unnecessary antibiotic usage.

For the treatment of childhood overweight/obesity, this will require further research to critically investigate if the associations seen in our and other studies are actually causal as most of the previous studies have been cross-sectional and causality cannot be established by such studies. Prospective studies or birth cohorts with multiple followup time-points from birth throughout infancy and childhood, and with faecal samples obtained at the same time of anthropometric outcomes will enable us to better monitor the composition of the microbiome and its association to weight development. This should also include an extensive documentation of lifestyle factors to better control for confounding factors. Some human intervention studies involving the transplantation of gut microbiota obtained from healthy donors to diseased recipients have already been carried out in adults. ${ }^{4,5}$ Such studies could be used to investigate if effects of the microbiota are causal in both adults and children. Future studies, could then implement the method of synthetic faecal transplantation ${ }^{6,7}$ to investigate the causal effect of the gut microbiota on childhood over (weight) development. Such studies should be extended to the different continents of the world by carrying out a high interrogation of the gut microbiota composition up to the species level to enable us to have a deeper insight into whether effects are similar in different geographic and ethnic populations. Also advanced statistical methodology for high dimensional data reduction and longitudinal data analysis applied to data with larger sample sizes are needed. 
Above all, it is important to mention that this is still a very new area of research which so far has revealed new leads as to how the gut microbial composition relates to different aspects of human health especially childhood obesity. Akkermansia has consistently been reported in previous studies, as well as in our study, to be inversely associated with body weight in both mice ${ }^{8}$ and humans. ${ }^{9,10}$ We therefore recommend further studies (e.g. trials) to investigate the potential use of Akkermansia as a probiotic with a positive effect on weight management. Methanogenic archaea (specifically $M$. smithii) on the other hand have been found to be positively associated with body weight. It is thought that to achieve a reduction or elimination of $M$. smithii from the colon, bacteria such as sulphate reducing bacteria (SRB) could be incorporated into the colon to outcompete the methanogens for $\mathrm{H}_{2}$. However, this should be preceded by experiments aiming at determining the conditions that would effectively reduce the methanogenic population. ${ }^{11}$ Future animal studies, which involve the administration of only archaea or in combination with other microbes that compete with archaea for hydrogen are warranted.

Such studies might enable us to confirm causal relationships between Akkermansia, methanogenic archaea and weight development and provide new leads for intervention strategies such as the production of probiotics. Current evidence for probiotics in the prevention and treatment of most diseases is very limited. However, most probiotic strains and products were initially not specifically selected to treat or prevent a single disease. Therefore, if causality is finally established, these new candidates that appear to be specifically involved in weight development might appear to be more promising by administering the bacteria to overweight subjects through probiotics. From all previous studies conducted in this area of research including ours, there are strong indications that the gut microbiota remains a promising target in the fight for childhood (over) weight development. However, only when causality is established can we be very sure to start applying the findings obtained for treatment purposes.

\section{References}

1. “What Is Valorisation?” Netherlands Proteomics Centre. [Cited 10 June 2016]; retrieved from http://www.netherlandsproteomicscentre.nl/npc/valorisation/ what-is-valorisation.

2. Adriaenssens N, Coenen S, Versporten A, Muller A, Minalu G, Faes C, et al. European Surveillance of Antimicrobial Consumption (ESAC): outpatient quinolone use in Europe (1997-2009). The Journal of antimicrobial chemotherapy. 2011;66 Suppl 6:vi47-56

3. Rossignoli A, Clavenna A, Bonati M. Antibiotic prescription and prevalence rate in the outpatient paediatric population: analysis of surveys published during 20002005. European journal of clinical pharmacology. 2007;63:1099-106.

4. Vrieze A, Van Nood E, Holleman F, Salojarvi J, Kootte RS, Bartelsman JF et al. Transfer of intestinal microbiota from lean donors increases insulin sensitivity in individuals with metabolic syndrome. Gastroenterology 2012; 143: 913-6 e7.

5. Alang N, Kelly CR. Weight gain after fecal microbiota transplantation. Open forum infectious diseases 2015; 2: ofv004.

6. Petrof EO, Gloor GB, Vanner SJ, Weese SJ, Carter D, Daigneault MC et al. Stool substitute transplant therapy for the eradication of Clostridium difficile infection: 'RePOOPulating' the gut. Microbiome 2013; 1: 3.

7. Allen-Vercoe E, Reid G, Viner N, Gloor GB, Hota S, Kim P et al. A Canadian Working Group report on fecal microbial therapy: microbial ecosystems therapeutics. Canadian journal of gastroenterology = Journal canadien de gastroenterologie 2012; 26: 457-62.

8. Everard A, Lazarevic V, Derrien M, Girard M, Muccioli GG, Neyrinck AM et al. Responses of gut microbiota and glucose and lipid metabolism to prebiotics in genetic obese and diet-induced leptin-resistant mice. Diabetes 2011; 60: 2775-86.

9. Remely M, Hippe B, Geretschlaeger I, Stegmayer S, Hoefinger I, Haslberger A. Increased gut microbiota diversity and abundance of Faecalibacterium prausnitzii and Akkermansia after fasting: a pilot study. Wiener klinische Wochenschrift 2015.

10. Santacruz A, Marcos A, Warnberg J, Marti A, Martin-Matillas M, Campoy C et al. Interplay between weight loss and gut microbiota composition in overweight adolescents. Obesity (Silver Spring, Md.) 2009; 17: 1906-15.

11. Conway de Macario E, Macario AJ. Methanogenic archaea in health and disease: novel paradigm of microbial pathogenesis. Int J Med Microbiol 2009; 299(2): 99108. 


\section{ACKNOWLEGEMENT}

Thank you! 
The process of creating this doctoral thesis was without question a complex one. However, Nelson Mandella once said; "everything seems impossible until it is done" I finally realised it was possible. Working through this material, as I read, reflected and wrote, I learned so much not only about the subject matter and the methodological processes involved but also about myself. Exploring my own understanding and experiences on this topic required more courage and discipline than I had anticipated and I would like to thank everyone who supported and encouraged me along this journey with this material.

First of all, great thanks go to the University of Maastricht and TI Food and Nutrition (TIFN) for giving this opportunity to pursue a multi-disciplinary study in the field of scientific research.

Many thanks to my promotor Prof. dr. Ilja C. W. Arts and co-promotor Dr John Penders who inspired me, without who's insight, guidance, and support I would not have had the ability nor the courage to attempt this challenging task, much less complete it. They challenged me to question my understanding of what my research topic was all about, thereby opening the door to the wonderful area of reflexive work. Sincere thanks also go to Dr. Carel Thijs who provided me with the experimental data and his endless critical reviews of my manuscripts which deepened my understanding of my work, pushing me to think more deeply, look more closely and explore more thoroughly as I wandered through this process. To them, I say, I am very grateful.

Special thanks to the members of the thesis assessment committee: Prof. dr. E.E. Blaak, Prof. dr. C. A. M. V. A. Bruggeman, Prof. dr. N. Hens, and Prof. dr. T. Nawrot for taking off their busy schedule to evaluate my thesis. To Prof. dr. E.E. Blaak, I say, thank you for all the encouragements and motivation you gave me as my project leader.

Sincere thanks also go to Prof. dr. Pieter Dagnielie, for his moral support throughout this journey. He actually encouraged me to stay strong regarding my Christian life and in his first christmas greeting card to me during the first year of my program, he wrote; "Despite being far away from home, in a cold country, I hope the love of the radiant star will fill your life with joy and trust and warmth!" Indeed, it did! Thank you for those inspiring words that I have never and will never forget as I move on in life. My sincere thanks to Dr. Limapassos Valeria for her moral support during this period of my reseach.

I am also grateful for the contributions given by Hauke Smidt, Gerben Hermes and Erwin Zoetendaal from the GH004 team of TIFN in the writing of some of the manuscripts in this thesis.
I also cease this opportunity to thank the entire staff of both the Departments of Epidemiology and Medical Microbiology for the love and co-operation they showered on me especially during departmental activities. A special thanks to Erik Beuken for his great assistance and patience during my entire period at the medical microbiology laboratory. I have also benefited from the many presentations from colleagues during our departmental research meetings where I developed some ideas through both coursework and informal discussions that helped me in writing this thesis. I cannot imagine what this process would have been like without them.

This great achievement in my educational career could still remain a dream if not for the constant support and encouragements from my lovely uncles Prof. dr. Ajaga Nji and Dr. Agwe Jonathan. My deepest and sincere thanks to them. Many thanks also go to Dr. Ako Ayuk M. for the endless support he gave me throughout this period. The outstanding support of my friends (Drs, Forcheh Anyiawung, Pascaline Fonteh, and Okwen Marvice, Danyta Tedjo and Susan Nakiweewa) and family was also influential in the completion of this work.

To my husband, Boja Pepsicolman, I want to say thank you so much for being there for me and our son when I was not there. I do appreciate all your efforts. In particular, the understanding, care and encouragement I received from my father (Mr. Mbakwa Martin), Mother (Mrs, Mbakwa Grace), sisters and brothers helped throughout this process while their constant trust in my ability kept me going even when I had fears. To them I dedicate this thesis. A very big thanks to my kids Theophile Chick and Urie Abiniseh for being patient with mummy during this period of her academic career. Thank you so much for your understandings sons! Thanks to my nieces and nephews who as little kids dedicated their prayers to the Lord Almighty to see their struggling aunt through this period of her life. A special thanks to Afesi Mbangowah who stood by me during the difficult moments of my life when my husband was far from me. This chain of gratitude would be definitely incomplete if I would forget to thank the Almighty for inspiring and guiding me through my program. 
About the author 
Curriculum Vitae 
Catherine Akwi Mbakwa was born in the town of Victoria (presently known as Limbe), Cameroon, on the $5^{\text {th }}$ of May 1976. In 1989, She attended Baptist High School Mankon, Cameroon and graduated in 1994. She became a high school student at the Cameroon College of Arts, Science, and Technology (CCAST) Bambili, and graduated in 1996. She then decided to take a one-year course in computer sciences and completed this course in 1997. In 1997 -

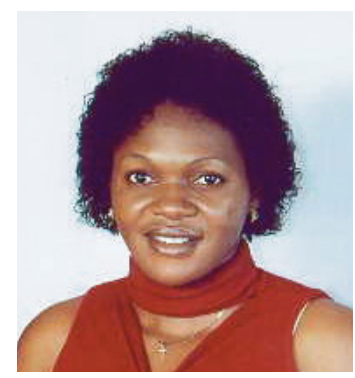
2000 she attended the Anglo-Saxon University of Buea, Cameroon where she studied Microbiology with a minor in medical laboratory technology and obtained a bachelor degree in Microbiology. Upon obtaining her bachelor degree, she worked at One Stop Medical Diagnostic Laboratory Bamenda, Cameroon till 2008. During her term at the laboratory, she was amazed with the effect of a medication developed by a botanist for the treatment of HIV and because she sought for scientific explanation for the effect of this medication with no answers, she became motivated to take a course involving clinical trials. In 2008, she started her master in Biostatistics at Hasselt University, Belgium. In her Master thesis entitled "Kids on Track", she investigated the effect of a therapeutic camp on children with special needs and how it can be predicted if a child will benefit from the activities of the camp before he/she participants in it under the supervision of Herbert Thijs. She graduated with a Master in statistics, specialising in Biostatistics in 2011. She became a PhD research student at the University of Maastricht in December 2011 where she researched on the topic, "Gut Microbiota and Weight Development in Children". This is part of the Koala Birth Cohort, a prospective study which was initiated in 2000 to identify factors influencing the incidence of atopic diseases, and overweight/obesity, focusing, on lifestyle, diet, breast milk composition, intestinal microbiota composition, and gene-environment interactions.

In her research, she investigated how the differences in gut microbiota composition among children and early exposure to antibiotics influence their weight development. $\mathrm{Her} \mathrm{PhD}$ research project was part of a large project embedded in the Gastrointestinal Health theme from the Top Institute Food \& Nutrition (TIFN) entitled, "The Gut Microbiome and Weight development" (GH003) under the supervision of Dr. John Penders, Dr. Carel Thijs, and Prof. dr. Ilja Arts.

Contact: mcakwi@yahoo.co.uk 